\title{
ESTUDIOS SISTEMÁTICOS EN TURNERA (TURNERACEAE) II. SERIES ANNULARES, CAPITATAE, MICROPHYLLAE Y PAPILLIFERAE
}

\author{
por MARIA MERCEDES ARBO'
}

\section{Summary}

Turnera L. includes around 100 American species and two African ones, arranged in nine series. In this paper, the following four series embracing 21 species are revised: Annulares, Capitatae, Microphyllae and Papilliferae. Six new taxa are described: T.hatschbachii, T.hatschbachii var. miniata, T.maracasana, and T.princeps of the series Capitatae, T.asymmetrica of the series Microphyllae, and T.caatingana of the series Papilliferae. The species of these four series share the common features of simple and glandular hairs, generally well-developed floral peduncle, absent pedicel, linear or elliptic prophylls, generally warty or granulate fruit, and a floral tube, appendicular in nature, in that it is the product of the fusion of the lower part of the calyx and corolla, with the staminal filaments adnate only at the base. In the series Annulares, Microphyllae and Papilliferae the leaves and young stems are fragrant, the scent being produced by the glandular hairs, and the floral peduncle is shortly adnate to the petiole. Three series, Annulares, Capitatae and Microphyllae, have leaves with generally well developed stipules and a disjunct geographical distribution. The series Annulares and Capitatae have nectaries and villous or hirsute styles, while Microphyllae and Papilliferae lack nectaries and their styles are glabrous or somewhat pilose. In some species of Microphyllae the staminal filaments are joined at the base, forming an annular structure 0,05-0,50 mm high. The seeds are peculiar in Annulares, being very short, with a central, prominent and slightly concave chalaza. In the series Capitatae, the flowers are gathered in short, capitate inflorescences, the length of the peduncles being variable or sometimes wanting, and the seeds are obovoid, reticulate or striate. The leaves of Microphyllae are small, with the stipules adnate to the foliar base; setiform glandular hairs, similar to those of Piriqueta, are exclusive to Turnera collotricha. The only series in the genus with stipitate glandular hairs is Papilliferae. Keys for the identification of series and species as well as illustrations and distribution maps are provided.

\section{Introducción}

El género Turnera L. cuenta con más de 100 especies en América y dos en África. Urban (1883a) lo dividió en nueve series que pueden distribuirse en dos grupos según su organización floral.

Un grupo está formado por las series Turnera (=Canaligerae Urb.) y Anomalae Urb., que presentan la estructura más compleja, con el tubo floral constituido por la adnación de cáliz, co-

\footnotetext{
'Facultad de Ciencias Agrarias - Instituto de Botánica del Nordeste (UNNE - CONICET), C.C. 209, 3400 Corrientes, Argentina. Email: ibone@espacio.com.ar
}

rola y androceo; los filamentos estaminales están soldados por sus bordes a ia uña de los pétalos hasta la garganta, formando bolsillos nectaríferos entre cada filamento estaminal y el sépalo correspondiente; en estas series los profilos se insertan en la base del cáliz (Arbo, 1986).

En el otro grupo, compuesto por las series Salicifoliae Urb., Stenodictyae Urb., Annulares Urb., Microphyllae Urb., Papilliferae Urb., Capitatae Urb. y Leiocarpae Urb., el tubo floral está constituido en su mayor parte por la adnación del tubo calicino y las uñas de los pétalos, ya que los filamentos estaminales están soldados solamente $\mathrm{cn}$ la base y por su cara externa. 
Las series Salicifoliae y Stenodictyae incluyen la mayoría de las especies selváticas del género. Algunas especies de Salicifoliae presentan inflorescencias axilares cimosas, reducidas en las demás especies a una flor axilar, que puede tener pedúnculo floral y pedicelo (hipopodio y epipodio según Weberling, 1989) desarrollados o nulos. En Stenodictyae el pedúnculo floral es libre y los profilos se insertan en la base del cáliz (Arbo, 1997b). Leiocarpae Urb. (la serie más numerosa del género) se diferencia por tener el pedúnculo soldado al pecíolo, hojas generalmente con nectarios y fruto liso, como lo indica su nombre.

En la presente contribución se presenta la revisión de las series Annulares, Capitatae, Microphyllae y Papilliferae que comparten los siguientes caracteres: indumento formado por pelos simples y pelos glandulares, pedúncuio floral generalmente desarrollado, pedicelo comúnmente nulo, profilos lineares o elípticos y fruto labrado, excepcionalmente punteado o casi liso (Arbo \& González, 1998). Se proveen claves para la identificación de las series y de las especies. En la primera contribución (Arbo 1997b) se trataron las 2? especies correspondientes a las series Salicifoliae y Stenodictyae, de manera que las especies aquí consideradas se numeran a partir dei número 22. Se omiten las descripciones de las especies nuevas publicadas previamente (A rbc, 1981 y 1993), así comc los ejemplares citados en aichos trabajos, aunque se los incluye en el índice de exsiccatae.

Las series Annulares, Microphyllae y Papilliferae presentan hojas y ramas nuevas con pelos glandulares cuya secreción tiene aroma agradable, las de varias especies se usan en medicina popular con propósitos diversos. Las áreas de las series Annulares, Capitatae y Microphyllae son disyuntas, pero todas están representadas en los estados nordestinos de Brasil, especialmente en Bahia.

\section{Clave para las series de Turnera}

1. Filamentos estaminales soldados en la base al tubo floral (raramente libres) y a veces entre sí

2. Pedúnculo floral desarrollado; flores solitarias, a veces reunidas en inflorescencias

3. Pedúnculo floral completamente libre o inserto en la base del pecíolo siendo el resio iibre. Fruto tuberculado o verrucoso

4. Pedicelo desarrollado, raramente muy breve, flores solitarias, a veces reunidas en in florescencias axilares cimosas

1. Serie Salicifoline

4. Pedicelo nulo, flores solitarias o reunidas en inflorescencias terminales o axilares racemosas

5. Hojas con nectarios en el pecíolo o en la base de la lámina foliar, sobre el márgén

6. Plantas sin pelos glandulares. Estípulas insertas a ambos lados de la base foliar. Anteras casi basifijas. Semilla obovoide, cara rafeal generalmente plana

2. Serie Stenodictyae

6. Plantas con pelos glandulares capitado-sésiles o pulos glandulares microcapitados. Estípulas soldadas a la base foilar y iigeramente al pecíolc. Anteras dorsifijas. Semilla subglobosa, cara rafeal convexa

3. Serie Annulares

5. Hojas sin nectarios.

7. Plantas con pelos glandulares capitado-sésiles o con pelos glandulares setiformes. Hojas pequeñas $(0,4-4,5 \mathrm{~cm}$ long.) con estípulas bien desarrolladas

4. Serie Microphyllae

7. Plantas con pelos capitado-estipitados en toda la planta, muy visibles al menos en el cáliz. Hojas pequeñas o medianas (hasta $10 \mathrm{~cm}$ long.) con estípulas reducidas o reemplazadas por coléteres

5. Serie Papilliferae

3. Pedúnculo floral parcial o totalmente adnato al peciolo, al menos las flores apicales epifilas. Fruto liso o impreso-reticulado por fuera, raramente verrucoso

8. Hojas medianas o amplias (2-21 cm long.), estipulas notorias, 0,5-4,5 mm long., fruto impresoretic slado, semillas con cálaza prominente y ligeramente cóncava

6. Serie Capitatae 
8. Hojas pequeñas o medianas (0,5-12 cm long.), frecuentemente con nectarios en la unión de pecíolo y lámina, estípulas ausentes a bien desarrolladas (hasta $3 \mathrm{~mm}$ long.), fruto iiso (rugoso en $\vec{r}$. sidoides, única especie con semilla tuberculada), semillas con cálaza generalmente no prominente, nunca cóncava

7. Serie Leiocarpae

2. Pedúnculo floral no desarroliado, o brevísimo; flores reunidas en inflorescencias terminales o axilares densas, excepcionalmenie solitarias en la axila de nomófilos

9. Fruto tuberculado o verrucoso. Semilla pubérula.

9. Fruto impreso-reticulado o punteado (casi liso). Semilla generalmente glabra o papilosa.

1. Serie Salicifoliae

6. Serie Capitatae

1. Filamentos estaminales soldados por sus bordes a la uña de los pétalos hasta la garganta, formando bolsillos nectaríferos entre cada filamento y el sépalo correspondiente

10.Pedúnculo floral libre o nulo. Hojas con o sin nectarios

8. Serie Anomalae

10. Pedúnculo floral adnato al pecíolo, a veces la porción apical libre. Hojas con nectarios en la unión de pecíolo y lámina

9. Serie Tumera (=Canaligerae)

Serie Annulares Urb.

Mapa 1

Urban I., Jahrb.Königl.Bot.Gart.Berlin 2: 123. 1883. Urban I. en Martius C.F.P., Fl.bras. 13(3): 143. 1883.

Arbustos 0,3-4 $\mathrm{m}$ alt. con pelos glandulares. Hojas con estípulas bien desarrolladas; nectarios en la unión de pecíolo y lámina o en el margen de la lámina. Flores heterostilas axilares solitarias o reunidas en racimos abreviados capituliformes. Pedúnculo flcral libre o inserto en la base del pecíolo. Profilos angostos, sin lacinias en la base. Sépalos soldados entre sí aproximadamente hasta la mitad o más, lóbulos de prefloración quincuncial, los internos generalmente con indumento igual al de los externos. Filamentos estaminales de base ancha, llegando hasta la uña de los pétalos y adheridos por su cara externa al tubo floral, determinando allí una banda anular; anteras dorsifijas, obtusas o apiculadas. Ovario piloso, estilos villoso-hirsutos. Fruto generalmente rugoso. Semilla breve, obovoide a subglobosa y casi recta, cara rafeal convexa, cálaza apical, casi central, prominente y ligeramente cóncava; episperma reticulado con aréolas grandes en relación con el tamaño de la semilla, o estriado reticulado, epidermis notoriamente papilosa; arilo unilateral, más corto que la semilla.

Especie tipc (aquí desigriadà): Turnera odorata Rich.

Todas las especies de este grupo tienen hojas de tamaño mediano (2-10 cm long.), con pelos glandulares capitado-sésiles o pelos glandulares microcapitados (Arbo \& González, 1998; González, 200C). Dos especies tienen hojas aromáticas, y se usan localmente como plantas medicinales. Las semillas breves son inconfundibles, se distinguen por la posición de la cálaza, y por el episperma papiloso, con aréolas de tamaño relativamente grande.

La serie Annulares presenta área disyunta, T.aromatica A rbo vive en América Central y en el norte de América del Sur, y las otras especies van desde Venezuela hasta el centro de Brasil (Mapa 1). Se las encuentra desde el nivel del mar hasta los $2000 \mathrm{~m}$ de altitud. La especie más írecuente, con área más amplia, es T.odorata, mientras T.annularis Urb. es una especie rara, de la cuaí se han recolectado apenas tres especimenes en este siglo. 


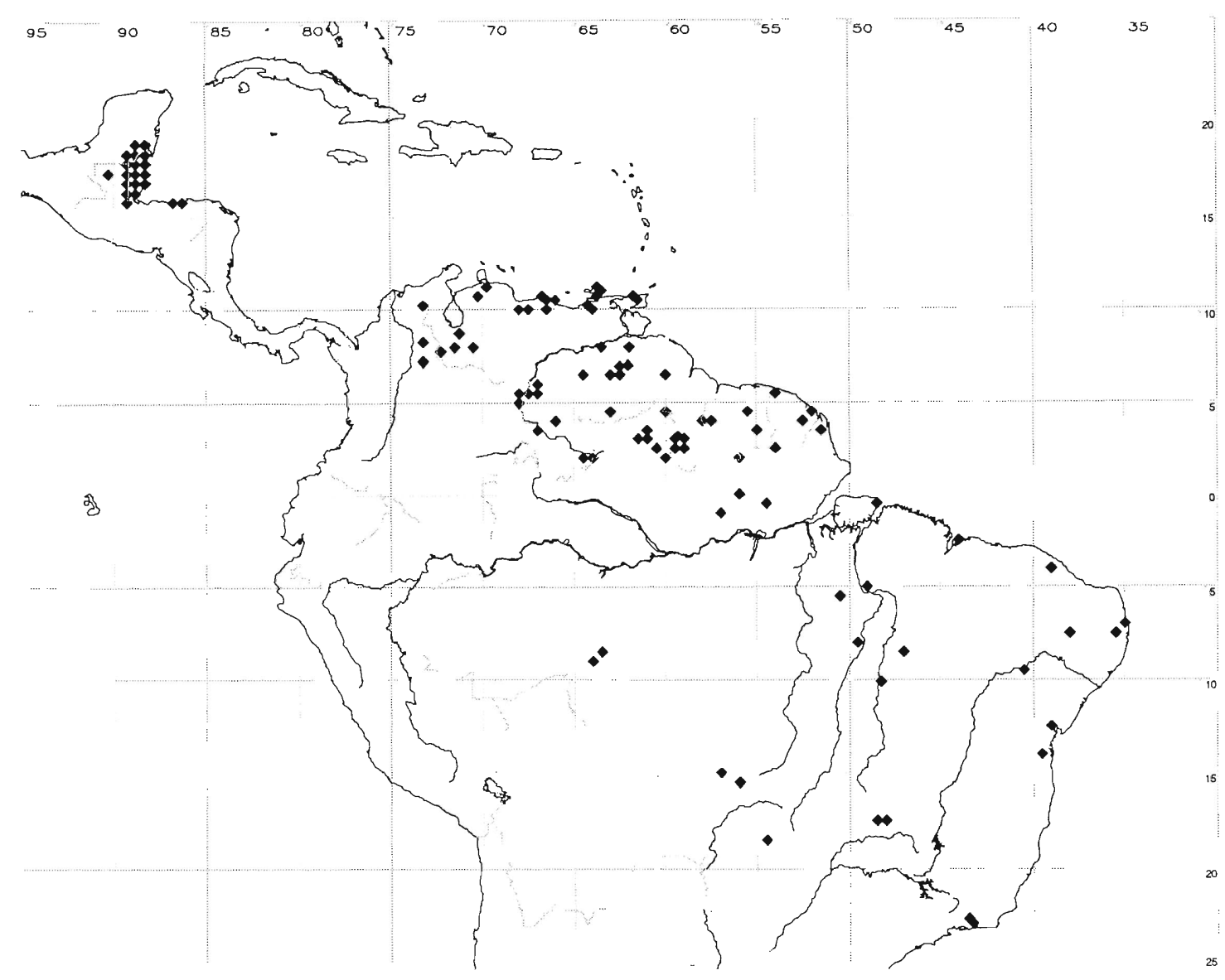

Mapa 1. Distribución de la serie Annulares

\section{Clave para las especies de la serie Annulares}

1. Cáliz 4,5-8 mm long. Pétalos blancos. Estípulas 2-3,5 mm long.

1. Cáliz 7-15 mm long. Pétalos amarillo-dorados. Estípulas 0,4-1 $\mathrm{mm}$ long.

22. T. annularis Urb.

2. Envés foliar tomentoso a glabrescente, con pelos glandulares microcapitados esparcidos, de color amarillo pálido, brevemente pediculados, a veces difícilmente visibles. Venas laterales con ángulo de divergencia $30-48^{\circ}$

3. Hojas con envés tomentoso o villoso-tomentoso. Cáliz villoso o tomentoso por fuera desde la base

23. T. aromatica Arbo

3. Hojas glabrescentes o con indumento laxo. Cáliz estriguloso, glabro o con escasos pelos en la base

24. T. breviflora Moura

2. Envés foliar tomentoso, con abundantes pelos glandulares capitado-sésiles, de color amarillodorado, raramente rojizos. Venas laterales con ángulo de divergencia $45-60^{\circ}$

25. T. odorata Richard 
22. Turnera annularis Urb.

Fig. 1, Mapa 2

Turnera annularis Urb. var. $\alpha$, Jahrb. Königl. Bot. Gart. Berlin 2: 124. 1883. Urban, I. en Martius C.F.P. Fl.bras. 13(3): 144. 1883. Lectotipo (aquí designado): BRASIL. Rio de Janeiro: Jurujuba, près de la mer, fl jaunes, 19 IX 1873, Glaziou A. 6812 (P!; isotipos: 2C!, 2K!; P!; B destruido, Foto F 13565!).

Turnera annularis Urb. var. conglomerata Urb., Jahrb.Königl.Bot.Gart.Berlin 2: 124. 1883. Urban I. en Martius C.F.P., Fl.bras. 13(3): 145. 1883. Lectotipo (aquí designado): BRASIL. Bahia: prope Cachoeira, Casaretto J. 2074 (P!).

Subarbusto o arbusto 0,5-1 m, ramas viejas cilíndricas, con corteza parda o cenicienta; ramas del año estriadas, angulosas, la porción apical con pelos simples cortos, crespos o curvados. Yemas axilares seriales 1-2, la basal origina una inflorescencia, ramas seriales a veces desarrolladas. Hojas herbáceas, concoloras. Estípulas subuladas, 2-3,5 $\mathrm{mm}$ long., persistentes, brevemente soldadas a la base foliar saliente. Pecíolo 2-5(-10) mm long. Nectarios 3-4 pares, discoideos, diminutos, 0,3-0,4 mm diám., en la porción basal del margen foliar. Lámina ovada, elíptica u obovada, 3-8 x 1,8-3 cm, relación largo: ancho $=2-3: 1$, base cuneada, margen crenado-aserrado, a veces las crenas terminadas en coléteres, ápice agudo; haz con pelos simples breves, dispersos, envés con algunos pelos glandulares capitado-sésiles y pelos simples curvado-antrorsos sobre las venas; vena media y laterales hundidas en la haz, la vena media a veces formando una prominencia linear, venación menor inconspicua. Flores reunidas en racimos abreviados terminales pauci- o plurifloros, las flores basales alejadas en la axila de nomófilos. Brácteas bruscamente acortadas, con estípulas, pecioladas, $30-3 \times 8-1,5 \mathrm{~mm}$, margen ciliado-piloso, las externas ovadas, agudas, margen serrulado, las internas espatuladas, obtusas, con margen entero. Pedúnculo libre, acortándose en flores sucesivas, 0,5-2 mm long. Profilos insertos en el ápice del pedúnculo, espatulados, 7-3 $\mathrm{mm}$ long., plurinervados, base largamente atenuada, ápice agudo o apiculado, a menudo recurvo, margen entero, ciliado, haz glabra, envés con pelos glandulares capitado-sésiles y pelos simples sobre las venas. Cáliz 4,5-7(-8) mm long., tubo 3-4,5 mm long. (sépalos soldados en 60$70 \%$ de su longitud), por fuera glabro, por dentro brevemente piloso en el tercio superior; lóbulos trinervados, por fuera con pelos simples sobre las venas, por dentro glabros. Pétalos unguiculados, uña soldada al tubo, pilosa en el tercio superior, lámina $3 \times 1,5 \mathrm{~mm}$, blanca con una mácula amarilla y pelos simples en la base de la cara interna. Filamentos estaminales con base ensanchada, de $1 \mathrm{~mm}$ long., laminar en seco, soldada por su cara externa al tubo, luego cilíndricos y pilosos, 3-4 mm long. en flores longistilas, $5-6 \mathrm{~mm}$ long. en flores brevistilas; anteras elípticas, dorsifijas, 0,8-1,5 $\mathrm{mm}$ long., base emarginada, ápice obtuso o apiculado, no o apenas recurvadas después de la dehiscencia. Ovario ovoide o elipsoide, 1,5 $\mathrm{mm}$ long., el ápice con pelos simples largos, placentas 3-5-ovuladas; estilos cilíndricos, la base con pelos simples largos, la mitad superior glabra, 4-5 mm long. en flores longistilas, 2-3 mm long. en flores brevistilas; estigmas 0,5$1 \mathrm{~mm}$ long. Fruto ovoide, 4-5 ×3-3,9 mm, valvas ovadas, ápice recurvado, por fuera lisas, glabras o pilosas en la base, con algunos pelos simples y pelos glandulares capitado-sésiles en el ápice, cara interna amarillenta o rojiza, glabra. Semilla obovoide o elipsoide, casi recta, 1,5-2,1 x 1-1,4 mm, relación largo:ancho =

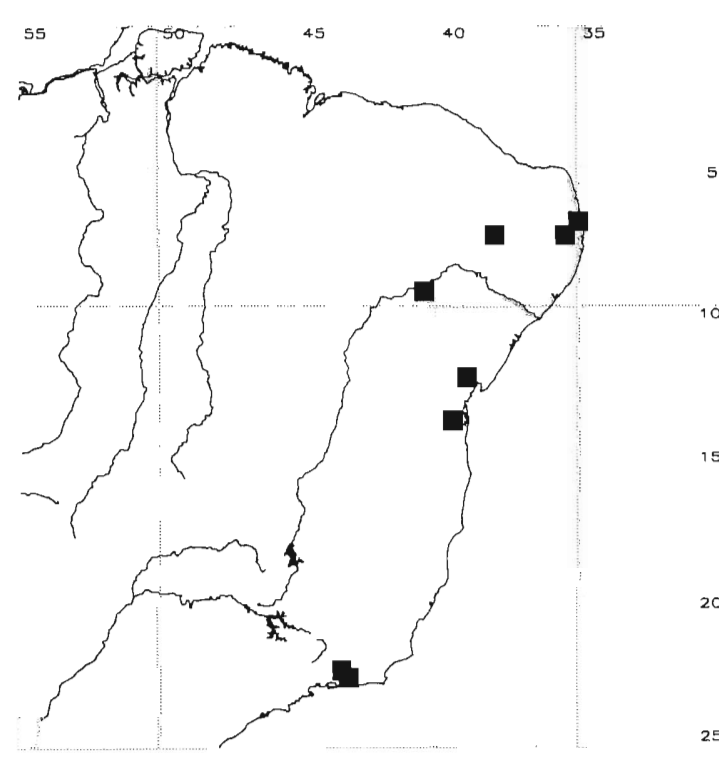

Mapa 2. Distribución de Turnera annularis 


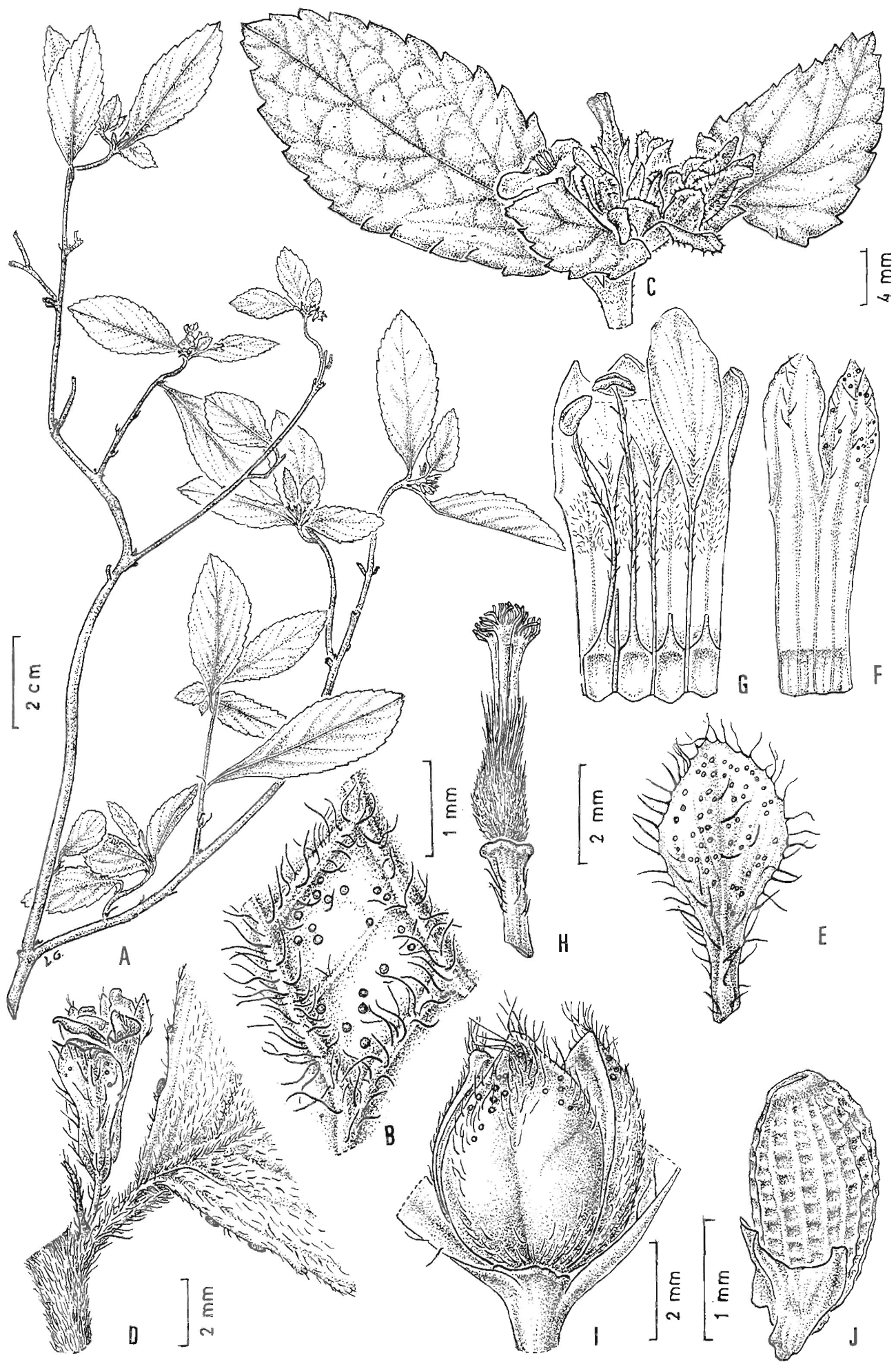

Fig. 1. Turnera annularis. A, rama florífera. B, detalle del envés foliar mostrando pelos simples y pelos glandulares capitadosésiles. C, inflorescencia apical capituliforme. D, flor axilar, hoja con nectarios en cl margen. E, profilo, cara extcrna. F, porción del cáliz, cara externa: lóbulos interno (izquierdo) y externo (derecho). G, porción del cáliz, cara interna, con pétalos y estambres adnatos, flor brevistila (se han cortado dos filamentos). H, yineceo de flor brevistila. I, fruto con profilos seccionados. I, semilla con arilo, vista de perfil, mostrando la rafe hacia la izquierda (A, Moraes 1083; B-C, jardim 1032; DJ, Glaziou 6812). 
1,2-1,9:1, parda c negruzca; exóstoma central, hemisférico y obtuso; rafe linear, convexa, cálaza casi central, prominente y ligeramente cóncava; episperma reticulado, muros longitudinales marcados, ios transversaies más tenues, aréolas transrectangulares o cuadrangulares con una depresión punctiforme en e! centro; arilo amarillento.

Material examinado. Brası.. Bahia: sin localidad, Blanchet 877 (BM, G), Blanchet 1267 (BR); Mun. itacaré, Fazenda Monte Alegre, entrada a ca. $1 \mathrm{~km}$ da BR-101 na estrada para Itacaré, ca. $10 \mathrm{~km}$ da entrada, 6 IV 1997, Jardim 1032 (CEPEC, CTES, NY); ad Joazeiro, IV, Martius 2293 (M, Foto F 20738); sin localidad, Riedel s.n. (P). Paraíba: prope Parahyba, V [1824], Riedel 8 (K). Pernambuco: Nazaré da Mata, 12 IV 1954, Moraes 1083 (UB); Tapera, 31 III 1931, Pickel 2967 (US). Rio de Janeiro: Lund 33 (C).

Distribución y fenología. Especie rara, vive en los estados nordestinos de Brasil, en lugares altos, secos, y también en matorrales y capoeiras. No se conocen ejemplares de Espírito Santo, ni ha sido recolectada en este siglo en Rio de Janeiro. El tipo fue recciectado en septiembre, los restantes ejemplares corresponden a los meses de marzo, abril y mayo.

\section{Nombre vulgar: "malva" (Moraes 1083).}

Obs. En flores longistilas el gineceo es 2-2,5 $\mathrm{mm}$ más largo que el androceo; en flores brevistilas el androceo es 1,5-1,7 mm más largo que el gineceo.

\section{Turnera aromatica Arbo Mapa 3}

Arbo M.M., Bonplandia 7: 63-99, fig. 1, A-H. 1993. Holotipo: BELIZE. Orange Walk: between London and Carmelita along the old Northern Highway between Orange Walk and Maskall, $17^{\circ} 59^{\prime} \mathrm{N}$ $88^{\circ} 28^{\prime}$ W, 50 m, 20 III 1987, Davidse G. \& A.E.Brant 32816 (CTES!; isotipo: MO!).

Materia! examinado. Méxıco. Quintana Roo: a $16 \mathrm{~km} \mathrm{~S}$ de San José, rumbo a Tomás Garrido, 10 XII 1980, Cabrera \& Durán 686 (CAS); $16 \mathrm{~km} \mathrm{~N} \mathrm{de}$ La Unión sobre camino a Aserradero, 7 V 1980, Téllez \& Cabrera 2128 (MO); 8 km N de La Unión, $9 \mathrm{VI}$ 1980, Téllez \& Cabrera 2455 (MO); 1 km S de San josé, sobre camino a Tomás Garrido, 13 X 1980,
Téllez \& Cabrera 3614 (MEXU, MO). BeLIze. Indian Church, 25 X 1977, Arnason 17848 (MO); San Agustín National Park, en el rio sobre el camino a San Agustín, 6 V 1982, Téllez et al. 5777 (MEXU, MO). Belize: Maskall, old Northern Highway, mile

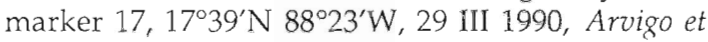
al. 384 (MO); 19,5 mi NW of Belize along Northern Hwy., 27 V - 6 VI 1973, Croat 23297 (MO); Mi 28 on the western Highway between Belize City and Belmopan, Tropical Education Cenier of the Belize Zoo, $17^{\circ} 21^{\prime} \mathrm{N} 88^{\circ} 32^{\prime} \mathrm{W}, 30$ m, 8 VI 1997, Davidse \& Holland 37021 (CTES, MO); Salt Creek Estates mi 18 N Hwy., 15 II 1970, Dieckman 153 (MEXU); Airport Belize, 18 VIII 1969, Dwyer 9101 (MO); mile 7,5 N Hwy., aside Belize river, 25 V 1974, Dwyer 12395 (MO, NY); mile 7,5 Northern Hwy., 25 V 1974, Dwyer 12409 (MO) y Doyer 12433A (MO); Colonel English pine ridge, Belize-Cayo road, 2 XII 1957, Gentle 9453 (MO); Belize City, 5 VII 1972, Huston 552 ( $\mathrm{NiC}$ ); between Mr Bombgardners road, mile 11, Northern Hwy., 18 I 1974, Liesner 1426 (MO); Belize River, Big Fall Pine Ridge, 14 VI 1933, Lundell 4192 (F, MICH); Burrellboom, ca. 30 ft, 22 III 1970, Mc Daniel 12852 (F, MO); near Manatee Lagoon, 16 VII 1905, Peck 66 (GH, K); 1 mi E of Boomtown, 17 IX 1936, O’Neill 8834 (MICH); lower Belize River, II 1926, Record s.n. (US); ca. mile 15 W Hwy., 26 VII 1971, Spellman et al. 291 (MO); ca. $1 / 2$ mi N of Western Hwy. at mile 15, ca. 5 m, 2-4 VII 1970, Spellman 1507 (MO) y Spellman 1526 (MO); 5,10 mi S of Orange Walk on Northern Hwy., 22 VIIl 1980, Sutton et al. 165 (MO); Western Hwy., mile 30, Parrots Wood, 3 $\mathrm{V}$ 1981, Whitefoord 2704 (MEXU, MO); $2 \mathrm{mi} \mathrm{W}$ of Hattieville, 11 VIII 1970, Wiley 235 (CTES, MO); Mountain Pine Ridge Blancaneaux Lodge, 13 VIII 1970, Wiley 274 (CTES, MO); along road from Belize city to Ladyville near the Haulover bridge, $1 \mathrm{~m}, 9$ VIII 1992, Worthington 21231 (MO). El Cayo:vicinity of Privacion Creek, Mountain Pine Ridge ca. $12 \mathrm{mi}$ S Cayo, ca. 600 m, 22 IV 1972, Burch 6230 (MO); Along road at Rio Ma Cal, between San Luis and Cuevas, 1050 m, 28 V 1973, Croat 23521 (MO); Along Hummingbird Highway S of Belmopan between 30$38 \mathrm{mi}, 300 \mathrm{ft}, 21$ VI 1973, Croat 24816 (CTES, MO, NY); Lookout Station and down trail, 18 III 1967, Dwyer et al. 201 (MO); Mayan Ruins near Cayo, 18 III 1967, Dwyer et al. 247 (MO); Road S to Augustine \& San Luis to Camp Six, 19 III 1967, Dwyer et al. 319A (MO); Macaw River Bridge, road from San Luis to Cuevas, 28 V 1973, Dwyer 10757 (MEXU, $\mathrm{MO})$; Blancaneaux Lodge, Mount Pine Ridge, on road to Augustine, 7 VII 1973, Dwyer 11521 (MO); 2-5 mi N of Blancaneaux Lodge, Mount Pine Ridge, 12 VII 1973, Dwoyer 11629 (F, MO); Mountain Pine Ridge, vicinity of Blancaneaux Lodge, 4 VI 1974, Dwyer 12669 (MO, NY); Maskall Pine Ridge, I 1934, 


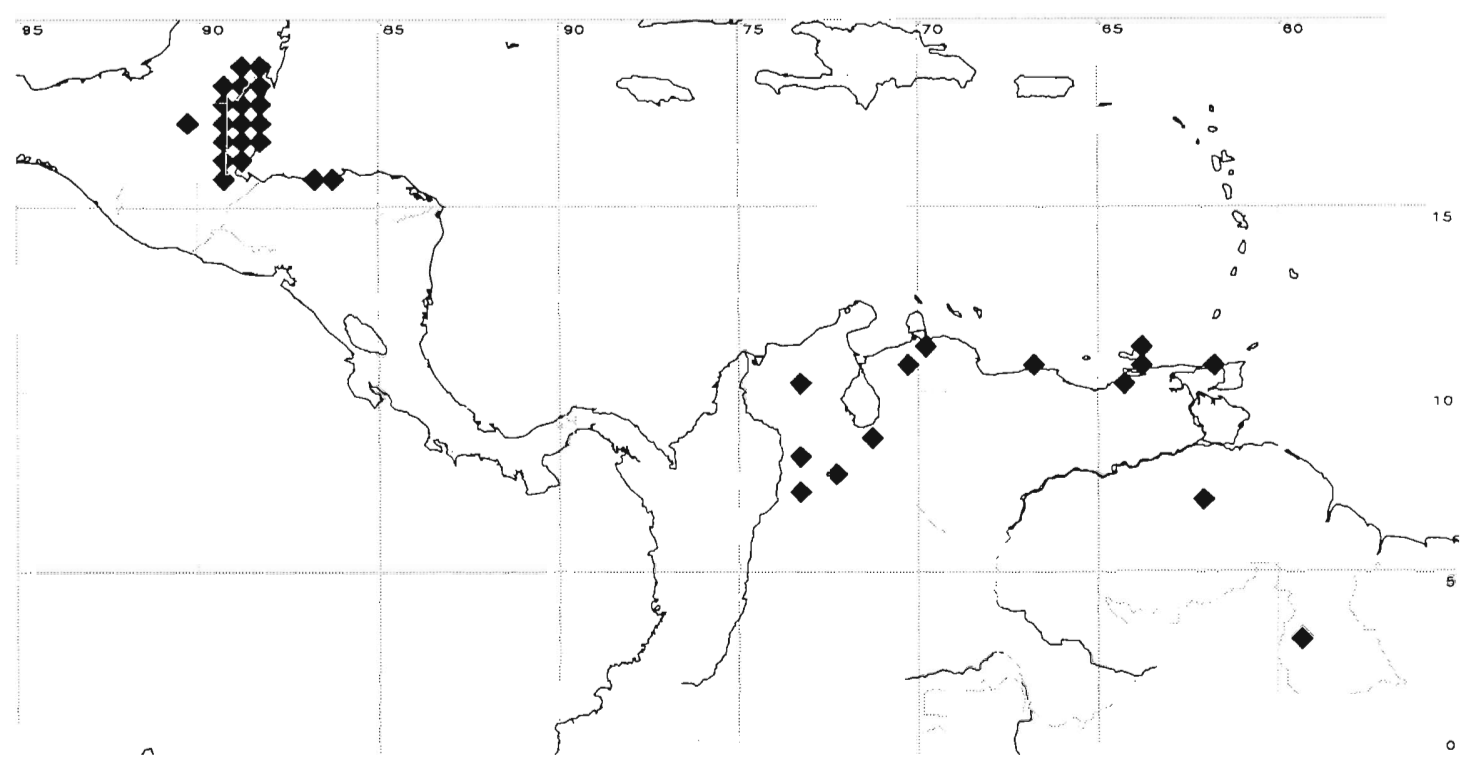

Mapa 3. Distribución de Turnera aromatica

Gentle 1095 (A, GH, MO, S), Sibun River, 6 XI 1954, Gentle 8434 (MO); Near Bridge over Mc Cal River (Rio Guacamayo) S of San Luis, 1050 ft, 27 V 1973, Gentry 7615 (F, MO); S of Belmopan, mile 28-29 on Hummingbird Hwy., 200-300 ft, 21 VI 1973, Gentry 8451 (F, MO); zona forestal de Agustín, 23 III 1954, $400 \mathrm{~m}$, Molina 57 (F). Orange Walk: Rio Bravo Conservation and Management Area, $17^{\circ} 49^{\prime} \mathrm{N}$ 8902'W, 2-30 XI 1991, Brokaw \& Schulze 212 (MO); ca. $5 \mathrm{~km}$ N of August Pine ridge on the road to Tri-

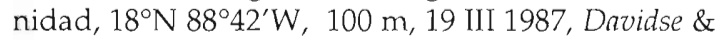
Brant 32767 (CTES, MO); Honey Camp, XI 1928, Lundell 71 (F, MICH); Honey Camp: Coastal Region, IX 1929, Lundell 432 (A, GH, K); Near Honey Camp, 30 VIII 1930, Meyer 113 (F). Toledo: Southern Maya Mountains, Bladen Nature Reserve, Ek Xux canyon, 1,8 airline $\mathrm{km}$ NW of the Ek Xux archeological site,

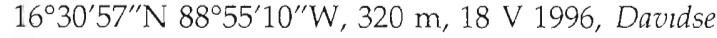
36062 (CTES, MO); Swasey branch, Monkey river, 12 XI 1941, Gentle 3776 (A); Southern Hwy. at border with Stann Creek District, 11 VI 1973, Gentry 8068 (MO); 3,5 mi NE of Medina Bank, 50-100 ft, $10 \mathrm{~V}$ 1976, Proctor 36182 (MO). Guatemala. Izabal: En La Mina, a $5 \mathrm{~km}$ al O de El Estor, $50 \mathrm{~m}, 28$ VIII 1989, Martinez \& Stevens 23286 (MO), Mun. El Estor La Mina de Exmibal, al E de El Estor, $15^{\circ} 31^{\prime} \mathrm{N} 89^{\circ} 23^{\prime} \mathrm{W}$, 50 m, 17 VII 1988, Martínez S. et al. 14588 (MO). Petén: Santa Elena, S of km 10 of Melchor de Mencos Road, 9 V 1966, Contreras 5710 (DS) y 5712 (DS, F, US). Honduras. Islas de la Bahía: Isla de Roatán: camino entre ciudad de Roatán y Fowers Bay, nivel del mar, 10-13 IV 1974, Nelson 2056 (UNAH); camino entre New Port Royal y Alligator Nose Beach, 095 m, 14 IX 1982, Nelson 8457 (TEFH); Oak Ridge, 030 m, 30 III 1984, Nelson \& Cruz 8732 (UNAH). CoLombia. Magdalena: Romero-Castañeda 7559 (US). Santander: escarpas de la meseta de Bucaramanga, quebrada Chapinero, 4 I 1968, Rivera C. I-153 (CUVC). Venezuela. Bolívar: Mun. Piar, Bajo Caroni, orilla del río Caroni, $7^{\circ} 04^{\prime} \mathrm{N} 62^{\circ} 05^{\prime} \mathrm{W}, 75 \mathrm{~m}$, III 1994, Valera 181 (US). Distrito Federal: Between Cotiza and Los Venados, near Caracas, X 1924, Allart 15 en parte (US); Savanna grande near Caracas, XII 1854, Buschel s.n. (K), ídem, 1 1855, Buschel s.n. (K). Falcón: Democracia Distr. alrededores de Avaria y ladera oriental del Cerro Montero, $10^{\circ} 52^{\prime} \mathrm{N} 70^{\circ} 25^{\prime} \mathrm{W}, 850-1200 \mathrm{~m}, 2-5$ III 1972, Agostini \& Agostini 1069 (NY). Mérida: Bernardi 2218 (CTES, G, NY). Nueva Esparta: Island of Margarita, Ascencion, 30 VII 1901, Miller \& Johnston 223 (MO, US); Island of Margarita, El Valle, 30 VII 1901, Miller \& Johnston 266 (BM, F, K, MO, NY), ídem, 15 VII 1903, Johnston 288 (C, F, K, NY, US, W). Sucre: Buena Vista, Parque Nacional Mochima, 18 VIII 1983, Montes 1572 (MO); Isla Los Venados, lado occidental, S de Playa Las Barracas Azules, 0-30 m, 9 IX 1973, Steyermark et al. 94096 (VEN); Playa Cachimena, W del Hotel Cumanagoto \& SW de Cumaná, 8 IX 1973, Steyermark et al. 108150 (MO). Táchira: dep. Capacho, La Laja, caserío Hierba Buena, 1300-1400 m, 11 VI 1985, Bono 4887 (MO); ca. Pericos, aldea a unos 7 km al SW de San Cristóbal, 800-900 m, 22 VIIl 1985, Bono 5020 (VEN); Dep. Lobatera, Mun. Lobatera, al- 
dea Potrero Nuevo, 5 X 1980, Chacón 94 (CTES); 7 km W of Rubio, $7^{\circ} 42^{\prime} \mathrm{N} 72^{\circ} 25^{\prime} \mathrm{W}, 900-1000$ m, 18 III 1981, Liesner \& González 10710 (CTES, MO); Sierra El Casadero, $13 \mathrm{~km} \mathrm{~N}$ of Rubio, between Las Dantas y Las Adjuntas, $7^{\circ} 43^{\prime} \mathrm{N} 72^{\circ} 23^{\prime} \mathrm{W}, 900-1050 \mathrm{~m}, 12$ XI 1979, Steyermark et al. 120134 (CTES, MO). GuYana. Kanuku Mts., Nappi Mt., 0319'N 59³3'W, 960 m, 11 XI 1987, Jansen-Jacobs et al. 853 (US). Trinidad y Tobago. Trinidad, Botanic Gardens Herbarium No 1093 (NY); Botanic Gardens Herbarium $N^{\circ} 2820$ (US); Chacachacare Island, 13 IV 1920, Britton \& Hazen 1722 (US, NY); ídem, 3 IV 1921, Britton et al. 2680 (K, NY, US).

Distribución y fenología. Especie con área disyunta, propia del extremo S de México, Belize, Guatemala y Honduras, y norte de América del Sur en Colombia (Magdalena y Santander), Venezuela (generalmente al norte del río Orinoco), Guyana y Trinidad. Vive en sabanas, bosques de pinos, encinales y laderas secas, también en matorrales, selvas y bosques al borde de pantanos; prospera bien en lugares alterados con vegetación secundaria y aun en cultivos (café y camellones de arrozales). Vive en sitios con suelo arenoso o pedregoso, en riscos de piedra caliza o granito, desde el nivel del mar hasta una elevación aproximada a los $2000 \mathrm{~m}$. Florece todo el año, preferentemente desde marzo hasta agosto.

Nombres vulgares: "cabeza de negro" (Venezuela: Valera 181); "skabon che" (Belize: Arnason \& Lambert 17151); "wild damiana" (Belize: Arvigo R. et al. 384).

Uso medicinal. La decocción de hojas jóvenes y tallos tiernos en agua se utiliza como antitusivo y tranquilizante (Arvigo R. et al. 384, Belize).

Obs. El aspecto vegetativo, así como el indumento, son muy similares a los de T. odorata, y también posee hojas aromáticas, pero no presenta los pelos glandulares capitado-sésiles, dorados o a veces rojizos, que caracterizan a T.odorata. Los pelos glandulares de esta especie, que en la descripción original figuran como estipitados, con cabeza diminuta, posteriormente se designaron como "microcapitados" (Arbo \& González, 1998; González, 2000). T. breviflora Moura, que se distingue por sus hojas glabrescentes o con indumento laxo y su cáliz glabro o con algunos pelos en la base, también presenta pelos microcapitados.

El ejemplar Tún Ortiz 1093 (F 1710677) fue muestreado para glucósidos cianogénicos con resultado negativo (sub T.odorata en Spencer, Seigler \& Fraley, 1985).

\section{Turnera breviflora Moura}

Fig. 2, Mapa 4

Moura F., Phyton (Horn.) 13(3-4): 267-269. 1969. Holotipo: BRASIL. Pará: Marabá, beira do rio Itacaiuna, arbusto pequeno, flor amarelo-vivo, 28 VII 1949, Fróes R.L. \& G.A. Black 24740 (IAN; isotipos: UB!, UEC!, W!).

Arbusto 0,5-2 m de alto, ramas viejas con corteza rojiza, longitudinalmente estriada, cicatrices foliares salientes; ramas del año con pelos cortos simples y otros más largos antrorsos. Hojas casi glabras. Estípulas triangular-subuladas, 0,3-0,7 mm long., rojizas, pilosas. Yemas seriales 2, la basal florífera. Pecíolo semicilíndrico, 2-5 mm long., indumento como el del tallo, más denso. Lámina foliar ovada o elíptica, 24-60 x 12-26 mm, base cuneada o atenuada, ápice agudo o acuminado, borde simple o doblemente aserrado, dientes subagudos, a veces con nectarios diminutos en las escotaduras; haz con epidermis lisa o ligeramente rugosa, con pelos largos curvado-antrorsos, laxos, de base cónica; envés a veces grisáceo en seco, glabrescente, pelos cortos simples, erectos, esparcidos y pelos glandulares microcapitados; 68 pares de venas iaterales alternas o subopuestas, hundidas o apenas visibles en la haz, glabras o en parte pilosas, salientes en el envés, con pelos largos, ángulo de divergencia 30-48 , divididas antes del borde en dos ramas, una a cada lado de las escotaduras; venas terciarias recurvas, a veces también hundidas en la haz, salientes en el envés, venación menor inconspicua. Nectarios foliares 1-2 pares, discoideos, 0,3-0,5 mm diám., brevemente pediculados, situados en el borde, a 1-3 mm de la base, orientados hacia el envés. Flores heterostilas, solitarias, a veces dispuestas en ramas axilares breves. Pedúnculo floral 1,5-3 mm long., rojizo, con pelos más cortos que el tallo. Profilos triangular-subulados o angustiovados, con la base ensanchada, 3-6 x 0,5-1,5 mm, borde aserrado, dientes glandulosos, haz glabra en la base, envés piloso. Cáliz 


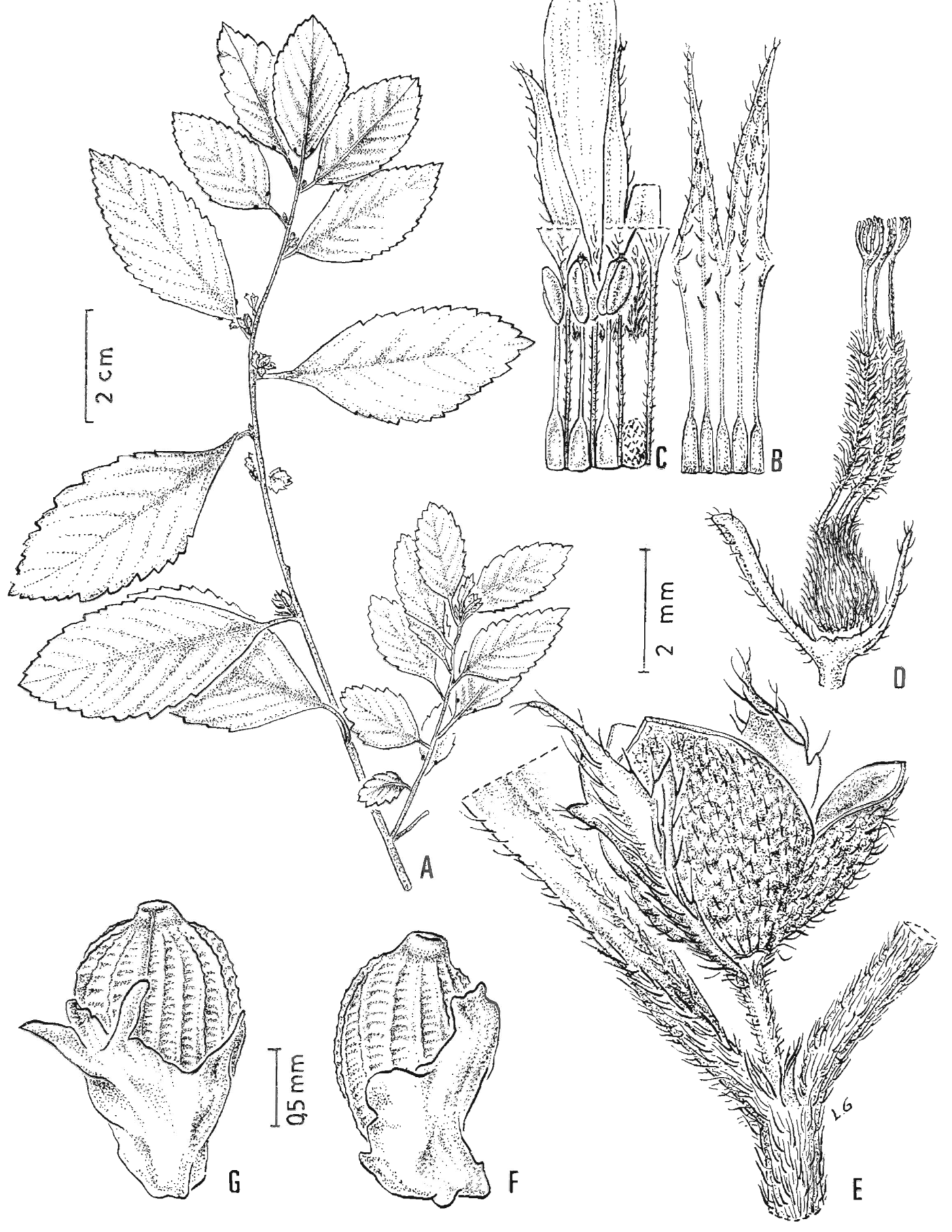

Fig. 2. Turnera breviflora. A, rama florífera. B, porción del cáliz, cara externa: lóbulos externo (izquierdo) e interno(derecho). C, porción del cáliz, cara interna, con pétalos y estambres adnatos, flor longistila (se ha marcado la cicatriz dejada al desprender un cstambre). D, gineceo de flor longistila con profilos. E, fruto con profilos en la axila de una hoja. F, semilla con arilo, vista lateral, rafe hacia la derecha. G, semilla con arilo, vista rafeal (A-G, Sperling et al. 6171). 


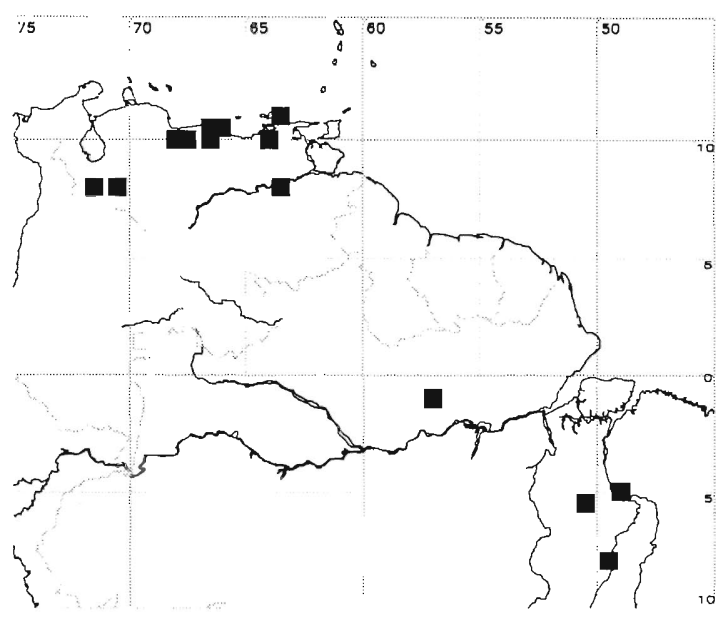

Mapa 4. Distribución de Turnera breviflora. No se conocen las localidades de Colombia

6,2-11 mm long., tubo calicino 5-6 mm long., por fuera glabro en la base, estriguloso hacia el ápice, por dentro piloso en la porción superior hasta la garganta; lóbulos triangulares, con pelos largos por fuera, glabros por dentro, bordes internos membranáceos, mucrón 0,3-1,5 mm long. Corola amarilla, 0,8-3 mm más larga que el cáliz, pétalos con la uña pilosa, lámina obovada. 5-8 x 2-5 mm, ápice redondeado, base pilosa. Filamentos estaminales con base ancha, engrosada, llegando el borde hasta la vena media del pétaio, soldada al tubo calicino 0,9-1,2 mm, más arriba cilíndricos, brevemente pilosos o giabros, 5-6,5 mm long. en flores brevistilas, 4,5 mm iong. en flores longistilas; anteras 1,3-2 x 0,4-0,6 mm, angustiovadas, obtusas o brevemente apiculadas, filamento inserto a $1 / 3$ de la base emarginada. Ovario ovoide o elipsoide, hirsuto, 1-1,2 mm long., placentas 2-4 ovuladas; estilos cilíndricos, hirsutos, 1,5-3 $\mathrm{mm}$ long. en flores brevistilas, 4,8-8 mm long. en flores longistilas; estigma penicilado $0,6-1 \mathrm{~mm}$ long., glabro. Fruto ovoide, 3-3,8 mm diám., tuberculado y piloso por fuera, a veces más hacia el ápice, por dentro lustroso, glabro, amarillento. Semilla obovoide, subglobosa, 1,5-1,9 x 0,8-1,5 mm, relación largo:ancho = 1-2:1, rafe linear convexa, exóstoma cónico muy pequeño, cálaza saliente, cóncava, pigmentada, episperma reticulado, muros longitudinales más prominentes, aréolas transrectangulares; arilo unilateral, ancho, lobado, 1,5 mm long.
Material examinado. Cozombia. Sin localidad, Karsten s.n. (G); sin localidad, Moritz 519 (BM). VENezuela. Los Mangos to La Moca, 17 VII 189i, Eggers 13380 (C, US). Aragua: Dep. Girardot, carretera Cata-Cuyagua, 100-400 m, 19 IX 1980, Badillo 7467 (F). Barinas: Ticoporo forest reserve, bank of Bumbum R., ca. 350 m, 15 IX 1965, Breteler 4608 (U). Bolívar: Dep. Rocío, Caño Orocopicne, carretera Cd. Bolívar-Cd. Piar, carretera Cd. Piar - Pto. Ordáz, 16 V 1982, Stergios et al. 3456 (CTES) y Stergios et al. 3469 (CTES). Carabobo: Valley and hills of Patanemo near end E of Puerto Cabello, 4-5 Xil 1919, Pittier 8654 (NY, US); Patanemo Valley, XIı 1919, Pittier 8655 (NY, US). Distrito Federal: Near Caracas, between Cotiza and Los Venados, X 1924, Allart 15 en parte (US); cerca de los cenos de Caruso, Los Caracas, i V 1969, Aristeguteta 7108 (F, MO, NY); Caracas, Avila, X 1846, Landsberger 260 (S); around Caracas 800-1200 m, 14 V 1913, Pittier 6158 (US); Lower Catuche wood above Caracas, 1000-1200 m, 4 III 1917, Pittier 7028 (US); Lower Cotiza, near Caracas in savannas, $800-1200 \mathrm{~m}, 26 \times 1918$, Pittier 8240 (F, US); Around Caracas, Quebradita de Las Ruinas, 900-1000 m, 10 IV 1921, Pittier 9451 (NY, US); near El Portachuelo, Km 16, road Caracas-La Guaira, 4 V 1922, Pittier 10304 (US); Caruao, 15 VII 1925, Pittrer 11845 (G, K, NY, US); Curucutí, $300 \mathrm{~m}, 30$ VII 1927, Pittzer 12455 (G, NY, US); between Caracas and La Guaira, 23 X 1916, Rose 21823 (US); Cordillera del Avila, dry $S$ acing slopes above Caracas, 1065-i 520 m, 511944 Steyermark 55188 (F); near Caracas, 8 VII 1940, Vogl 372 (US); Savana de monte, 1500 m, 28 iX 1940, Vogl 409 (F); Avila, sabana del monte, 1100 m, 15 IX. 1940, Vogl 701 (F); above Catia, 950 m, 24 XI 1938, Willuams \& Alston 48 (F, NY, US); falćas del Avile, $1200 \mathrm{~m}, \mathrm{~V} 1938$. Willams 10109 (F). Mérida: prope Cnia. Tovar, Fendler 214 (K, MO, US). Miranda: El Carenero, 9 III 1923, Pittier 11041 (G, NY, US); carretera Carenero-Chirimena, 2 km NW of Carenero, 0-5 m, 22 XI 1969, Steyermark \& Bunting 102295 (K, P). Nueva Esvartã: Rio Matasiete, $100 \mathrm{~m}$, sin fecha, Hermarro Ginés 2774 (US); C. Guayamurí, 300 m, ix 1953, Hermano Ginés 3359 (US). Sucre: Tataracual, Parque Mochimá, 7 VIII 1983, Cumana 1977 (VEN). Brasil. Pará. River Trombetas, $1 \mathrm{~km}$ above Cachoeira Porteira, $2 \mathrm{~V}$ ! 1974, Campbell et ai. P22467 (NY); Acarai Mins., Mapuera rapids, 28 X 1952, Forest Dep. Brit. Guiane G 502, 7517 (CTES, NY); Mun. Conceição do Araguaia, Alacilandia, $42 \mathrm{~km}$ W of Conceição do Araguaia along highway PA-287 at Kio Arraias do Araguaia, ca. $8^{\circ} 13^{\prime} \mathrm{S} 49^{\circ} 36^{\prime} \mathrm{W}, 300 \mathrm{~m}, 23$ II 1980, Plowman et al. 9028 (CTES, HPR, US); Serra dos Carajás, river banks of Rio Itacaiunas, $2 \mathrm{~km}$ downriver from berry crossing to AMZA camp 3-Alfa, $5^{\circ} 53^{\prime} \mathrm{S} 50^{\circ} 30^{\prime} \mathrm{W}$, ca. 150 m, 14 V! 1982, Sperling et al. 6171 (CTES). 
Distribución y fenología. Especie propia de Venezuela, Colombia y Pará (Brasil). Vive en matorrales, sabanas y selva en galería, desde el nivel del mar hasta los $1500 \mathrm{~m}$ de altitud. Florece todo el año, más en mayo-julio y septiembre-octubre.

Obs. Moura (1969) ubicó esta especie en la serie Stenodictyae sin haber visto las semillas, cuya morfología señala claramente que pertenece a la serie Annulares. Es muy afín a T.aromatica y a T.odorata.

En flores brevistilas el androceo es $1,7 \mathrm{~mm}$ más largo que el gineceo; en flores longistilas el gineceo es 1,5-3 mm más argo que el androceo.

\section{Turnera odorata Rich.}

Fig. 3, Mapa 5

Richard L.C.M., Actes Soc.Hist.Nat.Paris 1: 107. 1792. Urban I., Jahrb.Königl.Bot.Gart.Berlin 2: 123, t.2, fig. 65-66. 1883. Urban I. en Martius C.F.P., Fl.bras. 13(3): 143, tab. 43. 1883. Holotipo: GUAYANA FRANCESA. Cayenne, Baume savanne vulgo pro-balneis. In campestribus suburbanis frequent, Richard L.C. s.n. (P!; isotipos: C!, P!).

Turnera corchorifolia Willd. ex Schult., Roemer J.J. \& J.A.Schultes, Syst.veg. 6: 678. 1820. Holotipo: BRASIL. Sin localidad, Hoffmannsegg C. s.n. (B-W 6081, microficha IDC 424!).

Turnera frutescens Aubl. var. latifolia DC., Prodr. 3: 347. 1828. Holotipo: GUAYANA FRANCESA. Cayenne, Herb. Poiret (P!).

Turnera parviflora Benth., J.Bot.(Hooker) 4: 116. 1842. Lectotipo: GUAYANA FRANCESA. Cayenne, 1835, Leprieur M. 121 (K!; isotipos: P!, W!).

Turnera tomentosa Kunth en Humboldt A., A.Bonpland y K.Kunth, Nov.gen.sp. 6: 125. 1823. Turnera hexandra Spreng., Syst.veg. 4(2). Cur.Post.: 124. 1827. Nombre superfluo. Holotipo: VENEZUELA. [Carabobo] inter Porto Cabello et Barbula, II, fl. Feb. Holotipo: Humboldt A. \& A.Bonpland s.n. (PBonpl.!).

Arbusto de 0,3-4 m de alto, ramas delgadas, corteza lisa, pardo-rojiza o negruzca, longitudinalmente estriada, cor lenticelas pequeñas suborbiculares; cicatrices foliares a veces salientes; ramas del año a veces tomentoso-hirsutas, con pelos crespos densos, pelos antrorsos cortos o largos y pelos capitado-sésiles. Yemas seriales 2-3, de desarrollo acrópeto, la basal florífera, ramas seriales desarrolladas, a veces dos en la misma axila. Hojas aromáticas. Estípulas triangular-subuladas, 0,3-1,4 mm long., rojizas, pilosas. Pecíolo semicilíndrico 2$9 \mathrm{~mm}$ long., indumento como el del tallo. Nectarios 1-3 pares, discoideos, 0,3-1 mm diám., brevemente pediculados o sésiles, situados sobre el pecíolo o a veces sobre el borde de la lámina, distantes 1,5-3 mm de la base. Lámina ovada o elíptica, 30-85(-103) x 15-42 mm, base atenuada o cuneada, ápice agudo, borde simple o doblemente aserrado, ligeramente revoluto; haz con epidermis lisa o rugosa, glabrescente o con pelos cortos erectos, laxos o densos, a veces con la base cónica; envés con pelos blandos, cortos, erectos y numerosos pelos glandulares capitado-sésiles, amarillo-dorados, a veces villoso; venas laterales 6-8 pares, alternas o subopuestas, ángulo de divergencia $45-60^{\circ}$, incurvas, divididas antes del borde en dos ramas, una a cada lado de las escotaduras del borde, o formando arcos que se unen con las superadyacentes, de los cuales nacen ramas hacia el borde; venas terciarias más o menos perpendiculares a las venas secundarias, venación menor a veces visible en el envés. Flores solitarias, axilares, vistosas, con olor agradable. Pedúnculo floral inserto en la base del pecíolo, cilíndrico, 0,5-2 mm long., indumento como el del tallo o subglabro. Profilos 2, lineares o elípticos, a veces angustiobovoides, 3-8 $\times 0,5-2 \mathrm{~mm}$, base a veces ensanchada, ápice agudo, borde entero o serrulado; haz glabra en la porción basal, envés piloso. Cáliz 8-10 mm long., tubo 4-6 mm long., por fuera glabro en la base o con pelos cortos, por dentro glabro en la base, hacia arriba piloso hasta la garganta; lóbulos triangulares con pelos largos sobre las venas, bordes internos membranáceos, mucrón 0-0,5 mm long. Corola 1-2 mm más larga que el cáliz, pétalos amarillo-limón a amarillo-anaranjado, uña pilosa, lámina obovada a espatulada, 3-6 $x$ 1,5-4 mm, pilosa en la base. Filamentos estaminales ensanchados en la base, soldados al tubo 0,8-1,3 mm, engrosados en esa porción, más arriba cilíndricos, generalmente pilosos desde la base, 5-7 mm long. en flores brevistilas, 3-4,5 mm long. en flores longistilas; anteras angustiovadas, 1,1-2 x 0,4-0,6 mm, base emarginada, ápice con apículo brevísimo, rec- 
tas o con el ápice recurvo después de la dehiscencia, filamento inserto dorsalmente a 0,7-1 $\mathrm{mm}$ de la base. Cvario ovoide, 0,9-1 mm long., hirsuto, placentas 4-9 ovuladas; estilos cilíndricos, hirsutos, 1,5-3 $\mathrm{mm}$ long. en flores brevistilas, 6-7 $\mathrm{mm}$ long. en flores longistilas; estigma glabro, ramas de 0,3-1,2 mm long. Fruto globoso, 3-8 mm long., verrucoso o suavemente tuberculado por fuera, piloso, a veces con pelos glandulares; por dentro glabro, lustroso, reticulado o liso, amarillento o castaño. Semilla obovoide, globosa, subrecta, 1,3-2,1 x 1-1,5 mm, relación largo:ancho $=1-1,6: 1$, exóstoma brevísimo, rafe linear, cara rafeal convexa, á́laza generalmente prominente y cóncava; epidermis con células a veces papilosas; episperma reticulado, aréolas transrectangulares; arilo unilateral, amplio, lobuiado, 1-1,8 $\mathrm{mm}$ İong.

Material examinado. Colombia. Vichada: behind Casuarito, across from Puerto Ayacucho, $100 \mathrm{~m}$, ca. $5^{\circ} 40^{\prime} \mathrm{N} 67^{\circ} 40^{\prime} \mathrm{W}, 4$ IV 1984, Gentry \& Stein 46344 (CTES, MO); prope Maypures, ad fl. Orenoco, VI 1854, Spruce 3597 (BM, BR, K, P, W). Venezuela. Raudal de los Guaharibos, 26 VII 1951, Croizat 384 (F, NY); Alto Orinoco, Isla del Esfuerzo, 4 IX 1951, Ciroizat 558 (NY). T.F.Amazonas: $12,5 \mathrm{~km}$ S of Puerto Ayacucho, 230 m, 1 XI 1971, Davidse 2797 (MO, NY); dep. Atures: $23 \mathrm{~km} \mathrm{NE}$ of Puerto Ayacucho along the ruad to El Burro, $5^{\circ} 51^{\prime} \mathrm{N} 67^{\circ} 29^{\prime} \mathrm{W}, 80-150$ m, 17 IV 1978, Davidse \& Huber 15251 (CTES, MO, NY, US); $9 \mathrm{~km} \mathrm{~S}$ of Puerto Ayacucho on road to Samariapo, 100 m, 28 VI 1975, Gentry \& Berry 14452 (MO); dep. Atures, app. $5 \mathrm{~km}$ al SE de Limon de Parhueña, 20 II 1993, Gröger 777 (VEN); Atures, alred. Puerto Ayacucho, ca. $12 \mathrm{~km}$ al S, $5^{\circ} 34^{\prime} \mathrm{N}$ 67³5’W, 90-250 m, 20 VII 1977, Huber \& Tillett 914 (NY, US); alrededores de Puerto Ayacucho, ca. 33 $\mathrm{km}$ al NE, cerca del Caserío de Rincones de Chacorro, aprox. $05^{\circ} 48^{\prime} \mathrm{N} 67^{\circ} 20^{\prime} \mathrm{W}$, ca. $80 \mathrm{~m}, 13 \mathrm{XI}$ 1978, Huber 2719 (US); dep. A tabapo, Salto Yureba, Cerro Yureba, lower Ventuari, ca. $4^{\circ} 03^{\prime} \mathrm{N} 66^{\circ} 01^{\prime} \mathrm{W}$, 350 m, 14 III 1985, Liesner 18660 (CTES, MO); Santa Bárbara savanna, junction of ríos Orinoco and Ventuari, 21 II 1951, Maguire et al. 31590 (MO, NY, P); Santa Bárbara, Río Orinoco, 30 IV 1968, Medina 479 (VEN); dep. Atures, Raudales de Atures, $10 \mathrm{~km}$ S of Puerto Ayacucho, downstream on Río Orinoco, $5^{\circ} 35^{\prime} \mathrm{N} 67^{\circ} 34^{\prime} \mathrm{W}, 175 \mathrm{~m}, 6$ IX 1985, Steyermark et al. 131455 (MO, NY); Puerto Ayacucho, 120 m, 27 VI 1942, Williams 15941 (F, US). Bolívar: San Pedro de las Dos Bocas, $\mathrm{W}$ bank of river, $6^{\circ} 59^{\prime} \mathrm{N} 62^{\circ} 59^{\prime} \mathrm{W}$, ca. 200 m, 24 VII 1978, Liesner \& González 5520 (MO), ídem, 25 VII 1978, Liesner \& González 5601 (MO); ca. 16,8 km ESE of Upata, 400 m, 21 XII 1979, Pruskı \& Steyermark 1464 (NY); Municipio Autónomo Piar, El Frío, parcelas de Regeneración, $07^{\circ} 1^{\prime} \mathrm{N} 62^{\circ} 40^{\prime} \mathrm{W}$, 390 m, 26 V 1989, Rosales \& Briceño 254 (CTES); Rio Caura, arriba del Salto Para, en las islas 2-3 km arriba del campamento "Las Pavas», 250-300 m, 14 y 17 I 1977, Steyermark et al. 113047 (NY, VEN); Parguasa, 12 IV 1946, Velez 2330 (US); ídem, 22 IV 1946, Velez 2451 (US); Salto de Para, Medio Caura, 250 m, 3 III 1939, Williams 11358 (F, US); Laja de La Prisión, Medio Caura, 150 m, 5 IV 1939, Willanms 11711 (CTES, F), Mojasilla, al $\mathrm{S}$ de La Paragua, $70 \mathrm{~m}, 5 \mathrm{IV}$ 1940, Williams 12779 (US); Río Orinoco, Cerro San Borja, 100-300 m, 12 XII 1955, Wurdack \& Monachmo 39815 (CTES). Guyana. Takutu, Appun 2210 (K); N Rupununi, IV 1968, Davis 866 (NY); Region iX, Upper Takutu Dist., Southern Rupununi Savanna, E side of Rupununi River, Dadanawa, $2^{\circ} 50^{\prime} \mathrm{N}$ 59²5'W, 110-120 m, 21 VIII 1995, Hill 27325 (US); Kanuku Mts., Rupununi river, bush mouth near Witaru falls, $03^{\circ} 04^{\prime} \mathrm{N} 59^{\circ} 28^{\prime} \mathrm{W}, 90-120 \mathrm{~m}, 7$ II 1985 , Jansen-iacobs et al. 35 (US), 8 iI 1985, Jansen-jacobs et al. 67 (US); Rupununi Distr., Dadanawa, Tawatawun Mountain, $2^{\circ} 50^{\prime} \mathrm{N} 5^{\circ} 9^{\circ} 5^{\prime} \mathrm{W}, 100-250 \mathrm{~m}$, 16 I 1991, Jansen-jacobs et al. 2080 (MO, US); Rupununi Distr., N of Shea, Camp 1, ${ }^{\circ} 57^{\prime} \mathrm{N}$ 5909’W, 190 m, 18 I 1994, Jansen-Jacobs et al. 3249 (US); Rupununi Distr., Kanuku Mts., Crabwood Cr., Camp 2, 307' N 5906' W, 260 m, 4 il 1994, JansenJacobs et al. 3554 (MO, US); Rupununi Distr., Shea Rock, $2^{\circ} 49^{\prime} \mathrm{N}$ 5909' W, 160-220 m, 10 II 1994, JansenJacobs et al. 3673 (MO); Rupununi Distr., Dadanawa, $2^{\circ} 49^{\prime} \mathrm{N} 59^{\circ} 31^{\prime} \mathrm{W}, 120 \mathrm{~m}, 7$ VI 1995, Jansen-Jacobs et al. 3959 (CTES); sin localidad, Jenman 3755 (K); Rupununi Distr. Chaakoitou, near Mountain Point, just $\mathrm{S}$ of Kanuku Mts., 2 $2^{\circ} 56^{\prime} \mathrm{N} 59^{\circ} 40^{\prime} \mathrm{W}, 27$ X 1979, Maas \& Westra 4062 (NY); Rupunoony, Schomburgk s.n. (K); Basin of Rupununi River, near mouth of Charwair Creek, about ${ }^{\circ} 35^{\prime} \mathrm{N}, 1-4$ XI 1937, Smith 2353 (F, K, MO, NY, P, S, US); Western extremity of Kanuku Mountains, in drainage of Takutu River, 422 III 1938, Smith 3121 (B, F, K, NY, P, US, W); Makubere savanna, Kanuku Mts., X 1948, Wilson \& Browne 406 (K, NY). Suriname. Near km 25 in line from Paka Paka (Saramacca R.) to Ebbatop (v.Asch v.Wijck-Ranje), 17 II 1951, Florschiutz \& Florschiitz 1524 (C, NY); sin localidad, 1841, Hostmann 252 (FI, K, P, W), sin localidad, Hostmann 1303 (BM, FI, K, $\mathrm{P}, \mathrm{W})$; Sipaliwini savanna area on Brazilian frontier, $340 \mathrm{~m}, 10$ XII 1968, Oldenburger et al. 621 (NY); Corentyne river near Wonotobo Falls, 14 X 1916, Stahel \& Gonggrijp 3124 (U); sin localidad, Wullschlaegel 773 (BR, W). Guayana Francesa. Vicinity of Cayenne, 21 IV 1921, Broadway 55 (NY, US); ídem, 23 V 1921, Broadway 265 (NY, US); Massif 


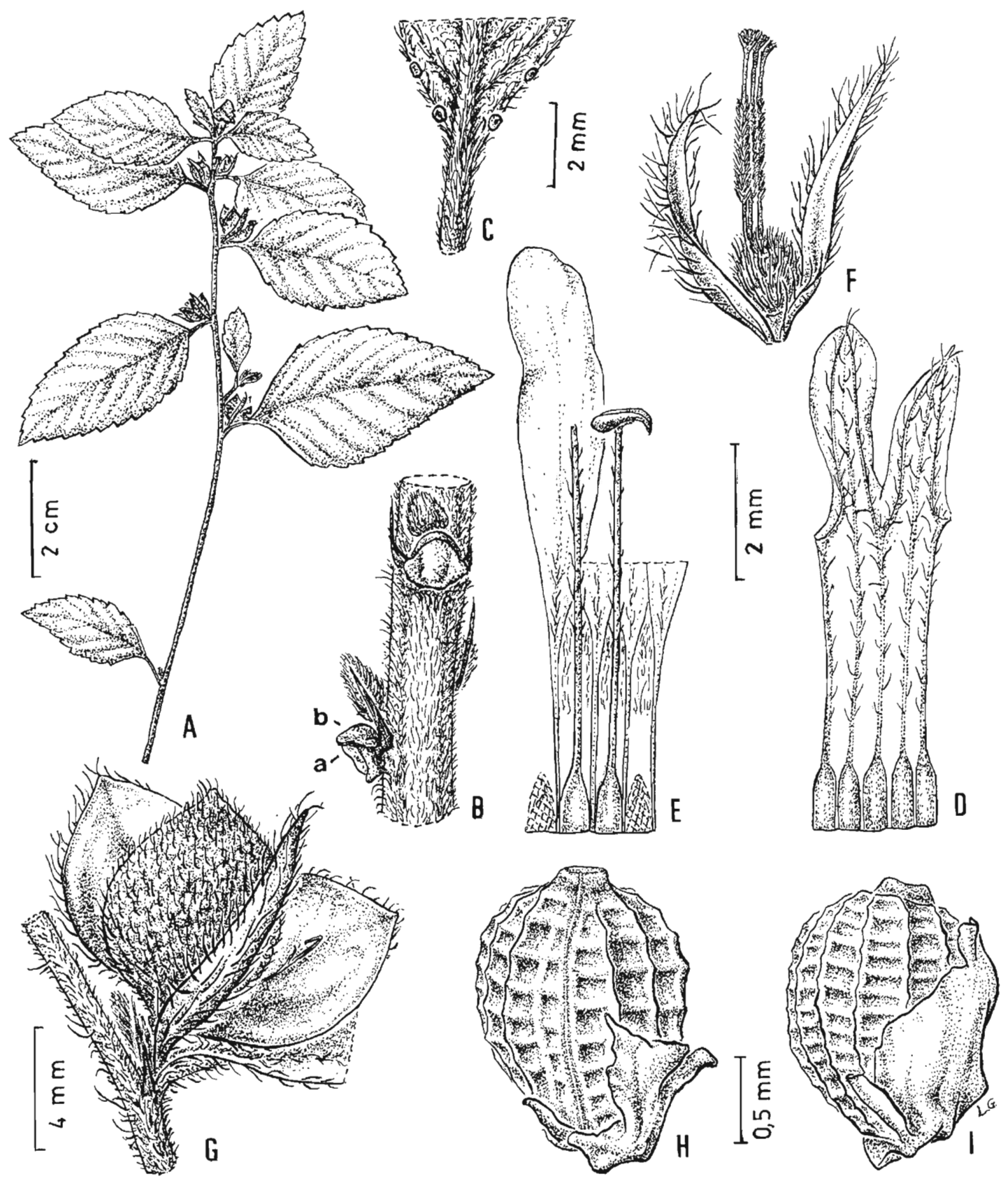

Fig. 3. Turnera odorata. A, rama florífera. B, porción de tallo con cicatrices prominentes, estípulas persistentes y yemas seriales, a: cicatriz del pecíolo; b: cicatriz del pedúnculo floral. C, hoja, envés, mostrando los nectarios. D, porción del cáliz, cara externa: lóbulos interno (izquierdo) y externo (derecho). E, porción del cáliz, cara interna, con pétalos y estambres adnatos, flor brevistila (se han marcado las cicatrices dejadas al desprender dos estambres). F, gineceo con profilos, flor brevistila. $\mathrm{G}$, fruto abierto, con profilo. $\mathrm{H}$, semilla con arilo, vista rafeal. I, semilla con arilo, vista lateral mostrando la cara rafeal (derecha) convexa (A, G-I, Oldeman B-788; B-F, de Granville 5110). 


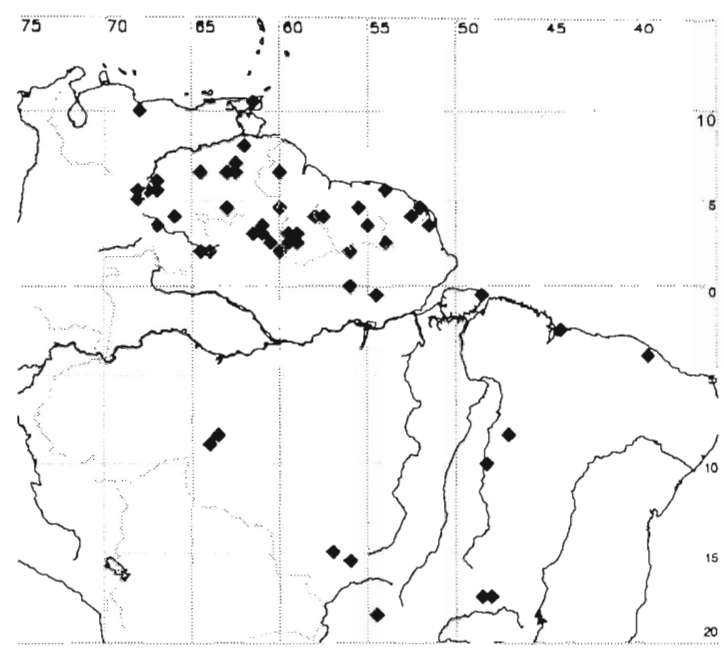

Mapa 5. Distribución de Turnera odorata

des Emérillons, vallée de l'Approuague la DZ, [approx. $3^{\circ} 30^{\prime} \mathrm{N} 55^{\circ} 05^{\prime} \mathrm{W}$ ] 19 XII 1983, Feuillet 1320 (US); littoral de l'Ile de Cayenne, pointe de Montabo, 29 V 1982, Granville 5110 (CTES); Roche forteresse Roche Koutou, Bassin du Haut-Marouini, piton coheux forteresse à $4 \mathrm{~km}$ à l'Ouest versant Sud, $54^{\circ} 07^{\prime} \mathrm{W} 2^{\circ} 52^{\prime} \mathrm{N}, 280 \mathrm{~m}, 20$ VIII 1987, Granville et al. 9574 (US); Montalbo, X 1900, Lemée s.n. (P); Cabassou IRAT, environs de Cayenne, 9 XII 1982, Merlier 236 (CTES); Ile de Cayenne, carrière MC, 27 XII 1966, Oldeman 788 (CTES, P); sin localidad, VII 1824, Poiteau s.n. (K); Maroni, 1862, Rech 27 (P); Cayenne: Rohr s.n. (BM), Rohr 46 (C), 1853, Rothery 112 (K), 25 I 1845, Rothery 251 (K), VIII 1854, Sagot s.n. (P), 1859, Sagot s.n. (P), 1857, Sagot 54 (P), 1858, Sagot 1288 (K, P); Montabo, I 1951, Service Forestier 3351 (P); près Cayenne, III 1897, Soubirou s.n. (P). Trinidad y Tobago. Trinidad: Chacachacare, Baker 14687 (K), Baker \& Simmonds 14887 (K), Crueger s.n. (K); sin localidad, Lockhart s.n. (K). Brasil. Sin localidad, Endlicher s.n. (P); Ferreyra s.n. (P-Juss. 13570A); Copacabana, bas Amazone, Jobert 291 (P); sin localidad, Pohl 68 (W). Amapá: Rio Oiapoque, Cachoeira Grande Roche, $3^{\circ} 48^{\prime} \mathrm{N} 51^{\circ} 53^{\prime} \mathrm{W}$, 11 VIII 1960, Irwin et al. 47413 (CTES, MO, NY, P); Aldeia do Manga-Tribo Karipuma Oiapoque, 20 VIII 1981, Rabelo \& Nonato 1318 (ULM). Amazonas: Terr. Guaporé, Porto Velho, beira da Estrada de Ferro Madeira Mamoré, vizinhanças do Km 4, 28 V 1952, Black \& Cordeiro 52-14575 A (UB). Ceará: sin localidad, 1860, Freire-Allemão s.n. (R); Serra de Maranguape, X 1910, Ule 9041 (K). Goiás: Mun. Caldas Novas, estrada que leva a Alternativa 4, ca.
$5,7 \mathrm{~km}$ da estrada que liga a Obra-UHE Corumbá a Caldas Novas, $17^{\circ} 54^{\prime} \mathrm{S} 48^{\circ} 30^{\prime} \mathrm{W}, 9$ II 1993, Dias et al. 271 (CEN, CTES); Mun. Ipameri, margem esquerda do R.Corumbá, em frente a estação de medicão de vasão S.O.3, area de influencia, 600 m, 23 III 1993, Silva et al. 1265 (CEN, CTES). Maranhão: S.Luiz do Maranhão, Paço do Limiar-Capoeira, 24 I 1976, Barroso \& Guimarães 358 (RB). Mato Grosso: 1833, Gaudichaud 906 (P); Sta. Cruz da Barra, 24 III 1894, Lindman 3217 (S); Cuyabá, 28 XI 1902, Malme 2672 (F, S); Cuyabá, 4 II 1902, Malme 2672a (S); 1891-92, Moore 476 (K, NY, P); prope Cuyabá, I 1827, Riedel 758 (K, P). Mato Grosso do Sul: Rio Coxim, Riedel s.n. (NY). Pará: S.João-S.Anna, Burchell $9151(\mathrm{~K})$; Burchell 9437 (K, P); Salvaterra, Joanes, estrada a Salinas, 10 I 1982, Rosario \& Taylor 134 (NY); Joanes, Marajó, 22 I 1979, Silva \& Rosarno 4936 (NY); Sete

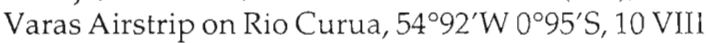
1981, Strudwick et al. 4503 (CTES, NY). Rio de Janeiro: culta, Glaziou 9855 (C, K, P); Glaziou 10880 (C, P). Rondônia: Cachoeira Santo Antonio, $9 \mathrm{~km} \mathrm{~S}$ de Porto Velho, 25 V 1985, Krapovickas et al. 40176 (CEN, CTES, K); Falls of Madeira, X 1886, Rusby 1972 (BM, F, K, MO, NY, P, US, W). Roraima: Serra Grande, Rio Branco, 30 VI 1937, Ducke s.n. (RB); Mun. Alto Alegre, Ilha de Maracá, SEMA Estação, $3^{\circ} 24^{\prime} \mathrm{N} 61^{\circ} 26^{\prime} \mathrm{W}$, Furo Paraná de Firmino of Rio Uraricuera on S side of island, 14 VI 1986, Hopkins et al. 744 (CTES, NY); SEMA Ecological Reserve, Ilha de Maracá, Ilha Nova Clinda, $3^{\circ} 20^{\prime} \mathrm{N} 61^{\circ} 33^{\prime} \mathrm{W}, 3 \mathrm{VII}$ 1987, Milliken \& Bowles 391 (CTES); Dormida,

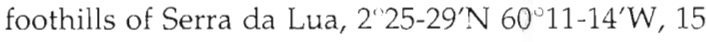
I 1969, Prance et al. 9305 (R); Rıo Branco, Serra de Cacrauma, XI 1908, Ule 7739 (K); Rio Branco, Surumú, Serra de Pracauá, Il 1909, Ule 7954 (K, U). Tocantins: between Porto Real et Funil, Burchell 8832 (K, US); near Conceição, II 1840, Gardner 3753 (K).

Distribución y fenología. Especie propia de Colombia, Venezuela (principalmente al S del río Orinoco), Trinidad, Guayanas y norte y centro de Brasil. Vive en savanas y matorrales, en selva marginal, frecuentemente en lugares rocosos o con suelo arenoso; también en vegetación secundaria, subruderal. Elevación: 80-600 m. Florece durante todo el año.

Nombres vulgares: "cabeza de negro" (Venezuela: Rosales \& Briceño 254); "clavo de especie amarilla" (Venezuela: Liesner \& González 5520); "clavo de especie de savana" (Venezuela: Liesner \& González 5601); "poporamoe" (Suriname: Stahel \& Gonggrijp 3124); "radier anglais" (Guayana Francesa: Sagot s.n.). 
Uso medicinal. "A decoction of the leaves is used as a medicine" (Suriname, Stahel \& Gonggrijp 3124).

Obs. En flores brevistilas el androceo es 2,2$4 \mathrm{~mm}$ más largo que el ginecco; en flores longistilas el gineceo es 3-3,5 mm más largo que el androceo.

Las cicatrices de las hojas tectrices son prominentes, con las estípulas persistentes, y tienen dos caras, hacia arriba está la cicatriz del pedúnculo floral y hacia abajo la cicatriz del pecíolo (Fig. 3B, a-b).

Los ejemplares Dias et al. 271 (Goiás) y Hopkins et al. 744 (Roraima) tienen indumento laxo.

Algunos ejemplares de herbario de esta especie resultan similares a los de Turnera curassavica Urb., de la serie Leiocarpae, que presenta pelos glandulares microcapitados.

\section{Serie Capitatae Urb.}

Mapa 6

Urban 1., Jahrb. Königl.Bot.Gart.Berlin 2: 129. 1883, en parte Urban I. en Martius C.F.P., Fl.bras. 13(3): 143. 1883, en parte.

Sufrútices, arbustos o arbolitos hasta $3 \mathrm{~m}$, pelos simples y glandulares microcapitados (Arbo \& González, 1998). Hojas generalmente de tamaño mediano (2-12 cm long.). Estípulas bien desarrolladas, insertas junto a la base del pecíoio. Nectarios en la unión de pecíolo y lámina o en su margen. Flores generalmente pequeñas, agrupadas en racimos capituliformes terminales o laterales. Pedúnculo floral ausente o desarrollado, inserto en la base del pecíolo en las flores basales de la inflorescencia, y totaimente adnato al pecíoio en las flores apicales. Profilos generalmente iineares, opuestos en la base del receptáculo, a veces estipulados. Pedicelos brevísimos o nulos. Sépalos soldados entre sí aproximadamente hasta la mitad, lóbulos de prefloración quincuncial, los internos frecuentemente con indumento diferente al de los externos. Pétalos blancos, amarillos o rojos, en algunas especies con un apéndice cilíndrico y piloso o con lígula, en la unión de uña y lámina. Filamentos estaminales adheridos ai tubo en su base, por su cara externa; anteras dorsifijas, obtusas c apiculadas. Estilos densamente pilosos c villoso-hirsutos. Fruto de superficie varıble, desde punteado o apenas verrucoso hasta granuloso. Semilla curvada, obovoide u oblongo-obovoide con cálaza prominente y ligeramente cóncava; episperma reticulado o estriado, epidermis lisa, papiiosa o pılosa; arilo unilateral, más corto o más largo que la semilla.

Especie tipo (aquí designada): Turnera capitata Cambess.

Urban (1883a) reunić en la serie Capitatae las especies con flores dispuestas en inflorescen-ias capituliformes axilares o terminales, aclarando en la introducción de su monografía que dicha serie es artificial. En este trabajo el criterio adoptado es que las especies cuyas flores presentan bolsillos nectaríferos (T.blanchetiana Urb. y T.stipularis Urb.) deben excluirse de Capitatae para ser inciuidas en ia serie Anomalae (Arbo, 1997a). También T.dichotoma Gardn. con frutos iisos y aspecto vegetativo peculiar, debe exciurse de Capitatae para ser ¿ransferida a la serie Leiocarpae.

Todas las especies presentan hojas de tamaño mediano, excepto ${ }_{2}^{n}$.marmorata Urb. con ho-

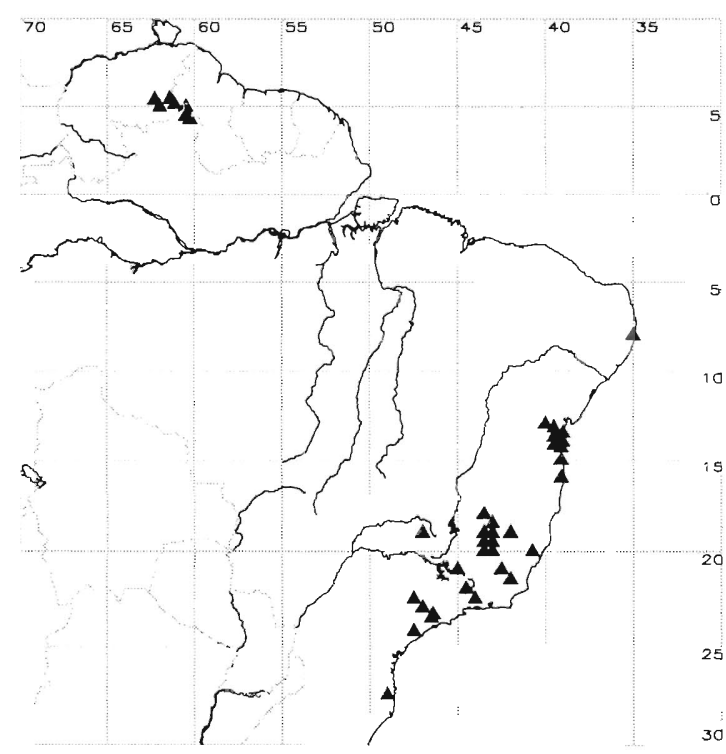

Mapa 6. Distribución de la serie Capitatae 
jas grandes (hasta $21 \mathrm{~cm}$ long.), glabras, que recuerdan las hojas de algunas especies de la serie Salicifoliae. Varias especies presentan flores blancas, otras tienen flores amarilias, y una variedad se diferencia por poseer pétaios rojos.

En esta serie una especie y una variedad presentan pétalos con una lígula membranácea, translúcida y laciniada, difícil de observar con microscopio estereoscópico. Su estructura es iguai a la de la corona (González, 2000), siempre presente en las flores de Piriqueta Aubl. (Arbo, 1995; González, 1993).

Esta serie también presenta área disyunta, dos especies: T. schomburgkianay T. waltherioides, viven en la región donde confluyen Venezuela, Guyana y Roraima (Brasil), entre 400 y 1400 m de altitud, y las restantes son endémicas de Brasil oriental, extendiéndose desde Pernambuco hasta Santa Catarina, desde el nive! del mar hasta los $1500 \mathrm{~m}$ de altitud. La mayor parte de estas plantas vive en el sotobosque, a la sombra de especies arbóreas.

La especie más frecıente y la de área más amplia es T.capitata; dos especies, T.albicans Urb. y T.marmorata Urb. son exclusivas de lá mata de restinga del sur de Bahia, en grave peligro de extinción. Varias especies se conocen solamente a través de la coiección tipo c de unos pocos especímenes.

\section{Clave para las especies de la serie Capitatae}

1. Inflorescencias terminales

2. Estípulas triangulares o subuladas de $0,5-1,5(-2) \mathrm{mm}$ long. Pétalos sin apéndice cilíndrico piloso en la unión de uña y lámina

3. Hojas pilosas en ambas caras o tomentosas en el envés. Flores longistilas con estilos arqueados en la porción media

4. Hojas de pecíolo 1-7 mm long., aserradas o crenado-aserradas, haz densamente pilosa; valvas del fruto con apéndice apical corniforme

5. Hojas ovado-oblongas, elípticas o lanceoladas, relación largo: ancho=2-5:1, flores heterostilas, brácteas apicales lineares o lanceolado-lineares

27. $T$. capitata Cambess.

5. Hojas ovadas u ovado-elípticas, relación largo:ancho $=2-3,5: 1$, flores homostilas, brácteas apicales pecioladas, ovado-oblongas

28. T. dasystyla Urban

4. Hojas subsésiles o el pecíolo hasta 1,5 mm long., ligeramente serruladas, haz escasamente pilusa; valvas del fruto sin apéndice apical corniforme

32. T. pernambucensis Urb.

3. Hojas con pelos simples antrorsos en las venas principales, haz glabra, frecuentumente lustrosa, o muy laxamente pilosa. Flores longistilas con estilos rectos

6. Envés con pelos brevísimos. Pedúnculos nulos. Profilos orbiculares u obovado-espatulados. Cáliz 3-4 mm long. Corola blanca

26. T. albicans Urb.

6. Envés glabro, algunos pelos sobre las venas. Pedúnculos breves, 1-2 mm long., adnados a la bráctea en la base. Profilos lineares. Cáliz $5 \mathrm{~mm}$ long. o más. Corola amarillo-oro

31. T.marmorata Urb.

2. Estípulas subuladas, rojizas, de 1,5-4,5 mm long. Pétalos con apéndice cilíndrico piloso en la unión de uña y lámina (excepto T.hatschbachii var. miniata)

7. Flores 11-14 mm long. (cáliz 7-9 mm long., corola 4-5 mm más larga que el cáliz). Hojas con 0-2 nectarios apenas visibles

30. T. maracasana Arbo

7. Flores 5,5-8 mm long. (cáliz ca. $5 \mathrm{~mm}$ long., corola hasta $3 \mathrm{~mm}$ más larga que el cáliz). Hojas con 4 o más nectarios

8. Hojas anchas, 1,5-5 cm lat., relación largo:ancho =2,4-2,6:1, pilosas en ambas caras, nectarios visibles en la unión de pecíolo y lámina

33. T. princeps Arbo 
8. Hojas angostas, 0,8-1,5 cm lat., relación largo:ancho = 4-6,5:1, haz con pelos simples esparcidos o glabra excepto la vena media, nectarios diminutos en los dientes inferiores

9. Arbusto hasta 1,2 $\mathrm{m}$ alt. Corola blanca 1,5-5 mm más larga que el cáliz, pétalos con apéndice piloso en la unión de uña y lámina

29a. T.hatschbachii Arbo var. hatschbachii

9. Arbolito de $3 \mathrm{~m}$ alt. Corola roja, ligeramente más larga que el cáliz, pétalos con lígula, sin apéndice piloso en la unión de uña y lámina

29b. T.hatschbachii var. miniata Arbo

1. Inflorescencias laterales, subsésiles o brevemente pedunculadas

10. Hojas cartáceas, latielípticas o lanceoladas, indumento formado por pelos simples, curvado-antrorsos, laxamente dispuestos, a veces el envés tomentoso. Brácteas externas con nectarios pediculados

34. T. schomburgkiana Urb.

10. Hojas coriáceas, ovadas, ovado-elípticas u obovadas, indumento tomentoso-velutino en ambas caras. Brácteas externas a veces con nectarios diminutos

35. T. waltherioides Urb.

\section{Turnera albicans Urb.}

Fig. 4, Mapa 7

Urban i., Jahrb.Königl.Bot.Gart. Berlin 2: 135, tab. 2: figs. 56-57. 1883. Urban I. en Martius C.F.P., Fl.bras. 13(3): 155, tab. 47, 1883 . Tipo: BRASIL. Bahia: in sylvis umbrosis prope Ilheos [Ilhéus], II 1822, Riedel L. 743 (holoiipo LE; isotipos: BR!, C!, $\mathrm{K} !, 3 \mathrm{P}$ !, S!, W!).

Arbusto $40-80 \mathrm{~cm}$, ramificado, parte basal del tallo con corteza de color castaño claro, súber blanquecino; ramas del año cilíndricas, rojizas, con pelos simples, cortos y antrorsos. Yemas seriales 1-2, ramas seriales floríferas a veces desarrolladas. Hojas generalmente coriáceas. Estípulas insertas junto a la base del pecíolo, triangulares, 0,3-1,5 mm long., pilosas. Pecíolo semicilíndrico 2,5-10 mm long., indumento como el del tallo. Nectarios 1-3 pares, de contorno circular o elíptico, 1,5-2 mm long., en la unión de pecíolo y lámina, o en la base de la lámina, sobre el margen, orientados lateralmente, reborde glabro, parte central con membrana cuticular amarillenta o parda en seco. Lámina elíptica u obovada, 8-13 x 2,5-5 $\mathrm{cm}$, relación largo:ancho $=2,4-3,6: 1$, base atenuada, margen ligeramente revoluto, entero en la porción basal, hacia arriba serrulado, dientes glandulosos, ápice agudo u obtuso brevemente apiculado; haz glabra excepto la vena media con pelos simples; envés con pelos erectos muy cortos; 5-11 pares de venas laterales hundidas en la haz, prominentes en el envés, alternas o subopuestas, ángulo de divergen- cia $57-80^{\circ}$, incurvas, perdiéndose hacia el margen; venas terciarias a veces visibles en la haz, perpendiculares a la vena media o recurvas; venación menor a veces visible en el envés. $R a^{-}$ cimos apicales bracteosos capituli-formes 0,7$2 \mathrm{~cm}$ diám. Brácteas basales estipuladas, con 1-2 pares de nectarios, ovado-elípticas, apiculadas o agudas; las siguientes exestipuladas, sin nectarios, suborbiculares o latiovadas, 2,5$3,5 \times 2-2,3 \mathrm{~mm}$, ápice obtuso o emarginado, cara externa pilosa, con pelos simples dorados o rojizos más largos y crespos sobre la vena media y el borde, cara interna glabra. Flores sésiles heterostilas. Profilos dispuestos en la base del cáliz, obovados o espatulados, 1,9-2,8 x 0,8-1,5 mm, base atenuada, ápice obtuso, indumento como el de las brácteas. Cáliz 4-5 $\mathrm{mm}$ long., tubo 2-2,5 mm long., cara externa a veces casi glabra en la base, con pelos simpies brevísimos y pelos más largos sobre ias venas, cara interna glabra excepto la garganta vellosa; lóbuios densamente pilosos por fuera, pelos simples ca. $1 \mathrm{~mm}$ long., dorados o ferrugíneos, cara interna glabra, ápice agudo, lóbulos internos con márgenes membranáceos. Corola blanca, ca. 1 mm más larga aue el cáliz; pétalos con uña glabra, lámina ca. 3 × 1 $\mathrm{mm}$, haz vellosa hasta la mitad, envés glabro. Filamentos estaminales soldados $0,8-1 \mathrm{~mm}$ al tubo en la base, porción libre pilosa en ambas caras, $3 \mathrm{~mm}$ iong. en flores longistilas, $4 \mathrm{~mm}$ long. en flores brevistilas; anteras ovadas, 0,6$0,8 \times 0,3-0,5 \mathrm{~mm}$, base emarginada, ápice agudo, con pelos en el borde inferior y ápice, filamento inserto dorsalmente cerca de la mitad. 


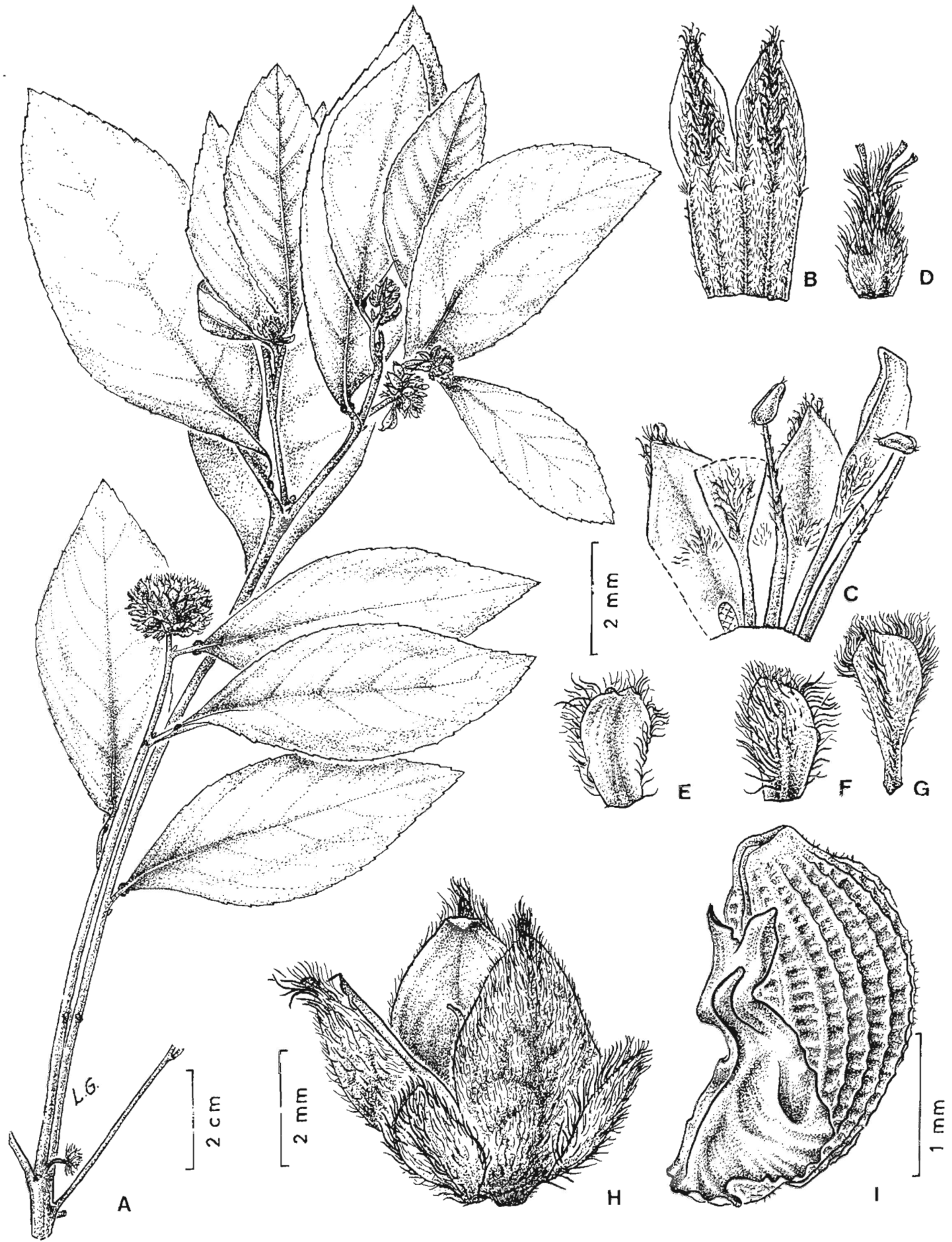

Fig. 4.Turnera albıcans. A, rama florífera. B, porción del cáliz, cara externa: lóbulos interno (izquierdo) y externo (derecho). C, porción del cáliz, cara interna, con pétalos y estambres adnatos, flor brevistila (se ha marcado la cicatriz dejada al desprender un estambre). D, gineceo de flor brevistila. E, bráctea, cara interna. F, brác:ea, cara externa. G, profilo, cara externa. II, fruto abierto en la axila de bráctea (izquierda), con un profilo (derecha). I, semilla con arilo, vista lateral mostrando el extremo superior de la rafe hacia la izquierda (A,Morletal. 10924; B-G,Mattos Silía et al. 1414, I 1-i,Santos 1282). 
Ovario elipsoide, 1-1,7 mm long., hirsuto, pelos cortos en la base y más largos hacia el ápice, placentas 2-3 ovuladas; estilos cilíndricos, rectos, densamente pilosos excepto en la base y en el ápice, 3,5-4 $\mathrm{mm}$ long. en flores iongistilas, 1-1,5 mm long. en flores brevistilas; estigma brevísimo, 0,3 mm long. Fruto ovoide, 2,5-5 mm long., valvas con cara externa impreso-reticulada o verrucosa, pilosa, parda, cara interna lisa, castaña, amarillenta o jaspeada, glabra, ápice con un apéndice corniforme y piloso, recurvadas a la dehiscencia y separándose hasta cerca de la base. Semilla obovoide, 2,2-3 x 1,1-1,5 $\mathrm{mm}$, relación largo:ancho $=1,5-2: 1$; ligeramente curvada, exóstoma cónico o hemisférico, 0,2-0,3 mm long., rafe linear, cara rafeal sigmoidea, cóncava hacia la base y ligeramente convexa hacia la cálaza, ésta prominente y cóncava; episperma reticulado, epidermis papilosa, muros longitudinales prominentes, muros transversales tenues, aréolas transrectangulares o cuadrangulares con una depresión punctiforme; arilo blanquecino, borde lobulado, casi tan largo como la semilla.

Material examinado. Brasil. Bahia: Santa Cruz Cabrália, 5 XI 1966, Belem \& Pinheiro 2830 (NY, UB, US); Mun. Ilhéus, Fazenda Barra do Manguinho, ramal com entrada no Km 10 da Rod. Pontal/ Olivença, lado direito, $3 \mathrm{~km}$ a oeste da rodovia, 5 II 1982, Mattos Silva et al. 1414 (CEPEC, CTES, UEC); Mun. Sta. Cruz de Cabrália, 2-4 km a W de Sta. Cruz de Cabrálıa, pela estrada antiga, 21 X 1978, Mori et al. 10924 (CTES); Mun. Ilhéus: Rodovia Pontal/ Olivença, 12 XI 1970, Santos 1282 (CTES, UEC); 10 $\mathrm{km} \mathrm{S}$ of Ilhéus airport on road to Olivença, then 3 $\mathrm{km} \mathrm{W}, 14^{\circ} 59^{\prime} \mathrm{S} 39^{\circ} 03^{\prime} \mathrm{W}, 3$ II 1993, Thomas et al. 9734 (NY).

Distribución y fenología. Especie rara, aparentemente endémica de la selva de restinga ai sur de Bahia, y probablemente en peligro de extinción. Florece desde octubre a febrero.

Obs. Los nectarios de las hojas basales muestran la cutícula rasgada, y muchos están comidos. En flores longistilas el gineceo es 1,7$2 \mathrm{~mm}$ más largo que el androceo. En flores brevistilas el androceo es 1,5 mm más largo que el gineceo.

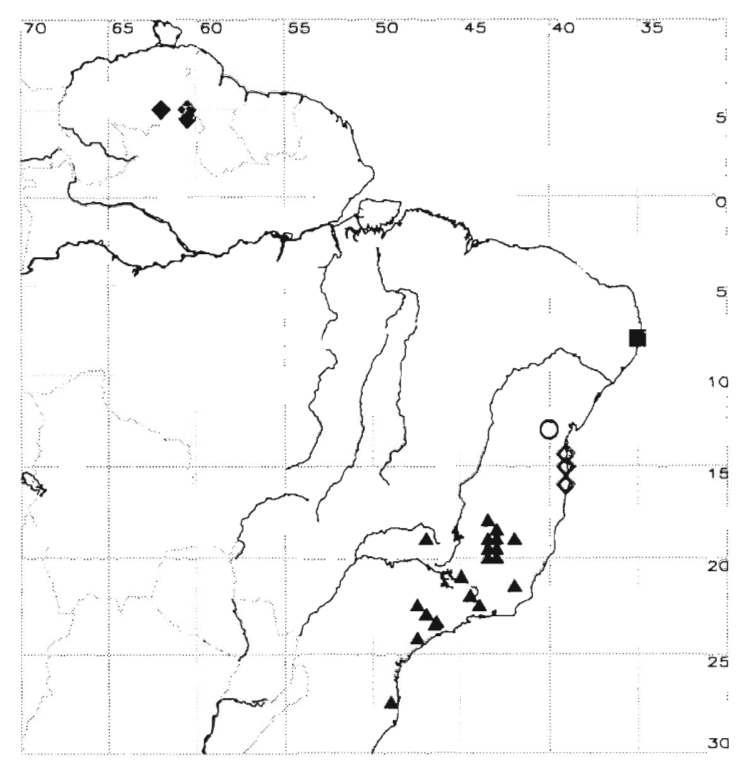

Mapa 7. Distribución de Turnera albicans $\diamond$, T.capitata T.maracasana $O ; T$.pernambucensis $\mathbf{\square} T$. schomburgkiana

\section{Turnera capitata Cambess.}

Fig. 5: Mapa 7

Saint Hilaire A., A. de Jussieu \& J. Cambessèdes, Fl.Bras.merid. 2: 215. 1830. Urban I., Jahrb. Königl. Bot. Gart. Berlin 2: 133, tab. 2: figs. 74 y 75. 1883. Urban I. en Martius C.F.P., Fl.bras. 13(3): 153. 1883. Lectotipo (aquí designado): BRASIL. Minas Gerais: bords d'un bois près Pouso Alto, Saint Hilaire A. $D$ 562 (P!).

Turnera capitata Cambess. subsp. capitata forma rufescens Urb., Jahrb.Königl.Bot.Gart.Berlin 2: 134. 1883. Urban I. en Martius C.F.P., Fl.bras. 13(3): 154. 1883. Tipo: BRASIL. São Paulo: in fruticetis montosis prope Bananal, X 1833, Riedel L. 1402 (holotipo, LE!; isotipos: K!, M!, P!; B destruido, Foto F 13570!).

Arbusto o subarbusto 0,3-1,5 m, laxamente ramificado, ramas apoyantes, las viejas rojizas, pilosas o glabrescentes, estriadas longitudinalmente; ramas del año cilíndricas, con pelos cortos crespos y pelos largos curvado-antrorsos, hacia los ápices dorado-tomentosas; yemas axilares seriales 2 , ramas seriales a veces desarrolladas. Hojas algo discoloras; estípulas 0,6-1,5(-2) mm long., triangulares a subuladas, pilosas, rojizas, insertas en la base del pecíolo; 


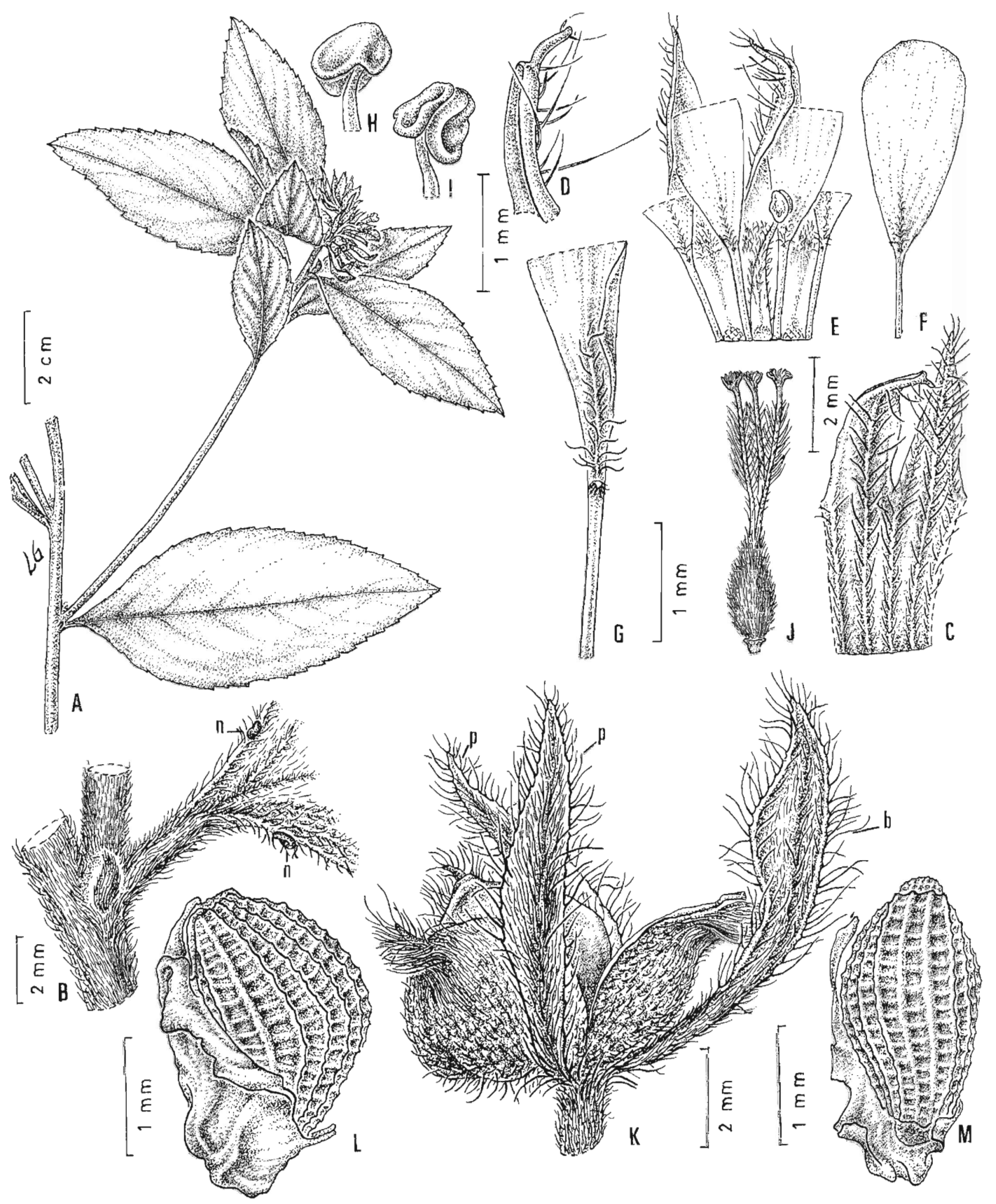

Fig. 5. Turnera capitata. A, rama florífera. B, porción de tallo mostrando una base foliar con estípulas, la hoja con nectarios (n) y una rama axilar. C, porción del cáliz, cara externa: lóbulos interno (izquierdo) y externo (derecho). D, porción apical cuculada de un sépalo interno, con mucrón. E, porción del cáliz, cara interna, con pétalos y esta mbre adnatos, flor longistila (se han marcado las cicatrices dejadas al desprender dos estambres). F, pétalo, cara interna. G, detalle del pétalo mos trando la lígula. $\mathrm{H}$, antera, vista de perfil. I, antera, vista de frente. J, gineceo de flor longistila. $\mathrm{K}$, fruto abierto con profilos (p) y bráctea axilante (b) L, semilla con arilo, vista lateral, rafe hacia la izquierda. M, semilla, cara opuesta a la rafeal (A-B, E-F y J-M, Saint Hilarre D-562; C-D y G-I, Saint Hilaire 770). 
pecíolo semicilíndrico 1-7 $\mathrm{mm}$ long., indumento como el del tallo; lámina foliar 32-108 (hasta $140 \mathrm{~mm}$ según Urban) x 9-41 mm, relación largo:ancho $=2-5: 1$, angustiovada, elíptica o angustielíptica, a veces ovada, base obtusa, brevemente atenuada o cuneada, ápice agudo o acuminado, a veces obtuso, margen serrulado o aserrado, simple o doblemente, desde la base, plano o ligeramente revoluto, densamente piloso, con 1-5 pares de nectarios 0,3-1 mm diám. ubicados en los dientes basales; haz rojiza o parda, con pelos simples densos, base cónica prominente en seco, frecuentemente rojiza; envés más claro, con indumento igual, más denso, pelos de base no ensanchada; venas principal y 6-9 pares de venas laterales alternas, a veces subopuestas, perdiéndose hacia el margen, hundidas en la haz, pero formando prominencias en los surcos, prominentes en el envés, densamente cubiertas de pelos largos, dorados o rojizos, antrorsos, ángulo de divergencia $27-45^{\circ}$, venas terciarias ligeramente visibles en el envés, más o menos perpendiculares a la vena media o un poco recurvas, venación menor poco conspicua. $R a-$ cimos apicales bracteosos muy abreviados, al principic capituliformes, 30-60-floros (seg. Urban) las flores basales a veces separadas; hojas tectrices súbitamente reducidas a brácteas, las basales elíptico-lanceoladas, 9-11 $\times 2,5-4 \mathrm{~mm}$, dentadas, las apicales lineares, 5 $8 \times 0,5-1,5 \mathrm{~mm}$, enteras. Flores heterostilas. Pedúnculos 1-3,5 $\mathrm{mm}$ long., los basales insertos en la base del pecíolo, los siguientes adnatos al pecíolo de la bráctea, adnación gradualmente mayor hasta ser total en las flores apicales. Pedicelos brevísimos en flores basales, en las apicales nulos. Profilos opuestos en la base del receptáculo, 4,5-9(-11) x 0,3$0,7(-1,5) \mathrm{mm}$, lanceolados en flores basales, :uego lineares, enteros, pilosos, a veces con estípulas breves $0,3 \mathrm{~mm}$ long. Cáliz 5,5-8 mm long., tubo 1,5-2,8 mm long., por fuera con pelos simples densos, por dentro glabro en la base y velloso en la garganta, lóbulos triangulares 3-nervados, cara externa con pelos más largos que el tubo, mucrón apical 0,4-1 mm long. Corcla iguai que el cáliz hasta $1,5 \mathrm{~mm}$ más larga, pétalos con ìa uña soldada al tubo, con una lígula membranácea, translúcida en seco, laciniada, de 0,1-0,3 mm long. inserta hacia el ápice de la uña, lámina obovada, 3,3-6 x 1,5-2 $\mathrm{mm}$, blanca, porción basal vellosa y amarilla, ápice obtuso o brevemente apiculado. Filamentos estaminales complanado-subulados, adnatos 0,3-0,5 $\mathrm{mm}$ al tubo en la base, vellosos en ambas caras en la mitad superior, 2-2,5 mm long. en flores longistilas, $4-5 \mathrm{~mm}$ long. en flores brevistilas, anteras ovadas, $0,5-0,9 \times 0,4-0,7$ $\mathrm{mm}$, dorsifijas, base emarginada, ápice obtuso brevemente recurvo a la dehiscencia. Ovario 0,8-1,8 mm long., ovoide, hirsuto, placentas 48-ovuladas; estilos cilíndricos, 2,8-3,5 mm long. en flores longistilas, en el tercio inferior con pelos escasos o densos, en la porción media dilatados e hirsutos, incurvo-arqueados, extremo glabro; 0,7-0,9 $\mathrm{mm}$ long. en flores brevistilas, excurvos, hirsutos; estigma con ca. 25 ramas de 0,3-1 mm long. en flores longistilas, 0,2-0,4 mm long. en flores brevistilas. Fruto ovoide, 2,5-5 mm long., valvas ovadas, por fuera verrucosas, pilosas, con un apéndice corniforme, piloso, 0,7-1,5 mm long. en el ápice (probablemente prolongación de la vena marginal), por dentro lisas, lustrosas, glabras excepto algunos pelos en la base, vena placentaria poco prominente, llegando hasta la mitad de la valva. Semilla obovoide, 1,8-2,4x 1-1,5 mm, recta o curvada, cálaza prominente, cóncava, rafe linear, exóstoma cónico, episperma negro a la madurez, glabro, estriado-reticulado, muros longitudinales muy prominentes, muros transversales poco salientes, muy próximos entre sí, células epidérmicas no papilosas; arilo amplio, envolvente, blanquecino en seco, borde lobulado, más corto o más largo que la semilla.

Material examinado. Brasil. Sin indicación de estado: sin localidad, 31 V 1864, Regnell s.n. (S); $\sin$ localidad, Sellow s.n. (K). Minas Gerais: Serra do Cipó, 16 I 1951, Andrade-Lima 51-851 (IPA); Mun. Alvorada de Minas, alrededores de Itapanhoacanga, base de la Serra do Espinhaço, $18^{\circ} 46^{\prime} \mathrm{S} 43^{\circ} 27^{\prime} \mathrm{W}, 17$ $\checkmark 1990$, Arbo et al. 4335 (CTES, GH, K, LIL, SPF); Mun. Santa Bárbara, Serra do Caraça, camino a la Capelinha, ca. $20^{\circ} 05^{\prime} \mathrm{S} 43^{\circ} 27^{\prime} \mathrm{W}, 1270-1350 \mathrm{~m}, 18 \mathrm{II}$ 1991, Arbo et al. 5269 (CTES, F, LPB, MEXU, NY, SI, SPF); Mun. Santa Bárbara, Parque Natural do Caraça, arredores da Cascatinha, ca. $20^{\circ} 07^{\prime} \mathrm{S}$

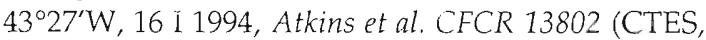
SPF); BR-267, km 238, 24 km antes de Bom Jardim de Minas, na direção de Juiz de Fora, 2 II 1998, Dutilh 
\& Marcondes Ferreira 51 (CTES, UEC); Campus Icex, Belo Horizonte, IV 1978, Ferrari s.n. (BHCB, CTES); Campus UFMG, Belo Horizonte, III 1979, Ferrari 411 (BHCB, CTES); Pozo Alegre, X 1840, Gardner 4440 (K, W); Faria, 27 I 1891, Glaziou 17621 (P); Itabira do Campo, 21 XII 1888, Glaziou 18260 (BR, C, K, P); Mun. Itamonte, Serra de Mantiqueira, 10 X 1982, Hatschbach \& Kummrow 45579 (CTES, MBM, MO); Sabará, I 1916, Hoehne 6889 (SP); prox. Belo Horizonte, estrada para Lagoa Santa, 15 I 1951, Joly 1128 (SP); Belo Horizonte, Jardim Botánico, 2 II 1978, Krapovickas \& Cristóbal 33396 (CTES, LIL, MBM); Serra do Cipó, 16 I 1951, Kuhlmann \& Edmundo s.n. (RB); ca. $5 \mathrm{~km} \mathrm{~N}$ of São João da Chapada, road to Inhaí, 1200 m, 28 III 1970, Irvin et al. 28509a (P); Serra do Mesquita, 1893, Magalhäes Gomes 1265 (EM); Mun. Belo Horizonte, Serra do Taquaril, 23 III 1933, Mello Barreto 8182 (F); sin localidad, 25 I, Riedel 1372 (NY, US); probablemente "prope Nossa Snra. da Conceção", Saint Hilaire 770 (P); Lagoa Santa, 25 I 1864, Warming s.n. (C); Mun. Itabirito, Pico de Cata Branca, ca. 1300 m, 21 VI 1945, Williams \& Assis 7364 (SP). Rio de Janeiro: Santa Maria Madalena, Pedra Dubois, 1000 m, 8 III 1935, Santos Lima \& Brade s.n. (RB). Santa Catarina: Pilões, Palhoça, 350 m, 23 II 1956, Reitz \& Klein 2845 (B, NY, US), 28 IX 1956, Reitz \& Klein 4002 (NY, S, US); Mun. Palhoça, Pilões, ca. $27^{\circ} 40^{\prime} \mathrm{S} 48^{\circ} 40^{\prime} \mathrm{W}, 50-700$ m, 14 III 1952, Smith 6220 (US). São Paulo: São Paulo, Parque Estadual das Fontes do Ipiranga, trilhas do núcleo de Lazer, 5 XI 1996, Catharmo et al. 2154 (CTES); São Paulo, grounds of the Instituto Botanico, 860 m, 21 II 1976, Davidse \& D'Arcy 10496 (MO, SP); São Paulo, Jardim Botânico, 13 I 1943, Gehrt s.n. (CTES, SP); Parque E.S.Paulo, Cap., 10 III 1944, Hoehne 1226 (CTES, SP); Mun. Campinas, perto do Aeroporto de Viracopos, 21 I 1976, Leitão Filho et al. 1607 (UEC); São Paulo, nativa no Jardim Botânico, 5 II 1965, Moura s.n. (CTES, SP); inter S.Carlos et Y:ú, II 1834, Riedel 1996 (BR, C, FI, K, M, P, S, W); São Paulo, Sto. Amaro, 23 I 1942, Roth 91 (SP); São Paulo, Santoro 801 (US); Mun. S. Paulo, Instituto de Botanica, Parque do Estado, 8 XI 1966, Sendulsky 408 (RB, SP); São Paulo, jardim Botânico e Parque do Estado, 6 VIII 1968, Sendulsky 824 (CTES, SP); Villa Mariana, 15 I 1906, Usteri 22 (BM, SP).

Distribución y fenología. Especie propia de Minas Gerais, Rio de Janeiro, São Paulo y Santa Catarina; crece en selva marginal y cerrado, a veces en campos, generalmente en terreno pedregoso y húmedo, de 50-1500 m alt. Prospera también en ambientes modificados como bordes de caminos o selva degradada. Las plantas están aisladas en el sotobosque, no for- man grupos. Florece desde agosto hasta junio, la mayor parte de los ejemplares han sido recolectados desde enero a marzo.

Obs. Las primeras hojas que nacen sobre las ramas seriales son filiformes, oscuras, $2-7 \mathrm{~mm}$ long.

En flores longistilas el gineceo es 2-3 mm más largo que el androceo; en flores brevistilas, el androceo es 1,4-2,5 mm más largo que el gineceo. Los lóbulos del cáliz y la corola no están retorcidos en las flores marchitas. En las inflorescencias terminales los frutos se desprenden dejando cicatrices notables; en ia axila de las brácteas se desarrollan 1-2 ramitas seriales floríferas.

En los especímenes Santos Lima \& Brade s.n y Williams \& Assis 7364 se indica que las flores son amarillas.

En Arbo ct al. 5269 todas las plantas examinadas presentan flores brevistilas, con el androceo 0,9-1,5 mm más largo que el gineceo, a veces la base de las anteras ligeramente en contacto con el ápice del estigma.

El ejemplar Leitão Filho et al. 1607 presenta en la base de un racimo, dos frutos en la axila de una hoja, como si un profilo fuera fértil y de su axila nace el pedúnculo que sostiene al otro fruto.

El ejemplar Mello Barreto 8182 (F 930874) fue muestreado para glucósidos cianogénicos, con resultado negativo (Spencer, Seigler \& Fraley, 1985).

\section{Turnera dasystyla Urb.}

Fig. 6, Mapa 8

Urban I., But.Jahrb.Syst. 25, Beibl. 40: 10. 1898. Tipo: BRASIL. Minas Gerais: Barra, Ouro Preto, terreno pedregoso, flores brancas, 1893, Magalhães H. de s.n. (holotipo destruido: herb. Schwacke 9335, B; lectotipo aquí designado: EM!).

Arbusto o subarbusto $0,30-0,80 \mathrm{~m}$, las ramas viejas rojizas, glabrescentes, estriadas longitudinalmente; ramas del año cilíndricas, con pelos simples, cortos, crespos y pelos largos, curvado-antrorsos o adpresos, hacia los ápices dorado-tomentosas; yemas axilares seriales 2, ramas seriales a veces desarrolladas. Hojas algo discoloras; estípulas $0,5-1(-1,8) \mathrm{mm}$ long., subuladas, rojizas, pilosas, insertas junto a la base del pecíolo; pecíclo semicilíndrico 3-7 mm 


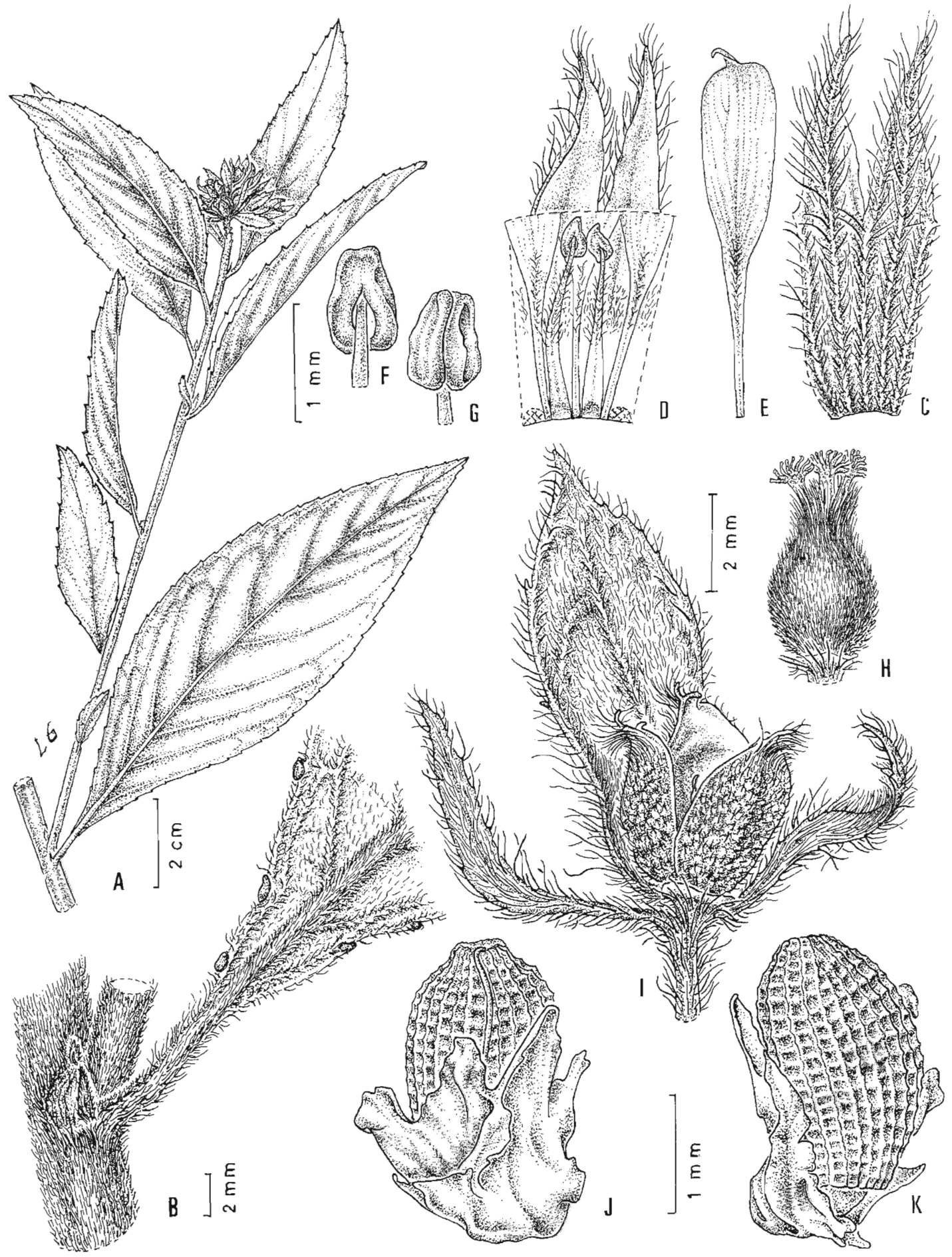

Fig. 6. Turnera dasystyla. A, rama florífera. B, porción de tallo mostrando una base foliar con estípulas, la hoja con nectarios, una rama axilar y una yema serial. C, porción del cáliz, cara externa: lóbulos interno (izquierdo) y externo (derecho). D, porción del cáliz, cara interna, con pétalos y estambres adnatos, flor homostila (se han marcado las cicatrices dejadas al desprender dos estambres). E, pétalo. F, antera, cara externa. G, antera, cara interna. $\mathrm{H}$, gineceo de flor homostila. I, fruto abierto con profilos y bráctea. J, semilla con arilo, vista rafeal. $K$, semilla con arilo, cara opuesta a la rafe (A-B, E y I-K, Irvin et al. 30589; C-D y F-II, Leitão Filho et al. 9657). 
long., !ndumento como el tallo; lámina foliar 25-125 x 8-39 $\mathrm{mm}$, relación !argo:ancho $=2$ 3,9:1, ovada, angustiovada o elíptica, base cuneada, ápice agudo c acuminado, a veces obtuso, margen simple o doblemente aserracio casi desde la base, plano o ligeramente revoluto, densamente piloso, con 2-6 pares de nectarios 0,3-1,2 mm diám. ubicados en los dientes basales; haz rojiza o parda, con pelos simples curvos, base cónica en seco, frecuentemente rojiza; envés más claro, con indumento igual, más denso; vena principal y 6-9 pares de venas laterales alternas, a veces subopuestas, ligeramente saiientes en la haz, prominentes en el envés, densamente cubiertas de pelos largos, aorados o rojizos, adpresos, ángulo de divergercia $25-45^{\circ}$, perdiéndose hacia el margen, venas terciarias ligeramente visibles en el envés, más o menos perpendiculares a la vena media o un poco recurvas, venación menor poco conspicua. Racimos apicales bracteosos muy abreviados, al principio capituliformes, las flores basales a veces separadas; hojas tectrices súbitamente reducidas a brácteas, 5$11 \times 1,5-6 \mathrm{~mm}$, ias basales ovadas u obovadas, dentadas, agudas, ias apicaìes lanceoladas, serruladas o enteras. Flores blancas, homostilas. Pedúncuios 1,5-2 mm long., los basales casi libres, los apicales totalmente adnatos. Pedicelos nulos, a veces ligeramente desarrollados. Profilos opuestos en la base del receptáculo, 5$9 \times 0,5-1,5 \mathrm{~mm}$, lanceolados o lineares, enteros, pilosos, a veces con estípulas breves 0,3 $\mathrm{mm}$ long. Cáliz 6-7,5 mm long., tubo 2-3,5 mm long., por fuera con pelos simples densos, por dentro glabro en la base y velloso en la garganta, lóbulos triangulares 3-nervados, cara externa con pelos más largos que el tubo, mucrón apical 0,5-0,7 mm long. Corola igual que el cáliz o hasta $2 \mathrm{~mm}$ más larga, pétalos con la uña soldada al tubo, lámina obovada, 4,5-6 x 1,5-2 mm, blanca, vellosa en ia base, ápice obtuso o brevemente apiculado. Filamentos estaminales complanado-subulados, adnatos $0,5 \mathrm{~mm}$ al tubo en la base, vellosos en ambas caras en la mitad superior, 2-5 mm long., anteras ovadas, 0,6-0,8 x 0,4-0,6 mm, dorsifijas, base emarginada, ápice obtuso. Ovario 0,8-2,3 mm long., ovoide, hirsuto, placentas 4-8ovuladas; estilos cilíndricos, 0,7-3,2 mm long., ligeramente excurvos, glabros en la base, lue-

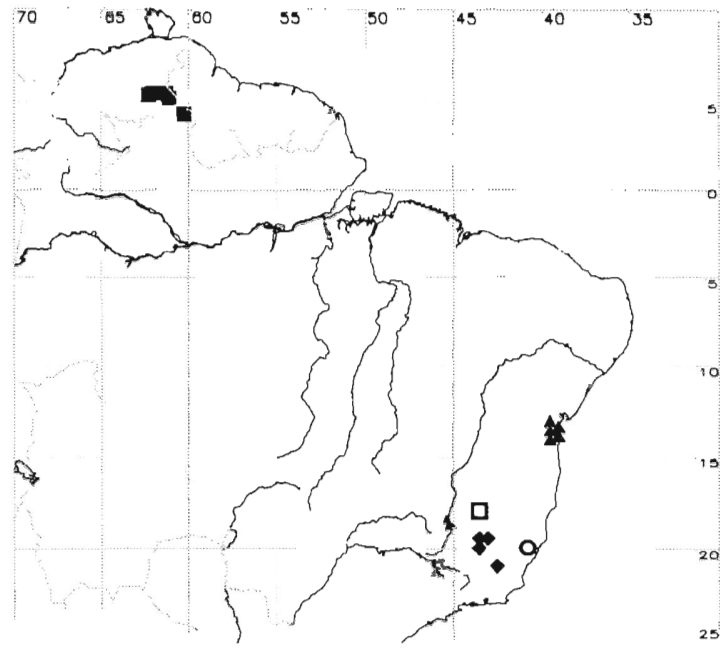

Mapa 8. Distribución de Turnera dasystyla $\bullet$, Thatschbachii $\bigcirc$, T.marmorata $\mathbf{\Lambda}$, T.princeps $\square$ y T.waltherioides

go hirsutos; estigma penicilado, 0,3-0,5 mm long. Fruto ovoide, $3-5,5 \mathrm{~mm}$ long., valvas ovadas, por fuera verrucosas, pilosas, con un apéndice corniforme, piloso, 0,3-1 mm long. en al ápice (probablemente prolongación de la vena piacentaria), por dentro lisas, lustrosas, glabras, vena placentaria poco prominente, llegando hasta la mitad de la valva. Semilla recta, obovoide, 1,7-2,1 x 1-1,3 mm, reíación largo:ancho =1,4-1,7:1, cálaza prominente, cóncava, rafe linear, exóstoma cónico, episperma negro a la madurez, glabro, estriado-reticulado, muros longitudinales más prominentes que los transversales; arilo amplio, envolvente, blanquecino en seco, borde lobulado, tan largo como la semilla o más.

Material examinado. 3rasil. Minas Gerais: Venda do Campo, Badint s.n. (EM 20510); Itamarati de Minas/São João Nepomuceno, Mineração de Alumínio-CBA, I 1998, Costa s.n. (CTES); Serra do Espinhaço, ca. $34 \mathrm{~km}$ E of Belo Horizonte, road BR31 to Roças Novas, ca. 1500 m, 17 I 1971, Irwin et al. 30589 (P, UB); Mun. Santa Bárbara, Serra do Caraça, 13 XII 1978, Leitão Filho et al. 9657 (UEC); Mun. Ouro Preto, Saramenha, 1892, Magallines Gomes 2622 (EM 1758); prope Ouro Preto, locis graminosis ad Tripuhy, XII, Herb. Schwacke 9973 (B destruido, Foto F 13575!). 


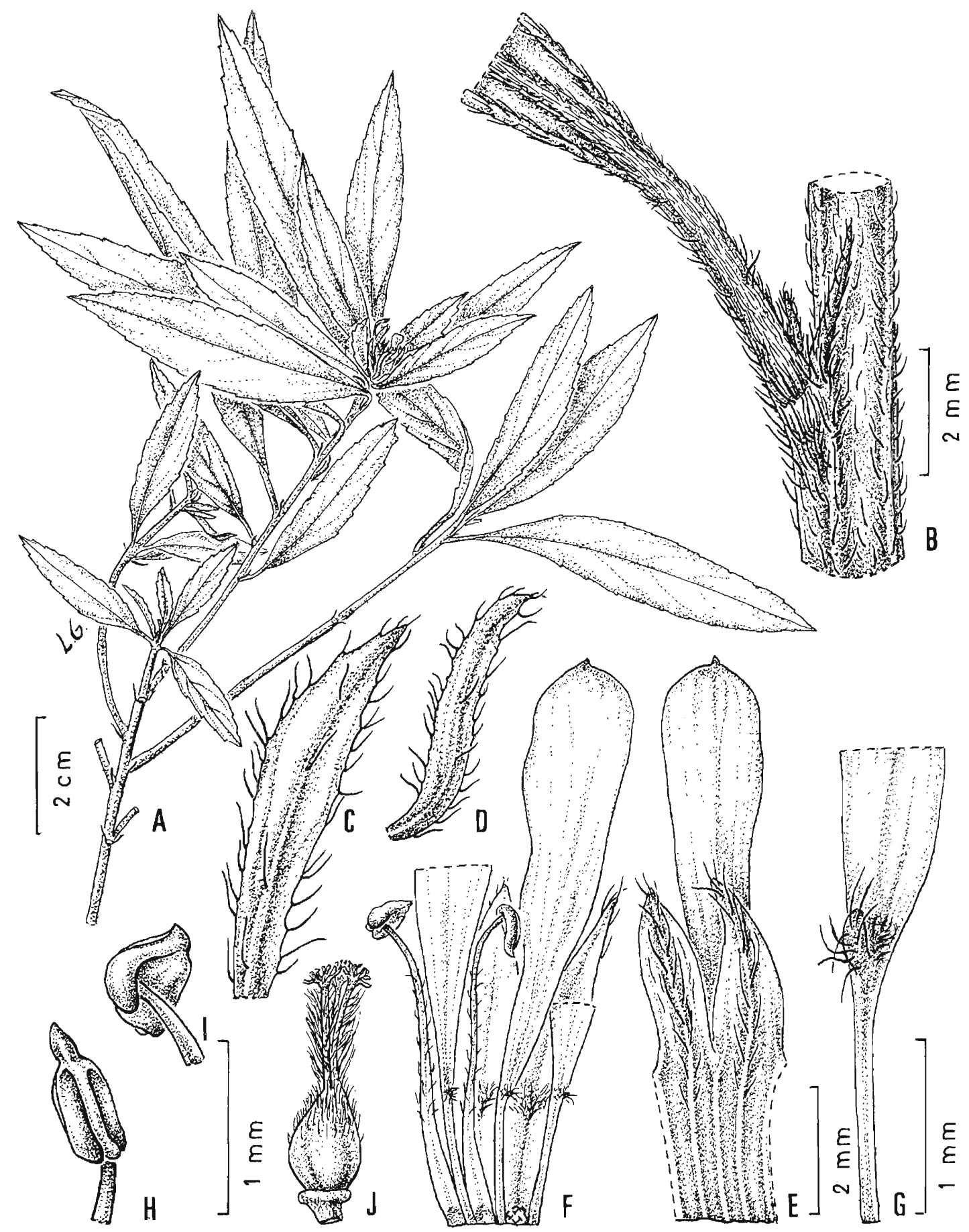

Fig. 7. Turnera hatschbachii var. hatschbachii. A, rama florifera. B, detalle del nudo mostrando las estípulas. C, bráctea, envés. D, profilo, envés. E, porción del cáliz, cara externa. lóbulos externo (izquierdo) e interno (derecho). F, porción del cáliz, cara interna, con pétalos y estambres adnatos, flor brevistila (se ha marcado la cica triz dejada al desprender un estambre). G, detalle del pétalo mostrando el apéndice cilíndrico. H, antera con apículo, cara interna. I, antera, cara externa. J, gineceo de flor brevistila (Hatschbach E Hatschbach 59722). 
Distribución y fenología. Especie endémica de Minas Gerais, donde vive en la Serra do Espinhaço, en selva y campos aledaños, también prospera en terrenos alterados. Florece y fructifica en diciembre y enero.

\section{9a. Turnera hatschbachii Arbo sp. nov. var. hatschbachii}

Fig. 7, Mapa 8

Frutex $1 \mathrm{~m}$ altus. Folia 11-12 $\mathrm{mm}$ lata. Floribus heterostylis in racemis terminalibus abbreviatis collecti. Pedunculi florum exteriorum sublibert, interiorum usque ad prophylla petiolis adnati. Petala alba, 2-3 $\mathrm{mm}$ calycem superantia; appendices pubescentes ex petalorum basl prodeuntes. Filamenta glabra basi tubo imo adnata; antherae apiculatae.

Tipo: BRASIL. Espírito Santo: Mun. Domingos Martins, Chapéu, Rio Jucu, Braço Norte, 8 XI 1993, Hatschbach G. \& M. Hatschbach 59722 (holotipo: MBM; isotipo: CTES).

Arbusto $1 \mathrm{~m}$, ramas viejas pardas, longitudinalmente agrietadas, súber blanquecino; ramas del año cilíndricas, rojizas, con pelos simples curvado-antrorsos, amarillentos, cicatrices foliares salientes; yemas seriales 2, ramas seriales desarrolladas. Hojas herbáceas, algo discoloras; estípulas subuladas, a veces laciniadas, 1,5-4,5 mm long., rojizas, pilosas, persistentes, insertas junto a la base del pecíolo, éste semicilíndrico, 2-5 mm long., indumento como el del tallo; lámina lanceolada, 44-80 x 11-12 mm, relación largo:ancho $=4-6,5: 1$; base atenuada o cuneada, ápice agudo o acuminado, margen aserrado, ligeramente revoluto, piloso, con 2-4 pares de nectarios hasta $0,5 \mathrm{~mm}$ diám. en los dientes basales; haz glabra o con pelos simples laxos, de base cónica, envés más claro, con pelos simples laxamente dispuestos; vena principal y 4-8 pares de venas laterales alternas, a veces subopuestas, incurvas, perdiéndose hacia el margen, ligeramente salientes en la haz, prominentes en el envés, cubiertas de pelos largos, dorados, antrorsos, ángulo de divergencia $30-40^{\circ}$, venas terciarias ligeramente visibles en el envés, más o menos perpendiculares a la vena media, venación menor poco conspicua. Flores heterostilas. Pedúnculos basales ca. $2 \mathrm{~mm}$ long., insertos en la base del pecíolo, los apicales más cortos. Pedicelos 1 $\mathrm{mm}$ long. en flores basales, nulos en las apicales. Profilos opuestos en la base del receptáculo, 5-7 x 0,6 mm, lineares, enteros, pilosos, borde con peios simples $1 \mathrm{~mm}$ long., con base dilatada, cónica. Cáliz aprox. $5 \mathrm{~mm}$ long., tubo 1,5-1,8 mm long., por fuera con pelos simples largos, por dentro glabro excepto en la garganta, lóbulos ovados o triangulares 3-nervados, cara externa con pelos largos sobre las venas, mucrón apical brevísimo. Corola blanquecina, 2-3 mri más larga que el cáliz, pétalos con un apéndice piloso inserto en la unión de uña y lámina. Filamentos estaminales complanado-subulados en seco, laxamente pilosos, a veces glabros, adnatos $0,3 \mathrm{~mm}$ al tubo en la base, a veces con un nectario calloso y amarillento en la inserción, 2,5-3 mm long. en flores longistilas, $5 \mathrm{~mm}$ long. en flores brevistilas; anteras elípticas, 0,6-0,7 x 0,4 mm, base emarginada, ápice con un breve apículo, dorsifijas, filamento inserto casi en la mitad. Ovario 1,5 mm long., glabro o con escasos pelos en la base, piloso en el ápice; estilos cilíndricos, en flores longistilas 4,5 mm long., con la porción media arqueado-incurva e hirsuta y la porción apical erguida y glabra, en flores brevistilas 1,5 mm long., excurvos, hirsutos excepto en el ápice; estigma penicilado 0,5-0,7 $\mathrm{mm}$ long. Fruto inmaduro ovoide, glabro en la base, piloso hacia el ápice. Semillas desconocidas.

Distribución. Se conoce solamente la colección tipo.

Obs. En su aspecto vegetativo esta especie es similar a T.capitata, de la que se diferencia por las hojas más angostas. Está relacionada con T.maracasana y T princeps, presentando igual que ellas estípulas muy desarrolladas. La subespecie típica se caracteriza por presentar pétalos blancos con un apéndice cilíndrico, piloso en la unión de uña y lámina, también presente en las últimas especies mencionadas. Dedico esta especie al Dr. Gert Hatschbach y su esposa María, como homenaje por sus magníficas colecciones, testimonio insuperable de la flora de Brasil.

En flores longistilas el gineceo es $2 \mathrm{~mm}$ más largo que el androceo; en flores brevistilas, el androceo es 1,5-2,5 mm más largo que el gineceo. 


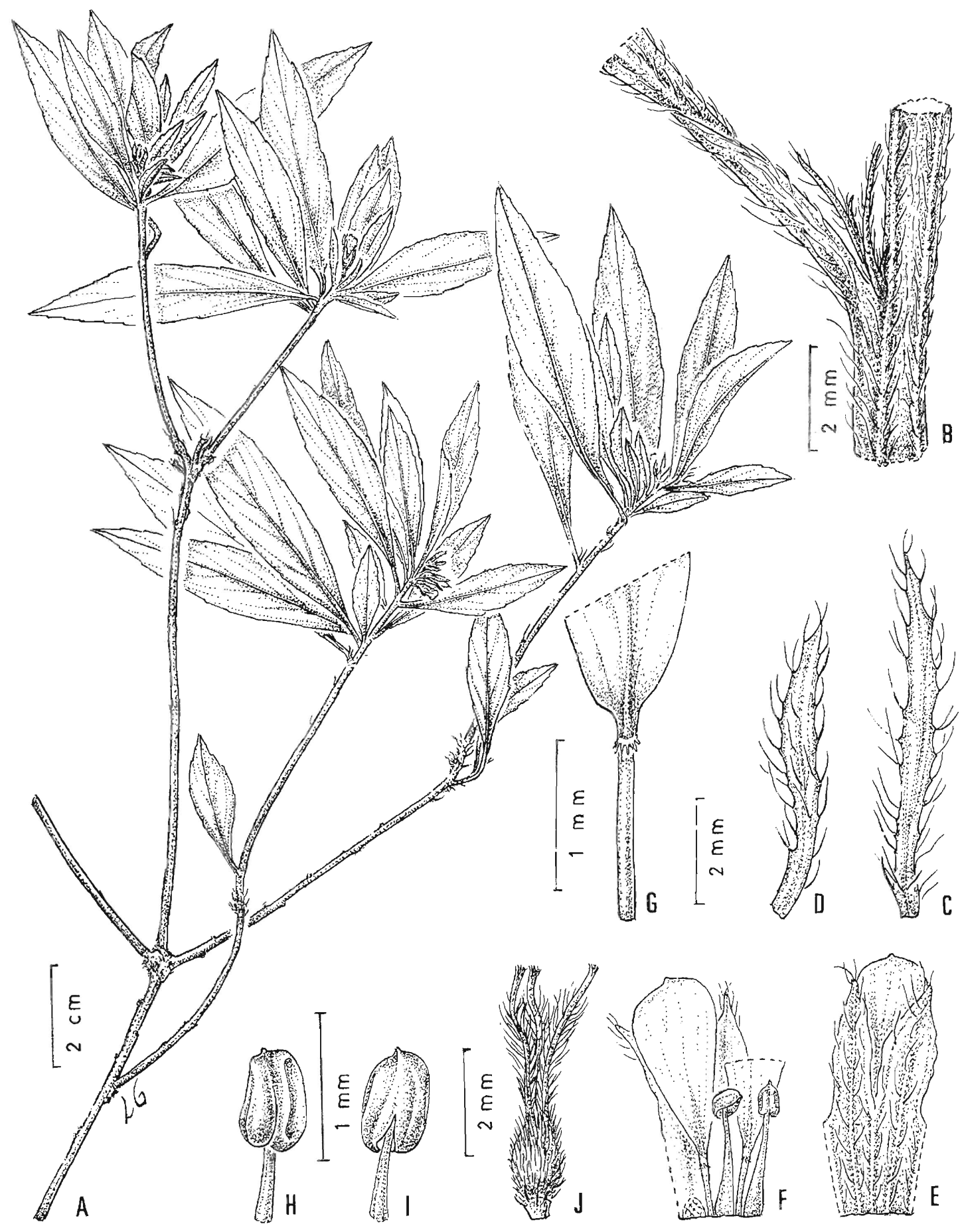

Fig. 8. Turnera hatschbachu var miniata. A, rama florífera. B, nudo mostrando la inserción de la hoja y las estípulas. C, bráctea. D, profilo. E, porción del cáliz, cara externa: lúbulos externo (izquierdo) e interno (derecho). F, porción del cáliz, cara interna, con pétalos y estambres adnatos, flor longistila (se ha marcado la cicatriz dejada al desprender un estambre). G, pétalo, detalle de ia lígula. $\mathrm{H}$, antera, cara interna. I, antera, cara externa. J, gineceo de flor longistila (Hatschbach $\mathcal{E}$ Hatschbach 59721). 
29b. Turnera hatschbachii Arbo var. miniata Arbo var. nov.

Fig. 8, Mapa 8

Arbuscula $3 \mathrm{~m}$ alta, stipulis $1,5-4,5 \mathrm{~mm}$ longis. Flores verisimiliter heterostyli in racemis terminalibus abbreviatis collecti. Pedunculi florum exteriorum subliberi, interiorum usque ad prophylla petiolis adnati. Petala miniata calycem vix superantia, glabra, ligula fimbriata ad basin lamina adnata. Filamenta glabra basi tubo imo adnata. Styli ad medium vix curvati.

Holotipo: BRASIL. Espírito Santo: Mun. Domingos Martins, Chapéu, Rio Jucu, Braço Norte, 8 XI 1993, Hatschbach G. \& M. Hatschbach 59721 (MBM; isotipo CTES).

Arbolito $3 \mathrm{~m}$, laxamente ramificado. Hojas con lámina angustielíptica, 38-72 x 8-15 mm, relación largo:ancho $=4,6-5,1: 1$, margen serrulado desde la base, plano o ligeramente revoluto, piloso, con 1-2 pares de nectarios diminutos ubicados en los dientes basales; haz parda en seco, con escasos pelos simples antrorsos; envés con indumento igual. Racimos apicales bracteosos muy abreviados, capituliformes, las flores basales a veces separadas; hojas tectrices reduciéndose a brácteas de tamaño cada vez menor, las apicales $5 \times 1$ $\mathrm{mm}$, subenteras. Flores presumiblemente heterosti-las. Cáliz 4-5 mm long. Corola roja 0,2-1 mm más larga que el cáliz, pétalos con la uña glabra soldada al tubo, lígula membranácea, fimbriada, en la unión de uña y lámina, ésta obovada, 3 x 1,2-1,4 mm, ápice obtuso o brevemente apiculado. Filamentos estaminales glabros, 1,8-2 mm long. en flores longistilas, anteras apiculadas. Ovario 1-1,2 mm long., ovoide, con pelos simples más largos hacia el ápice; estilos cilíndricos, 2,3-3 mm long. en flores longistilas, pilosos en la porción inferior, en la porción media hirsutos, apenas incurvo-arqueados, extremo glabro; estigma 0,3-0,4 mm long. Fruto 2,5 mm long., valvas ovadas, cara externa parda, superficie verrucosa, pilosa, con pelos más largos hacia el ápice, cara interna glabra, lustrosa, amarillenta. Semilla desconocida.

Distribución. Se conoce solamente la colección tipo.
Obs. Aunque su aspecto vegetativo es prácticamente igual al de la variedad típica, se diferencia de ella por su porte arbóreo y por sus pétalos rojos (color raro en el género Turnera), pero sin apéndice piloso en la unión de uña y lámina. En lugar del apéndice, cada pétalo presenta una lígula, similar a la que se observa en T.capitata.

En flores longistilas, el gineceo es 1,3-1,9 mm más largo que el androceo.

\section{Turnera maracasara Arbo sp. nov.}

Fig. 9, Mapa 7

Frutex $1 \mathrm{~m}$ altus, stipulis 3-7 mm longis. Floribus heterostyli in racemis terminalibus abbreviatis collecti. Pedunculi petioli basin inserti. Calyx 7,5-9 mm longus. Petala alba calycem $4-5 \mathrm{~mm}$ superantia, appendices lineares pubescentes ex petalorum basi prodeuntes. Filamenta puberula basi tubo imo adnata. Stylt longiort ad medium arcuati et pilosi.

Holotipo: BRASIL. Bahia: Mun. Maracás, Rod. BA-250, Faz. dos Pássaros a $24 \mathrm{~km}$ al E de Maracás, 900 m, 4 V 1979, Mori S.A. \& T.S. dos Santos 11774 (CEPEC; isotipos: CTES, MO).

Arbusto hasta $1 \mathrm{~m}$ de altura, laxamente ramificado, porción basal del eje con corteza cenicienta, súber blanquecino; ramas viejas con cicatrices foliares salientes; ramas del año cilíndricas, estriadas longitudinalmente, con pelos cortos crespos y pelos más largos curvadoantrorsos; yemas axilares 2, ramas seriales a veces desarrolladas. Hojas herbáceas, lustrosas, un poco discoloras; 3-4 pares de estípulas subuladas, a veces laciniadas, pilosas, purpúreas, de longitud decreciente hacia los lados, las internas 3-7 mm long., insertas junto a la base del pecíolo, éste semicilíndrico, 1,5-3 mm long., indumento como el del tallo. Nectarios microscópicos, 0-1 par, ubicados sobre el margen foliar, 0,2-0,3 mm diám. Lámina elíptica, angustielíptica u obovada, 25-83 x 10-27 mm, relación largo:ancho $=2,7-3: 1$; base brevemente atenuada o aguda, ápice agudo o acuminado, margen serrulado, plano o ligeramente revoluto, piloso; haz rojiza o parda en seco, glabra; envés más claro, con pelos simples laxos hacia el margen; vena principal y 5-7 pares de venas laterales ligeramente salientes en la haz, pro- 


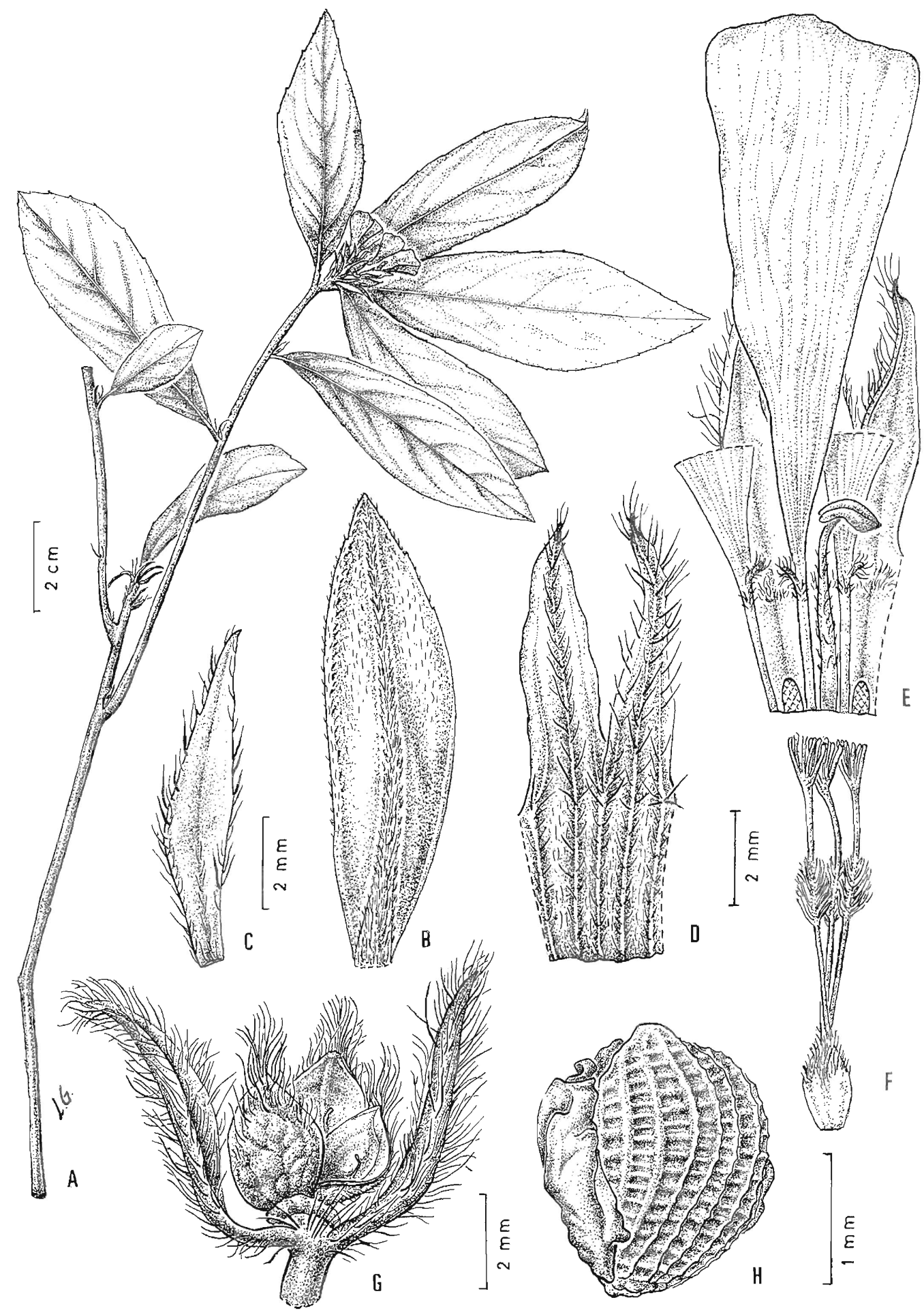

Fig. 9. Turnera maracasana. A, rama florífera. B, bráctea, cara externa. C, profilo, cara externa. D, porción del cáliz, cara externa: lóbulo interno (izquierdo) y externo (derecho). E, porción del cáliz, cara interna con pétalos y estambre adnatos, flor longistila (se han marcado las cicatrices dejadas al desprender dos estambres). F, gineceo de flor longistila. $G$, fruto con profilos. H, semilla, cara opuesta a la rafe (A-F: Mori $\mathcal{E}$ dos Santos 11774; G-H: Arbo et al. 7708). 
minentes en el envés, con largos pelos dorados y antrorsos, alternas, a veces subopuestas, ángulo de divergencia $35-50^{\circ}$, incurvas, perdiéndose hacia el margen; venas terciarias ligeramente visibles en el envés, más o menos perpendiculares a la vena media, venación menor poco conspicua. Racimos apicales bracteosos muy abreviados, capituliformes, hojas tectrices súbitamente reducidas a brácteas, las basales elípticas, enteras, 9-10 x 2$2,8 \mathrm{~mm}$, ias apicales lineares, cara externa y margen con pelos simples, largos, hirsutos, 0,5$1 \mathrm{~mm}$ long. Flores heterostilas. Pedúnculo 1-2 $\mathrm{mm}$ long., inserto en la base del pecíolo. Profilos lineares, 5,5-8 $\times 1 \mathrm{~mm}$, indumento como el de las brácteas apicales. Pedicclo ausente. Cáliz 7,5-9 mm long., tubo 2,5-3,2 mm long., cara externa con pelos simples, cortos, antrorsos, cara interna glabra en la base, vellosa en la garganta; lóbulos angustiovados o triangulares, cara externa con pelos largos sobre las venas, márgenes internos membranáceos, ápice de los lóbulos internos cuculado, mucrón 0,3-0,5 mm long. Corola blanca, pétalos con la uña soldada al tubo, pilosa en la mitad apical, lámina obovada, $12 \times 6 \mathrm{~mm}$, con un apéndice cilíndrico, piloso, 0,4-0,5 mm long., inserto en la unión de uña y lámina. Filamentos estaminales soldados en la base $0,7 \mathrm{~mm}$ al tubo, complanado-subulados en seco, pilosos, $4 \mathrm{~mm}$ long. en flores longistilas, $6 \mathrm{~mm}$ long. en flores brevistilas; anteras ovadas, 1-1,2 x 0,4 $\mathrm{mm}$, base emarginada, ápice agudo, filamento inserto en una cavidad basidorsal 0,3 $\mathrm{mm}$ long. Ovario ovoide, $2 \mathrm{~mm}$ long., glabro en la base, con pelos largos hacia el ápice, placentas 5-6 ovuladas; estilos cilíndricos, porción basal erguida, glabra, porción media arqueadoincurva, densamente pilosa especialmente en la cara interna, ápice glabro, 4,8 mm long. en flores longistilas, $2 \mathrm{~mm}$ long. en flores brevistilas; estigma glabro, aprox. 12 ramas de 0,5-1,2 mm long. Fruto ovoide, $3 \mathrm{~mm}$ long., valvas ovadas, cara externa suavemente verrucosa, venas impresas, base con escasos pelos, ápice con un mechón de pelos largos, cara interna lustrosa, lisa, vena placentaria saliente, llegando hasta la mitad. Semilla obovoide, ligeramente curvada, $2 \times 1,5 \mathrm{~mm}$; episperma negruzco, reticulado, muros longitudinales más salientes que los transver- sales, aréolas transrectangulares, epidermis papilosa; exóstoma conoidal, asimétrico, más corto hacia la rafe, ésta linear, cálaza prominente y cóncava; arilo unilateral, tan largo como la semilla.

Paratipos: BRASIL. Bahia: Fazenda dos Pássaros, $24 \mathrm{~km}$ al E de Maracás, camino a Itiruçu, aprox. 1328'S 4013'W, 800 m, 23 I 1997, Arbo et al. 7708 (CEPEC, CTES); Lagedo do Tabocal, ca. 7 km $W$ da sede do município na estrada para Maracás, entre as fazendas de Sinhô e a de Alírio, 1328 $57^{\prime \prime} S$ 4016'52”W, 845 m, 5 XII 1999, Melo \& França 3210 (CTES, HUE!S)

Distribución y fenología. Probablemente endémica de Bahia, donde vive en la mata de cı́ć, a una elevación de 800-900 m. Florece desde enero a mayo.

Obs. Especie vinculada con T.princeps y T.hatschbachii, con estípulas notoriamente desarrolladas. En la serie Capitatae es la especie con flores de mayor tamaño, de 11-14 mm long.

En flores longistilas, el gineceo es 2,5-3 mm más largo que el androceo.

\section{Turnera marmorata Urb.}

Fig. 10, Mapa 8

Urban 1., Bot.Jahrb.Syst. 25, Beibl. 60: 9. 1898. Tipo: BRASIL. Bahia: ad Nazareth, Sellow F. s.n. (holotipo destruido: B, Foto F 13591!; lectotipo aquí designado: $K !)$.

Subarbusto o arbusto $0,8-3 \mathrm{~m}$, con pelos simples. Ramas viejas cilíndricas, pardas o cenicientas, ramas nuevas pardas, estriadas en seco, hacia los ápices con pelos simples breves, amarillentos, antrorsos. Hojas coriáceas, glabras. Estípulas triangulares, pilosas, 0,7-1 mm long., insertas junto a la base del pecíolo, éste 10-35 $\mathrm{mm}$ long., indumento como el del tallo. Nectarios 1-2 pares, elípticos, 0,9-1,2 mm long., ubicados en la porción basal de la lámina, sobre el margen y orientados hacia el envés. Lámina obovada a elíptico-lanceolada, $13-21,5 \times$ $2,5-5,5 \mathrm{~cm}$, relación largo:ancho $=3-5: 1$; base atenuada, ápice agudo o brevemente acuminado; haz verde oscura, lustrosa; en seco maculada, recorrida por líneas irregulares, laberínticas, pardas (probablemente determi- 


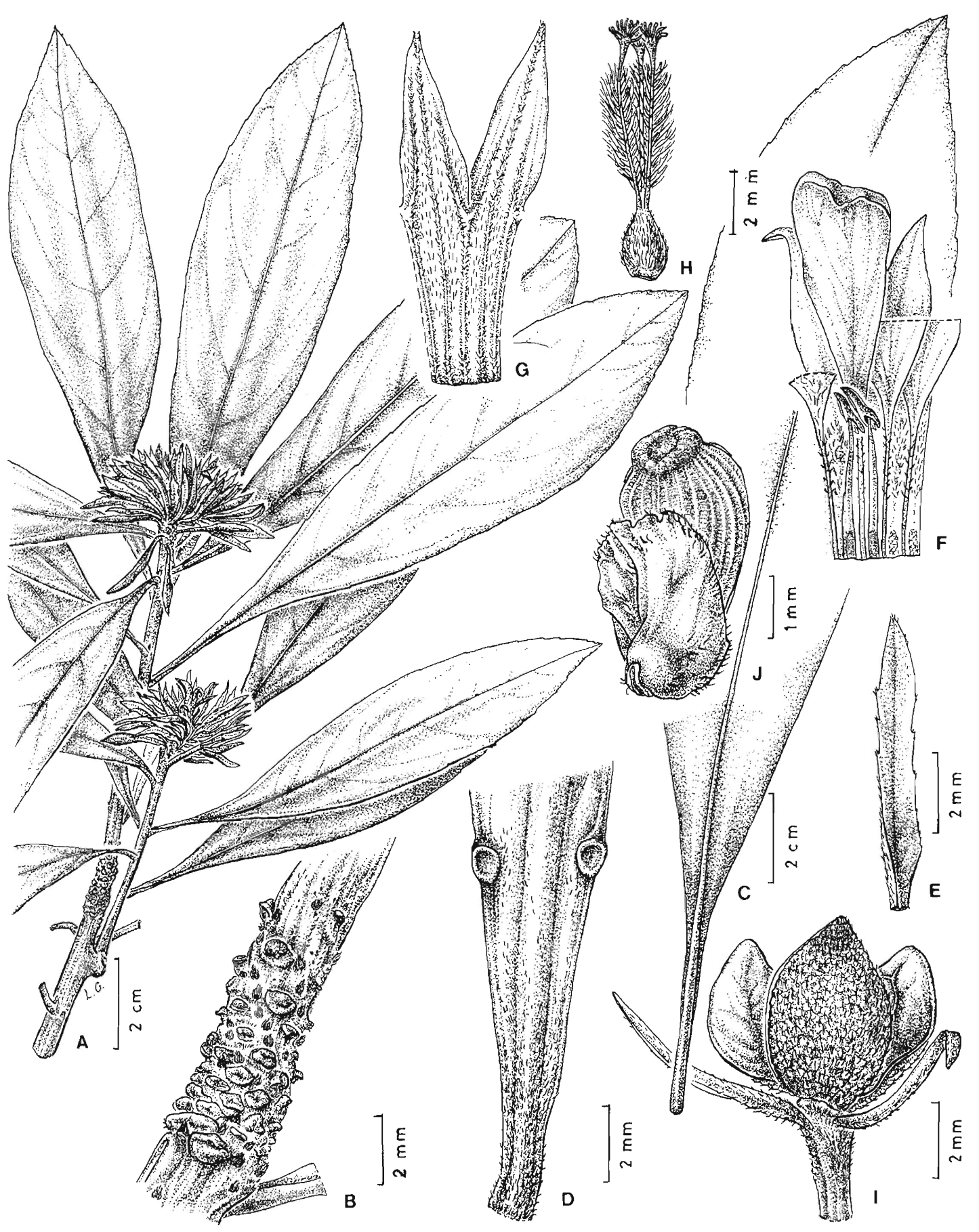

Fig. 10. Turnera marmorata. A, rama florífera. B, braquiblasto, mostrando las cicatrices foliares prominentes y las estípulas persistentes. C, hoja. D, bractea externa, porción basal, mostrando los nectarios en el envés. E, profilo, cara interna. F, porción del cáliz, cara interna con pétalos y estambre adnatos, flor longistila (se han marcado las cicatrices dejadas al desprender dos estambres). G, porción del cáliz, cara externa: lóbulos externo (izquierdo) e interno (derecho). II, gineceo de flor longistila. I, fruto abierto con bráctea (izquierda) y un profilo (derecha). J, semilla con arilo, vista rafeal (A-BeI:Mort et al. 11467; C, dos Santos 2169; D-H y J: Carvalho et al. 215). 
nadas por grupos de células epidérmicas taníferas), contrastando con el fondo oliváceo, envés más pálido, igualmente maculado; margen ligera o marcadamente aserrado-crenado en la porción apical; vena media apenas saliente en la haz, deprimida en el envés; venas laterales prominentes en haz y envés. Racimos apicales bracteosos muy abreviados, capituli-formes, 2025-floros, hojas tectrices súbitamente reducidas a brácteas coriáceas, lineares, 20-6,5 × 3-0,8 mm, color verde pálido, acuminadas, margen con pelos simples breves, denticulado hacia el ápice, con un par de nectarios ca. $1 \mathrm{~mm}$ diám. en el envés, cerca de la mitad, haz glabra, a veces la vena media con pelos simples, cortos y adpresos, envés con pelos breves, adpresos, amarillentos. Flores heterostilas. Pedúnculo 1-2,2 mm long., adnato totalmente a la bráctea o sólo en la base y con la porción apical libre. Profilos linearsubulados, más o menos cóncavos, 8-5 x 0,7-0,4 $\mathrm{mm}$, enteros o denticulados, sin nectarios, envés adpreso-piloso. Cáliz 10-11 mm long., por fuera estrigoso, tubo 3-5 mm long., por dentro con pelos blanquecinos excepto en la base; lóbulos triangulares u ovados, 3-5-nervados, bordes internos membranáceos, ápice con mucrón 0,3-0,8 mm long. Corola amarillo-oro, ligeramente más larga o más corta que el cáliz, pétalos con la uña soldada al tubo, lámina obovada, 9-11 x 2,5-4 mm. Filamentos estaminales glabros, soldados 0,8-1 $\mathrm{mm}$ al tubo en su base, por su cara externa, 4,4 mm long. en flores longistilas, $7 \mathrm{~mm}$ long. en flores brevistilas, anteras elípticas, 1,7-3,1 x 0,5-1 mm, base emarginada, ápice agudo o brevemente apiculado, filamento inserto en una cavidad basi-dorsal de 0,6-1,1 mm. Ovario ovoide, 2,8$3 \mathrm{~mm}$ long., cubierto de pelos breves, erectos; placentas uniovuladas, óvulos insertos cerca del ápice; estilos rectos, vellosos, $5 \mathrm{~mm}$ long. en flores longistilas, $3 \mathrm{~mm}$ long. en flores brevistilas; estigma de 0,8-1 mm long. Fruto ovoide, 5-6x 3,5-5 mm, uni-biseminado, valvas recurvadas a la dehiscencia, cara externa granulosa, brevemente pilosa, cara interna glabra, pardo-amarillenta. Semilla piriforme, ligeramente curvada, 3,9-4,3 x 1,7-2,3 mm, relación largo-ancho $=1,9-$ $2,4: 1$; episperma negruzco, estriado-reticulado, muros longitudi-nales bien marcados, los transversales muy tenues, epidermis papilosa, exóstoma cónico, obtuso, rafe linerar, cálaza breve, prominente y cóncava; arilo unilateral tan largo como la semilla, piloso, borde subentero y piloso.

Material estudiadc. Brasil. Bahia: Maraú, 25 IV 1965, Belém \& Magalhães 912 (CEPEC, RB, UB); Maraú, 6 X 1965, Belém 1850 (CEPEC); Maraú, 9 V 1966, Belém \& Pinheiro 2107 (CEPEC, CTES, UB) y Belém \& Pinheiro 2109, (CEPEC, RB, UB); Maraú, 12 I 1967, Belém \& Pinheiro 3090 (CEPEC, NY, UB); Mun. Maraú, Rod. BR-030, trecho Porto de CampinhosMaraú, km 11, 26 II 1980, Carvalho et al. 215 (CTES); Mun. Maraú, estrada Ubaitaba/Ponta do Mutá, ramal no km 71, estrada para o Sitio São Marcos, 2 II 1983, Carvalho \& Plozuman 1393 (CEPEC, CTES, F); $65 \mathrm{~km}$ NE of Itabuna, at the mouth of the Rio de Contas on the $\mathrm{N}$ bank opposite Itacare, $39^{\circ} 01^{\prime} \mathrm{W}$ 141'ㅇ, nivel del mar, 1 IV 1974, Harley et al. 17602 (CEPEC, CTES); $5 \mathrm{~km}$ SE of Maraú at the junction with the new road $\mathrm{N}$ to Ponta do Mutá, $39^{\circ} 00^{\prime} \mathrm{W}$ $14^{\circ} 08^{\prime} \mathrm{S}, 0-50 \mathrm{~m}, 2$ II 1977, Harley et al. 18468 (CTES, NY, US); near Maraú, $20 \mathrm{~km} \mathrm{~N}$ from road junction from Maraú to Ponta do Mutá, approx. $38^{\circ} 57^{\prime} \mathrm{W}$ $13^{\circ} 57^{\prime} \mathrm{S}, 0-50 \mathrm{~m}, 3$ II 1977, Harley et al. 18550 (CTES, NY); Coastal Zone, ca. $5 \mathrm{~km}$ SE of Maraú, near junction with road to Campinho, 38 $59^{\prime} \mathrm{W} 14^{\circ} 08^{\prime} \mathrm{S}$, 0-50 m, 14 V 1980, Harley et al. 22060 (CTES, IPA, NY, US); Mun. Valença, ramal a esquerda da rodovia que liga Valença ao Guaibim (litoral) com entrada no Km 9, ca. 10 m, 11 XII 1980, Mattos Silva et al. 1268 (CTES, HUEFS); Mun. Maraú, Rod. BR-030, a 3 km ao S de Maraú, Folha SD 24 (14-39b), 7 II 1979, Mori et al. 11467 (CEPEC, CTES, NY); restinga de $10 \mathrm{~km}$ de Maraú, 21 I 1965, Pereira 9605-Pabst 8494 (CTES, HB, R); Mun. Maraú, Km 5 da rodovia Maraú/ Ubaitaba, lado direito da estrada, 11 I 1988, Santos 229 (HPR, HUEFS); Maraú, 17 XI 1971, Santos et al. 2169 (CEPEC, CTES, R); Valença, Km 9 da Rod. Valença/Guaibim, 21 il 1975, Santos et al. 2887 (CEPEC, CTES, R).

Distribución y fenología: Endémica de Bahia, vegeta en suelo blanco-arenoso en la restinga, en la transición de mata litoral a restinga, y en capoeira. Florece y fructifica desde ociubre hasta mayo.

Obs. En flores longistilas, el gineceo es 1,6 $\mathrm{mm}$ más largo que el androceo; en flores brevistilas, el androceo es 2,8 $\mathrm{mm}$ más largo que el gineceo.

Su aspecto vegetativo es similar al de $T$. glaziovii Urb., con flores solitarias axilares grandes. 


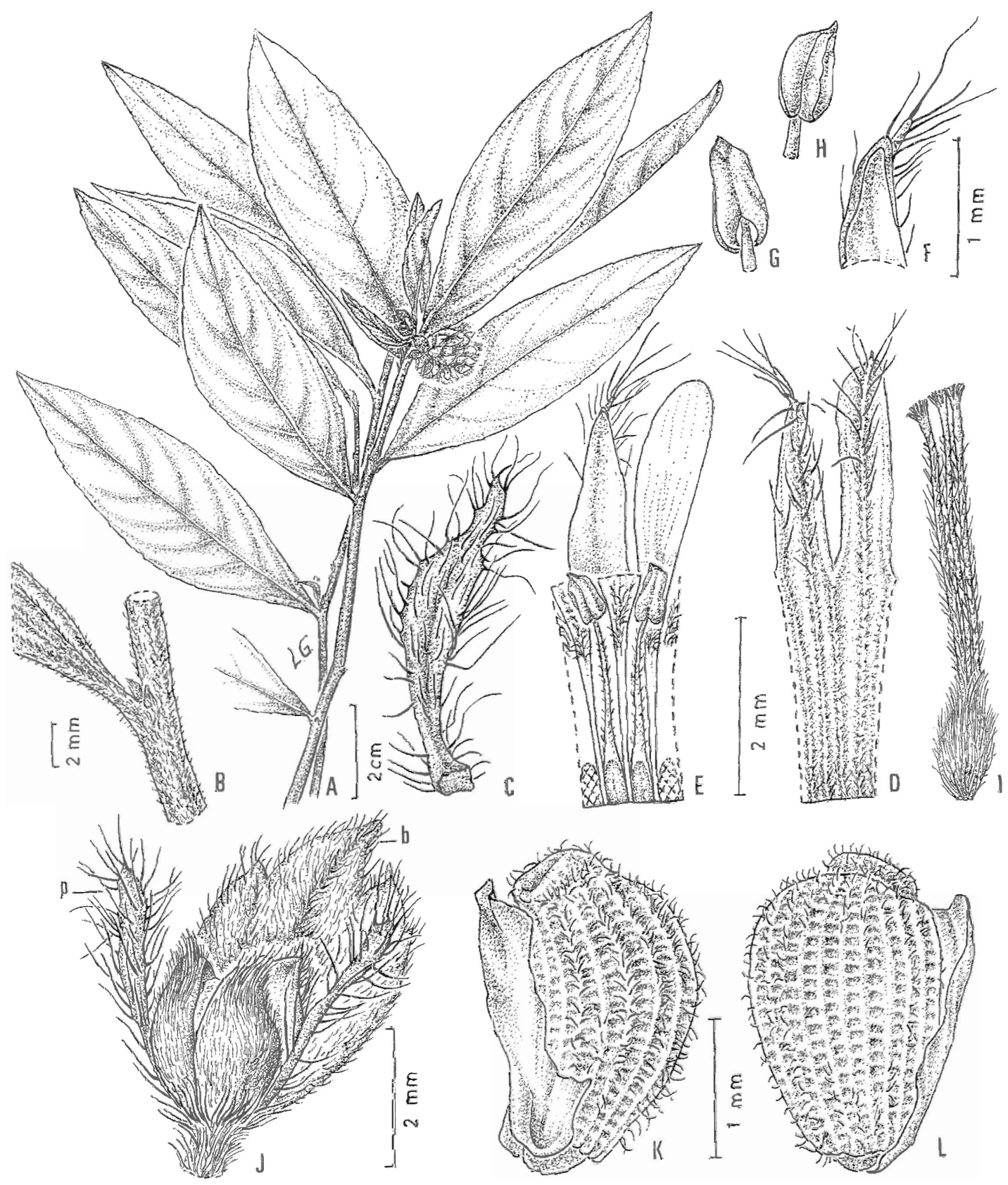

Fig. 11. Tumera pernambucensis. A, ramas floríferas. B, detalle del nudo inostrando las estípulas. C, profilo. D, porción del cáliz, cara externa: lóbulos externo (izquierdo) e interno (derecho). E, porción del cáliz, cara interna con pétalos y estambres adnatos, flor longistila (se han marcado las cicatrices dejadas al desprender dos estambres). F, porción apical de un lóbulo interno del cáliz, mostrando el mucrón. G, antera con apículo, cara externa. H, antera con apículo, cara interna. I, gineceo de flor longistila. J, fruto abierto con bráctea (b) y profilos (p). K, semilla con arilo, vista lateral, rafe hacia la izquierda. L, semilla con arilo, cara opuesta a la rafe (Gardner 1154). 


\section{Turnera pernambucensis Urb.}

Fig. 11, Mapa 7

Urban I., Jahrb.Königl.Bot.Gart.Berlin 2: 133. 1883. Urban I. en Martius C.F.P., Fl.bras. 13(3): 153. 1883. Tipo. BRASIL. Pernambuco: Catucá, [ 30 millas al W de Recife], shady woods, Xl 1837, Gardner G. 1154 (holotipo: K!; isotipos: K!, B destruido, Foto F 13596!).

Subarbusto $60 \mathrm{~cm}$, ramas viejas cilíndricas, corteza parda, ramas del año estriadas, con pelos simples breves, dorados o rojizos, antrorsos o adpresos, laxos en la parte inferior, más densos hacia el ápice. Yemas seriales poco evidentes. Hojas cartáceas. Estípulas insertas jurito al pecíolo, triangular-subuladas, 0,6-1 mm, pilosas; pecíolo 0,3-1,5 mm long., indumerto como el del tallo. Lámina lanceolada, 7-10 x 1,8-2,7 cm, relación largo:ancho $=3,5-4,5: 1$, base atenuada, margen plano o apenas recurvado, serrulado, con 1-3 pares de nectarios circulares $0,3-0,5 \mathrm{~mm}$ diám., situados en la porción basal y orientados hacia la haz, ápice agudo; haz laxamente pilosa, envés con indumento más denso; vena media y 5-6 pares de venas secundarias pilosas, ligeramente salientes en la haz, prominentes en el envés, ángulo de divergencia $47-57^{\circ}$, incurvas, perdiéndose hacia el margen, venas terciarias visibles en el envés, más o menos perpendiculares a la vena media, venación menor inconspicua. Racimos terminales muy abreviados, capituliformes. Brácteas con estípulas diminutas, pecíolo 1-1,5 mm long., lámina ovada, las basales o externas hasta $10 \mathrm{~mm}$ long., las superiores o internas 4-6 x 2-3 mm, haz y envés pilosos, 1-3nervadas, borde entero o serrulado, ápice agudo. Flores probablemente heterostilas. Pedúnculo 1-1,5 mm long., soldado al pecíolo. Profilos lineares, 3-4,5 x 0,3-0,9 mm, enteros, hirsutos. Pedicelo ausente. Cáliz 3-5 mm long., tubo 1,5-2,6 mm long., cara externa con pelos breves, adpresos, cara interna glabra excepto en la garganta, lóbulos con pelos largos hirsutos en la cara externa, en la mitad superior, ápice con mucrón $0,3 \mathrm{~mm}$ long. Corola tan larga como el cáliz, pétalos con lámina obovada, la haz con pelos en la base. Filamentos estaminales adnatos ca. $0,5 \mathrm{~mm}$ en la base al tubo, tenuemente pilosos; anteras ovadc-elípticas, $0,6-0,8 \times 0,3-0,4 \mathrm{~mm}$, apiculadas, filamen- to inserto en una cavidad basi-dorsal de 0,3 $\mathrm{mm}$. Cvario elipsoide, ca. $1 \mathrm{~mm}$ long., densamente piloso, placentas 1-2-ovuladas; estilos cilíndricos, densamente pilosos, ca. $3,5 \mathrm{~mm}$ long. en flores iongistilas; estigma brevísimo, penicilado. Fruto ovoide, ca. 2,5-3 mm long., valvas con cara externa pilosa, lisa 0 punctulada, cara interna amarillenta o jaspeada, ápice sin apéndice corniforme. Semilla obovorde, curvada, 2-2,4 x 1,2-1,4 mm, relación largo:ancho $=1,6-1,7: 1$, episperma pardo-negruzco, reticulado-estriado, pubérulo, cálaza prominente, cóncava, exóstoma hemisférico; arilo unilateral, casi tan argo como la semilla.

Distribución. Se conoce solamente el tipc, recolectado en bosques umbríos.

Obs. En flores lorgistilas, ei girieze es 1,5 mm más largo que el anciroseo.

\section{Turnera princeps Arbo sp.nov.}

Fig. 12, Mapa 8

Turnera capitata Cambess. subsp. intermedia Urb., I., Jahrb. Königì. Bot. Gart. Berlin 2: 135. 1883. Urban I. en Martius C.F.P., Fl.bras. 3(3): 154. 1883 Holotipo: BRASIL. Sin localidad ni fecha, Herbarno Martuls s.n. (BR!). Según Urban (1883b) el tipo podría haber sido recolectado por el Príncipe Maximilian A.P. zu Wied-Neuwied.

Fruticulus 50-60 cm altus, stipulis subulatis 2,5-4 $\mathrm{mm}$ longis. Flores heterostyli in racemis terminalibus abbreviatis collecti. Pedunculi florum exteriorum subliberi, interiorum usque ad prophylla petiolis adnati. Petala alba, 1,5 $\mathrm{mm}$ calycem superantia; appendices lineares pubescentes ex petalorum bast prodeuntes. Filamenta puberula basi tubo imo adnata. Styli longiori ad medum arcuati et pilosi. Valvae fructi non cornutae, obsolete verrucosae

Holotipo. BRASIL. Minas Gerais: Serra do Espinhaço, ca. $22 \mathrm{~km}$ E of Diamantina, $900 \mathrm{~m}, 15 \mathrm{III}$ 1970, Irwin H.S., S.F. da Fonsêca, R.Souza, R.Reis dos Santos \& J.Ramos 27623 (UB; isotipos: CTES, NY).

Subarbusto 50-60 cm, eje de 5-6 mm diám., parte basal con corteza castaño claro, súber blanquecino, ejes con macroblastos y braquiblastos alternantes; ramas del año cilíndricas, rojizas, con pelos simples largos, curvado-antrorsos, amarillentos y pelos simples 


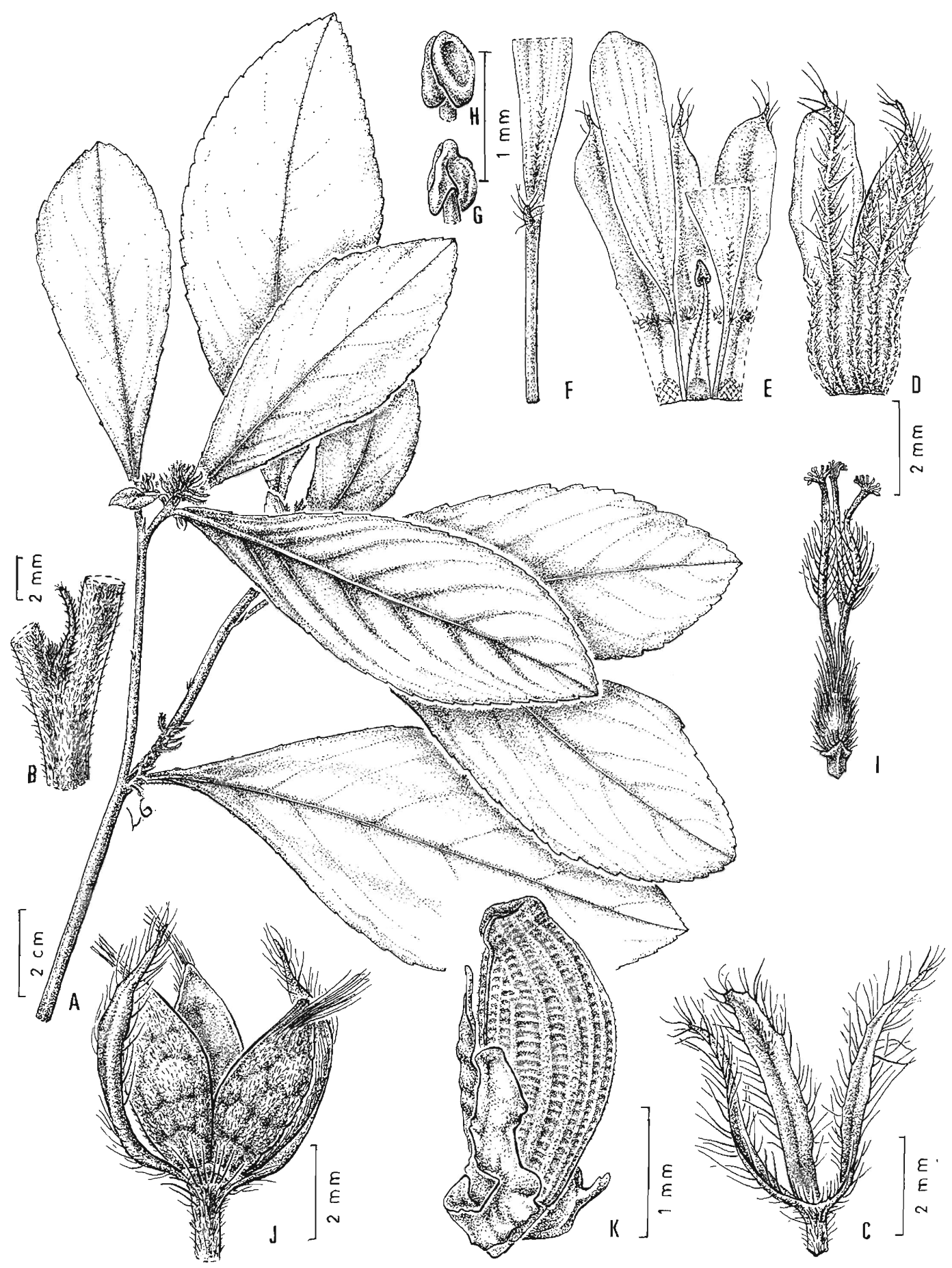

Fig. 12. Turnera princeps. A, rama florífera. B, detalle del nudo mostrando las estípulas. C, bráctea y profilos. D, porción del cáliz, cara externa: lóbulos interno (izquierdo) y externo (derecho). E, porción del cáliz, cara interna con pétalos y estambre adnatos, flor longistila (se han marcado las cica trices dejadas al desprender dos estambres). F, detalle del pétalo mostrando el apéndice cilíndrico. G-H, anteras, caras externa e interna. I, gineceo de flor longistila. J, fruto abierto con profilos. K, semilla con arilo, vista lateral, rafe a la izquierda (Irwin et al. 27623). 
más cortos y crespos; yemas seriales escasas. Hojas herbáceas. Estípulas subuladas, 2,5-4,5 $\mathrm{mm}$ long., pilosas, a veces laciniadas. Pecíolo semicilíndrico, 2-10 $\mathrm{mm}$ long., indumento como el del tallo. Nectarios 2-5 pares, situados en los dientes basales de la lámina, de tamaño progresivamente menor, los inferiores hasta $1 \mathrm{~mm}$ diám. Lámina elíptica u obovada, 7-12,5 x 2,5-5,4 cm, relación largo:ancho 2,42,6:1, base atenuada, ápice agudo, a veces obtuso, margen aserrado, piloso, ligeramente revoluto, haz opaca o lustrosa, con pelos simples, cortos, oblicuamente dispuestos, envés con indumento más denso; vena media ligeramente saliente y pilosa en la haz, prominente en el envés, 5-8 pares de venas laterales, alternas o subopuestas, incurvas, salientes y densamente pilosas en el envés, perdiéndose hacia el margen, ángulo de divergencia $35-50^{\circ}$, venas terciarias visibles en el envés, venación menor inconspicua. Racimos bracteosos apicales abreviados, 1,5-3 cm diám. Brácteas inferiores brevemente pecioladas, lámina lanceolada, $10 \times 3 \mathrm{~mm}$, ápice agudo, vena media ligeramente deprimida en la haz, saliente en el envés; brácteas superiores lineares, 10-4,5 x 1-0,6 $\mathrm{mm}$, pilosas. Flores heterostilas. Pedúnculos 1-1,5 mm long., los basales insertos en la base del pecíolo de la bráctea, los siguientes adnatos al pecíolo, siendo más prolongada la adnación en las flores superiores. Profilos linearlanceolados, 5-10 x 0,5-2 mm, opuestos, insertos en la base del receptáculo. Pedicelo ausente. Cáliz rojo, 5-6 mm long., tubo 2-2,7 mm long., con pelos simples cortos por fuera, glabro por dentro en la base, velloso en la garganta, lóbulos angustiovados o triangulares, bordes internos membranáceos, cara externa con pelos más largos que el tubo, cara interna glabra, ápice con mucrón $0,3 \mathrm{~mm}$ long. Corola blanca, 1,5-2,5 mm más larga que el cáliz, pétalos con un apéndice 0,1-0,3 mm long., densamente piloso, inserto en la unión de uña y lámina, ésta de 6-8,5 x 1,5-4 mm. Filamentos estaminales adnatos en la base $0,3-0,5 \mathrm{~mm}$ al tubo, complanado-subulados en seco, pilosos, 2-2,5 mm long. en flores longistilas, 5,2 mm long. en flores brevistilas; anteras ovadas, 0,6 x 0,4 mm, base emarginada, ápice obtuso, dorsifijas, filamento inserto cerca de la mitad. Ovario ovoide, aprox. $1 \mathrm{~mm}$ long., densamen- te cubierto de pelos blancos, ca. $1 \mathrm{~mm}$ long., placentas con 1-2 óvulos insertos hacia la mitad; estilos cilíndricos, $4 \mathrm{~mm}$ long. en flores longistilas, con pelos esparcidos en el tercio inferior, en la porción media hirsutos e incurvoarqueados, extremo glabro, $2 \mathrm{~mm}$ long. en flores brevistilas, pilosos y excurvos; estigma de aprox. 20 ramas, 0,4-0,7 mm long. Fruto ovoide, 4-5 mm long., liso o apenas verrucoso por las venas hundidas en la cara externa, valvas ovadas, pardas, con pelos cortos y laxos en la base, largos y densos en el ápice, éste no corniculado. Semilla obovoide, 2,5-3 x 1-1,2 $\mathrm{mm}$, ligeramente curvada, reticulada, muros verticales más notables que los transversales, aréolas cuadrangulares o transrectangulares, con una depresión punctiforme en el fondo, episperma negruzco, epidermis papilosa; exóstoma cónico, 0,3 $\mathrm{mm}$ long., rafe linear, cálaza saliente, $0,2 \mathrm{~mm}$ long., cóncava; arilo unilateral, más corto que la semilla.

Distribución. Probablemente endémica de la Serra do Espinhaço, donde se la ha recolectado en selva en galería y cerrado adyacente.

Obs. En flores longistilas, el gineceo es 3,5 $\mathrm{mm}$ más largo que el androceo. En flores brevistilas, el androceo es $2 \mathrm{~mm}$ más largo que el gineceo.

Urban (1883b) sugiere que los apéndices de los pétalos podrían representar un círculo interno de estaminodios. Lamentablemente, no se dispuso de material fresco para estudiar su estructura, y constatar si son equivalentes a la lígula de Turnera capitata o si están vascularizados. Estos apéndices se presentan también en T.hatschbachii var. hatschbachii y en T.maracasana.

\section{Turnera schomburgkiana Urb.}

Fig. 13, Mapa 7

Urban I., Jahrb.Königl.Bot.Gart.Berlin 2: 132. 1883. Urban I. en Martius C.F.P., Fl.bras. 13(3): 152. 1883. Lectotipo (aquí designado). GUYANA [VENEZUELA. Bolívar, según Steyermark J.A., 1981]: Roraima, 1842-43, Schomburgk R.H. 624 (P!; isotipos: BM!, K!, W!).

Arbusto $2 \mathrm{~m}$, ramas viejas glabrescentes, ligeramente estriadas, pardo-cenicientas, ramas 


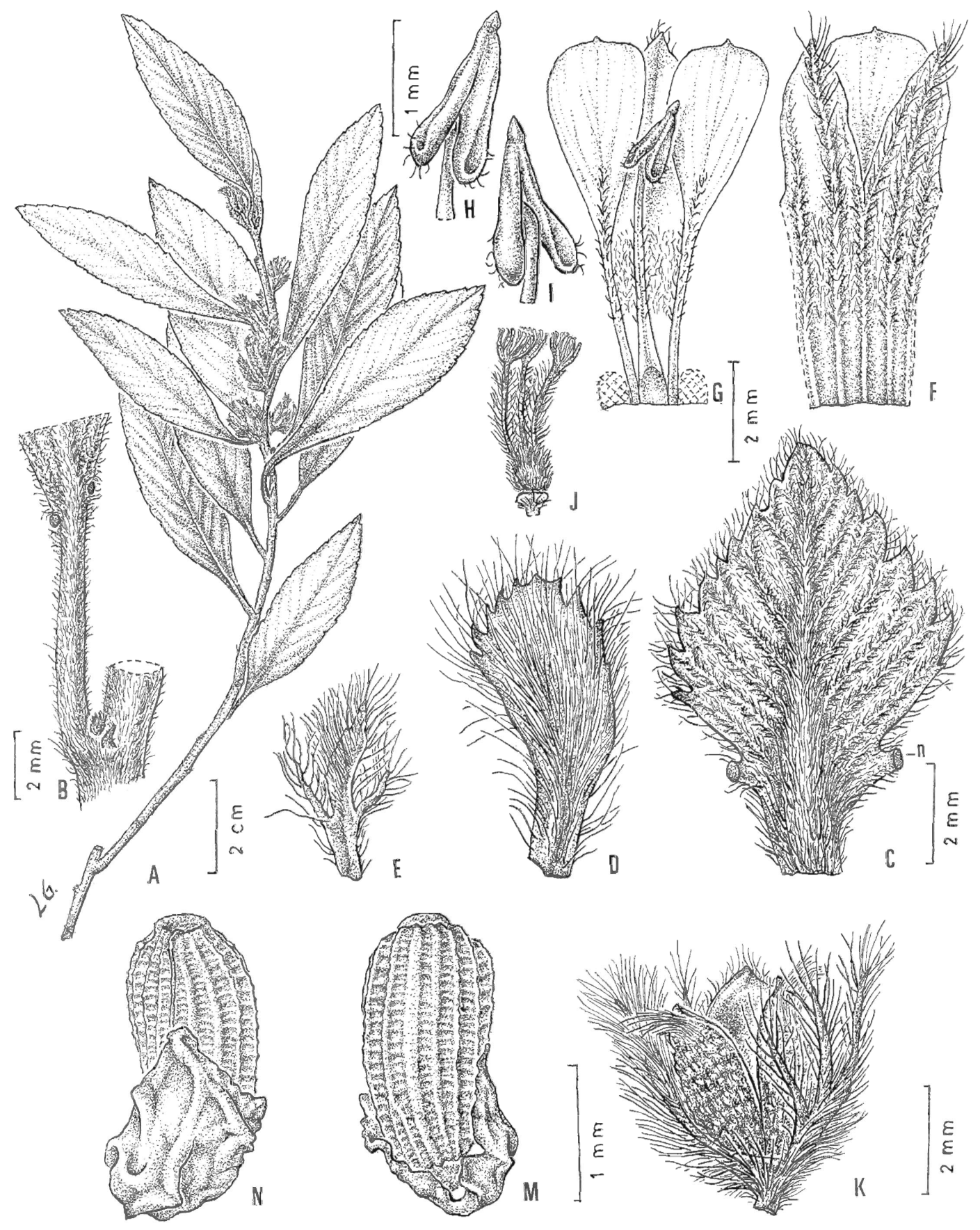

Fig. 13. Turnera schomburgkıana. A, rama florifera. B, detalle de un nudo mostrando una hoja con nectarios, una estípula y una yema axilar. C, bráctea externa, envés, con nectarios (n). D, bráctea interna, e.vés. E, profilo. F, porción del cáliz, cara externa: lóbulos interno (izquierdo) y externo (derecho). G, porción ciel cáliz, cara interna con pétalos y estambre adnatos, flor brevistilc (se han marcado las cicatrices dejadas al desprender dos estambres). H, antera con apículo, cara interna. I, antera con apículo, cara externa. J, gineceo de flur brevistila. K, fruto abierto con profilos. L, semilla con arulo, vista rafeal. M, semilla con arilo, cara opuesta a la rafe (A-B, Schomburgk 624; C-M, Maguire 40267). 
del año cilíndricas, con pelos simples, amarillentos, breves, densamente dispuestos, ápices velutinos. Yemas seriales a veces desarrolladas en ramas floríferas. Hojas algo discoloras. Estípulas insertas junto a la base del pecíolo, triangular-subuladas, $0,5-1 \mathrm{~mm}$ long. Peciolo 5-12 mm long., indumento como el del tallo. Nectarios 1-2 pares, situados en la unión de pecíolo y lámina o en la base de la lámina, discoideos, 0,3-0,5 mm diám., borde glabro. Lámina lanceolada o latielíptica, 30-90 x 9-40 $\mathrm{mm}$, relación largo:ancho $=2-4: 1$; base atenuada, margen ligeramente recurvado, crenado, crenas terminadas en coléteres diminutos y redondeados, ápice agudo; haz con pelos simples, cortos y largos, curvado-antrorsos o crespos, amarillentos; envés tomentoso; vena media saliente en la haz, 9-11 pares de venas secundarias impresas en la haz, todas prominentes en el envés, ángulo de divergencia $37-55^{\circ}$, venas terciarias poco visibles en el envés, más o menos perpendiculares a la vena media, rectas o recurvadas, venación menor inconspicua. Racimos muy abreviados, laterales, sésiles o brevemente pedunculados, hojas tectrices bruscamente reducidas de nomófilos a brácteas, las basales involucrales, 10-4 mm long., estípulas 0,5-0,7 mm long., brevemente pecioladas o subsésiles, ovado-orbiculares u ovadas, con nectarios pediculados en la base, margen crenado-aserrado, ápice agudo u obtuso; brácteas subsiguientes gradualmente más angostas, 6-3 x 4-0,6 mm, las apicales lineares, sésiles, sin nectarios, hirsutas, con estípulas subuladas de 1-2 mm long. Flores heterostilas, sésiles. Profilos laciniados a linear-subulados, 2-5 x 0,3-0,6 mm. Cáliz 5-8 mm long., tubo 3$4,5 \mathrm{~mm}$ long., cara externa con pelos cortos, a veces glabra en la base, hacia arriba álbido-hirsuta, cara interna con pelos laxos; lóbulos angostos, trinervados, con pelos más largos, vena media prolongada en un breve mucrón. Corola poco más larga que el cáliz, pétalos amarillos, lámina obovada, 4-5 mm long., con pelos en la base. Filamentos estaminales tenuemente pubescentes, porción basal engrosada, 0,6$0,8 \mathrm{~mm}$ long., soldada al tubo calicino; $3 \mathrm{~mm}$ long. en flores longistilas; $4,5-4,8 \mathrm{~mm}$ long. en flores brevistilas; anteras oblongas, 1,3-1,5 x 0,4$0,7 \mathrm{~mm}$, dorsifijas, base emarginada, pilosa, ápice apiculado, rectas después de la dehiscen- cia. Ovario elipsoide, hirsuto, 0,7-1 mm long., placentas 2-4-ovuladas; estilo hirsuto excepto en el ápice, recto, $5,5 \mathrm{~mm}$ long. en flores longistilas; excurvo, 1,5-2 mm long. en flores brevistilas; estigma 0,7-1 mm long., 8-12 ramas desiguales. Fruto ovoide, 3-3,6 x 2-3 mm, valvas rectas o algo recurvadas a la dehiscencia, con la cara externa pilosa, punctulada, ligeramente áspera, ápice con pelos largos, blanquecinos, cara interna glabra, jaspeada. Semilla obovoide, 1,9-2,1 x 0,8-1,2 mm, ligeramente curvada; epidermis papilosa, episperma reticulado-estriado, muros transversales menos conspicuos que los longitudinales y más próximos entre sí, exóstoma breve, cálaza saliente, ligeramente cóncava; arílo unilateral, lobulado, más corto que la semilla.

Material examinado. Venezuela. Bolívar: Roraima, XI 1842, Schomburgk 922 (B destruido, Foto F 13601!); Chimantá Massif, rapids of rio Apácara over igneous rock, $1 / 4 \mathrm{mi}$ downstream from mouth of rio Abácapa to mouth of rio Apácara, western side of Apácara-tepui, 415 m, 29 III 1953, Steyermark 74699 (F, K, NY, VEN). BRASIL. Roraima: 5 mi SE of Serra Sabang, 18 XII 1954, Maguire 40267 (CTES).

Distribución y fenología. Vive en la Guayana venezolana y Roraima (Brasil) a lo largo de cursos de agua. Florece desde diciembre a marzo.

Obs. En flores longistilas, el gineceo es 2,5 mm más largo que el androceo; en flores brevistilas, el androceo es $3 \mathrm{~mm}$ más largo que el gineceo.

\section{Turnera waltherioides Urb.}

Fig. 14, Mapa 8

Urban I., Repert. Spec. Nov. Regni Veg. 13: 158. 1914. Tipo. BRASIL, Rio Branco [Roraima]: Surumu, Serra de Mairary, 1100 m, Bl. gelb, IX 1909, Ule E. 8421 (holotipo destruido: B, Foto F 13611!; lectotipo aquí designado: $\mathrm{K}$ !; isotipos: 2U!).

Subarbusto, ramas leñosas cilíndricas, $6 \mathrm{~mm}$ diám., corteza parda, ligeramente estriada, cicatrices foliares salientes; ramas del año con entrenudos bien desarrollados, tornentosas, pelos breves, simples, curvos o crespos, patentes, ferrugíneos. Hojas coriáceas, discoloras. Estípulas linear-subuladas ca. $1 \mathrm{~mm}$ long. Pe- 


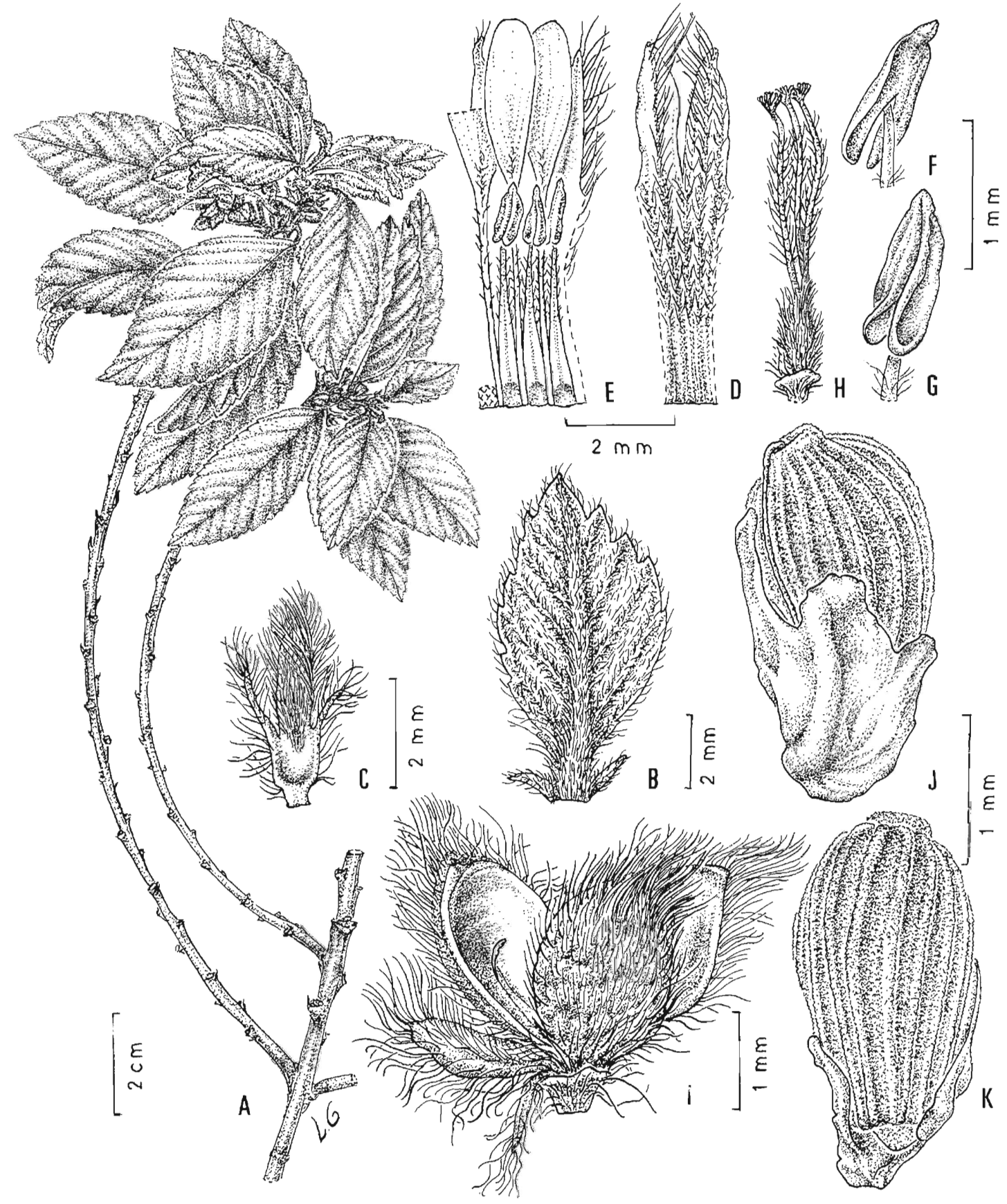

Fig. 14. Turnera waltheriozdes. A, rama florífera. B, bráctea externa, envés. C, profilo, cara interna. D, porción del cáliz, cara externa: lóbulo interno (izquierdo) y externo (derecho). E, porción del cáliz, cara interna con pétalos y estambres adnatos, flor longistila (se ha marcado la cicatriz dejada al desprender un estambre). F, antera apiculada, cara externa. G, antera, cara interna. $\mathrm{H}$, gineceo de flor longistila. I, fruto abierto con profilo. J, semilla con arilo, vista lateral, rafe hacia la izquierda. $\mathrm{K}$, semilla con arilo, cara opuesta a la rafe (A-H y J-K: Huber E Gorzula 11155; I, Ule 8421). 
cíolo 4-8 mm long., indumento como el del tallo. Nectarios 2 en la unión de pecíolo y lámina, orientados hacia el envés, diminutos, 0,5 mm diám., borde glabro. Lámina ovada, ovado-elíptica u obovada, 2-8 x 1,2-4 cm, relación largo:ancho $=2-2,5: 1$; base redondeada, a veces cuneada, borde doblemente aserradocrenado, ápice agudo u obtuso, indumento dorado, tomentoso-velutino en ambas caras, pelos simples; haz olivácea en seco, envés amarillento, con pelos muy crespos y más largos que en la haz; 9-14 pares de venas laterales alternas u opuestas, impresas, poco visibles en la haz, salientes en el envés, ángulo de divergencia ca. $45-65^{\circ}$, incurvas, perdiéndose hacia el margen, venas terciarias apenas visibles en el envés, oblicuas con respecto a la vena media, venación menor inconspicua. Racimos axilares muy densos, capituliformes, $1-1,3 \mathrm{~cm}$ diám. Brácteas externas ovadas a brevemente obovadas, 7-8 x 4-5 $\mathrm{mm}$, borde aserrado, indumento como en los nomófilos, con estípulas filiformes, pilosas, 1,5 mm long., algunas con nectarios diminutos, $0,2 \mathrm{~mm}$ diám. Flores heterostilas, subsésiles. Profilos laciniados o linear-lanceolados, 2,5-5 x 0,8-1 mm, hirsutos, excepto la base de la cara interna. Cáliz 5,7-6,5 $\mathrm{mm}$ long., cara externa con escasos pelos en la base, luego densamente piloso; tubo 3,2-4 mm long., glabro o velloso por dentro. Corola hasta $1 \mathrm{~mm}$ más larga que el cáliz, pétalos amarillos, pilosos en la base, lámina ca. $3 \mathrm{~mm}$ long. Filamentos estaminales triangular-subulados en seco, pubescentes, soldados 0,5-0,7 $\mathrm{mm}$ en la base al tubo, 2,5-3 $\mathrm{mm}$ long. en flores longistilas, 3,3-4 mm long. en flores brevistilas; anteras ovadas, 1-1,2 x 0,6-1 mm, dorsifijas, brevemente apiculadas, no recurvadas a la dehiscencia. Ovario ovoide o globoso, aprox. $1 \mathrm{~mm}$ long., hirsuto, placentas 1-2-ovuladas; estilos álbidohirsutos, rectos, 3,6-4 $\mathrm{mm}$ long. en flores longistilas; excurvos, $1 \mathrm{~mm}$ long. en flores brevistilas, estigma paucirramoso, glabro, 0,3-1 mm long. Fruto ovoide, 3-4 × 2-3,6 mm, valvas elipsoides, cara externa rugosa, densamente pilosa, cara interna glabra, jaspeada. Semilla obovoide, recta o ligeramente curvada, 1,5-2,4 $\times 1,1-1,2 \mathrm{~mm}$, relación largo:ancho $=1,4-2: 1$; epidermis parda, papilosa, episperma estriado o estriado-reticulado, muros longitudinales muy notorios, los transversales no siempre visibles; exóstoma hemisférico, rafe linear, cálaza saliente y cóncava; arilo unilateral, lobado, blanquecino en seco, más corto que la semilla.

Material examinado. Venezuela. Bolívar: Dist. Roscio, 1-5 km N del Campamento de la CVG en Parupa, sector N de la Gran Sabana, $5^{\circ} 43^{\prime} \mathrm{N} 61^{\circ} 32^{\prime} \mathrm{W}$, 1250 m, 2 III 1983, Huber et al. 7232 (US); dist. Piar, planicie del $2^{\circ}$ escalón de la vertiente meridional del Auyantepui, por encima de Uruyén, aprox. 10 $\mathrm{km}$ NW de la Misión de Kamarata, $5^{\circ} 44^{\prime} \mathrm{N} 62^{\circ} 27^{\prime} \mathrm{W}$, 1360 m, 16 I 1986, Huber \& Gorzula 11155 (CTES); la Gran Sabana, falda W de Uaipan, 1400 m, I 1948, Phelps 323 (VEN); dep. Sifontes, Parupa via Toron

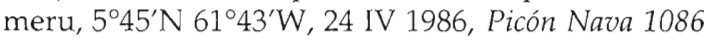
(US, VEN); $75 \mathrm{~km} \mathrm{~N}$ de Santa Elena de Uairén, 232 $\mathrm{km} \mathrm{S}$ de Eldorado, $5^{\circ} 15^{\prime} \mathrm{N} 61^{\circ} 15^{\prime} \mathrm{W}, 1200 \mathrm{~m}, 19$ XII 1978, Steyermark \& Carreño 117874 (F, MO, VEN).

Distribución y fenología. Propia de la Guayana venezolana y el estado de Roraima, Brasil; vive en matorrales, sabanas y selva en galería a 1100-1400 m de altitud. Florece y fructifica de noviembre a abril.

Obs. En flores longistilas, el gineceo es 2 $\mathrm{mm}$ más largo que el androceo; en flores brevistilas el androceo es 1,7-2,7 mm más largo que el gineceo.

Muy afín a T.schomburgkiana que se diferencia por sus hojas lanceoladas con indumento menos denso y más corto, estilos multirramosos y ovario con mayor número de óvulos.

\section{Serie Microphyllae Urb. \\ Mapa 9}

Urban I., Jahrb.Königl.Bot.Gart.Berlin 2: 125. 1883. Urban I. en Martius C.F.P., Fl.bras. 13(3): 145.1883.

Arbustos hasta $2 \mathrm{~m}$, o hierbas $20-30 \mathrm{~cm}$ alt. con pelos simples y glandulares capitadosésiles, excepcionalmente setiformes. Hojas pequeñas, pecioladas, de base foliar dilatada y persistente, generalmente con estípulas bien desarrolladas, persistentes, soldadas a la base foliar; nectarios ausentes; lámina foliar con margen recurvado o revoluto, dientes terminados en coléteres, venas secundarias generalmente hundidas en la haz. Flores axilares solitarias, amarillas o blancas. Pedúnculo floral 


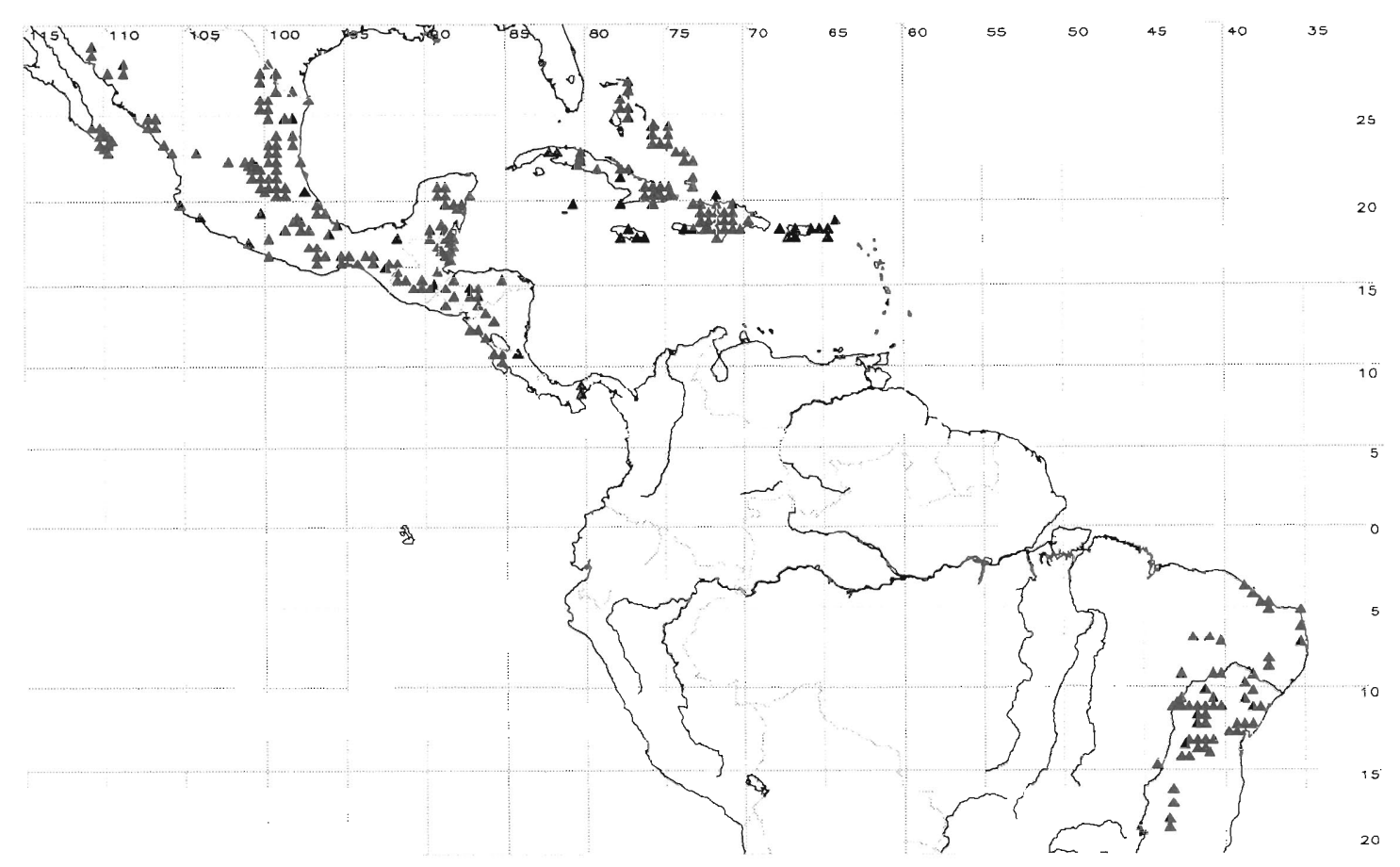

Mapa 9. Distribución de la serie Microphyllae

inserto en la base foliar, la porción apical libre, acrescente en el fruto. Profilos generalmente sin apéndices en la base. Pedicelo nulo. Sépalos soldados entre sí hasta la mitad o más, lóbulos de prefloración quincuncial, los internos con frecuencia con escasos pelos a ambos lados de la vena media. Filamentos estaminales soldados brevemente en la base, por su cara externa al tubo, libres entre sí, a veces unidos ligeramente en la base formando un anillo, anteras brevemente apiculadas. Estilos glabros o laxamente pilosos. Fruto granuloso o rugoso por fuera. Semilla obovoide, corta, curvada, nunca subglobosa; episperma reticulado, epidermis no papilosa, exóstoma corto, rafe linear, ligeramente saliente, cálaza redondeada, no prominente, a veces ligeramente cóncava; arilo unilateral, más corto que la semilla.
Especie tipo (aquí designada): Turnera diffusa Willd. ex Schult.

El tamaño de las hojas así como la adnación de las estípulas a la base del pecíolo caracterizan a esta serie; cuatro especies presentan hojas fragantes, con pelos glandulares capitadosésiles, en tanto que los pelos glandulares setiformes de Turnera collotricha son únicos en el género (Arbo, 1981).

Esta serie también presenta área disyunta, su distribución es muy similar a la de T.diffusa, una de las especies más abundante del género, que vive en el hemisferio norte en Texas, México, el Caribe y América Central, y en el hemisferio sur en los estados nordestinos de Brasil. Las otras especies son endémicas del nordeste de Brasil, excepto T.collotricha, endémica de la Serra do Espinhaço en Minas Gerais.

\section{Clave para las especies de la serie Microphyllae}

1. Profilos anchos, ovados, asimétricos; estípulas glandulosas

1. Profilos lineares, estípulas eglandulosas

36. '. asymmetrica Arbc

2. Pelos glandulares setiformes de base conoidal

38. 2. collotriche Arbo 


\section{Pelos glandulares capitado-sésiles}

3. Cáliz soldado hasta la mitad o más, pétalos amarillos (excepcionalmente blanquecinos), glabros o pilosos en la base. Semilla arqueada

4. Hojas adultas y profilos seríceos, lanosus, tomentosos o laxamente pilosos. Pedúnculos florales generalmente 0,3-1 $\mathrm{mm}$ long. Pétalos generalmente pilosos en la base de la cara superior

39a. T. diffusa Willd. ex Schult. var. diffusa

4. Hojas adultas y profilos glabros, a veces algunos pelos sobre las venas. Pedúnculos florales generalmente 1-2 mm long. Pétalos glabrus

39b. T.diffusa Willd. ex Schult. var. aphrodisiaca (Ward) Urb.

3. Cáliz soldado sólo en el tercio basal. Pétalos blancos (en T.calyptrocarpa con mácula basal amarilla), pilosos hasta la mitad. Semilla apenas curvada

5. Estípulas 1,5-3 mm long. Hojas generalmente obovadas, crenadas cası hasta la base, a veces discoloras

37. T. calyptrocarpa Urb.

5. Estípulas 0,5-2 mm long. Hojas frecuentemente angustiobovadas son 1-4 pares de dientes en la porción apical

40. T. hebepetala Urb.

\section{Turnera asymmetrica Arbo sp. nov.} Fig. 15, Mapa 10

Frutex ca. $1 \mathrm{~m}$ altus, pilis glandularibus capitatis sessilibus dense adspersis. Stipulac 0,2-0,3 mm long. ex singults glandulis dentgricans terminantibus. Flores verisimiliter monomorphi. Pedunculi ex parte petioli adnatz. Prophylia ovata, asymmetrica. Calyx 9-11 mm in $1 / 3$ coalitus. Petala flava, filamenta glabra, basi tubo imo adnata. Semina reticulata, arilo breve, laterale.

Tipo. BRASIL. Bahia: Mun. Tanhaçu, $1 \mathrm{~km} \mathrm{~S}$ de Tanhaçu, camino a Brumado, aprox. $14^{\circ} 02^{\prime} S 41^{\circ} 15^{\prime} \mathrm{W}$, ca. 420 m, 22 XI 1992, Arbo M.M., R.Mello-Silva \& J.Vicente Nunes 5694 (holotipo: SPF; isotipos: CEN, CTES, HUEFS, IPA, K, MBM, MO, NY, SI, UB).

Arbusto erecto, muy ramoso, aprox. $1 \mathrm{~m}$ alt.; ramas cilíndricas, corteza pardo-rojiza, con estrías longitudinales y cicatrices foliares prominentes, las ramas del año con pelos simples blandos y abundantes pelos glandulares capitado-sésiles. Yemas axilares 2-3, la basal florífera, ramas seriales desarrolladas. Hojas vegetativas herbáceas, discoloras, viscosas, fragantes y algo abolladas. Estípulas 0,2-0,3 mm long., persistentes, situadas a cada lado de la base foliar, soldadas a la misma o desplazadas hasta $2 \mathrm{~mm}$ sobre el pecíolo, rematadas en un coléter capitado, negruzco, rojo en hojas jóvenes. Base foliar voluminosa, rojiza y persistente. Pecíolo 0,3-1 mm long., indumento como el del tallo. Lámina obovada o elíptica, 10-25x
4-8 mm, relación largo:ancho $=2,5-3,1: 1 ;$ base atenuada o cuneada, borde revoluto, aserrado, 1-4 pares de dientes agudos u obtusos, terminados en una glándula capitada diminuta 0,1 mm diám., ápice agudo u obtuso; haz oscura, lustrosa en seco, con pelos simples blandos y pelos glandulares capitado-sésiles; envés opaco, verde claro, con indumento más denso; 3-4 pares de venas hundidas en la haz, prominentes en el envés, incurvas, divididas cerca del borde en dos ramas que se dirigen a los dientes, venas terciarias ligeramente visibles en el envés; venación menor inconspicua. Hojas floríferas no abolladas, concoloras en seco. Pecíolo 1-4 mm long. Lámina ovada o elíptica, 8-12 x 4-6 mm, relación largo:ancho $=$ 1,6-2,6:1; base cuneada, a veces redondeada, borde plano, ápice agudo, indumento laxo.Flores axilares solitarias, homostilas aparentemente, agrupadas en el ápice de las ramas en un racimo hojoso. Pedúnculo cilíndrico, 4-11 mm long., soldado 1-2 mm al pecíolo, porción apical libre. Profilos ovados, asimétricos, 6-11 x 2-3,5 $\mathrm{mm}$, indumento como el de las hojas florales, 1-2 pares de venas laterales, base cuneada o redondeada, borde denticulado, con pelos simples largos, ápice agudo o acuminado, frecuentemente rojizo, dispuestos en el ápice del pedúnculo. Cáliz 9-11 mm, tubo campanulado, 3-4 mm long., venas comisurales excurvas, formando una prominencia al dividirse, las ramas para los lóbulos en ángulo muy abierto en su 


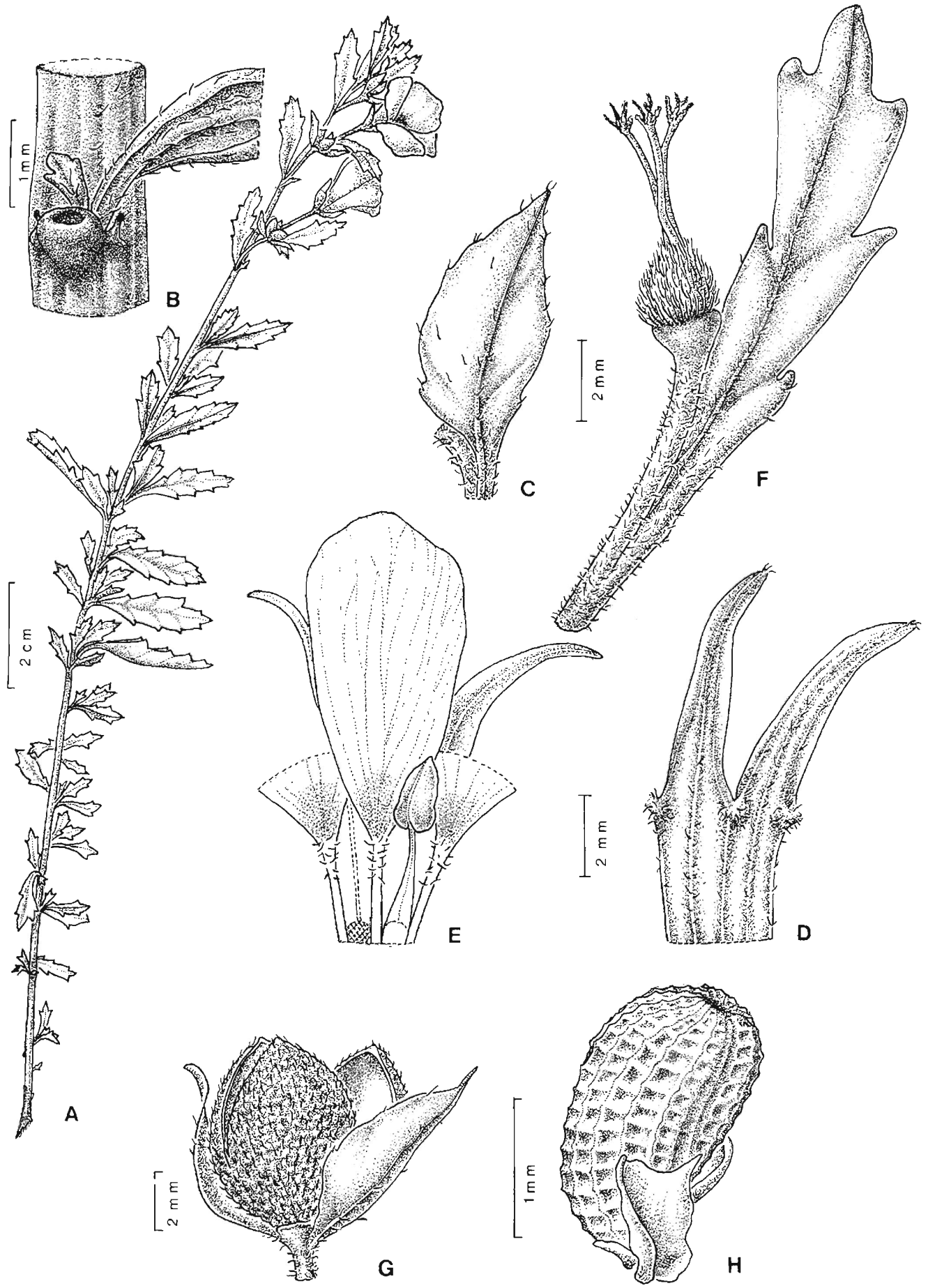

Fig. 15. Turnera asymmetrica. A, rama florífera. B, detalle del nudo mostrando la base foliar persistente con estípulas terminadas en coléteres y una rama axilar en desarrollo. C, profilo, cara externa. D, porción del cáliz, cara externa. E, porción del cáliz, cara interna con pétalos y estambre adnatos, flor aparentemente homostila (se ha marcado la cicatriz dejada al desprender un estambre). F, gineceo de la misma flor, pedúnculo floral soldado en la base al pecíolo de la hoja tectriz, luego libre. G, fruto abierto con profilos. H, semilla con arilo, vista lateral, rafe hacia la derecha (Arbo et al. 5694). 
origen, por fuera con pelos simples blandos y pelos capitado-sésiles, por dentro glabro; lóbulos triangulares, con pelos simples, los internos con bordes membranáceos, ápice agudo frecuentemente rojizo. Pétalos amarillos con mancha purpúrea en la base, rosados en flores marchitas, uña pilosa adnata al tubo hasta la garganta, lámina obovada, glabra, 7-10 x 3,5-5 mm. Filamentos estaminales glabros, complanado-subulados en seco, soldados brevemente en la base al tubo, $3 \mathrm{~mm}$ long.; anteras ovadas, $1,5-1,8 \times 0,6-1 \mathrm{~mm}$, base emarginada, filamento inserto a $0,6 \mathrm{~mm}$ de la base, ápice apiculado, recto a la dehiscencia. Ovario ovoide, $2,5 \times 2 \mathrm{~mm}$, pelos simples densos, placentas 7-ovuiadas; estilos cilíndricos, glabros, erectos, $3 \mathrm{~mm}$ long.; estigmas rojizos, paucirramosos, ca. $1 \mathrm{~mm}$ long. Fruto ovoide o elipsoide, 5-6 $\mathrm{mm}$ long., inicialmente vestido con ios restos del perianto persistentes; valvas ovadas, cara externa parda, granulosa, con pelos simples largos y pelos capitado-sésiles, cara interna glabra. Semilla inmadura obovoide, $2 \times 1,2 \mathrm{~mm}$, epidermis glabra y lisa, episperma reticulado, aréolas cuadrangulares o transrectangulares con una depresión punctiforme, exóstoma pequeño, brevísimo, rafe linear poco visible, cálaza redondeada no prominente; arilo corto, unilateral, células papilosas.

Distribución. Especie propia del sur de Bahia, sólo se conoce el tipo.

Obs. Especie de hábito muy similar al de $T$. chamaedrifolia. Cuando se desprenden las hojas floríferas, en cada nudo se observan dos cicatrices sobre la base foliar persistente, la del pedúnculo floral orientada hacia arriba, y por debajo la del pecíolo. Afín a T.diffusa que se diferencia por sus flores más pequeñas, con profilos lineares y tubo floral proporcionalmente más largo.

\section{Turnera calyptrocarpa Urb.}

Fig. 16, Mapa 12

Urban I., Jahrb. Königl. Bot. Gart. Berlin 2: 128. 1883. Urban I. en Martius C.F.P., Fl. bras. 13(3): 148, tab. 45. 1883. Lectotipo (aquí designado): BRASIL. Bahia: partie Méridionale, Pouço d'Areia, VI 1844, Blanchet J.S. 3863 (BR!; isotipos F!, P!).
Arbusto ca. 2,5 m, ramas viejas con corteza parda, longitudinalmente estriada, lenticelas circulares, pequeñas, blanquecinas; macroblastos y braquiblastos alternantes; cicatrices foliares prominentes, con base foliar y estípulas persistentes; ramas del año con pelos simples cortos, curvado-antrorsos, pelos crespos y pelos glandulares capitado-sésiles, amarillentos. Yemas axilares 1-2, ramas seriales generalmente no desarrolladas, a veces dando braquiblastos floríferos. Hojas pequeñas, discoloras, cuando adultas a veces glabrescentes. Base foliar abultada. Estípulas 1-2 pares, subuladas, negruzcas, el par apical más desarrollado, 1,5$3,5 \mathrm{~mm}$ long., brevemente pilosas. Pecíolo cilíndrico, 2-3 mm long., indumento como el del tallo. Lámina obovada, a veces elíptica, raramente ovada, 4-33 x 2,5-20 mm, relación largo:ancho $=1,4-3: 1$; base cuneada o atenuada, ápice obtuso o agudo, borde revoluto, aserrado, dientes agudios, a veces terminados en coléteres; haz obscura, rugosa, con pelos simples cortos, curvado-antrorsos y pelos glandulares esparcidos, envés castaño con pelos simples, crespos y abundantes pelos glandulares capitado-sésiles, amarillo-dorados; vena media y 4-5 pares de venas laterales alternas 0 subopuestas hundidas en la haz y prominentes en el envés, con pelos simples, gruesos, curvado-antrorsos, ángulo de divergencia ca. $30^{\circ}$, perdiéndose hacia el borde, originando ramas hacia los dientes, venas ierciarias a veces visibles en el envés, venación menor inconspicua. Flores blancas con garganta amarilla, axilares, heterostilas, a veces agrupadas en los ápices de braquiblastos floríferos. Pedúnculo cilíndrico, inserto en la base foliar, 1-3 mm iong., indumento como el del tallo. Profilos obovados, 3-4,5 x 0,8-1 mm, estipulados, ápice agudo, indumento como el de las hojas. Cáliz 3,5-6 mm long., con pelos tenues, crespos y pelos glandulares, pelos más gruesos, curvados, sobre las venas; tubo campanulado, 1,5-2 mm long., cara interna glabra o con pelos simples laxos, en la parte superior; lóbulos triangulares, cara interna glabra, lóbulos externos con la cara externa pilosa, lóbulos internos pilosos sólo en la vena media y un poco a los lados en la parte basal, con bordes membranáceos, a veces ciliados, ápice brevemente mucronado, 0,1-0,3 mm. 


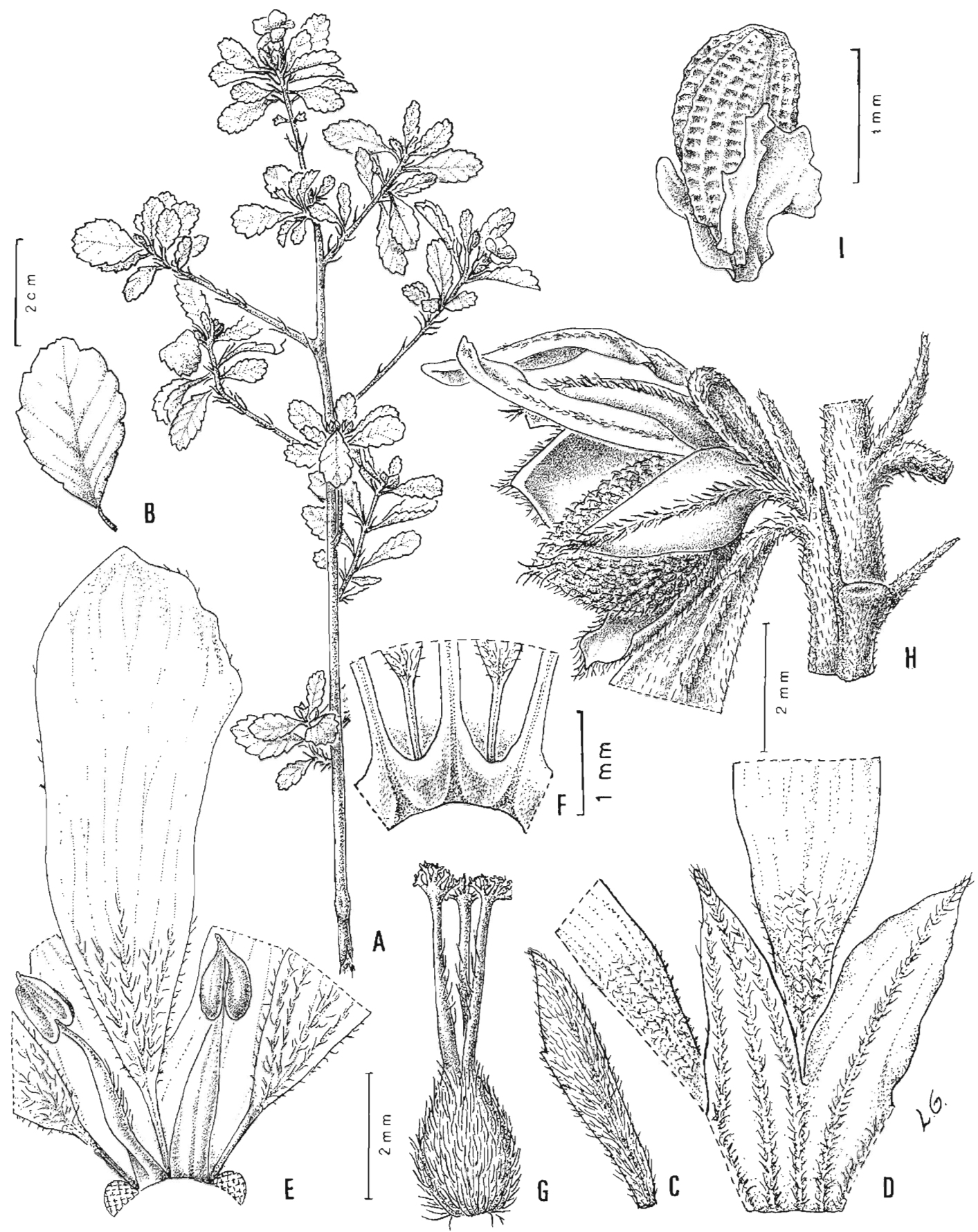

Fig. 16. Turnera calyptrocarpa. A, rama florífera. B, hoja. C, profilo, cara externa. D, porción del cáliz, cara externa: lobulos externo (izquierdo) e interno (derecho), y dos pétalos seccionados. E, porción del cáliz, cara interna con pétalos y estambres adnatos, flor brevistila (se han marcado las cicatrices dejadas al desprender dos estambres). F, porción de la base del cáliz, cara interna, con pétalos y estambres adnatos, las bases de los filamentos estaminales coherentes formando un anillo estaminal. G, gineceo de flor longistila. II, porción de tallo mostrando la base foliar y las estípulas persistentes, y un fruto abierto, vestido con los restos florales. I, semilla con arilo, vista rafeal (A, C-E y G: Arbo et al. 5363; B: Harley et al. 27724; F, Lemos 47; H-I: Arbo et al. 5506). 


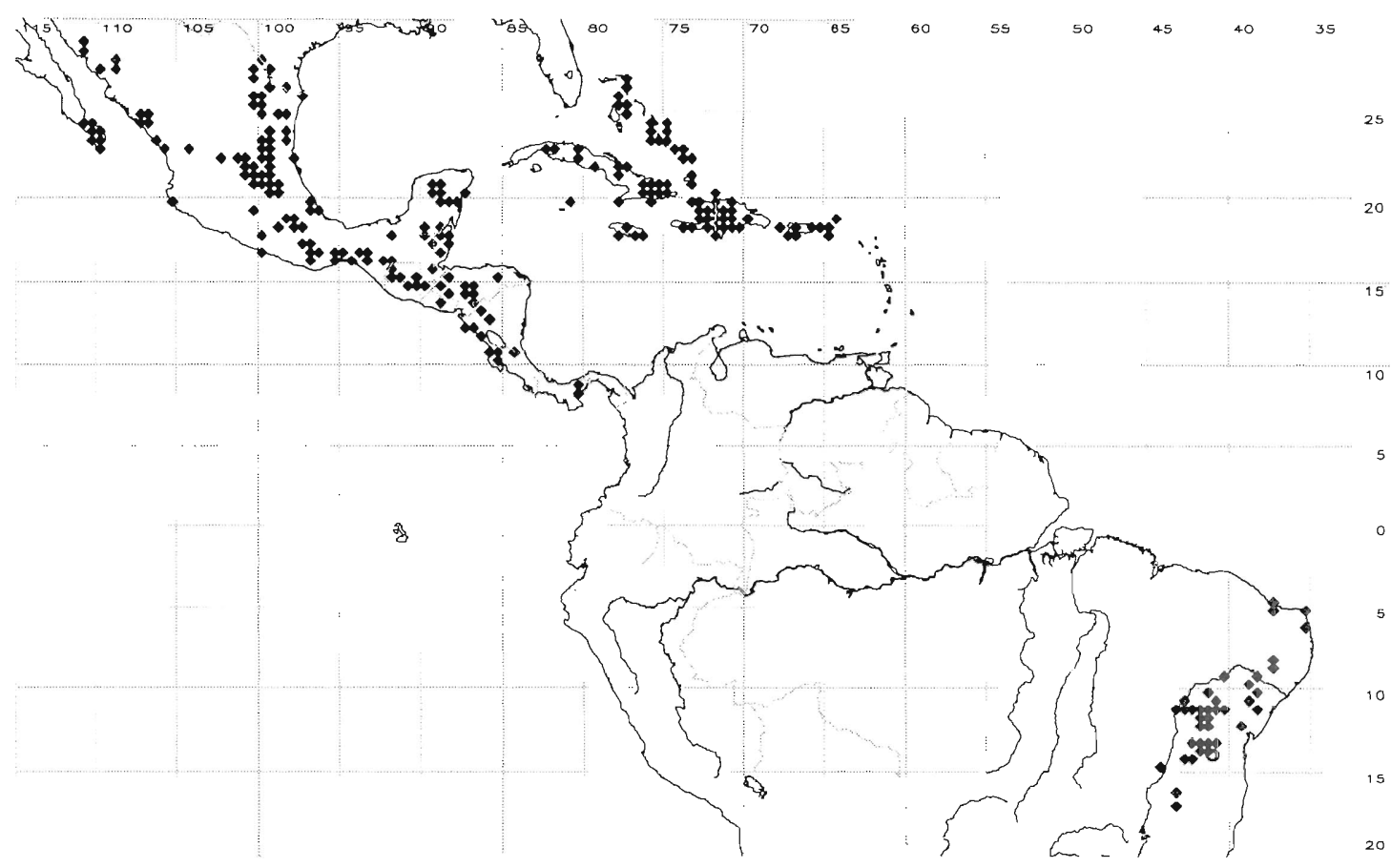

Mapa 10. Distribución de Turnera asymmetrica $\bigcirc$ y T. diffusa var. diffusa

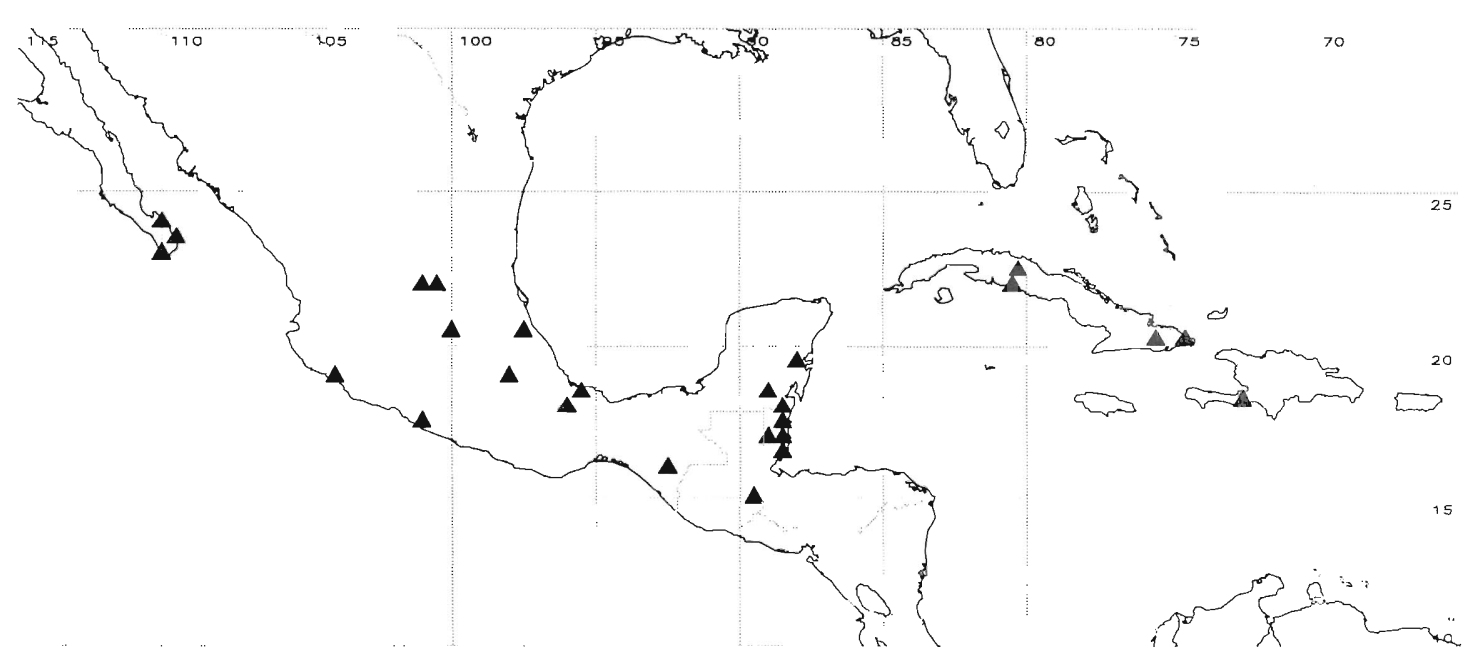

Mapa 11. Distribución de Turnera diffusa var. aphrodisiaca

Corola más larga que el cáliz, pétalos con la uña pilosa soldada al tubo, lámina obovada, 5$12 \times 2,5-5 \mathrm{~mm}$, pilosa en ambas caras desde la base hasta la mitad, borde ciliado. Filamentos estaminales complanado-subulados en seco, a veces unidos entre sí en la base formando un anillo de 0,2-0,4 mm, soldados $0,5 \mathrm{~mm}$ en la base al tubo, con un nectario en el dorso en la inserción, pilosos sólo en el dorso, 3-4 mm long. en flores longistilas, 5-7 mm long. en flores brevistilas, anteras ovadas, 0,8-1 x 0,5-0,6 mm, base emarginada, ápice recurvado a la dehiscencia, filamento inserto en una cavidad basidorsal a 0,4 $\mathrm{mm}$ de la base. Ovario latiovoide, 
1,5-2,3 mm long., placentas 6-8-ovuladas, estilos cilíndricos, 2,7-3 mm long. en flores longistilas, $1-1,3 \mathrm{~mm}$ long. en flores brevistilas, estigmas 0,3-0,5 mm long., a veces papilosos. Fruto 4-5 mm long., envuelto por los restos ilorales persistentes, cara externa granulosa o rugosa, con pelos simples y pelos glandulares, cara interna lisa, lustrosa, castaña, vena placentaria prominente hasta más allá de la parte media. Semilla obovoide, 1,4-1,7 x 0,9$1,2 \mathrm{~mm}$, reticulada, aréolas cuadranguiares o transrectangulares con una depresión punctiforme, epidermis papilosa, exústoma cónico, rafe linear, a veces resaltada hacia ia cálaza, ésta apical, no prominente; arilo amplio, envolvente.

Material examinado. Brasil. Bahia: $16 \mathrm{~km}$ SW de Morro do Chapéu, camino a Utinga, aprox.

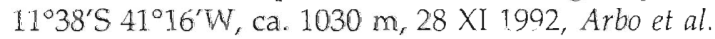
5363 (CTES, HUEFS, K, MICH, SPF, UB, YUTO); 10 km W de Coração de Maria, camino a Feira de Santana, aprox. $12^{\circ} 15^{\prime} \mathrm{S} 38^{\circ} 50^{\prime} \mathrm{W}$, ca. $200 \mathrm{~m}, 2$ XII 1992, Arbo et al. 5506 (CTES, HUEFS, SPF, UB, YUTO); sin localidad, 1857, Blanchet 2939 p.p. (P); Jacobina, 1843, Blanchet 3869 (G); Pocatú, entre Feira de Santana e Serrinha, 20 VII 1959, Gomes \& Labouriau 839 (RB); Serra do Jatobá, Morro de Nossa Senhora dos Milagres, just W of Milagres, 500-600 m, 12 54'S 39 $52^{\prime}$ W, 3 VI 1977, Harley et al. 19445 (CTES, IPA, US); Mun. Rio de Contas, $8 \mathrm{~km}$ da cidade na estrada para Juciape, $13^{\circ} 36^{\prime} \mathrm{S} 41^{\circ} 47^{\prime} \mathrm{W}$, 900 m, 25 XII 1988, Harley et al. 27724 (CEPEC, CTES, $\mathrm{SPF})$; Serra do Tombador, ca. $23 \mathrm{~km}$ E of Morro do Chapéu, road to Mundo Novo, ca. 1000 m, 21 II 1971, Irwin et al. 30732 (CTES, MO, UB, US); Faz. Mocambo, Dom Macedo Costa, 25 VIl 1982, Lemos 47 (ALCB, CEPEC, CTES, HPR, HUEFS); a $13 \mathrm{~km}$ de Mucugê, 16 XII 1984, Lewis et al. s.n., CFCR 6999 (CTES, SPF); Faz. Pinto, Castro Alves, $27 ! 1957$, Lordêlo 57-20 (ALCB); Itatim, Sta. Teresinha, IV 1958, Lordêlo 58-19 (ALCB); Itatim: Morro do Agenor ou da Madeira, $12^{\circ} 43^{\prime} \mathrm{S} 39^{\circ} 42^{\prime} \mathrm{W}, 310-430 \mathrm{~m}, 17$ XII 1995 , Melo et al. 1413 (CTES, HUEFS); Itatim: Morro das Tocas, $12^{\circ} 42^{\prime} \mathrm{S} 39^{\circ} 46^{\prime} \mathrm{W}, 280-410 \mathrm{~m}, 24$ il 1996, Melo 1458 (CTES, HUEFS); Alagoinhas, 14 II 1980, Pinto 20/80 (CEPEC, HPR); Estação Ecológica do Raso da Catarina, $9^{\circ} 20^{\prime}-9^{\circ} 55^{\prime} \mathrm{S} 38^{\circ} 29^{\prime}-38^{\circ} 43^{\prime} \mathrm{W}, 26$ VI 1982, Quetroz 379 (ALCB, HUEFS); Mun. Feira de Santana, campus da UEFS, Quadru I, $12^{\circ} 15^{\prime} \mathrm{S} 38^{\circ} 58^{\prime} \mathrm{W}$, Queiroz \& Crepaldi 1479 ( $\triangle$ LCB, CEPEC, CTES, HRB, HUEFS); Caetité, Brejinho das Ametistas, $14^{\circ} 15^{\prime} 37^{\prime \prime} \mathrm{S}$ 42 $31^{\prime} 27^{\prime \prime}$ W, 900-1000 m, 8 IiI 1994, Roque et al. CFCR 14960 (CTES, SPF); Paulo Affonso, IV 1954, Vidal
IV-814 (R). Ceará: sin localidad ni fecha, Allemão \& Cysnetros 797 (R); entre Aquiraz e Aracati, 31 I 1968, Andrade-Lima 68-5217 (IPA); Fortaleza, Campo da Escola de Agronomía do Ceará, 8 VII 194.1, Bezerra s.n. (CTES); Fortaleza, Éscola de Agronomia, 4 II 1955, Ducke 2411 (UB); confins of Piauhy, between Olho d'Agua do Inferno et Poço do Cavalo, II 1839, Gardner 2406 (K); Mun. Aiuaba, Estação Ecológica de Aiuaba, $6^{\circ} 44^{\prime} 32,5^{\prime \prime} \mathrm{S} 40^{\circ} 21^{\prime} 0,9^{\prime \prime} \mathrm{W}, 620 \mathrm{~m}, 20 \mathrm{~V}$ 1998, Lima-Verde \& Andrade 930 (CTES, EAC); Sitio Cipó Caucaia, 10 III 1992, Matos s.n. (CTES); BR304, próximo ao km 61, córrego de Ubarana, Aracati, 11 III 1979, Nunes et al. s.n. en parte (CTES). Minas Gerais: Serra da Mantiqueira, 22 IX 1879, Glazıou 10881 p.p. (K, P) [localidad dudosa]. Pernambuco: Arcoverde, Estação Experimental do IPA, Serra das Varas, 26 IX 1973, Ferreira s.n. (F, IPA); Petrolina, CPATSA, 8 IV 1983, Fotius 3415 (IPA); Itambé, X 1937, Vasconcellos Sobrinho s.n. (IPA). Piauí: São Joãc Vermelho-São Raimundo Nonato, 23 I 1984, Emperaire 2111 (CTES). Rio de Janeiro: IX 1879, Glaziou 10877 (C, K, P) [localidad dudosa]. Sergipe: São Cristovão, 11 XI 1981, Carneiro 167 (IPA).

Distribución y fenología. Se la conoce de "campos gerais, cerradão, caatinga y tabuleiro" en Bahia, Ceará, Pernambuco, Piauí y Sergipe entre 200 y $1030 \mathrm{~m}$ de altitud. Florece casi todo el año.

Son dudosas las localidades de Glaziou, de Minas Gerais y Rio de Janeiro (Wurdack, 1970). Glaziou (1909) cita su ejemplar 10877 para la siguiente localidad: Minas Gerais, serra da Mantiqueira.

\section{Nombre vulgar. "guaxuma" (Ceará: Matos} S.n.)

Cbs. Las nojas son deciduas, hay especímenes desnudos como Gomes \& Labouriau 839. Sespués que se desprenden las hojas floríferas, en cada base foliar se pueden distinguir dos cicatrices: la cicatriz del pedúnculo floral, y a su lado, orientada hacia arriba, la cicatriz del pecíolo.

En algunas flores se observa en la cara interna de los sépailos, una fila de pelos o papilas en la garganta, en el lugar donde se inserta la corona en las flores de Piriqueta.

\section{Turnera collotricha Arbo}

Mapa 12

Arbo M.M. Bonplandia 5(14); 115-122. 1981. Holotipo: BRASIL. Minas Gerais: Serra do 


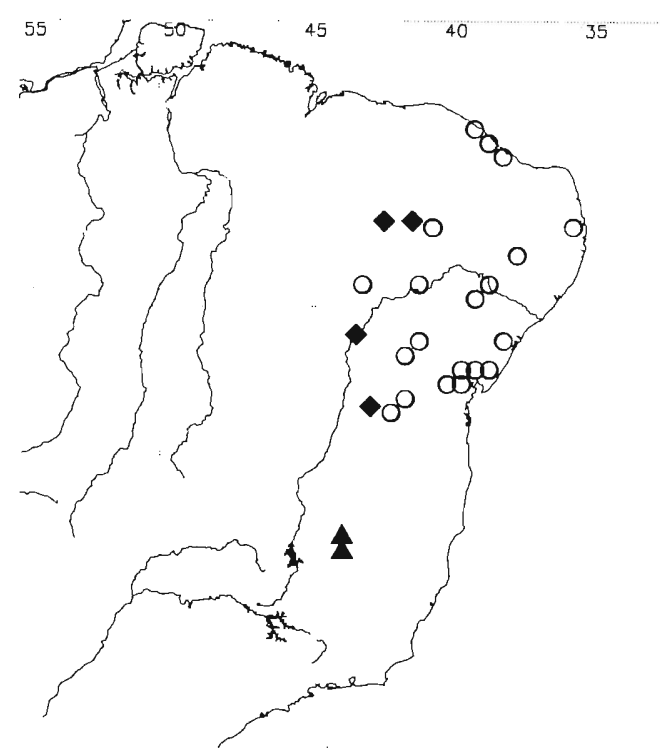

Mapa 12. Distribución de Turnera calyptrocarpa O, T.collotricha $\Delta$ y T.hebepetala

Espinhaço, Rod. BR-259, 1100-1300 m, 22 II 1975, Hatschbach G., W. Anderson, G. Barneby \& B. Gates 36434 (MBM).

Material examinado. Brasil. Minas Gerais: Hatschbach et al. 27315 (CTES); Mun. Gouveia, Córrego do Tigre, 26 X 1999, Hatschbach et al. 69774 (CTES, MBM).

Distribución y fenología. Especie rara, aparentemente endémica de la Serra do Espinhaço, sólo ha sido recolectada en campos rupestres del municipio Gouveia, entre 1100 y 1300 m de altitud. Florece y fructifica de septiembre a febrero.

Obs. Es la única especie de la serie sin pelos glandulares capitado-sésiles. Presenta en cambio, pelos glandulares setiformes similares a los de Piriqueta (Arbo, 1995). Es la única especie del género Turnera con tal tipo de pelo glandular; en Piriqueta la porción basal de los pelos es bulbosa, siendo conoidal en $T$. collotricha.

Los pedúnculos florales, cuya porción apical libre es de 0,6-1 mm long., se insertan en la base foliar. En plantas brevistilas el androceo es 2,5$3 \mathrm{~mm}$ más largo que el gineceo; en plantas longistilas, el gineceo es 1,5-2,5 mm más largo que el gineceo. 39a. Turnera diffusa Willd. ex Schuilt. var. diffusa

Fig. 17, Mapa 10

Schultes J.A. in Roemer \& Schultes, Syst.veg. 16 ed., 6: 679. 1820. Urban I., Jahrb. Königl. But. Gart. Berlin 2: 125. 1883. Urban I. en Martıus C.F.P., Fl.bras. 13(3): 146, tab. 44. 1883. Holotipo: [REPÚBLICA DOMINICANA, Santo] Domingc, Herb. Willdenow 6092 (B; International Microfiche Center IDC NV, microficha 424!).

Turnera microphylla Desv. in Hamilton W., Prod. pl. Ind. occ.: 33. 1825. Tracis microphylla (Desv.) Griseb., Mem. Amer. Acad. Arts 8: 189. 1862. Bohadschia microphylla (Desv.) Griseb., Cat.pl.cub.: 114. 1866. Holotipo: Hab. in America, [prope Cibao, in parte orientali Hispaniolae] XIl, Herb. Desvaux (P!).

Bohadschia humifusa Presl, Rel.haenk. 2: 98, t. 68. 1831. Turnera humifusa (Presl) Endl. ex Walp., Rep. bot. syst. 2: 230. 1843. Holotipo: MÉXICO. [Guerrero.] Acapulco, Haenke T. s.n. (PRC!; isotipos: BM!, $\mathrm{W} !)$.

Turnera pringlei Rose, Contrib.U.S.Natl.Herb. 5(4): 166. 1899. Holotipo. MÉXICO. Puebla: Dry limestone ledges near Tehuacan, $6500 \mathrm{ft} ., 29$ VIII 1897, Pringle C.G. 6692 (US!; isotipos: BM!, BR!, F!, GH!, GOET!, HBG!, K!, LY!, MO!, NY!, P!, S!, W!).

Turnera pumilea auct. non L., Poiret J.L.M. en J.B.Lamarck, Encycl. 8: 143. 1808.

Arbusto o subarbusto muy ramificado, hasta $2 \mathrm{~m}$, erecto, decumbente o postrado (a gran altitud), ramas viejas con corteza rojiza, longitudinalmente estriada, lenticelas blanquecinas oblongas, cicatrices foliares prominentes; ramas del año cilíndricas o más o menos anguladas, subglabras a densamente cubiertas de pelos largos curvado-antrorsos, entremezclados con pelos blanquecinos crespos y pelos glandulares capitado-sésiles amarilios o blanquecinos; en algunas ramas se suceden macroblastos y braquiblastos hasta de $2 \mathrm{~cm}$ long. Yemas axilares 1-4 seriales, desarrollo acrópeto, la basal florífera, las apicales originan macroblastos o braquiblastos. Hojas muy variables, herbáceas, patentes, crespas, fragantes, frecuentemente discoloras. Base foliar prominente, estípulas triangular-subuladas, rojizas, 0,5-1 mm long., con pelos blanquecinos, persistentes después de la caída de las hojas. Pecíolo 0-3,5(-7) mm long. Lámina obovada, angustiobovada, a veces ovada, (2-)5-38(-50) $x$ 


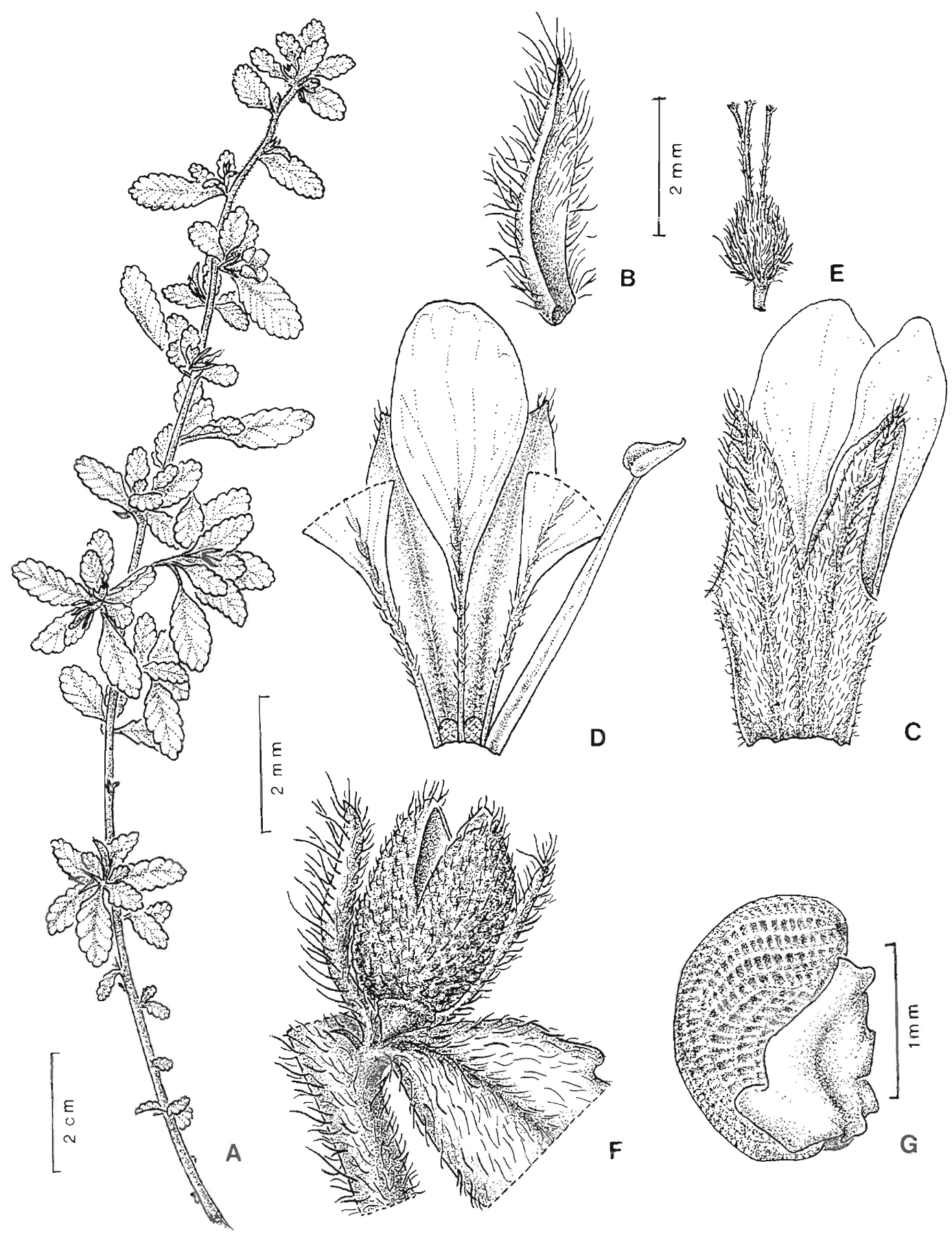

Fig. 17. Turnera diffusa var. diffusa. A, rama florífera. B, profilo, cara interna. C, porción del cáliz, cara externa: lóbulos extemo (izquierdo) e interno (derecho) y dos pétalos. D, porcion del cáliz, cara interna con pétalos y estambres adnatos, flor brevistila (se han marcado las cicatrices dejadas al desprender dos estambres). E, gineceo de flor brevistila. F, fruto abierto con profilos inserto en la base del pecíolo. G, semilla con arilo, vista lateral (A y G: Arbo et al. 5758; B-E, Arbo et al. 5401; F- Harley et al. 22955). 
(1-)2-15(-19) mm, base cuneado-atenuada, ápice obtuso, a veces agudo, borde marcadamente revoluto, crenado-aserrado, dientes obtusos, raramente agudos, los basales generalmente terminados en coléteres trocleares (González, 1998), discoideos en seco, 0,12-0,19 mm diám.; haz verde-oscura, rugosa, parda en herbario, opaca o lustrosa, glabra o estrigosa a densamente cubierta de pelos simples, blandos, envés verde-claro o grisáceo, castaño o verdoso o blanquecino en herbario, subglabro, laxamente piloso, álbido-pubescente, hirsuto (Haenke 23), tomentoso o lanoso (Purpus 7135), con pelos simples y pelos glandulares capitadosésiles amarillos o blanquecinos; vena media y 5-8 pares de venas laterales hundidas en la haz y prominentes en el envés, ángulo de divergencia $45-60^{\circ}$, rectas o incurvas hacia los bordes, terminando en las escotaduras o dividiéndose inmediatamente antes, rama basal excurva, venación menor inconspicua. Flores dimorfas, axilares. Pedúnculo cilíndrico, inserto en la base foliar, la porción apical libre de 0,3-1(-2) mm long., en los frutos acrescente $1-4,5 \mathrm{~mm}$ long. Profilos insertos en el ápice del pedúnculo, opuestos o alternos, ovados, lanceolados, ovado-lanceolados o subulados, a veces asimétricos, 2,5-7 x 0,4-2,5 mm, frecuentemente con un par de apéndices subulados en la base, ápice agudo, borde entero o paucidentado, piloso, 1-3-nervados, indumento como el de las hojas. Cáliz velloso, tomentoso o hirsuto, a veces glabro en la base, 3-8 mm long., tubo del cáliz 2-5 mm long., cara interna álbido-pubescente en la porción media o en ioda su extensión, lóbulos del cáliz triangulares o angustiovados, trinervados, agudos, mucrón 0,2-0,5 mm long. Corola 0,7-3(-8) mm más larga que el cáliz, pétalos amarillos, excepcionalmente blanquecinos, uña soldada al tubo, lámina obovada, 4-7(-9) × 1,5-4(-7) mm, glabra o con algunos pelos en la base de la cara adaxial, ápice truncado o brevemente apiculado. Filamentos estaminaies complanadosubulados en seco, glabros o con pelos simples en la cara externa, soldados $0,2 \mathrm{~mm}$ en la base al tubo, 3-3,5 mm long. en flores longistilas, (2-) 4,5-7,5 mm long. en flores brevistilas; anteras ovadas, a veces triangulares, exertas en flores brevistilas, 0,6-1 × 0,3-0,7 mm, dorsifijas, base emarginada, ápice brevemente apicuiado, no recurvado a la dehiscencia. Ovario elipsoide, $0,8-2,1 \times 0,8-1,2 \mathrm{~mm}$, piloso, a veces glabro en la porción basal, placentas 2-4-ovuladas; estilos cilíndricos, villosos en la porción basal o en toda su extensión, 1-2 mm long. en flores brevistilas, 2-4,5 $\mathrm{mm}$ long. en flores longistilas; estigmas de ramas amarillas o rojizas, $0,3-1 \mathrm{~mm}$ long. Fruto ovoide, 2,5-4,5 × 2-3 mm, a veces vestido con los restos del perianto, valvas ovadas, cara externa rugosa o verrucosa, venas impresas, con pelos simples largos y pelos glandulares especialmente hacia el ápice, a veces densamente piloso, otras veces la porción basal glabra, cara interna lisa u ondulada, glabra o pilosa, lustrosa, castaña o jaspeada, vena placentaria prominente o no. Semilla angusti-obovoide, negruzca a la madurez, curvada, 1,5-2,2 x 0,7-1,1 mm, exóstoma asimétrico, brevemente cónico, cálaza redondeada; episperma reticulado, ca. 14-16 filas longitudinales de aréolas pequeñísimas, transrectangulares o hexagonales, a veces triangulares; arilo membranáceo en seco, más corto que la semilla.

Material examinado. Estados Unidos. Texas: Zapata Co., Banks of Arroyo Loma Blanca, near Zapata, 29 I 1934, Clover 1686 (NY); Starr Co., just E of Roma, 17 III 1966, Correll 32288 (S); Starr Co., just SE of La Posta, 5,5 mi SE of Rio Grande city, 14 XII 1967, Correll 35466 (GH, S); Zapata Co., Tiger creek, 3 mi SE of Lopeno, 1 IV 1938, Cory s.n. (GH); Starr Co., 6,3 mi SE of Rio Grande City, 9 XI 1940, Cory s.n. (A); Roma, 1890, Nealley 12 (SI); Roma, 1889, Nealley 267 (F, US); near Rio Grande, 200 ft, 20 III 1928, Runyon 150 (K, US); Brownsville, I 1923, Runyon 316 (US); Cameron Co., near Brownsville, X 1928, Runyon 1102 (NY); Starr Co., Rio Grande, near highway 48, 50 m, 13 iV 1941, Runyon 2535 (ㄷ); Roma hills, lower Rio Grande, Schott s.n. (NY); Rio Bravo, Roma hills, IX 1853, Schott 142 (F); Mission, Iidalgo Co., IV 1941, Shiller 885 (US); Hidalgo Co., Mission, 12 I 1936, Walker 17813 (A). Méxıco. 2 km al NE de Flora de Canales, borde del Rio Guayalejo, 12 V 1982, González Medrano 12456 (MEXU); Tropic of Cancer, 29 VIII 1948, Kenoyer \& Crum 3514 (A); Chamal, Tampo, 30 VIII 1948, Kenoyer \& Crum 3643 (A); Consoquitla, Liebmann 4271 (C); Ejutla, XII 1842, Liebmann 4273 (C); Consoquitla, VIII 1841, Liebmann $4278(\mathrm{C})$; sin localidad, Linden 831 (K); Northwestern Mexico, Ortega 6121 (GH, US); 1875, Rothrock s.n. (F); sin localidad, 1937, Taylor Edwards 7441 (F). Baja California Sur: Todos Santos, 19 I 1890, Brandegee 
227 (F); Dist. del Sur, 8,3 km N of San José del Cabo, 15 XII 1947, Carter et al. 2196 (K, US); Dist. del Sur, $\mathrm{E}$ of Rancho El Porfirio, road to Las Cruces E of La Paz, $24^{\circ} 14^{\prime} \mathrm{N} 110^{\circ} 14^{\prime} \mathrm{W}, 30$ III 1949, Carter 2600 (GH, K, US); Carazal, VIII 1882, Holmes s.n. (K); La Paz, VIII 1882, Holmes s.n. (K); Todos Santos, Holmes s.n. (K); Cape San Lucas, 5 VIII 1932, Howell 10590 (A); Rancho Las Cruces, NW La Paz, 15 m, 26 XII 1989, León 4275 (MEXU); road from San Bernardo to Sierra La Laguna, 3000-3500 ft, 21 I 1906, Nelson \& Goldman 1450 (BM, US); Cal. peninsulae parte australe prope Todos Santos, 1882, Parke, Davis \& Co. s.n. (CORD); Cape San Lucas, 23 III 1911, Rose 16361 (NY, US); $7 \mathrm{mi}$ of Miguerino, $675 \mathrm{ft}, 23^{\circ} 10^{\prime} \mathrm{N}$, 26 III 1935, Shreve 7244 (F, GH, MO); $5 \mathrm{mi}$ N of Santiago, 233'스, 28 III 1935, Shreve 7289 (F, US); 15 $\mathrm{km}$ al SE de San Bartolo, Mun. La Paz, $120 \mathrm{~m}, \mathrm{X}$ 1985, Tenorio \& Romero de T. 10641 (MEXU); Cabo San Lucas, $200 \mathrm{ft}, 24$ I 1979, Walker 79416 (NY). Campeche: Mun. Hopelchen, $12 \mathrm{~km} \mathrm{~S}$ de las Delicias, Reserva de la Biosfera de Calakmul, $18^{\circ} 17^{\prime} \mathrm{N}$ 89³6'W, 2 VII 1991, Ortega \& Ucan 1493 (MO). Chiapas: Mun. La Trinitaria, along road to Lagos de Montebello, $11 \mathrm{mi}$ NE of La Trinitaria, $5300 \mathrm{ft}, 26$ I 1965, Breedlove 8417 (F); Mun. Jiquipilas, $8 \mathrm{mi}$ E of Cintalapa, along Mexican Hwy. 190, $2200 \mathrm{ft}, 12 \mathrm{VI}$ 1965, Breedlove 10294 (F); along Mexican Hwy. 190, $3 \mathrm{mi}$ S of La Trinitaria, $5100 \mathrm{ft}, 15$ VIII 1965, Breedlove 11776 (F); ídem, 14 X 1965, Breedlove \& Raven 13195 (F); Mun. Terán, 6,5 km W of Tuxtla Gutierrez along Mexican Highway 190, 700 m, 8 X 1971, Breedlove 20109 (MO); Mun. Jiquipilas, $16 \mathrm{~km}$ ESE of Tierra y Libertad along road to Villa Flores, $1000 \mathrm{~m}, 23$ VIII 1972, Breedlove 27324 (MEXU, MO); Mun. Cintalapa, 3-5 km N of Cintalapa, 900 m, 22 XII 1972, Breedlove \& Thorne 30515 (MO); Mun. Chicoasen, dry slopes along stream above Chicoasen, 800 m, 7 IX 1974, Breedlove 37251 (MEXU); $15 \mathrm{~km}$ S of Comitan on road to Tzimol and Tuxtla Gutierrez, $1200 \mathrm{~m}, 20$ III 1981, Breedlove 50219 (CAS); Comitan, 12 IV 1904, Goldman 841 (US); $9 \mathrm{~km}$ al $\mathrm{N}$ del entronque de La Trinitaria rumbo a Montebello, 1700 m, 2 VIII 1980, González Medrano \& Chimal 11755 (MEXU); along Mex 190, 1,3 mi E of Colonia Lizardo Gardenas, 24 VIII 1966, Kral 27766 (MO, US); Trapichito Comitán, 1350 m, 2 VI 1945, Matuda 5739 (F, MEXU); hacia Junchavín y Rancho Quijá, 23 XII 1948, Miranda 5043 (MEXU); Hacienda Monserrate, IX 1923, Purpus 9159 (F, GH, MO, NY, US); Mun. La Trinitaria, a $8 \mathrm{~km}$ al SE de La Trinitaria, camino a Cd. Cuahutemoc, 17 XI 1984, Téllez et al. 8054 (MO). Chihuahua: S.Agustin, X 1842, Liebmann 4270 (C, W). Colima: Manzanillo, $20 \times 1910$, Orcutt 4482 (F). Guanajuato: San Luis de la Paz, 12 XII 1965, Hernández 137 (MEXU); Escalante, $8 \mathrm{~km} \mathrm{~S}$ de Doctor Mora, $2300 \mathrm{~m}, 21$ XI
1988, Ventura \& López 6390 (MEXU); Cerro La Cuchilla, $15 \mathrm{~km}$ al N de Xichú, $1400 \mathrm{~m}, 7$ XII 1988, Ventura \& López 6411 (MEXU); Mun. Atarjea, Mangas Cuatas, 1300 m, Ventura \& López 8949 (MEXU). Guerrero: Road above Canyon de Zopilote, $8 \mathrm{~km} \mathrm{E}$ of Xochilapa on way to Filo del Caballo from Milpillas, 850 m, 9 XI 1973, Breedlove 35985 (MO, NY); Acapulco, VI 1834, Haencke 23 (W); in front of Hotel Mirador, Acapulco, 300-400 ft, 21 VIII 1935, MacDaniels 156 (F); Mun. Zumpango del Río, 2 km al $W$ de Milpillas, sobre camino Milpillas-Xochipala, Filo de Caballo, 800 m, 12 VI 1982, Martínez \& Ramos Diaz 682 (MEXU, MO, NY); Mun. Zumpango del Rio, $2 \mathrm{~km} \mathrm{~W}$ de Milpillas camino a Xochipala, 850 m, 16 X 1983, Martínez et al. 4890 (MEXU, MO); Acapulco and vicinity, X 1894 - III 1895, Palmer 133 (A, F, GH, K, MO, NY, US). Hidalgo: $2 \mathrm{~km} \mathrm{NW} \mathrm{de}$ la desviación de Río Venados a Metztitlan, $1400 \mathrm{~m}$, 14 VII 1980, González et al. 434 (MEXU); 8,5 km SSE de Ixmiquilpan, 2000 m, 12 VIII 1965, González Quintero 2790 (F); Zimapán, cuesta de Texquedo, 1630 m, 1 IX 1969, Hernández 630 (MEXU); Cuesta de Texquedo, cerca de Zimapán, 1700 m, 12 XI 1972, Hernández \& Vázquez de Hdez. 1731a (MEXU); Mun. Metzquititlán, $2 \mathrm{~km}$ EN de Barranca de Venados, 1500 m, 11 I 1980, Hernández 3939 (GH); Mun. Tasquillo, Danghu, $5 \mathrm{~km}$ al $\mathrm{W}$ de Tasquillo, $1900 \mathrm{~m}$, 27 VI 1981, Hernández et al. 6243 (MEXU, MO); Near Tasquillo, $8000 \mathrm{ft}, 17$ VII 1940, Hitchcock \& Stanford 7262 (F, GH, US); km 147, SE of Ixmiquilpan, of Mexico City-Lardeo Highway, 4 VIII 1943, Lundell \& Lundell 12341 (CTES, US); $2 \mathrm{~km}$ al NE del puente de Venados, Venados, 1700 m, 5 VII 1972, Medrano et al. 4166 (MEXU, MO); Barranca de Metztitlan, cañada de El Salitre, 5 V 1976, Medrano et al. 8955 bis (MEXU); Dist. Zimapán, Cuesta de Texquedo near Km 184 or. highway between Tasquillo and Zimapán, 2000 m, 26 X 1946, Moore 1648 (GH); Dist. Jacala, between Hilo Juanico and Barranca Seca on trail from Jacala to Pacula, 1400-1600 m, 9 VII 1948, Moore \& Wood 3843 (A, BM); Ixmiquilpan, IX 1905, Purpus 1396 (BM, F, GH, MO, NY); near Ixmiquilpan, 1905, Rose et al. 8957 (US); prope Atotomilco el Grande, V 1888, Seler \& Seler 865 (GH). Jalisco: Mun. La Huerta, camino a La Rumorosa, casi en frente de la Estación de Biología Chamela, $19^{\circ} 30^{\prime} \mathrm{N} 105^{\circ} 03^{\prime} \mathrm{W}, 12$ X 1982, Lott \& Hernández 1463 (MEXU, MO); Mun. La Huerta, Cañón en el Cerro Colorado que da al NO, Estación de Biología Chamela, $19^{\circ} 30^{\prime} \mathrm{N} 105^{\circ} 03^{\prime} \mathrm{W}, 6$ I 1983, Lott 1695 (MEXU). Michoacán: dist. Zitacuaro, Tuzantla, San Carlos, 1 VIII 1938, Hinton et al. 13081 (GH, K, NY, US). Nuevo León: $12 \mathrm{mi}$ of Sabinas Hidalgo, 26 III 1944, Barkley \& Heard 14548 (F, GH, MO, NY, US); Nuevo León, VI 1843, Berlandier 3155 (GH, K, 
ivO); 52 miles $S$ of Nuevo Laredo on Hwy. 85 to Ciudad Victoria, 30 VII 1959, Bell \& Duke 16517 (US); Campo Universitario Linares, 13 V 1987, Carrillo Parra AI-23 (MEXU); Mun. Sabinas Hidalgo, 12,8 mi S of Sabinas Hidalgo on Hwy. 85, 390 m, 2 VII 1985, Cowan et al. 5356 (MO); Mex 85, ca. $10 \mathrm{mi} \mathrm{S}$ of Sabinas Hidalgo, 5 IX 1978, D'Arcy 11753 (MO); ca. $22 \mathrm{mi} \mathrm{S}$ of Linares, 7 IX 1978, D'Arcy 11811 (MO); Ejido La Gloria, Anáhuac, 150 m, 14 III 1979, González 731 (MEXU); $12 \mathrm{mi} \mathrm{N}$ of Sabinas Hidalgo, 26 III 1944, Heard \& Barkley 14548 (GH); Mun. Rayones, Galeana-Rayones +24 km, 1260 m, 17 X 1990, Hinton et al. 20797 (GH); Monterrey, X 1937, Kenoyer s.n. (MO); Sabinas Hidalgo, Ojo de Agua, 2000 ft, 15 VI 1940, Leavenworth 71 (F); Calcareous hills near San Juan, 1500 ft, 22 VIII 1903, Pringle 11455 (F, GH, $\mathrm{K}, \mathrm{US}$ ); Terreno Universidad Autonóma de Nuevo León, Unidad Linares, 19 X 1988, Reid s.n. (MEXU); Edge of Mexico 85, $4 \mathrm{~km} \mathrm{~N}$ of the Tamaulipas-Nuevo León border, 20 XII 1990, Seigler et al. 13199 (MEXU, MO); $10 \mathrm{mi} \mathrm{S}$ of Sabınas Hidalgo, $1500 \mathrm{ft}$, 16 VIII 1940, Shreve \& Tinkham 9569 (GH); Camino a la Hacienda El Carrizo-Los Ramones, 210 m, 23 XII 1982, Villarreal 1798 (MEXU); 4-1 mi S of Montemorelos on Highway 85, 4 VII 1969, Weaver 2052 (MEXU, MO). Oaxaca: Flats of Tehuantepec river, 30 XII 1944, Alexander 219 (NY); Cañada de San Jerónimo Coatlán (Río Trapiches), dep. Miahuatlán, 28 VI 1990, Campos \& Toriz 3197 (MEXU, MO); Sierra al S de Ixtepec, $150 \mathrm{~m}, 8$ XII 1980, Cedillo Trigos \& Lorence 467 (MEXU); de Mitlá a Matatlán, 1700 m, 19-23 VI 1906, Conzatti 1477 (MO, NY, US); Cuesta de Huanclillo, Dep. Nochixtlán, 2000 m, 19 VI 1907, Conzatti 1877 (F); along Highway 190, $55 \mathrm{mi}$ SE of Oaxaca, $1100 \mathrm{~m}, 2$ VII 1977, Croat 39951 (MO); Mun. Yautepec, a 6 km al S de El Camarón, 1090 m, 25 XI 1977, Delgado et al. 731 (MEXU); Mun. Juchitán, a $19 \mathrm{~km}$ al SE de Juchitán y a $4 \mathrm{~km}$ sobre la desviación a Tuxtla Gutiérrez, 115 m, 26 XI 1977, Delgado et al. 755 (MEXU); Ixtepec, 200 m, 17 VIII 1935, Fisher s.n. (MO, S); Ixtepec, 60 m, 17 VIII 1935, Fisher 35432 (F, NY, US); Cordillera, rochers a 3000, XI-IV 1840, Galeottl 4077 (K, P); Km 639, Totoalapam, 3800 ft, 28 V 1961, Halberg 1207 (MEXU); along the PanAmerican highway, route 190, $22 \mathrm{~km} \mathrm{NW}$ of Zanatepec, $100 \mathrm{~m}, 10$ VII 1958, King 462 (US); $11 \mathrm{~km}$ NW of the village of La Ventosa, along the TransIsthmian highway (route 185), $50 \mathrm{~m}, 14$ VII 1958, King 561 (US); 10-12 km E of Tehuantepec on the road to Oaxaca (route 190), $50 \mathrm{~m}, 2$ VII 1959, King 1233 (US); 9-10 km N of La Ventosa, 15 VII 1959, King 1670 (NY, US); 10-12 km E of the village of Niltepec along the Pan-American highway (route 190), 50 m, 18 VII 1959, King 1817 (US); Dep.
Tehuantepec, ca. de La Salina del Marqués, al O de Salina Cruz, 2 VIII 1985, Martínez C. 93 (MEXU); dep. Tehuantepec, Rincón Bamba, al O de Salina Cruz, 9 VII 1986, Martínez C. 648 (MEXU, MO); 2 $\mathrm{km}$ al O de Salina Cruz, carr. a Pochutla, $16^{\circ} 90^{\prime} \mathrm{N}$ 95¹3'W, 19 VIII 1988, Martínez C. 1741 (MEXU); San Gerónimo, 5 X 1933, Mell 2103 (NY, US); ídem, 7 X 1933, Mell 2138 (NY, US); vicinity of Mitla, ca. 1650-1850 m, 8 VII 1971, Messer 135 (MEXU); between San Gerónimo \& La Venta, 200 ft, 13 VII 1895, Nelson 2780 (GH); Picacho, San Gerónimo, X 1913, Purpus 6691 (BAF, BM, F, GH, HBG, MO, NY, US); Cerro de Picacho, VII 1914, Purpus 7135 (BM, F, US); Cerro Nahualtepec, ca. 7-8 km al NW de Casa Blanca, dist. Teotitlan, 1030 m, 1 VII 1987, Salinas et al. 4183 (MO); slopes below Cueva Blanca, $16^{\circ} 55^{\prime} \mathrm{N} \mathrm{96} 25^{\prime} \mathrm{W}, 27$ VII 1966, Schoenwetter JSOX109 (US); Felixtlahuaca, 6000 ft, 5 VII 1895, Smith $519(\mathrm{GH})$; Along road to microwave tower about 3,6 mi S of Matatlán on Hwy. 190, about $1 \mathrm{mi} \mathrm{S}$ of $\mathrm{km}$ 595, 8 VII 1971, Stevens 1220 (MO); 7,1 km al NW de Tehuantepec, carr. Tehuantepec-Oaxaca, 4 IX 1982, Torres \& Cedillo 1524 (MEXU); $6,2 \mathrm{~km}$ al NE de Mitla, carr. a Tototepec, dist. Tlacolula, 1690 m, 1 VIII 1983, Torres \& Hernández 3396 (MEXU); 1 $\mathrm{km} \mathrm{N}$ de Chivela, carr. Transítsmica a Matías Romero, 26 VI 1984, Torres et al. 5349 (MEXU, TEX); 2 $\mathrm{km}$ al SW de Salina Cruz, carr. a Pochutla, $190 \mathrm{~m}$, 27 VII 1984, Torres \& Martínez 5676 (MO); Dist. Tehuantepec, Mun. Salina Cruz, en el camino de Carnero a Rincón Bamba, Torres \& Cortes 8771 (MEXU, MO); Almoloya, 100-250 m, VII 1937, Williams 9865 (F, US). Puebla: Mun. Jolalpan, 1 km $\mathrm{N}$ de La Junta, Huauchinantla, 22 I 1985, Campos 54 (MEXU); 20 km SE de Izúcar de Matamoros, 19 VIII 1991, Chavarría 16 (MEXU); Axamilpa, 3 km NW de Tepexi de Rodriguez, 19 I 1985, Felger 85-32 (MO); $11 \mathrm{~km}$ al S de S. Juan Ixcaquixtla, $1900 \mathrm{~m}, 29 \mathrm{Vl} 1982$, González Medrano et al. 12771 (MEXU); Hili above Balneario, Garci Crespo, Tehuacan, 6000 ft, 26 X 1938, Gourlay 8 (K); Las Cruces, carretera Matamoros-Acatlan, Km 178, 27 VIII 1970, Hernández \& Trigos 714 (MEXU); 5,4 km SW de Molcaxac, $1775 \mathrm{~m}$, 30 VII 1982, Nava et al. 44 (MEXU, MO); Tehuacan, VI 1905, Purpus 1234 (F, GH, MO, NY); near Tehuacan, 30 VIII 1905, Rose et al. 9958 (US). Querétaro: Entre Vizarrón e Higuerillas, 23 VIII 1905, Altamirano 16 (US); Peña Miller - Cerro del Picacho, III 1896, Altamirano 4118 (MEXU); subiendo a la mina de ópalos La Trinidad entre San Juan del Rio y Tequis, aprox. 2050 m, 29 III 1981, Argüelles 1560 (MEXU); entre Vizarrón y Pinal de Amoles, 1500-1700 m, 7 VII 1982, Argüelles 1828 (MEXU); Mun. Cadereyta, 1, $1 \mathrm{~km}$ S of Higuerillas on dirt road S of Hwy. Higuerillas-San Pablo Tolimán, 1610 m, 
8 VII 1985, Cowan et al. 5463 (MO); Cerro de la Mesa, ca. $20 \mathrm{mi} \mathrm{N}$ of Tequisquiapan, 30 VIFi 1965, Flyr 619 (MO); Mun. Cadereyta, $3 \mathrm{~km}$ al S de Peña Bolanca, 1350 m, 8 VI 1983, Fernández 1596 (MEXU); Mun. Toliman, Rancho Mercader, 8 VII 1979, Méndez Guerrero s.n. (MEXU); Hac. Ciervo, 20-23 VIII 1905, Rose et al. 9674 (GH; US); between Virasoro \& Higuerillas, 23 VIII 1905, Rose et al. 9768 (NY, US); 2 mi S of Higuerillas intersection, near $\mathrm{Km} 84$ on road from San Juan del Rio to Jalpa, route 120, 5 VII 1974, Sohmer 9237 (MEXU, NY); Mun. Cadereyta, a 7 km al $\mathrm{N}$ de Vizarrón, $1900 \mathrm{~m}, 27$ IV 1982, Tenorı \& Hernández 261 (MEXU). Quintana Roo: $8 \mathrm{~km} \mathrm{~S} \mathrm{de}$ Akumal, sobre la carretera Cancún-Tulum, 2 VI 1983, Cabrera \& Cabrera 4741 (MO); Mun. Cozumel, $1-3 \mathrm{~km}$ al $\mathrm{S}$ de Akumal, carretera Cancún-Tulum, 28 VII 1984, Cabrera \& Cabrera 6830 (MEXU); Reserva de la Biósfera Sianka an, a $10 \mathrm{~km}$ al SW del crucero del camino Chumpon-Vigía Chico, sobre el antiguo camino a Carrillo Puerto, 6 XII 1985, Cabrera 9927 (MO); Mun. F. Carrillo Puerto, Km 28 de Vigía Chico a Carrillo Puerto, Rancho Santa Teresa, 2 XI 1984, Durán et al. 1123 (MEXU); Km 6 carretera Vigía Chico-F.Carrillo Puerto, 8 m, 21 VII 1985, Villanueva 375 (MEXU); Km 4 carretera Vigía Chico-F.Carrillo Puerto, $19^{\circ} 47^{\circ} \mathrm{N} 87^{\circ} 36^{\prime} \mathrm{W}, 8 \mathrm{~m}$, 25 IX 1985, Villanueva 423 (MEXU). San Luis Potosí: Smelter Hill, 6300 ft, 20 IX 1908, Barnes \& Land 107 (F, US); Mun. Cd. Valles, Hwy. 85, 13,6 mi E of turnoff to Tamasopo and 2,3 $\mathrm{mi} \mathrm{W}$ of Cd Valles, 3 V: 1983, Barnett et al. 74 (MiO); Perto Valle, V 1938, Black 38-5094 (US); La Canoa, La Palma, Tamasopo, 800 m, 18 VII 1983, Chemin Bassler 71 (MEXU); Valles, $260 \mathrm{ft}, 18 \mathrm{VIII}$ 1937, Fisher 3765 (MO, NY, US); Cardenas, 6300 ft, 21 VIII 1937, Fisher 37193 (F, GH); Mun. Rioverde, 2,2 mi N of junction of Hwy. 85 and road to San Francisco, 10 mi $\mathrm{E}$ of Rioverde, 950 m, 27 V 1981, Fryxell \& Anderson 3631 (TEX); Mun. Sta.Maria de! Rio, $1 \mathrm{~km}$ sobre ei camino a Los Arbolitos, 19 IX 1985, 1870 m, Gómez-Lorence 802 (MEXU); Valles, 3 IX 1938, Kenoyer A 417 (F); Market of San Luis Potosí, VII-VIII 1898, Palmer 738 (GH, US); Minas de San Rafael, $22^{\circ} \mathrm{N}, 6000-8000 \mathrm{ft}, \mathrm{XI}$ 1910, Parry \& Palmer 93 (BM, BR, F, GH, K, MO, NY, US); Mts. W of San Luis Potosí, Sierra Madre Oriental, 1900-2111 m, 27-28 VII 1934, Pennell 17631 (GH, US); Las Tablas, Sierra Madre Oriental, 10001100 m, 9-10 VIII 1934, Pennell 18025 (GH, US); Hills near San Luis, 7 IX 1890, Pringle 3644 (F, GH); Micos, 1 VIII 1891, Pringle 5121 (GH); Las Tablas, 10 VII 1891, Pringle 5122 (A, GH); Minas de San Rafael, XI 1910, Purpus 4924 (BM, F, GH, MO, US); Minas de San Rafae!, VI 1910, Purpus 4924a (BAF, MEXU); in montibus San Miguelito, 1876, Schaffner $166(\mathrm{GH}, \mathrm{K})$; de México a San Luis, 1851, Virlet $d^{\prime}$ Aoust $584(\mathrm{P})$; sin localidad, 1851, Virlet d'Aoust 1519 (P). Sinaloa: Mun. Cosala, Loma de la Cruz, 29 III 1919, Conzatti 810 (MEXU); Capadero, Sierra Tacuichamona, 2500 ft, 11 II 1940, Gentry 5547 (GH, MO, NY); Mun. Cosala, Conitaca, Loma de la Cruz, González Ortega 256 (MEXU); Mazatlán, 10 m, III 1923, González Ortega 6315 (GH, US); Caliacán, XII 1926, González Ortega 6591 (GH, US); Mazatlán, III 1931, González Ortega 6753 (BR, F, MEXU, MO);1934, González Ortega 7251 (BR, F); Loma de la Cruz, Cosala, 180 m, 29 III 1919, Narvaez Montés \& Salazar 810 (US); Estero de Escuinapa, 1926, Ortega 6121 (US); between Rosario and Colomas, 12 VI 1897, Rose 1612 (F, GH, K, US); Mun. de San Ignacio Colomas, 31 III 1989, Vega et al. 3213 (MEXU). Sonora: San Bernardo \& vicinity, III 1963, Argiuelles 227 (US); Sierra Bojihuacame SE of Ciudad Obregón, 800-2000 it, $17-25$ X 1954, Gentry 14484 (US); San Bernardo, 1000-1500 ft, 2 V 1957, Gentry 16551 (US); 8 mi from Mina San José, E of Misa and Torres, 26 II 1938, Wiggins $6320 \mathrm{~B}$ (US). Tamaulipas: $35 \mathrm{mi} \mathrm{N}$ of Valles, 17 IV 1947, Barkley 17M050 (F); Mun. Tula, Km 22 Carr. Tula a La Laguna, 1500 m, 12 VI 1986, Baro 821 (MO); vicinity of San Miguel, $2000 \mathrm{ft}, 26$ VII 1930, Bartlett 10622 (F); vicinity of El Mulato, $1000 \mathrm{ft}, 17$ VIII 1930, Bartlett 11005 (F); Tampico, Berlandier 321 (BM, G, W); Mun. Aldama, Sierra de Tamaulipas, region of Rancho Las Yucas, ca. $40 \mathrm{~km}$ NNW of Aldama, ca. $23^{\circ} 14^{\prime} \mathrm{N}, 98^{\circ} 10^{\prime} \mathrm{W}$, above Juan Tomás, E of Las Yucas, 30 VII 1957, Dressler 2089 (GH, MO) $25 \mathrm{~km}$ S of Ciudad Victoria, $1000 \mathrm{ft}$, 2i III 1974, Fryxell \& Magill 2259 (MO, TEX); $4 \mathrm{~km}$ al E del Rivereño, 25 XII 1964, González Medrano 840 (MO); Mun. Tula, $4 \mathrm{~km}$ al N de San Rafael, entre San Rafael y El Salitrillo, 1070 m, 11 VIII 1972, González-Medrano et al. 4530 (MEXU); Mun. jaumave, $3 \mathrm{~km}$ al $W$ de La Unión, al NE de Jaumave, IX 1976, González-Medrano et al. 9693 (MEXU); 33 mi NW on Mex-180 from its jct. with Soto la Marina River in Soto la Marina, SE of Cjo de Agua de Miranda, 4 VII 1990, Jones et al. 5177 (MEXU); Mun. Tula, $3 \mathrm{~km}$ al O de Sta. Ana de Nahola, 1500 m, 30 VI 1985, Hiriart et al. 741 (MEXU) $5 \mathrm{~km}$ al O del Ejido Ei Salitrillo, $1500 \mathrm{~m}, 3 \mathrm{VIi} 1985$ Hiriart et al. 795 (MEXU); 8,5 km N of the junction of the S.L.P.-C. del Maíz Hwy. on the Hwy. to Jaumave, $31 \mathrm{~km} \mathrm{~S}$ of Tula, $22^{\circ} 48^{\prime} \mathrm{N}, 99^{\circ} 56^{\circ} \mathrm{W}, 1250$ m, 20 V 1973, Johnston et al. 11126 (MO, NY); San José, 17 II 1939, Le Sueur 302 (F); Los Coyotes, 15 II 1939, Le Sueur 604 (F); Buena Vista, VI 1842, Liebmann 4277 (C); Mun. Palmillas, $12 \mathrm{~km}$ anies de Palmillas en el Km 96 carr. Tula-Victoria, 1000 m, 10 IX 1986, Martinez 13165 (MO); $15 \mathrm{mi} \mathrm{S}$ of San Fernando, roadside of highway 101, 300-400 ft, 22 VI 1965, Maxwell 14 (MO); Entre Tampicu et Real del Monte, 22 V 1827, Mercier 321 (P); vicinity of Victoria, 320 
m, 1 V-13 VI 1907, Palmer 452 (F, GH, NY, US); Jaumave, 29 IX 1931, von Rozynskı 34 (F, MICH); 4 mi S of Jaumave, 3 VII 1949, Stanford et al. 2238 (US); San Lucas, Viereck 100 (US); Jaumave, IV 1930, Viereck 327 (US); San Lucas, VII 1930, Viereck 664 (US); Hda. Buena Vista, 18 VI 1919, Wooton s.n. (US). Veracruz: Mun. El Castillo, Rancho de la Sec. Salubridad y Asistencia, antes Rancho Tres Pasos, $19^{\circ} 32^{\prime} \mathrm{N} 96^{\circ} 50^{\prime} \mathrm{W}, 1050 \mathrm{~m}, 10 \mathrm{~V} 1977$, Avendano 228 (CTES, F); Mun. Úrsula Galván, Est. Biológica del Morro de la Mancha, 14 V 1981, Brigada de Dunas costeras 8 (MEXU); Cercanías de Limones, Cosautlán, 1000 m, 11 VI 1976, Calzada 2426 (F, NY); Mun. Coatepec, ejido de Tepeapulco, en las faldas del cerro de Chavarrillo, $19^{\circ} 25^{\prime} \mathrm{N} 96^{\circ} 48^{\prime} \mathrm{W}, 850 \mathrm{~m}, 7$ IX 1979, Castillo \& Tapia 813 (F, MEXU, NY); Mun. Emiliano Zapata, Presa Tiradores, 1000 m, 17 V 1972, Dorantes \& Márquez 603 (CTES); Mirador, II 1842, Liebmann 4272 (C); Poblado La Paz, carretera Coatepec-Huatusco, 1100 m, 11 IX 1975, Márquez \& Visconti 395 (F); Mun. Tlacotepec de Mejia, 7,5 km E of El Mirador on Totutla-Conejos Hwy., rio Comapa, $19^{\circ} 13^{\prime} \mathrm{N} 96^{\circ} 48^{\prime} \mathrm{W}, 820 \mathrm{~m}, 13$ XI 1981, Nee 23045 (F, NY); $1 \mathrm{~km}$ antes de Encinal, carretera puente nacional a Huatusco, 700 m, 29 VII 1971, Nevling \& Gomez Pompa 2394 (F); Veracruz u. Umgebung, Wawra 542 (W). Yucatán: Rancho Sip, Ejido de Tixcacaltuyub, Yaxcabá, $20^{\circ} 27^{\prime} \mathrm{N} 88^{\circ} 54^{\prime} \mathrm{W}, 22 \mathrm{~m}, 12$ X 1983, Flores 10012 (CTES); Gaumer 538 (BR, CAS, DS, FI, K, US, W); Yucatán, 1895, Gaumer 859 (BM, C, F, S, US); Chichankanab, Gaumer 1834 (B, BM, BR, C, CAS, K, S, W); San Anselmo, Gaumer 2002 (S); Kancabconot, I 1917, Gaumer 23527 (B, BM, C, CAS, DS, K, US, W); Mun. Yaxcabá, 3,5 km W de Yaxcabá, 3 VI 1981, Illsley 1186 (CAS); Chichén Itzá, 22 VI 1932, Steere 1466 (DS); Mun. Yaxcabá, 3 km S de Yaxcabá, 17 III 1979, Vara \& Arias 188 (CAS, F). Zacatecas: near San Juan Capistrano, 18 VIII 1897, Rose 3536 (US). Guatemala. Baja Verapaz: Santa Rosa, 5000 ft, IV 1887, Türckhetm 1200 (GH, K, P, US); cumbre de San Lorenzo, pass between Sierra De Chaucús and Sierra de las Minas, aprox. $15^{\circ} 5^{\prime} \mathrm{N}$ 908'W, 10 km SE of Salamá, 1400-1500 m, 24 I 1969, Willams et al. 40023 (F, NY). Chiquimula: Montaña Castilla, vicinity of Muntaña Cebollas, along rio Lucia Saso, $3 \mathrm{mi}$ SE of Quezaltepeque, 1200-1500 m, 6 XI 1939, Steyermark 31262 (F). El Progreso: 8 IV 1970, Harmon \& Dwyer 3539 (MO). Huehuetenango: Naxac Kanal-Quen Santo, 23 VIII 1896, Seler \& Seler 3029 (GH, K, US); high hills E of Aguacatán, 1500-1800 m, 14 I 1939, Standley 62556 (F); NW of Malacatancito, at km 8 of the Hwy. from Huehuetenango, about $1950 \mathrm{~m}, 4$ I 1941, Standley 82210 (A, F); 1890 m, 29 XII 1940, Standley 82744 (F, US); along rio Cuilco, between Cuilco and aldea of
San Juan, 2,5 mi W of Cuelco, 1200-1300 m, 18 VIII 1942, Steycrmark 50899 (F); between Nentón and Miramar, Sierra de los Cuchumatanes, 500-800 m, 29 VIIl 1942, Steyermark 51479 (F, MO, US); Canyon at head of Rio Chixoy, about $10 \mathrm{~km} \mathrm{SW}$ of Huehuetenango, 1800 m, 7 XII 1962, Williams et al. 22509 (F). Izabal: En La Mina, a $5 \mathrm{~km}$ al O de El Estor, 50 m, 28 VIII 1989, Martínez S. \& Stevens 23281 (MO). Jalapa: hills NE of Jalapa, 1400-1600 m, 10 XI 1940, Standley 76852 (F). Petén: Dos Lagunas, on Bajo Ixcanrio, 9 V 1969, Contreras E. 8492 (MO). Quiché: 1942, Aguilar 767 (F); 3 km E of El Rancho, above Rio Motagua, Rio Negro, 3600 ft., III 1892, Heyde \& Lux 3041 (GH, K, US). Belize. Belize: Northern Highway, mile marker $13,5,17^{\circ} 36^{\prime} \mathrm{N}$ 88²0'W, 26 III 1990, Arvigo et al. 350 (CTES); Maumgartner Preserve, $15 \mathrm{mi}$ NW Belize, 6 VII 1970, Crankshaw 9 (MO); 12,5 mi NW Belize, Northern Highway, 23 V 1973, Croat 23252 (MO); Ridge Lagoon plantation, ca.12 km NW of Belize Savanna, 9 VI 1973, Croat 24016 (MO, US); 3-4 km E of Crooked Tree village along the road to the main highway, $88^{\circ} 30^{\prime} \mathrm{W} 17^{\circ} 46^{\prime} \mathrm{N}, 50 \mathrm{~m}, 22$ III 1987 , Davidse \& Brant 33199 (CTES, MO); vicinity Hattieville, 5 VII 1972, Dwyer \& Pippin 10095 (MO); mile 7,5, Northern Highway, 25 V 1974, Dwyer 12417 (CTES, MO); $18 \mathrm{mi}$ from Belize-Mexico border, Highway 186, 14 VII 1977, Dwyer 14508 (MO, NY); near Belize internat. Airport, mile 9, N Highway to Mile 5, roadside collecting along Belize River, 20 VIII 1979, Dwyer 14667 (MiO); Savannah near Ridge Lagoon Plantation, $11 \mathrm{mi}$ from Belize on Northern Highway, near sea level, 4 VI 1973, Gentry 7857 (MO); $1.5 \mathrm{mi}$ E of Hattieville on the coastal pine savanna, 5 VII 1972, Huston 560 (MO); Boomtown, 28 VIII 1970, McDaniel \& Clark 14305 (MO); Pine Ridge, $12 \mathrm{mi} \mathrm{N}$ of Belize, 22 VIII 1936, O'Neill 8785 (MICI); Western Highway, Mi. 15, 18 IX 1970, Whitefoord 2536 (MO); 1/4 mi. of N Highway on Grace Landing Rd., 8 VIII 1970, Wiley 105 (CTES, $\mathrm{MO})$; Western Highway $12,5 \mathrm{mi} \mathrm{W}$ from Belize, 10 VIII 1970, Wiley 194 (CTES, F, MO); along road from Belize City to Ladyville near the Haulover Bridge (near $17^{\circ} 33^{\prime} \mathrm{N}, 88^{\circ} 15^{\prime} \mathrm{W}$ ), $1 \mathrm{~m}, 9$ VIII 1992, Worthington $21243(\mathrm{MO})$. Cayo: road S to Augustine \& San Luis to Camp Six, 19 III 1967, Dwyer et al. 319 (MO). Orange Walk: ca. $5 \mathrm{~km} \mathrm{~N}$ of August Pine Ridge on the road to Trinidad, $88^{\circ} 42^{\prime} \mathrm{W} 18^{\circ} \mathrm{N}, 100$ m, 19 ill 1987, Davidse \& Brant 32781 (CTES, MO). Horiduras. El Paraíso: Colinas rocosas, Quebrada El Muro, $20 \mathrm{~km} \mathrm{~N}$ de Yuscarán, 650 m, 23 XI 1938, Molina 1672 (F); Entre el Empalme y Quebrada El Muro, $20 \mathrm{~km}$ N de Yuscarán, drainage of the Rio Yeguare, about $87^{\circ} \mathrm{W}$ and $14^{\circ} \mathrm{N}, 600 \mathrm{~m}, 11$ VII 1951 , Molina 4015 (F, GH, US); Entre Las Pacayas y El 
Frijolar, 1500 m, 14 VIII 1964, Molina 14616 (F, NY); Along Amarateca Valley between Zambrano and Amarateca, 600 m, 5 IX 1968, Molina 22653 (F, NY); Between Manzaragua and San Lucas, 1350 m, 22 IX 1968, Molina 22697 (F, NY); Region of Quebrada de Dantas, $5 \mathrm{~km}$ S of Ojo de Agua, about $750 \mathrm{~m}, 11$ XII 1946, Standley et al. 1301 (F); Quebrada El Muro, between Las Mesas and Yuscarán, about 600 m, 23 XI 1948, Standley 14941 (F, US); Las Casitas, 14001500 m, 25 X 1951, Standley 29049 (F); Valley of Rio Dantas, barranco El Muro, 2200 ft, 5 VII 1962, Webster et al. 12035 (F, GH, MO, U, US); W of Ojo de Agua, 900 m, 11 VIII 1946, Williams \& Molina 10272 (BM, F, GH, MO); Quebrada de Dantas about $5 \mathrm{~km}$ S of Ojo de Agua, 730 m, 12 XII 1946, Williams \& Molina 11216 (BM, F, GH, US); Quebrada de Dantas about $5 \mathrm{~km}$ W of Ojo de Agua, $650 \mathrm{~m}$, $20 \mathrm{VI}$ 1954, Williams 18922 (F); Quebrada de Dantas about $5 \mathrm{~km}$ S of Ojo de Agua, $730 \mathrm{~m}, 28$ XII 1962, Williams \& Molina 23249 (B, BM, BR, C, CAL, DS, F, GH, MEXU, P, S, US, W). Francisco Morazán: La Enea, $4 \mathrm{~km} \mathrm{~N}$ y 2 km O de Zambrano, 1300 m, 8 VIII 1991, Nelson \& Andino 11754 (TEFH); El Guayabo, ca. de la aldea Las Moras, 16-22 VIII 1991, Nelson \& Andino 11935 (TEFH); Cerro de Las Limas (El Cerrón), 1700 m, 5-6 III 1992, Nelson \& Andino 13443 (TEFH); W of Chagüite, near Rio Yeguare, about $850 \mathrm{~m}$, 21. VIII 1949, Standley 22967 (F); Quebrada El Muro between Las Mesas and Yuscarán, $600 \mathrm{~m}, 9$ XII 1973, Williams 42803 (BM, F, MICH, MO, US). Nicaragua. Jinotega: $\mathrm{SE}$ of Jinotega, along road to La Cantera and Los Pinos, 1050-1350 m, 25 VI 1947, Standley 10155 (F). León: Carretera a León, Hacienda El Chanal a $2 \mathrm{~km}$ hacia León del empalme León-La Paz Centro, 26 IX 1982, Grijalva \& Grijalva 1270 (MO, TEX); Carretera vieja a León, Rio El Tamarindo, 6 X 1983, Grijalva et al. 3049 (CTES); Carretera vieja a León, en las cercanías del empalme Izapa, $12^{\circ} 16^{\prime} \mathrm{N}$ 8644’W, 40-60 m, 12 IX 1980, Guzmán et al. 1049 (CTES, MO); sobre la carretera vieja a León, $1 \mathrm{~km}$ antes del empalme con la carretera nueva, $\mathrm{km} 64$, $12^{\circ} 16^{\prime} \mathrm{N} 86^{\circ} 44^{\prime} \mathrm{W}, 60 \mathrm{~m}, 15$ X 1980, Moreno 3560 (CTES, MO); Puente Izapa, km 60 carretera a León, $12^{\circ} 15^{\prime} \mathrm{N} 86^{\circ} 44^{\prime} \mathrm{W}, 60-80 \mathrm{~m}, 13$ VII 1981, Moreno 9861 (MO); Las Peñitas, SE de Poneloya, $12^{\circ} 21^{\prime} \mathrm{N}$ $87^{\circ} 01^{\prime} \mathrm{W}, 10 \mathrm{~m}, 22$ VI 1982, Sandino 3137 (CTES, MO); along Hwy. 12, carretera vieja a León, ca. $4 \mathrm{~km} \mathrm{SE}$ of intersection with Hwy. 52 (to Puerto Somoza), ca. $\mathrm{km} 53$, ca. $12^{\circ} 11^{\prime} \mathrm{N} 86^{\circ} 40^{\prime} \mathrm{W}$, ca. $80 \mathrm{~m}, 8$ VIII 1978 , Stevens 9760 (CTES, MO); along Hwy. 12 ca. 1 km SE of junction with Hwy. 28 (first quebrada SE of junction), ca. $12^{\circ} 15^{\prime} \mathrm{N} 86^{\circ} 43^{\prime} \mathrm{W}$, ca. $30 \mathrm{~m}, 17 \mathrm{XII} 1978$, Stevens 11157 (CTES, MO); along Hwy. 12 ca. 1 km SE of junction with Hwy. 28 (first quebrada SE of junction), ca. $12^{\circ} 15^{\prime} \mathrm{N} 86^{\circ} 43^{\prime} \mathrm{W}$, ca. $30 \mathrm{~m}, 6$ X 1979,
Stevens 14670 (MO); ídem, $28 \mathrm{~V}$ 1980, Stevens et al. 17263 (CTES, MO); El Velero, at mouth of Estero San José, ca. $10 \mathrm{~km}$ by road S of Hwy. $32,12^{\circ} 08^{\prime} \mathrm{N}$ $86^{\circ} 45^{\prime} \mathrm{W}, 0-5 \mathrm{~m}, 9$ IX 1984, Stevens 23034 (CTES, MEXU, MO). Matagalpa: Municipio Darío, El Cuajiniquil, a $15 \mathrm{~km}$ de la carretera León-San Isidro, camino a la hidroeléctrica Carlos Fonseca (Santa Bárbara), 17 VIII 1981, Moreno 10516 (MO); Cerro El Apante, $1000 \mathrm{~m}$ aprox., 11 VI 1982, Fonseca 74 (MO). Costa Rica. Alajuela: vicinity of San Ramón, entre Guachipelín y Liberia, 27 V 1932, Brener 15586 (F, NY). Guanacaste: alrededores de Liberia, 1910, Brenes s.n. (NY); vicinity of Cañas, $11 \mathrm{mi} \mathrm{S}$ of Liberia, 12 XII 1969, Daubenmire 404 (F); near farmhouse at Las Delicias below Hacienda Santamaría, 380-400 m, 18 I 1930, Dodge \& Thomas 6342 (GH, MO); Comelco, Area G near Pan American highway N of Bagaces, 27 VII 1971, Gentry 1361 (MO); Comelco savanna, 15 VII 1971, Heithaus 215 (MO); $8 \mathrm{~km} \mathrm{NE}$ of Liberia, 1966, Harris 91, 105, 121 (F); 12 km S of La Cruz, 300 m, 7 XI 1971, Harmón \& Fuentes 6334 (MO, NY); Santa Rosa National Park, $30 \mathrm{~km} \mathrm{NW}$ of Liberia, ca. $10^{\circ} 50^{\prime} \mathrm{N} 85^{\circ} 35^{\prime} \mathrm{W}, 0-300$ m, 27 VI 1979, Janzen 11700 (MO); ídem, 20 XII 1979, Janzen 11851 (MO); Santa Rosa National Park, slope and top of ridge above Playa Naranjo, 0-300 m, $10^{\circ} 48^{\prime} \mathrm{N} 85^{\circ} 41^{\prime} \mathrm{W}$, 28 VI 1977, Luesner et al. $2664(\mathrm{MO})$; $4 \mathrm{~km} \mathrm{~N}$ of Bagaces, $10^{\circ} 34^{\prime} \mathrm{N} 85^{\circ} 15^{\prime} \mathrm{W}, 100-300 \mathrm{~m}, 20$ VII 1977, Liesner 3417 (MO); Santa Rosa National Park, N edge of park, $100-300 \mathrm{~m}, 10^{\circ} 54^{\prime} \mathrm{N} 85^{\circ} 39^{\prime} \mathrm{W}$, 1 II 1978, Liesner 4822 (MO); Cantón de Liberia, Guadalupe, márgenes del Río Claro, Río Santa Inés y quebradas innominadas adyacentes, $10^{\circ} 39^{\prime} \mathrm{N}$ $84^{\circ} 27^{\prime} \mathrm{W}, 90 \mathrm{~m}, 15 \mathrm{~V}$ 1993, Morales \& Salazar 1477 (MO); $4 \mathrm{~km} \mathrm{~N}$ of Liberia, 26 II 1972, Opler 579 (F); Prope Hac. Santa Rosa, III 1847, Orsted 569 (C) y Orsted 4269 (C). Panamá. Coclé: Penonomé, Llanos, 25 VIII 1960, Ebinger 1031 (MO, US); Penonomé and Puerto Posada, 23 II-23 III 1908, Williams 175 (NY, US). Bahamas. Sin localidad: Michaux 86 (P), Swainson s.n. (K). Acklins Island: Spring Point, 21 XII 1905-6 I 1906, Brace 4284 (NY, US); about $4 \mathrm{mi} \mathrm{N}$ of Pinefield, 21 II 1975, Correll 44456 (FTG, NY); 9 I 1888, Eggers 3889 (C, CTES, HBG, K, US). Berry Islands: Whale Cay, 29 I 1905, Britton \& Millspaugh 2192 (NY); near Beach Club, Great Harbour Cay, 16 X 1974, Correll \& Correll 43660 (FTG, NY). Cat Island: The Bight and vicinity, 1-6 III 1907, Britton \& Millspaugh 5906 (NY); Wilson's Bay, 16 VIII 1967, Byrne 237 (FTG); N of Stevenson, 21 XI 1975, Correll 46157 (FTG, MO, NY). Crooked Island: Landrail Point, 9-23 I 1906, Brace 4668 (NY, US); along road to Cabbage Hill, E of landrail landing, 6 VI 1977, Correll \& Proctor 48794 (FTG, NY, US); 2 mi inland from Landrail Point, 22 IV 1971, Gillis 10692 (FTG). 
Eleuthera: Miller's and vicinity, 23 II 1907, Britton \& Millspaugh 5602 (NY). Great Abaco: Along Queen's Highway about $3 \mathrm{mi} \mathrm{N}$ of Dundas Town, 10 IV 1979, Correll et al. 50535 (FTG, NY); $10 \mathrm{mi}$ S of Marsh Harbour, 1 VII 1969, Proctor 30503 (BM). Great Exuma: Georgetown, 22-28 II 1905, Britton \& Millspaugh 2993 (K, NY, JS); Perseverance, just NW of Hooper's Bay, 6 XII 1973, Correll 40729 (CTES, FTG, MO, NY); near Georgetown airport, 26 VI 1974, Correll \& Correll 42454 (FTG); just SE of Richmond hill, 5 III 1980, Correll et al. 51213 (FTG, NIY, US); Near Georgetown airport, 12 VI 1970, Gillis 9384 (FTG, MO). Great Guana Cay: 21-22 II 1905, Britton \& Millspaugh 2890 (NY, US). Inagua: Flats about Morton Salt pans., l VIII 1975, Correll 41650 (FTG, MO); Flats adjacent to Morton salt pans., 28 II 1974, Correll 45861 (FTG, MO, NY); 13 XII 1890, Hitchoock s.n. (FI, MO); Mathew town, 10 X 1904, Nash \& Taylor 881 (NY). Long Island: Clarence Town: at Harbour point, $14 \mathrm{~V}$ 1970, Hill 465 (FTG, NY); near Harbuur point, 16 VI 1974, Hill 2156 (FTG, NY). Mayaguana: Near western end of the airstrip, 11 II 1973, Proctor \& Gillis 33222 (MO). New Providence: 26 II 1878, Brace 95 (K, NY); near Tea House, 31 I 1905, Britton 3184 (NY, US); Near Nassau, 12 V 1903, Curtiss 201 (BMi, K, LY, MO, NY, P, US); Weat End Bight, 10 IV 1904, Millspaugh 2289 (NY). Rum Cay: near Port Nelson, 4 xiI 1905, Brace 3992 (CTES, US); from Port Nelson to cistern, 14 II 1976, Correll \& Wasshausen 46756 (FTG, NY, US). Islas Turcas ฯ Caicos. South Caicos: N of Cockburn Harbour, Simmons F Hill, 25 IV 1971, Burch 4372 (MO, NY); Cockburn Town, 30 XI 1977, Correll 49257 (FTG, MO, NY, US). CuBA. Sin localidad, Hioram \& Ramsden 2321 (C); 1843-4, Linden 1802 (BR). Camagüey: at $\mathrm{Km} 9$ of the line to Nuevitas in carrascai, 21 X 1922, Ekman 15565 (NY, US); Cromo, NW of Camagüey city, 6 IV 1940, [Bros.] León \& M.Victorin 17658 (GH); Cromo, NW of Camagüey city, 8 VII 1948, León 23376 (GH, US); Pastelillo beyond Nuevitas, 15-16 III 1909, Shafer 838 (NY, US); nills SE end, Cayo Guajaba, 7-8 XI 1909, Shafer 2814 (NY, US). Sancti Spiritus: Las Villas, Sabanas de Caimiabo, 1 VII 1952, Alain 1575 (NY); Caimiabo, SE of Sancti Spıritus, VIII 1950, [Bro.] Alain 1596 (GH). Granma:Coastal cliffs, Cabo Cruz, 1 VIII 1935, [Bro.] León 16342 (GH). Guantánamo: Guantanamo Bay, United States Naval Station, 1730 III 1909, Britton 1899 (CTES); Guantanamo Bay, Coude Beach, 17-30 III 1909, Britton 2146 (NY, US); prope Guantanamo (U.S. Naval Station), 24 IX 1914, Ekman 2897 (S); Esparto hill, Cajobabo, 17 VII - 4 VIII 1924, León 12106 (GH, US); Cajobabo, 17 VII-4 VIII 1924, León 12124 (GH). Holguín: Cerro de Cananova, Cananova, VII 1949, [Bros.] Alain \& Clemente 988 (GH, US); Moa, IX 1939, Bucher 108 (NY);
Sierra de Nipe, Loma La Mensura, 21 IV 1940, Carabia 3746 (CTES, NY); Cerro de Cananova, Cananova, VIII 1948, [Bro.] Clemente 6203 (GH); Sierra de Nipe, Loma Mensura, 800-900 m, 16 V 1915, Ekman 5759 (S); Serpentinous savanna, La Yaba, Holguín, 4 VII 1932, [Bro.] León 15711 (GH, NY, US); Serpentine barrens: Mensura Hill, Sierra de Nipe, ca. 1000 m, 27 VII 1940, [Bros.] León \& Alain 19225 (GH, NY, US); Moa, 20 VII 1945, [Bros.] León et al. $22488(\mathrm{GH})$; Moa, 16-23 IV 1943, Marie-Victorin et al. $21452(\mathrm{GH})$; Delta mine, near Cayoguan, Punta Gorda, Moa region, IV 1943, Marie-Victorin et al. 21704 (NY, US); Delta SE of Holguín, 9 IV 1909, Shafer 1289 (A, NY, US), SE of Holguín, 26-29 1909, Shafer 2932 (NY, US); Moa region, Playa de la Vaca, near sea level, aprox. $20^{\circ} 40^{\prime} \mathrm{N} 75^{\circ} \mathrm{W}$, 20 VII 1951 , Nebster 3869 (US). Santiago de Cuba: Sardinero, Santiago, VII 1949, [Bro.] Alain 807 (GH); vicinity of El Morro, Santiago Bay, 10-11 III 1912, Britton \& Cowell 12576 (NY, US); Aguadores, Santiago, XI 1936, [Bro.] Clemente 2121 (GH); Aguadores, Santiago, 2 V 1938, [Bro.] Clemente 2377 (GH); near Siboney, Santiago, IX 1949, [Bro.] Clemente 7020 (GH, US); Juraguá, Santiago, X 1950, [Bro.] Clemente 7437 (GH); pr. Santiago d.C. (inter Santiago urb. et El Morro), 25 IX 1916, Ekman 7714 (S); Mesa de Prada, Jauco, 17 VII - 4 VIII 1924, León 11943 (GH, US); near El Morro, Santiago, 12 IV 1940, IBros.J León et al. 17704 (GH); Santiago, vallee du rio Sagua, entre le pueblu et Sta. Catalina, v 1862, Linden 1852 (BM, BR, FI, K, P, W); St. Yago de Cuba, coilines arides du Cobre, 1844, Linden s.n. (P); Cobre, VIII 1844, Linden 2065 (BM, BR, FI, NY, P, W); Puntón de Cuero, a mountain $\mathrm{N}$ of Inúas, SE cciast of Oriente, 100600 m, 11 i 1956, Morton \& Alain 8888 (US); in Cuba orientali, Cobre, IX 1859-I 1860, Wright 210 (BA, BM, SR, FI, GH, GOET, K, MO, NY, P, S, US, W). Villa Clara: Casilda, 16 III 1910, Britton \& Wilson 5586 (NY, US); Palm Barren, Santa Clara, 8-9 IV 1912, Britton \& Cowell 13317 (NY, US); Sta. Clara city, 19 II 1923, Ekman 16332 (S); Mordazo, between Laguna Atacaosa and Laguna Yaiti, 10 VIII 1923, Ekman 17076 (S); E of Santa Clara city, 25 III 1924, Ekman 18839 (K, CTES, S); near Mordazo, 29 XII 1915, León \& Cazanas 5933 (NY). Islas Caimán. Little Cayman: 0,5 mi NE of the Airport terminal, 10 VII 1967, Proctor 28113 (BM, US). Jamaica. St.Catinerine: Port Henderson Hill, ca. 600 ft., 30 X 1966, Adams 12871 (BM); Sin localidad, Bertero s.n. (W); Santa Cruz Mountains, Loner's Leaf, 4 iX 1907, Britton 1146 (NY); Long Mountain, S side, 500 ft, 7 III 1907, Harrts 9608 (CTES, K, NY, US); Yardley Chase, 1600 ft, 9 IV 1907, Harrts 9679 (NY); Herb. Poiret (P); Saint Catherine, Hellshire hills inland from Half Moon Bay, 50-100 ft, 16 XI 1979, Proctor 38387 (MO, NY). 
Hartí. Gauthier, 26 III 1937, Bailey 170 (US); Port au Prince to Atalaye, 15 VII 1941, Bartlett 17564 (A, US); Dep. de l'Artibonite, Gonaives, Ennery, 400 m, 21 IV 1900, Buch 257 (GH); Base of Morne a' Cabrites, 50 m, 29 III 1942, Holdridge 1079 (BM, CTES, F, GH, MO, NY, US); vicinity of St.Marc, near sea level, 2528 II 1929, leonard 2882 (NY, US); vicinity of Fond Parisien, Etang Saumatre, 5-13 V 1920, Leonard 4114 (NY, US); vicinity of St. Michel de l'Atalaye, $350 \mathrm{~m}$, 17 XI 1925, Leonard 7104 (NY, US); Dep. du Nord, vicinity of Ennery, 325-900 m, 17 I 1926, Leonard 8893 (MO); vicinity of Ennery, 325-900 m, 18 I 1926, Leonard $8931(\mathrm{GH})$; vicinity of Gros Morne, $235 \mathrm{~m}$, 18 II 1926, Leonard 9958 (F, S, US); Tortue Island, Lagoon $W$ of La Vallee harbor, vicinity of La Vallee, 28 XII 1928- 9 I 1929, Leonnrd \& Leonard 11564 (A, K, MO, NY, US); Baie des Moustiques, West of Cabaret, vicinity of Cabaret, 12-18 I 1929, Leonard \& Leonard 11850 (A, K) y Leonard \& Leonard 11891 (MO, NY, US); vicinity of Bassin Bleu, road to Gros Morne, 630-1500 m, 15 IV 1929, Leonard \& Leonard 14692 (US); Plaine Cul-de-sac, $1 \mathrm{~km}$ de la plaza central de Croix-des-Bouquets, en el cruce de la carretera a Mirabelais y Thomazeau, Dep. 1'Ouest, $18^{\circ} 35^{\prime} \mathrm{N}$ $72^{\circ} 11^{\prime}$ W, 120 m, 16 VII 1983, Mcjia 26293 (NY); Near L'Arcahaie, 10 III 1925, Miller 266 (US); San Michel, $1500 \mathrm{ft}, 5$ VIII 1905, Nash \& Taylor 1410 (NY); Gonaives to La Hotte Rochée on road to Terre Neuve, 300 ft, 12 VIII 1905, Nash \& Taylor 1541 (NY, US); Prince, 6 III 1897, Ptcarda 1552 (S); Port au Prince, 14 VIII 1935, Potter 5028 (GH); near Les Poteau, IV 1960, Read 269 (A); 13 km desde Pedro Santana (RD) en la carretera internac. al N de Restauración ca. de la Torre "cortecito", $19^{\circ} 8,5^{\prime} \mathrm{N}$ $71^{\circ} 38^{\prime} \mathrm{W}, 1200 \mathrm{ft}, 5$ IIr 1982, Zanont et al. 19666 (NY); presq'île du Nord-Ouest, aprox. $5-7 \mathrm{~km}$ W de Gonaives en la carretera costera a Anse Rouge, $19^{\circ} 27^{\prime} \mathrm{N} 72^{\circ} 49^{\prime} \mathrm{W}, 15 \mathrm{~m}, 21$ X 1983, Zanoni et al. 27657 (FTG, NY); en el Presq' île du St. Nicolas, $19^{\circ} 50^{\prime} \mathrm{N}$ 7322-23'W, 0-87 m, 20 I 1984, Zanone et al. 28396 (NY). República Dominicana. S.D., scripsit Balbis (W); Azua, 28 XIl 1963, Basillo Augusto 1198 (NY); Saint Domingue, Beauvors s.n. (P); San Domingo, W.I. Bertero s.n. (FI, MO); Monte Cristi: Carretera Duarte, 35 km E Monte Cristi, 27 IV 1970, Burch 2435 (MO); Santiago, Pinar de! Caimito, entre Amina y El Rubio, San José de las Matas, 600 m, 16 IV 1976, Cicero et al. s.n. (CTES, NY); Peravia, Loma Las Tablas, al pie del Monte, $18^{\circ} 19^{\prime} \mathrm{N} 70^{\circ} 25^{\prime} \mathrm{W}, 200-350 \mathrm{~m}$, 14 X 1981, Czerwenka \& Pelaez 448 (NY); St. Domingo, Desportes s.n., Herb. Jussieu 13576 (P); Santiago, Valle de! Cibau, Santiago, Hatillo, in Loma Juan Dias, 9 X 1930, Ekman 16028 (A, C, F, MO, S, US); Barahona: Duvergé, 50 m, VIII 1910, Fuertes 368 (A, NY, US, W); Cordillera Central, Prov. Santiago
Rodríguez, $1 \mathrm{~km} \mathrm{~S}$ de Monción, $19^{\circ} 18,5^{\prime} \mathrm{N} 71^{\circ} 07^{\prime} \mathrm{W}$, 380 m, 9 VI 1987, García y Pimentel 2234 (MO); Pedernales, loma el Guano, $30 \mathrm{~km}$ SW of Pedernales, $17^{\circ} 57^{\prime} \mathrm{N} 71^{\circ} 75^{\prime} \mathrm{W}, 200$ m, 12 IV 1985, Gentry \& Mejia 50766 (MO); Azua: La Salina, 16 VIII 1946, Hozvard \& Howuard 8372 (GH, NY, S, US); Near town of Azua, 29 VIII 1946, Howard \& Howard 8641 (GH, NY, S, US); near Rio Yaque del Norte, $\mathrm{S}$ of Monte Cristi, 23-24 X 1946, Howard \& Howard 9586 (GH, NY, P, S, US); Bahoruco, Edge of Lake Enriquillo, 22 VII 1950, Howard 12105 (A, BM, BR, US); Monte Cristi, Loma de Cabrera, 20 VI 1943, Jiménez 452 (US); St. Domingo, Herb. Lamarck s.n. (C, P); Piedra Gorda, about $20 \mathrm{mi} \mathrm{W}$ of Santiago, near Mao road, 200-300 m, 14 IX 1968, Liogier 12676 (F, NY, US); Monte Rio, Azua, sea level, $10 \times$ 1970, Liogier 17570 (F, NY); Cofresi, Puerto Plata, 50 m, 24-25 II 1973, Ltogier 18834 (NY); en la carretera de S. José de Ocoa, 250 m, 15 IX 1973, Liogier 20153 (NY); km 98 entre Bani y Azua, 50 m, 4 XI 1973, Loogier 20561 (F, NY); El Número, 100 m, 5 III 1980, Mejia 131 (FTG, NY); 6,4 $\mathrm{km} \mathrm{SW}$ of Los Negros on road to Berrero, $18^{\circ} 19,5^{\prime} \mathrm{N}$ $70^{\circ} 53^{\prime} 2^{\prime} \mathrm{W}$, foothill and base of Sierra Martin Garcia, 100 m, 30 IV 1980, Mejia \& Zanoni 6141 (NY); San Juan: along road to El Guanal (El Coco), 4-6 km NNE of Guanito, 450-600 m, I XI 1982, Proctor 39116 (FTG, $\mathrm{MO})$; Santo Domingo, Herb. Richard (P); Las Tablas $15 \mathrm{~km} \mathrm{~W}$ of Bani, proyecto Caprino, $18^{\circ} 18^{\prime} \mathrm{N}$ 70²4’W, 1979-1980, Rewinkel s.n. (NY); Azua, III 1913, Rose et al. 3820 (NY, US); $19^{\circ} 53^{\prime} \mathrm{N} 71^{\circ} 40^{\prime} \mathrm{W}$, ca. $1 \mathrm{~km} \mathrm{~W}$ of Montecristi, 10-20 m, 20 II 1983, Sanders et al. 1596 (FTG); Pedernales, Cabo Rojo, 9 XI 1979, Smith 10124 (NY); N of Monte Cristi, Punta de la Granja, El Morro, 18 XII 1979, Smith 10539 (NY); St. Domingo, Schomburgk 45 (K); Dist. San José de las Matas, Jicome, 700 m, 26 VIII 1929, Valeur 97 (S, US) Muncion, 375 m, 25 II 1930, Valeur 97 (F, MO, NY); Cabo Rojo, II 1971, Votava \& Lioger 42 (MO, NY); between Azara and Barahona, II 1971, Votava \& l.ıogier 49 (NY); Agua, entre Cañada Cimarrona (700 $\mathrm{ft}, 7 \mathrm{~km} N$ de Las Charcas) y Los Quemados (1900 $\mathrm{ft}, 11 \mathrm{~km}$ N de Las Charcas), 18³0-31'N 70³5-36’ $\mathrm{W}$, 22 VII 1982, Zanont et al. 21915 (NY); base y ladera de Monte Hano, $3 \mathrm{~km}$ NW de Galeon o $15 \mathrm{~km}$ NW de Bani, en la carretera a Azua, $18^{\circ} 24^{\prime} \mathrm{N} 70^{\circ} 26^{\prime} \mathrm{W}$, 125 m, 30 XI 1982, Zanoni \& Mejia 24666 (NY); loma El Guano, $10,7 \mathrm{~km}$ E del cruce de Cabo Rojo y Pedernales en la carretera a Oviedo, $17^{\circ} 56^{\prime} \mathrm{N} 71^{\circ} 35^{\prime} \mathrm{W}$, 200 m, 18 V 1983, Zanoni \& Pimentel 25900 (NY); Peravia, base de la Cordillera Central, en el cauce del arroyo Cano, paralelo al poblado de Las Tablas, $12 \mathrm{~km}$ W y $4 \mathrm{~km}$ S de Bani, 18 18' N, $30 \mathrm{~V} 1983$, Zanon 26038 (FTG, MO, NY). Puerto Rico. Maguey Island, 24 II 1924, Britton 8060 (NY); Susua, 25 VIII 1989, Houghton et al. 1221 (FTG); La Paquera, 
24 II 1935, Sargent 156 (US); sin localidad, 1889, Stahl 1033 (S, SI). Aguadilla: Montalva, Punta Peñones, 2 4 III 1915, Britton et al. 4825 (F, MO, NY, US). Bayamón: Guayanilla, 10 III 1913, Britton \& Shafer 1811 (C, CTES, F, FI, MO, NY, US); Guayanilla, 30 m, 26 IX 1979, Liogier et al. 29539 (NY); Guayanilia, Bo. Maga, 21 II 1938, Otero \& Lopez 465 (A, F, MO); Guayanilla ad maris littor., I 1886, Sintenis s.n. (GH). Guánica: Guánica Forest Reserve, along Murciélago Trail from campamento, 50-150 m, 7 IX 1991, Axelrod \& Escobar 2902 (MO); Guánica Forest Reserve, 25 VIIl 1989, Houghton et al. 1227 (FTG); Guánica, Mariuca, 9 XI 1982, Llogier 33627 (NY); prope Guánica, 25 I 1886, Sintents 3535 (BR, K, LY); near Guánica, 13 VIII 1963, Wagner 351 (A, BM); Guánıca, 9 II 1968, Wagner 1327 (A). Isla Mona: Uvero, a lo largo de la carretera, $5 \mathrm{~m}, 30 \mathrm{~V} 1991$, Acevedo-Rdgz \& Siaca 4415 (FTG, US); near Sardiñera, 20-26 II 1914, Britton et al. 1771 (F, NY, S, US); trail to Gato Cave, 2 V 1944, Chardon \& Otero 1795 (NY). Isla Vieques: $1 \mathrm{~km}$ of extreme $\mathrm{E}$ end of island, $3 \mathrm{VI}$ 1978, Fosberg 57561 (US); Vieques, 17 V 1978, Griffis 30-14 (NY), 17 V 1978, Griffis 33-2 (NY). Mayagüez: Cabo Rojo, area aprox. $1 \mathrm{~km}$ E de Pole Ojeda, 4 IX 1985, Acevedo et al. 973 (NY); Salinas de Cabo Rojo, sea level, 18 XI 1980, Liogier et al. 31150 (NY); Salinas de Cabo Rojo, 5 II 1885, Sintenis $530 b$ (CTES, F, NY, US); Salinas de Cabo Rojo ad Los Morrillos, 14 II 1885, Sintents 530 (BAF, CORD, FI, GH, HBG, K, LY, P, S); Guaniba, 25 I 1886, Sintenis 3434 (F, K, NY, LS, W); Puerto Diablo to Salina, 17 II 1914, Shafer 2936 (NY, US); Campo Cielo to Ensenada Honda, 27 II 1914, Shafcr 3047 (NY, US); Rojo Niter Caceseas, 5 II 1885, Wud 530 (MO). Ponce: Ponce to Peñuelas, 22 III 1906, Britton \& Cowell 1294 (F, NY, US); $2,8 \mathrm{mi} \mathrm{W}$ of Ponce along the coast road (Hwy. 2) at the Holiday Inn, 18 XI 1981, Hansen et al. 9120 (FTG); $3 \mathrm{mi} \mathrm{W}$ of Ponce, 5 XII 1902, Heller s.n. (F, NY, US); ad Peñón, 16 VII 1886, Sintenis s.n. (GH, LY); near Ponce, 14 VI-22 VII 1901, Underwood \& Griggs 682 (NY, US). Islas Vírgfnes. St. Croix. Above Cotton garden Point, 19 VII 1970, D'Arcy 4702 (MO); Fabricio s.n. (BM). Anegada: Near Loblolly Beach, 14 IX 1967, D'Arcy 2112 (MO); Behind Loblolly Bay, 5 II 1971, D'Arcy 5111 (MO). St. Joinn: Reef Bay Quarter, Dittlif Point, 25 m, 20 I 1991, Acevedo Rdgz. \& Siaca 3979 (MO); E End Quarter, Eastern most part of Island, E of Southside Pond, 100 m, 19 VIII 1987, Acevedo-Rodriguez et al. 1834 (CTES); Little St. James island, 27 II 1913, Britton \& Rose 1408 (C, K, MO, US); Marias Bluff, 14 II 1976, Prance et al. 29296 (FTG); Ostenden, 7 III 1906, Raunkuter s.n. (BR, C, S, US); Ostenden, 3 VII 1906, Raunkiaer s.n. (C, P). St. Thomas: Green Key Bay, 12 II 1991, Acevedo Rdgz. et al. 4183 (MO); Eggers s.n.
(C, FI, LY, MO, S); Cowells Hill, XI 1880, Eggers s.n. (LY, US); Corvello Hill, XI 1880, Eggers 298 (B, BR, CORD, K, LY); Cowells Hill, II 1887, Eggers 354 (P); Cowells Hill, XI 1880, Eggers 1100 (BR, CORD, HBG, P, W); Madteget, 1871, Krebs s.n. (BAF, C). Virgin Gorda: near Balley, 21. II 1913, Britton \& Fishlock 1113 (NY, US); Valley, 13 I 1918, Fishlock 86 (NY); Valley, 6 I 1919, Fishlock 207 (US). Brasıl. Bahia: Entre Geremoabo e Forquilha, 20 III 1950, AndradeLima 50-441 (IPA); $14 \mathrm{~km}$ WNW de Morro do Chapéu, camino a America Dourada, aprox. $11^{\circ} 30^{\prime} \mathrm{S}$ $41^{\circ} 17^{\prime} \mathrm{W}$, ca. $1000 \mathrm{~m}, 28$ XI 1992, Arbo et al. 5354 (C, CTES, GH, HUEFS, K, MICH, SPF, UB); Morrão al $S$ de Morro do Chapéu, 11 $1^{\circ} 35^{\prime} S 41^{\circ} 13^{\prime} \mathrm{W}$, ca. 1100 m, 28 XI 1992, Arbo et al. 5401 (C, CTES, HUEFS, K, LIL, MICH, SPF, UB, YUTO); $18 \mathrm{~km} \mathrm{NE} \mathrm{de} \mathrm{Barra}$ da Estiva, $6 \mathrm{~km}$ antes de Sincorá Velho, aprox. $13^{\circ} 33^{\prime} \mathrm{S}, 41^{\circ} 16^{\prime} \mathrm{W}, \mathrm{ca} .850 \mathrm{~m}, 23$ XI 1992, Arbo et al. 5758 (CTES, HUEFS, K, SPF, UB, YUTO); BR-324, $12 \mathrm{~km}$ NW de Jacobina, camino a Umburanas, ca.

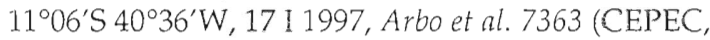
CTES, K, LIL, WIS); Serra do Tombador, $19 \mathrm{~km}$ al NW de Jacobina, BR-324, ca. $11^{\circ} 05^{\prime} \mathrm{S} 40^{\circ} 40^{\prime} \mathrm{W}, 171$ 1997, Arbo et al. 7394 (CEPEC, CTES, G, K); BA-426, $29 \mathrm{~km}$ al NE de Morro do Chapéu, camino a Varzea Nova, ca. $11^{\circ} 20^{\prime} \mathrm{S} 41^{\circ} \mathrm{W}, 17$ I 1997, Arbo et al. 7440 (CEPEC, CTES, K); Morrão, $8 \mathrm{~km}$ al $\mathrm{S}$ de Morro do

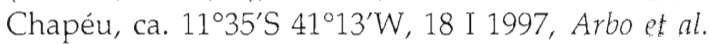
7455 (CEPEC, CTES, K); 10-15 km al W de Capão de Volta, camino a Jussiape, aprox. $13^{\circ} 30^{\prime} \mathrm{S} 41^{\circ} 30^{\prime} \mathrm{W}$, 20 I 1997, Arbo et al. 7583 (CEPEC, CTES, K); 3 km SW de Rio de Contas, camino a Livramento do Brumado, aprox. 13 $36^{\prime} \mathrm{S} 41^{\circ} 49^{\prime} \mathrm{W}, 21$ I 1997, Arbo et al. 7608 (CEPEC, CTES, K, LIL); Mun. Morro do Chapéu, localidade de Fedegoso, 11 ${ }^{\circ} 30^{\prime} S$ 41 $36^{\prime} \mathrm{W}$, 28 VIII 1981, Arouck Ferreira 42 (CTES, HPR, HUEFS); Rio de Contas, estrada $\mathrm{p} /$ Livramento em direção ao Rio Brumado, 13 XII 1984, Arraes et al. s.n. CFCR 6809 (CTES, SPF); Gloria, Brejo do burgo, caminho da serrota, 3 VII 1995, Bandeira 236 (HUEFS); Serra Jacobina, 1837, Blanchet 2641 (BM, K); Villa di Barra, 1837, Blanchet 2641 (G); sin localidad, 1857, Blanchet 2939 p.p. (P); Tamandua, Blanchet 3840 (BM, BR, P); Mun. Caetité, Brejinho das Ametistas, $2 \mathrm{~km}$ a WS da sede do povoado, $900 \mathrm{~m}$, 15 IV 1983, Carvalho et al. 1772 (CTES) y Carvalho et al. 1780 (CTES, HUEFS); Mun. Jacobina: ca. 20 km na rodovia Jacobina/Morro do Chapéu, 15 III 1990, Carvalho \& Saunders 2816 (CTES); ca. $23 \mathrm{~km}$ na rodovia Jacobina para Morro do Chapéu, 15 III 1990, Carualho \& Saunders 2828 (CTES, HUEFS); Mun. Campo Formoso, Agua Preta, estrada AlagoinhasMinas do Mimoso, $10^{\circ} 22^{\prime} \mathrm{S} 41^{\circ} 19^{\prime} \mathrm{W}, 1050 \mathrm{~m}, 26 \mathrm{VI}$ 1983, Coradin et al. 6066 (CEN, CTES); Mun. Morro do Chapéu, rodovia Lage do Batata - Morro do 
Chapéu, km 66, $11^{\circ} 27^{\prime} \mathrm{S} 41^{\circ} 07^{\prime} \mathrm{W}, 1000$ m, 28 VI 1983, Coradin et al. 6216 (CEN, CTES); Mun. Apora, 31 $\mathrm{km}$ S of Olindina along Highway BR-116, $310 \mathrm{~m}, 1$ IV 1976, Davidse et al 11745 (CTES, MO); Mirangaba, 1046'S 403' W, 23 IV 1981, Fonseca 404 (CTES, HPR, UB); Palmeira, Pau Ferro $2 \mathrm{~km}$ do Mun. de Palmeira, entrada para Caete-Açu, 700 m, 4 IV 1996, França et al. 1579 (CTES, HUEFS); Mun. Abaíra, caminho Ribeirão-Quebradas, próxima a última

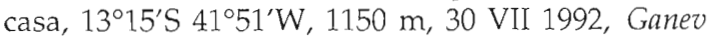
780 (C.ES, HUEFS, MBM, SPF); Mun. Abaíra, estrada Catolés-Ribeirão, próximo ao Escorregador,

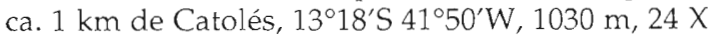
1992, Ganev 1341 (CTES, HUEFS); Mun. Nova Soure, V 1974, 10 km leste de Morro do Chapéu-Irecê, 3 II 1973, Gottsberger \& Gottsberger 22-3273 (ULM); Estação Ecológica do Raso da Catarina, Mata das Pororocas, 7 XII 1985, Guedes \& Sousa 1016 (ALCB); Serra do Rio de Contas, on road to Abaira, ca. $8 \mathrm{~km}$ $\mathrm{E}$ of town of Rio de Contas, 13 $33^{\circ} \mathrm{S} 41^{\circ} 47^{\prime} \mathrm{W}, 1000$ m, 18 I 1974, Harley et al. 15262 (IPA, MO, NY, US); $16 \mathrm{~km}$ NW of Lagoinha (5,5 km SW of Delfino) on side road to Minas do Mimoso, $10^{\circ} 22^{\prime} \mathrm{S} 41^{\circ} 16^{\prime} \mathrm{W}$, ca. 640 m, 5 III 1974, Harley et al. 16715 (CTES, IPA, MO, NY, US); Serra do Açuruá, $3 \mathrm{~km}$ S of São Inácio on the road to Gentio do Ouro, $11^{\circ} 08^{\prime} \mathrm{S} 42^{\circ} 44^{\prime} \mathrm{W}$, ca. 500 m, 27 II 1977, Harley et al. 19157 (CTES, IPA, NY, US); ca. $2 \mathrm{~km}$ SW of Morro do Chapéu on the Utinga Road, approx. $41^{\circ} 10^{\prime} \mathrm{W} 11^{\circ} 34^{\prime} \mathrm{S}$, ca. $1000 \mathrm{~m}$, 3 III 1977, Harley et al. 19322 (CEPEC); Serra Geral de Caitité, ca. $3 \mathrm{~km} \mathrm{~S}$ from Caitité, along the road to Brejinhos das Ametistas, $14^{\circ} 05^{\prime} \mathrm{S} 42^{\circ} 29^{\prime} \mathrm{W}$, ca. 1000 m, 10 IV 1980, Harley et al. 21185 (CEPEC, CTES, IPA, NY, US); Serra Geral de Caitité ca. $12 \mathrm{~km}$ SW of Caitité, by the road to Morrinhos, and ca. $9 \mathrm{~km}$ $W$ along this road from the junction with the CartiteBrejinhos das Ametistas road, $14^{\circ} 14^{\prime} \mathrm{S} 42^{\circ} 35^{\prime} \mathrm{W}, 950$ m, 10 IV 1980, Harley et al. 21201 (CTES); Serra Geral de Caitité, 1,5 km S of Brejinhos das Ametistas, 900 m, 11 IV 1980, Harley et al. 21210 (CEPEC, IPA, NY, US); ca. $16 \mathrm{~km}$ along the Morro do Chapéu to Utinga road, SW of Morro do Chapéu, 980 m, 1 VI 1980, Harley et al. 22955 (CEPEC, CTES, IPA, NY, US); Mun. Ibiquara, $13 \mathrm{~km}$ de Juciape na estrada para Morro Branco e Capão da Volta, $13^{\circ} 32^{\prime} \mathrm{S} 41^{\circ} 29^{\prime} \mathrm{W}$, 1000 m, 15 XI 1988, Harley et al. 26453 (CEPEC, CTES, SPF); Morro do Chapéu, arredores, 14 I 1977, Hatschbach 39583 (CTES); Morro do Chapéu, $15 \mathrm{~km}$ O, 13 X 1981, Hatschbach 44234 (CTES, MO); Mun. Igapora, Rod. BR-430, trevo para Tanque Novo, 1000 m, 5 IV 1992, Hatschbach et al. 56634 (CTES, MBM); Capão da Volta (Barra da Estiva), 8 IV 1992, Hatschbach et al. 56846 (CTES, MBM); Mun. Mucugê, Santa Cruz, 9 IV 1992, Hatschbach et al. 56876 (CTES, MBM); Mun. Macaubas, Macaubas, subida para
Serra Poção, 800-1000 m, 20 IV 1996, Hatschbach et al. 65137 (CTES, GH, K, MBM); Mun. Caetité, Palmeira, 16 I 1997, Hatschbach et al. 65850 (CTES, MBM); Hatschbach et al. 67773 (CTES, MBM); Serra da Agua de Rega, ca. $29 \mathrm{~km} \mathrm{~N}$ of Seabra, road to Agua de Rega, ca. 1000 m, 27 II 1971, Irwin et al. 31196 (F, P, UB); Serra do Tombador, at base of Morro do Chapéu, ca. $7 \mathrm{~km}$ S of town of Morro do Chapéu, ca. 1100 m, 17 II 1971, Irwin et al. 32331 (CTES, P); ca. $6 \mathrm{~km}$ S of town of Morro do Chapéu, base of Morro do Chapéu, ca. 1100 m, 18 II 1971, Irwin et al. 32449 (CTES, MO, NY); Estrada BA-5, 15 $\mathrm{km} \mathrm{N}$ de entroncamento a Tanquinho, 2 IV 1967, Krapouckas 12807 (CTES, MICH); km 30 da BR-242, 11 V 1975, Leal Costa \& Barroso s.n. (ALCB, HPR, HUEFS); Joazeiro, Löfgren 990 (RB); Mun. Caetité, a $2 \mathrm{~km}$ ao $\mathrm{S}$ de Caetité, ca. $800 \mathrm{~m}, 19$ III 1980, Mon \& Benton 13465 (CTES, NY); Caetité, Morro com torre de transmissão da TV, $14^{\circ} 04^{\prime} \mathrm{S} 42^{\circ} 30^{\prime} \mathrm{W}, 800-1000$ m, 25 V 1985, Noblick \& Clodoaldo 3779 (CTES, HUEFS); Morro do Chapéu, 1000 m, 11 IX 1956, Pereira 2150 (RB); Nova Soure, V 1974, Pinto 42321 (ALCB, CTES, HPR, HUEFS, IPA); Estação Ecológica do Raso da Catarina, 9²0'a 9 $9^{\circ} 5^{\prime} S 38^{\circ} 29^{\prime}$ a 3843’W, 24 VI 1982, Queiroz 356 (ALCB, HUEFS); Estação Ecológica do Raso da Catarina, próximo a Mata das Pororocas, 9²0'a 9 $55^{\prime} \mathrm{S} 38^{\circ} 29^{\prime}$ a $38^{\circ} 43^{\prime} \mathrm{W}$, 9 VI 1983, Queiroz 568 (HUEFS); Barra, Ibiraba (=Icatu), Santa C:uz, em frente ao povoado de Ibiraba, no caminho para os Brejos $10^{\circ} 48^{\prime} \mathrm{S} 42^{\circ} 50^{\prime} \mathrm{W}$, 23 II 1997, Queiroz 4806 (CTES, HUEFS); ídem, 24 II 1997, Queiroz 4822 (CTES, HUEFS); Nova Soure, ca. $5 \mathrm{~km} \mathrm{~N}$ de Nova Soure na estrada para Cipo (BR110), 23 VIII 1996, Queiroz \& Nascimento 4548 (CTES, HUEFS); Caetité, Brejinho das Ametistas, $14^{\circ} 15^{\prime} 37^{\prime \prime} \mathrm{S}$ $42^{\circ} 31^{\prime} 27^{\prime \prime} \mathrm{W}, 900-1000 \mathrm{~m}, 8$ III 1994, Roque et al. CFCR 14948 (CTES, SPF); Cafarnaum, prósimo a Várzea do Cerco, $12^{\circ} 00^{\prime} \mathrm{S} 41^{\circ} 32^{\prime} \mathrm{W}, 16$ III 1984, Salgado 373 (HPR); Mun. Itapicuru, Rod. Itapicuru/Tobias

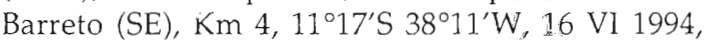
Sant'Anna et al. 487 (CTES); Mun. Tucano, Rod. Ribeira do Pombal/Tucano, Km 24, $10^{\circ} 55^{\prime} \mathrm{S} 38^{\circ} 42^{\prime} \mathrm{W}$, 16 VI 1994, Sant'Anna et al. 515 (CTES); Paulo Afonso, Raso da Catarina, 945'S 38 $37^{\prime} \mathrm{W}, 23 \mathrm{~V} 1978$, Silva 632 (CTES, SP); Mun. Abaíra: estrada CatolésRibeirão de Baixo-Inubia, 9-12 km de Catolés, 9001000 m, 19 III 1992, Stannard \& Silva H52705 (CTES, MBM, SPF); Serra do S. Ignacio, II 1907, Ule 7511 (K, HBG); Xique-Xique, Serra da Tiririca, Grota do Pequenino, 12 V 1912, Zehntner 99 (R). Ceará: near Aracaty, VII 1838, Gardner 1471 (BM, K); BR-304, próximo ao km 61, córrego de Ubarana, Aracatí, 11 III 1979, Nunes et al. s.n. [EAC 5708] (CTES). Minas Gerais: Serra da Mantiqueira, 22 IX 1877, Glaziou 10881 en parte (P) [localidad dudosa]; Mun. jura- 
mento, Rod. Montes Claros a Itacambira, Serra do Catuni, 17 III 1997, Hatschbach et al. 66360 (CTES, MBM); Serra do Espinhaço, ca. 38 km NE of Francisco Sá, road to Salinas, 1100 m, 13 II 1969, Irwin et al. 23245 (P, UB). Pernambuco: Buique, Fazenda Laranjeiras, Chapada de São Jose, $8^{\circ} 37^{\prime} \mathrm{S} 37^{\circ} 10^{\prime} \mathrm{W}$, 790 m, 20 V 95, Figueiredo et al. 66 (CTES, NY); ídem, 16 VI 1995, Figueiredo et al. 91 (CTES); idem, $5 \mathrm{~V}$ 1995, Gomes et al. 13 (CTES); Mun. Buique, Sitio Cajueiro, 6-7 km de Buique, 5 II 1981, Krapovickas et al. 38071 (C, CTES, IPA, MBM); Buique, $5 \mathrm{~km}$ da estrada de barro para Catimbau, 19 VI 1994, Miranda et al. 1746 (SP); Buique, Catimbau, Serra do Catimbau, $8^{\circ} 37^{\prime} \mathrm{S} 37^{\circ} 10^{\prime} \mathrm{W}, 790 \mathrm{~m}, 16 \mathrm{IX} 1994$, Sales 365 (CTES, PEUFR); ídem, 11 II 1995, Silva et al. 764 (CTES, PEUFR, US); Petrolândia, IV 1954, Vidal IV876 (R). Rio Grande do Norte: Mossoró, estrada do Tibau, 31 VIII 1984, Ataide et al. 567 (IPA); Vale de Maxaranguape, 26 I 1961, Castellanos 22995 (GUA, R); Natal, 11 X 1984, Fernandes et al. s.n. (CTES); Canguaretama, caminho para o Eng ${ }^{\circ}$. Estrêla, 4 VII 1959, Mello Filho 1758 (R); Natal, após o conjunto dos Bancários, 9 XII 1990, Pereira \& Lima s.n. (IPA).

Distribución y fenología. Especie con área disyunta, en el hemisferio norte vive en el S de Estados Unidos (Texas), México, Antillas y América central y en el hemisferio sur en los estados nordestinos de Brasil (Bahia, Ceará, Pernambuco y Rio Grande do Norte) y en el norte de Minas Gerais. Vive en sabanas, bosques secos, laderas de cerros, "campos gerais y campos rupestres", en suelo arenoso, también sobre rocas calizas o serpentinas; se adapta a lugares modificados como bordes de caminos. Elevación: desde el nivel del mar hasta los 2600 $\mathrm{m}$. En el hemisferio norte florece durante todo el año, si bien el mayor número de especímenes en flor se recolectó en julio y agosto. En el hemisferio sur también florece todo el año; las colecciones son más numerosas desde enero a abril.

Cromosomas: $2 \mathrm{n}=14$, Krapovickas et al. 38071 (Fernández, 1987).

Polen: PAL-CTES 890 (Krapovickas 12807).

Nombres vulgares: "damiana" (México: Argüelles 227, Carter et al. 2196, Carter 2600, Conzatti 810, González Ortega 256, 6315 y 6591, Holmes s.n, León 4275, Narvaez Montés \& Salazar
810; Estados Unidos, Texas: Runyon 2535); "escoba lisa" (Nicaragua: Standley 10155); "hierba de la pastora" (México: Corrêa, 1931); "hierba del Venado" (México: Baro 821, Chemin Bassler 71, González 731, Villarreal 1798); "mejorana" (Guatemala: Standley 82744, vendida en mercados); "moro" (México: Méndez Guerrero s.n.); "oreganillo" (Rep. Dominicana: Fuertes 368); "orégano cimarrón (Rep. Dominicana: Valeur 97); "rompe camisa macho" (Cuba: León y Alain, 1953); "swamp bush" (Belize, Arvigo et al. 350); "thé-bourrique" (Haití: Ekman, 1930); "yerba del pastor" (México: Altamirano 4118); "yerba del venado" (México: Berlandier 3155, Schaffner 166, Wooton s.n.).

Uso medicinal. Analgésico para variados propósitos: beber decocción de cualquier parte de la planta; antiodontálgico: mascar las hojas (Arvigo et al. 350, Belize). Medicinal para los nervios (Campos 54, México). Se emplea para curar el paludismo (Conzatti 810, México). La decocción del follaje se usa como tónico medicinal; también considerada como afrodisíaco (Gentry 16551, México). Helmick's Damiana, "said to be the plant from which the drug was originally manufactured, \& of which the locality was unknown, kept a secret, for a considerable time" (Holmes s.n., VIII 1882, K). Se utiliza para té (Torres \& Cortes 8771). "Good for tea" (Wooton s.n.).

Tiene propiedades tónicas, estimulantes, afrodisíacas, antidiarreicas, diuréticas, expectorantes, etc. (Corrêa, 1931). Se emplea como tónico y contra la disentería, malaria, sífilis, dispepsia y aún parálisis; se le atribuyen propiedades diuréticas, astringentes, espectorantes, laxantes y afrodisíacas (León \& Alain, 1953).

Obs: En flores brevistilas el androceo es 1,2$3 \mathrm{~mm}$ mayor que el gineceo. En flores longistilas el gineceo es 1-3 mm mayor que el androceo, los estigmas son exertos.

González Ortega 6753 y Martínez C. 648 tienen hojas y flores notablemente grandes, hojas $40 \times 15 \mathrm{~mm}$ y $53 \times 11 \mathrm{~mm}$, flores de $8 \mathrm{~mm}$ long., 17 mm diám.

La especie es perenne; es decidua al menos en México (Heard \& Barkley 14548, Seler \& Seler 865) y en el Caribe (hay ejemplares muy de- 
mostrativos en S). Después de la caída de las hojas floríferas se puede observar en cada base foliar, lateralmente, la cicatriz del pecíolo, y hacia arriba la cicatriz del pedúnculo floral.

Esta especie presenta coléteres trocleariformes en los dientes foliares, y coléteres sésiles en el ápice de las estípulas (González, 1998).

Tantiseurie et al. (1969) expresan que T.diffusa contiene un constituyente cianogénico principal diferente de la gynocardina. Spencer \& Seigler (1981) identificaron como tetraphyllina $\mathrm{B}$ al compuesto cianogenético presente en las hojas.

39b. Turnera diffusa Willd. ex Schult. var. aphrodisiaca (Ward) Uśb. Mapa 11

Urban I., Jahrb.Königl.Bot.Gart.Berlin 2: 127, tab. 2, figs. 16 y 26. 1883. Urban I. en Martius C.F.P., Fl.bras. 13(3): 147. 1883.

Turnera aphrodisiaca Ward, Virginia Med. Month. 3(1): 48-49, April 1876. Urban I., Arch.Pharm. 220(3): 9-11, figs. 1 a - 9 c. 1882 a. Urban I., Therap.Gaz. (3): 209-210, 1882 b y págs. 194-198. 1883. Tipo (establecido en Urban, 1882 a): MÉXICO occident., locis siccis saxosis, 1882, Parke, Davis \& Co. s.n. (B destruido; lectotipo aquí designado CORD!; isotipo W!).

Hojas concoloras o discoloras, pecíolo 1,5-6 mm long., lámina 15-26(-30) x 5-10 mm, a veces con pelos sobre las venas, haz glabra, parda en herbario, envés castaño en herbario, con pelos glandulares capitado-sésiles, borde ligeramente revoluto. Pedúnculo floral (0,7-)1-2 mm long., pedúnculo fructífero acrescente, 2$4,5 \mathrm{~mm}$ long., profilos casi glabros, algunos pelos sobre ia vena media; cáliz 4,5-7 $\mathrm{mm}$ long., tubo 2,3-3 mm long., pétalos glabros, 6-9 mm long., placentas 3-ovuladas; estilos glabros.

Material examinado. Méxıco. Consoquitla, $X$ 1841, Liebmann 4276 (C, F, GH, US). Baja California Sur: Mun. de los Cabos, Mesa de Santa Anita, Km 12 Carr. San José del Cabo-La Paz, 110 m, 7 IX 1984, Agundez 8 (MEXU); $23 \mathrm{~km}$ al S de San José del Cabo, carr. a Cabo San Lucas, $22^{\circ} 55^{\prime} \mathrm{N} 109^{\circ} 52^{\prime}$ W, 4 III 1992, Campos et al. 4505 (MEXU); near Gulf between San José del Cabo and Cape San Lucas, 21 X 1941, Hammerly 411 (US); I 1880, Le Roy 5 (GH); La Paz, 20 I-5 II 1890, Palmer 11 (C, F, K, MEXU, NY, US). Colima: Manzanillo, 1-31 XII 1890, Palmer 1071 (BM, GH, K, MO). Chiapas: Mun. La Trinitaria, 6 km
NE de La Trinitaria, 1550 m, 2 XI 1976, Breedlove 41195 (MEXU). Guerrero: Mun. Tecpan, Torre de microondas cerca de Papanoa, $54 \mathrm{~km}$ al NO de Tecpan, 380 m, 27 X 1982, Koch \& Fryxell 82219 (MEXU, TEX, US). Querétaro: Querétaro, Hda. de Jurica, 8 XI 1954, Fuentes s.n. (MEXU). Quintana Roo: en la brecha al ingenio Álvaro Obregón, a 5 $\mathrm{km}$ W de Ucum, 17 I 1981, Cabrera \& Torres 1013 (CAS, MEXU); Km 2,5 carretera Vigía ChicoF.Carrillo Puerto, $19^{\circ} 47^{\prime} \mathrm{N} 87^{\circ} 36^{\prime} \mathrm{W}, 3 \mathrm{~m}, 13$ XI 1985, Villanueva 502 (MEXU). San Luis Potosí: near San Luis Potosí, 18-20 VIII 1902, Palmer 41 (F, GH, MO, NY, US); San Miguelito, 1879, Schaffner 560 (B, BM, C, GOET, F, FI, HBG, NY, US). Veracruz: Mun. Cosautlan de C., $3 \mathrm{~km}$ al NE de Limones, $19^{\circ} 21^{\prime} \mathrm{N}$ 9554’W, 900 m, 20 V 1986, Arriaga \& Lopez 224 (MEXU); Zacuapan, Coulter 798 (K); Cuitlahuac, 17 V 1937, Matuda 1448 (A, CTES, K, MEXU, MO, NY); Zacuapan, IX 1906, Purpus 2005 (BM, F, GH, MO, NY, US); Zacuapan, IV 1932, Purpus 16040 (A); La Laja, 0,7 mi S of Corral Falso on road to Pinoltepec, $19^{\circ} 28^{\prime} \mathrm{N} 96^{\circ} 45^{\prime} \mathrm{W}, 2700 \mathrm{ft}, 15 \mathrm{VIII} 1976$, Webster \& Armbruster 20869 (GH). Belize. Near Manatee Lagoon, 25 XI 1905, Peck 228 (GH, K). Belize: Hatteville Boom Road, 3 II 1970, Dieckman 113 (MO); $20 \mathrm{~km}$ W of Belize on Western Highway, 24 III 1967, Dwyer et al. 662 (MEXU, MO); Bakers Pine Ridge, VI-VIII 1936, Lundell 6981 (C, DS, F, GH, MEXU, $\mathrm{MICH}, \mathrm{MO}, \mathrm{NY}, \mathrm{US}$ ); Burrellboom, ca. $30 \mathrm{ft}, 22 \mathrm{III}$ 1970, McDaniel 12851 (F, MO); $1 \mathrm{mi} \mathrm{W}$ of Boomtown, 17 IX 1936, O’Neill 8786 (GH, MICH); $1 \mathrm{mi} \mathrm{W}$ of $\mathrm{j}$. with rd. to Ferguson Bank c. 8 mi E of Hattieville, along Hector Creek Rd., 16 VIII 1971, Sorensen 7079 (MO); Western Highway, Mile 30, The Place, 16 IX 1980, Whitefoord 2509 (MEXU, MO). El Cayo: El Cayo, 15 II 1931, Bartlett 11519 (A, F, MICH, US). Orange Walk: $25,5 \mathrm{~km}$ al SW de Orange Walk Town, 4 VI 1985, Grether \& Quero 1943 (MEXU). Guatemala. Izabal: Mun. El Estor, La Mina de Exmibal, al E del Estor, $15^{\circ} 31^{\prime} \mathrm{N} 89^{\circ} 23^{\prime} \mathrm{W}, 50 \mathrm{~m}, 17$ VII 1988, Tenorio et al. 14585 (CTES, MO). CUBA Holguín: Moa, near Centeno, 23 VII 1941, [Bros.] León et al. 20213 (GH); Moa, 26 IIl 1942, [Bros.] León et al. $20760(\mathrm{GH})$; Moa, Playa de la Vaca, 16-23 IV 1943, Marie-Victorin et al. 21551 (GH, NY). Villa Clara: Mordazo, 24 VII 1920, [Bro.] Leon 9270 (GH, NY); $10 \mathrm{~km} \mathrm{~W} \mathrm{of} \mathrm{Santa} \mathrm{Clara,} \mathrm{VI-VIII} \mathrm{1941,} \mathrm{Howard}$ 5107 (GH); $6 \mathrm{~km}$ W of Santa Clara, 15 VII 1936, Smith et al. 3136 (GH, US). Haití. Massif de la Salle, Morne Fort Jacques, on walls at Fort Jacques, ca. 1300 m, 7 IX 1924, Ekman 1014 (GH, K, NY, S, US).

Distribución y fenología. La var.aphrodisiaca está restringida al hemisferio norte, vive en México, América Central, Cuba y Haití, de 10 
a $1550 \mathrm{~m}$ de altitud. Florece y fructifica todo el año, la mayor parte de los especímenes fueron recolectados en el verano.

Nombres vulgares: "damiana" (México, Agundez 8); "yerba del moro" (México, Fuentes s.n.).

Uso medicinal. Se emplea para recobrar los nervios y como remedio contra la impotencia (Urban 1883b).

Obs. En flores longistilas, el gineceo es 0,4$1,5 \mathrm{~mm}$ más largo que el androceo. En flores brevistilas, el androceo es 1,1-2,4 mm más largo que el gineceo.

\section{Turnera hebepetala Urb.}

Fig. 18, Mapa 12

Urban I., Jahrb. Königl. Bot. Gart. Berlin 2: 127. 1883. Urban I. en Martius C.F.P., Fl. bras. 13(3): 147. 1883. Lectotipo (aquí designado): BRASIL. Piauí: prope Oeiras, IV 1839, Gardner G. 2062 (K!; isotipos: FI!, P!, US!, W!).

Arbusto hasta $2 \mathrm{~m}$, ramas viejas con corteza pardo-negruzca longitudinalmente agrietada, lenticelas circulares, ritidoma desprendiéndose en tiras, cicatrices foliares prominentes, con las bases de las estípulas persistentes; ramas de' año con pelos simples, cortos, curvadoantrorsos y pelos glandulares capitado-sésiles; macroblastos y braquiblastos alternantes. Yemas axilares 1-2. Hojas oscuras en seco, frecuentemente dispuestas sobre braquiblastos. Base foliar saliente, abultada. Estípulas trianguiar-subuladas, 1-2 mm long., oscuras, con pelos simples adpresos, la porción basal con borde densamente piloso, a veces con coléteres. Pecíolo 0,5-i,5 mm long., semicilíndrico, indumento como ei del tallo. Lámina angustiobovada u obovada, 4-45 x 1,5-11 mm, relación largo:ancho = 2,1-4,7:1; base largamente atenuada, ápice agudo u obtuso, borde revoluto, a veces plano, con 1-4 dientes en la porción apical, agudos $u$ obtusos, terminados en coléteres cónicos en seco; haz pardo-rojiza, abollada en seco, con pelos simples cortísimos y pelos glandulares esparcidos, envés más claro, punteado, con pelos simples y abundantes pelos glandulares; vena media y 2-4 pares de venas iaterales opuestas o alternas, ángulo de divergencia ca. $25^{\circ}$, hundidas en ia haz, prominentes y estrigosas en el envés, perdiéndose hacia el borde, a veces originando ramas externas hacia los dientes, venas terciarias ausentes, venación menor inconspicua. Flores solitarias, axilares, heterostilas. Pedúnculo cilíndri$\mathrm{co}$, inserto en la base foliar, 1,5 $\mathrm{mm}$ long. Profilos elípticos, 1,6-3 x 0,3-0,7 mm, margen entero o denticulado, opuestos en la base del receptáculo, indumento como el de las hojas. Cáliz 4-5,5 mm long., cara externa con pelos simples cortos antrorsos, pelos crespos y pelos glandulares, cara interna glabra, tubo 1,7-2 mm long., lóbulos triangulares, los externos completamente pilosos por fuera, los internos con la vena media y la porción basal de las venas laterales pilosas, a veces sólo la vena media, bordes membranáceos, glabros o pilosos, ápice agudo. Corola blanca, más larga que $\mathrm{el}$ cáliz, uña glabra soldada al tubo, lámina obovada $8 \times 2 \mathrm{~mm}$, cara interna amarilla en la base, mitad basal pilosa en ambas caras, borde ciliado. Filamentos estaminales complanadosubulados en seco, laxamente pilosos, tocándose por los bordes en la base formando un anillo de 0,05-0,2 $\mathrm{mm}$ y soldados 0-0,5 $\mathrm{mm}$ al tubo, $2 \mathrm{~mm}$ long. en flores longistilas, 4,8-6,5 $\mathrm{mm}$ long. en flores brevistilas, anteras ovadas, $0,8 \times 0,5 \mathrm{~mm}$, dorsifijas, base ligeramente emarginada, ápice obtuso no recurvado a la dehiscencia. Ovario ovoide, 1,5-2 mm long., estrigoso, pelos simples y pelos glandulares, estilos cilíndricos, 2,7 mm long., pilosos en flores longistilas, 1,6-2 mm long., con algunos pelos en la base en flores brevistilas, estigma $0,3 \mathrm{~mm}$ long., pauci-ramoso. Fruto ovoide, envuelto por el perianto y androceo persistentes, cara externa granulosa, pilosa, cara interna glabra, lustrosa, castaña. Semilla obovoide, 1,5-1,8 x $1 \mathrm{~mm}$, exóstoma conoidal asimétrico, rafe linear, cálaza redondeada, obtusa, epidermis glabra, episperma reticulado, aréolas transrectangulares, algunas cuadrangulares; arilo más corto que la semilla.

Material examinado. Brasil. Bahia: Mun. Bom Jesus da Lapa, Juá, 14 II 1991, Hatschbach et al. 55140 (CTES, MBM, MO); Juá, 500 m, 5 IV 1992, Hatschbach et al. 56611 (CTES, ESA, MBM, SP, SPF); Mun. 


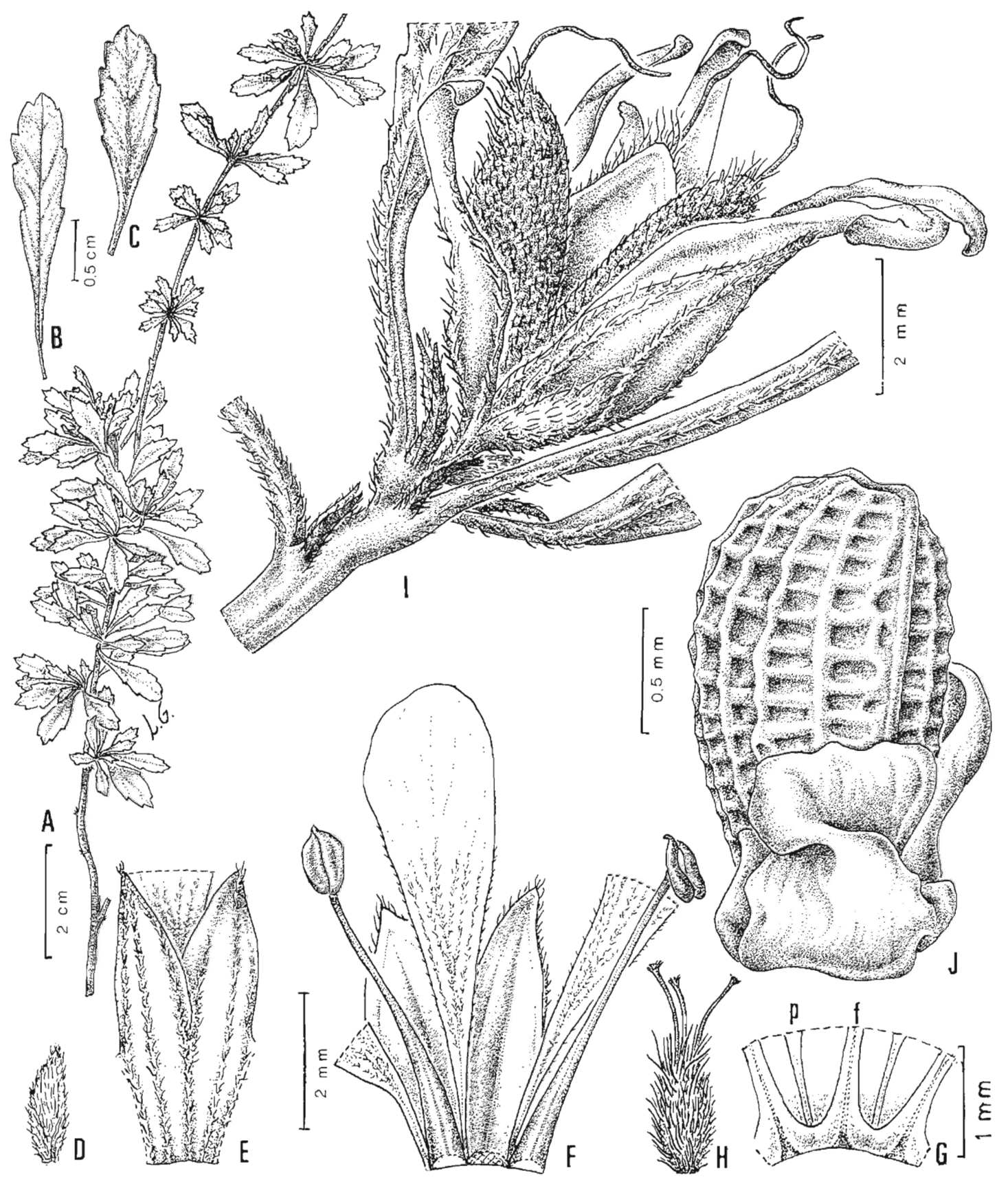

Fig. 18. Turncra hebepetala. A, rama florífera. B-C, hojas. D, profilo. E, porción del cáliz, cara externa: lóbulos externo (izquierdo) e interno (derecho), con un pétalo seccionado. F, porción del cáliz, cara interna, con pétalos y estambres adnatos; flor brevistila; se ha marcado la cicatriz dejada al desprender un estambre. G, porción de la base del cáliz, cara interna, con pétalos (p) y filamentos estaminales ( $f$ ) adnatos, las bases de los mismos coherentes formando un brevísimo anillo estaminal. H., gineceo de flor brevistila. I, porción de tallo mostrando las bases foliares y las estípulas persistentes, y un fruto abiertu, vestido con los restus florales y con los estilos persistentes. J, semilla con arilo, vista lateral-rafeal (A-C: Hatschbach ct al. 55140; D-]: Hatschbach ct al. 56611). 
Riacho de Santana, Barauninha, 550 m, 19 IV 1996, Hatschbach et al. 65059 (CTES, GH, LIL, MBM). Piauí: Oeiras, 1877-78, Jobert 1040 (P); Porcos, 15 XI 1979, Santino 236 (HRB, IPA). Rio de Janeiro: São Fidelis, près de Campos, 10 II 1876, Glaziou 9802 (C, K, P; B, destruido, Foto F 13584!) [localidad dudosa, Urban (1883a) indica "cult. "].

Distribución. Especie rara, hallada en unas pocas localidades de Bahia y Piauí, entre 500 y $600 \mathrm{~m}$ de altitud. Florece y fructifica desde noviembre hasta abril.

Obs. En flores longistilas, el gineceo es 2,2 $\mathrm{mm}$ más largo que el androceo. En flores brevistilas el androceo es $2,4 \mathrm{~mm}$ más largo que el gineceo.

El desarrollo del anillo estaminal es variable en T.hebepetala, en la misma planta se encuentran flores aparentemente sin anillo o con anillo de $0,1 \mathrm{~mm}$ long., visible con microscopio estereoscópico (Fig. 18 F-G). Cuando su altura es menor que $100 \mu \mathrm{m}$, se evidencia claramente sólo mediante cortes anatómicos seriados (González, 2000).

Esta especie presenta coléteres standard en los profilos, en las estípulas y en los dientes foliares apicales; los dientes foliares basales poseen coléteres sésiles (González, 1998).

Serie Papilliferae Urb.

Mapa 13

Urban I., Jahrb.Königl.Bot.Gart.Berlin 2: 129. 1883. Urban I. en Martius C.F.P., Fl.bras. 13(3): 149. 1883.

Arbustos 0,2-1 m alt. con pelos simples y pelos capitado-estipitados (única serie del género con tal tipo de pelos glandulares). Hojas con estípulas diminutas o reducidas a coléteres;

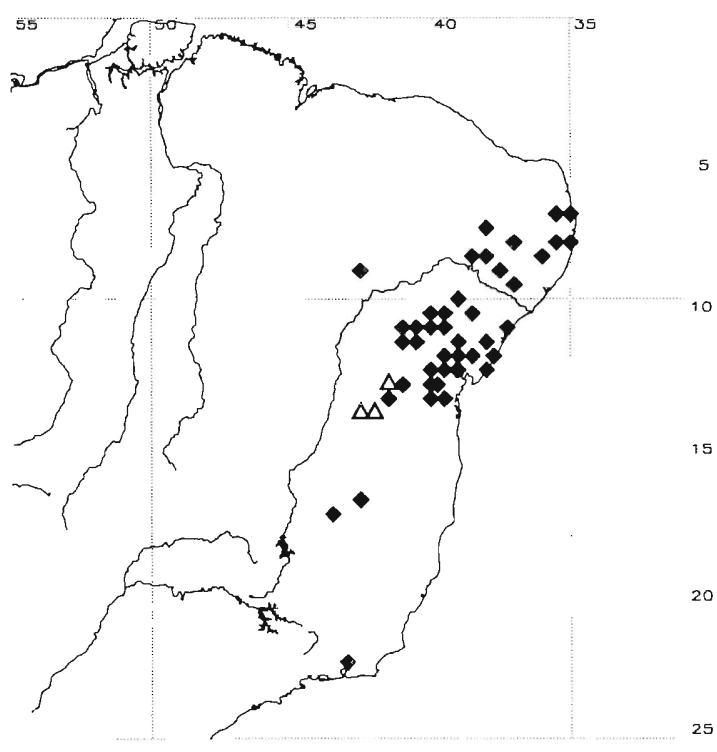

Mapa 13. Distribución de la serie Papilliferae: Turnera caatingana $\Delta$ y T.chamaedrifolia

nectarios ausentes. Flores axilares solitarias, imperfectamente heterostilas. Pedúnculo floral desarrollado, inserto en la base foliar. Profilos lineares. Pedicelo nuio o muy breve. Sépalos soldados entre sí en el tercio basal o menos; lóbulos de prefloración quincuncial. Filamentos estaminales adheridos al tubo en su base, por su cara externa, giabros; anteras dorsifijas, obtusas, ápice recurvado a la dehiscencia. Ovario piloso, estilos glabros, estigmas penicilados. Fruto granuloso. Semilla corta, obovoide, cálaza apical plana; episperma estriado reticulado, con aréolas medianas en relación con el tamaño de la semilla, epidermis lisa; arilo unilateral, igual o más corto que la semilla.

Especie tipo (aqui designada): Turnera chamaedrifolia Cambess.

\section{Clave para las especies de la serie Papilliferae}

1. Hojas discoloras, no viscosas, $2,5-10 \mathrm{~cm}$ long.

1. Hojas generalmente concoloras, viscosas, aromáticas, 1-3,5 $(-4,2) \mathrm{cm}$ long.

41. T. caatingana Arbu

42. T. chamaedrifolia Cambess. 


\section{Turnera caatingana Arbo sp. nov.} Fig. 19, Mapa 13

Frutex 0,4-1,2 $m$ altus, rami hornotini hirsuti, pills simplicibus et pulis glandularibus brevissime stipitatis. Folia discolora 2,5-10 cm longi, stipulis $0,3-0,5 \mathrm{~mm}$ longis. Flores heterostylt in axillis solitariis. Pedunculi ad prophylla petiolz usque 1,5 mm adnatz. Pedicell nulli. Petalis luters. Filamenta glabra bast tubo imo adnata.

Tipo: BRASIL. Bahia: Mun. Caetité, $20 \mathrm{~km} \mathrm{E} \mathrm{de}$ Caetité, camino a Brumado, aprox. $14^{\circ} 08^{\prime} \mathrm{S} 42^{\circ} 15^{\prime} \mathrm{W}$, ca. 500 m, 20 XI 1992, Arbo M.M., R.Mello-Silva $\mathcal{E}$ J.Vicente Nunes 5645 (holotipo: SPF; isotipos: CTES, HUEFS, K).

Arbusto 0,40-1,20 m, uni- o pluricaule, simple o ramificado, tallos cilíndricos con estrías longitudinales, ramas viejas con cicatrices salientes, ramas del año hirsutas hacia el ápice, con pelos simples 1,5-2 mm long. y pelos capitado-estipitados. Yemas axilares 2-3, la basal florífera, ramas seriales desarrolladas. Hojas herbáceas, abolladas en vivo, discoloras. Estípulas 2-3 pares, pilosas, reducidas, 0,3-0,5 $\mathrm{mm}$ long., terminadas en coléteres, soldadas a la base foliar saliente y persistente o a veces desplazadas sobre la base del pecíolo. Pecíolo acanalado en la haz, 3-20 mm long., indumento como el del tallo. Lámina ovada, angustiovada o elíptica, raramente obovada, $25-100 \times$ 13-53 mm, relación largo:ancho $=1,8-2,6: 1$; base atenuada, cuneada o redondeada, borde aserrado-crenado, ligeramente revoluto, dientes agudos terminados en coléteres, ápice generalmente agudo; haz verde oscura, olivácea en seco, venas hundidas, pelos simples largos, sedosos, antrorsos, oblicuamente orientados, de base cónica, escasos o abundantes, y pelos capitado-estipitados escasos; envés verde claro, hojas nuevas con envés blanquecino o ceniciento, densamente piloso, pelos simples delgados y pelos capitado-estipitados; venas secundarias 6-9 pares, ángulo de divergencia 36$50^{\circ}$, rectas o incurvas, dirigidas a las escotaduras, con ramas delgadas, ascendentes hacia los dientes; venas terciarias a veces visibles en el envés. Flores axilares, solitarias, heterostilas. Pedúnculo cilíndrico, brevemente soldado en la base (hasta $1,5 \mathrm{~mm}$ ) al pecíolo, 5-10 mm long. Profilos lineares o lanceolados, 8-15 $\times 1-2 \mathrm{~mm}$, opuestos o ligeramente alternos en el ápice del pedúnculo, 1-3-nervados, con pelos simples 1-2 $\mathrm{mm}$ long. y pelos capitadoestipitados. Pediceio 0-1 mm long. Cáliz verde claro, 10-14 mm long., tubo 2,5-4 mm long., por fuera con pelos simples largos y cortos $y$ pelos capitado-estipitados, por dentro con pelos simples sedosos; lóbulos con pelos más largos hacia el ápice por fuera, 2-2,5 mm long., glabros por dentro, los internos con bordes membranáceos, ápice cuculado, con un mucrón piloso 1-4,5 mm long. Pétalos amarillocremosos, envés blanquecino, en flores marchitas color salmón, 3-5 mm más largos que el cáliz; uña pilosa, soldada al tubo, lámina obovada, $12-13 \times 9-12 \mathrm{~mm}$, borde superior redondeado o brevemente apiculado. Filamentos estaminales glabros, complanado-subulados en seco, soldados en la base 0,5-0,6 mm al tubo, 4-4,5 mm long. en flores longistilas, 3-4,5 $\mathrm{mm}$ long. en flores brevistilas; anteras angustiovadas, $2-3 \times 0,7-1,4 \mathrm{~mm}$, base emarginada, filamento inserto a $0,8-1 \mathrm{~mm}$ de la base, ápice recurvado a la dehiscencia, agudo o con apículo $0,2 \mathrm{~mm}$ long.; polen pardo-negruzco o purpúreo en vivo. Ovario ovoide o subesférico, hirsuto, 2-3,5 mm long.; estilos cilíndricos, glabros, erectos, $6 \mathrm{~mm}$ long. en flores longistilas, ca. $3 \mathrm{~mm}$ long. en flores brevistilas; estigmas amarillos, 0,5-1 mm long. (más largo en flores longistilas). Fruto subesférico, ca. 5 mm diám., cara externa granulosa, pilosa, cara interna glabra. Semilla obovoide, ligeramente curvada, 1,5-1,7 x 0,7-1 mm, relación largo: ancho = 1,6-2:1; exóstoma cónico, rafe linear no prominente, cálaza apical, lateral, redondeada, no prominente, episperma reticulado, negruzco a la madurez, aréolas subcuadrangulares, epidermis lisa; arilo de borde lobulado, más corto que la semilla.

Paratipos. BRASIL. Bahia: BR-030, $7 \mathrm{~km} \mathrm{E}$ de Caetité, camino a Brumado, $14^{\circ} 04^{\prime} \mathrm{S} 42^{\circ} 26^{\prime} \mathrm{W}, 800$ 900 m, 22 I 1997, Arbo et al. 7643 (CEPEC, CTES); Mun. Caetité, Chapada Diamantina, 18 V 1983, Hatschbach 46557 (MBM); Mun. Abaíra, ca. $5 \mathrm{~km} \mathrm{SW}$ de Abaíra, ao longo da estrada Piatã-Abaíra, 840 m, 14 II 1992, Queiroz 2611 (HUEFS).

Distribución y fenología. Propia cie la "caatinga y mata de cipó", en suelos rojos, entre 500-900 m de altitud. Su período de flora- 


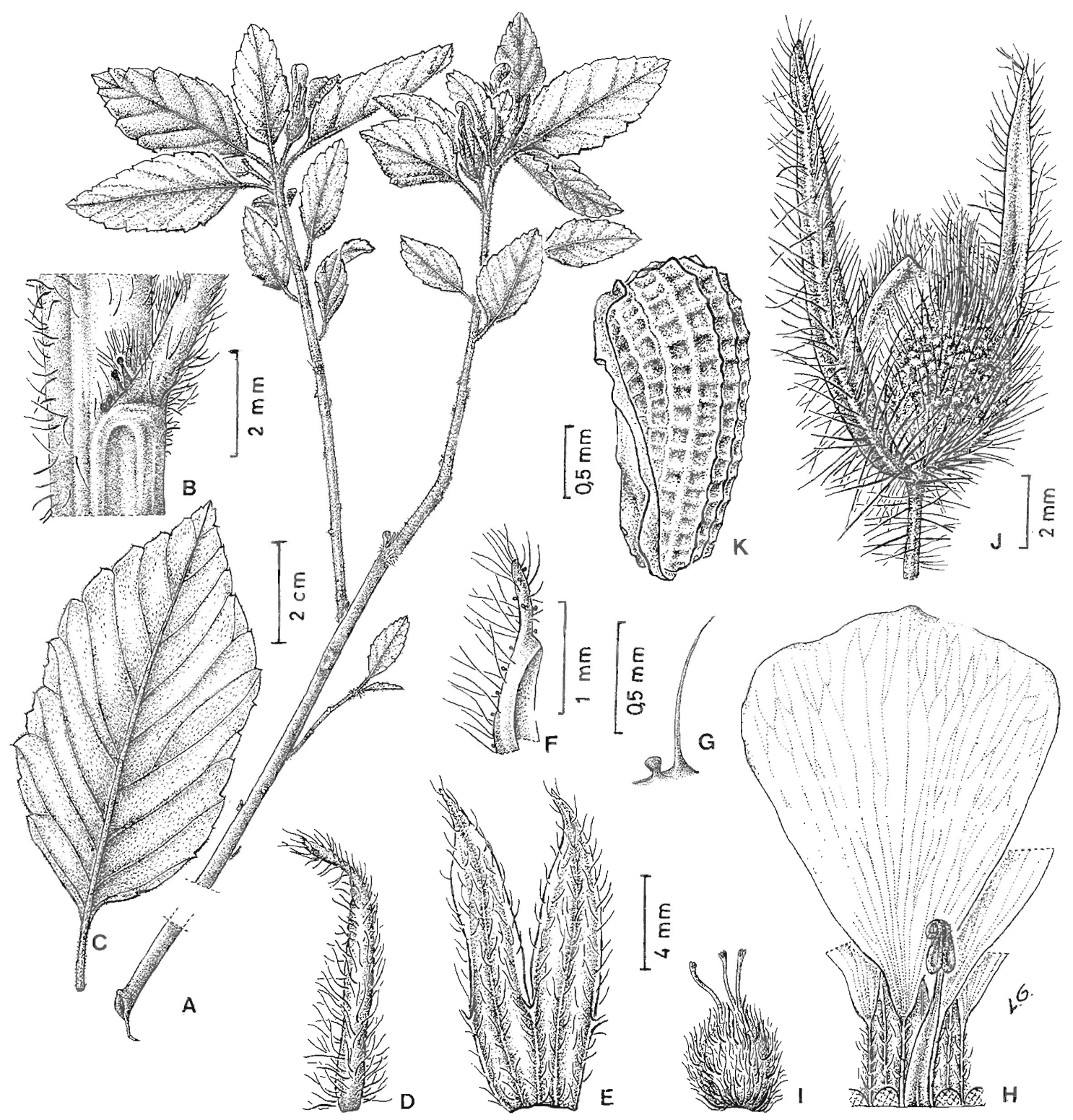

Fig. 19. Turnera caatingana. A, rama florífera. B, detalle de un nudo mostrando la base foliar, el peciolo y ias estípulas terminadas en coléteres. C, hoja. D, profilo. E, porción del cáliz, cara externa. F, extremo superior de un sépalo interno mostrando el mucrón. $G$, detalle de un pelo glandular estipitado y un pelo simple. I1, porción del cáliz, cara interna, con pétalos y estambre adnatos, flor brevistila (se han marcado las cicatrices dejadas al desprender otros estambres). I, gineceo de flor brevistila. J, fruto abierto con profilos. $K$, semilla con arilo, vista lateral (Arbo et al. j645). 
ción conocido se extiende desde noviembre hasta mayo.

Obs. En flores longistilas el gineceo es 1-5 $\mathrm{mm}$ más largo que el androceo. La forma brevistila aparentemente no está bien diferenciada, los filamentos estaminales presentan la misma longitud que en las flores longistilas, de manera que en todas las flores analizadas el androceo es 1,5-2,5 mm más largo que el gineceo, quedando el estigma en contacto con la base de las anteras.

La base foliar es saliente y persistente, el pecíolo está articulado por encima de la inserción del pedúnculo floral. La absición de la hoja se produce a la altura de la articulación; después que se han desprendido las hojas floríferas es posible ver la cicatriz circular del pedúnculo floral hacia arriba, y orientada lateralmente la cicatriz del pecíolo.

\section{Turnera chamaedrifolia Cambess.}

Fig. 20, Mapa 13

Saint Hilaire A., A. de Jussieu \& J. Cambessèdes, Fl.Bras.merid. 2: 221. 1830 Turnera chamaedryfolia Cambess. en Urban I., Jahrb.Königl.Bot.Gart.Berlin 2: 129. 1883. Urban I. en Martius C.F.P., Fl.bras. 13(3): 149, tab.48 III. 1883. Holotipo: BRASIL. Minas Gerais: Minas Novas ad ripas rio Jequitinhonha, Saint Hilatre A. B 1531 (P!).

Arbusto $60-80 \mathrm{~cm}$, erecto o decumbente, unipluricaule, muy ramificado, tallos cilíndricos con estrías longitudinaies, ramas basales radicantes, las del año con pelos simples largos entremezclados con pelos cortos crespos y abundantes pelos glandulares capitadoestipitados, 0,1 $\mathrm{mm}$ long. Yemas axilares 2-3, la basal florífera, ramas seriales desarrolladas. Hojas aromáticas, viscosas, con estípulas reducidas a coléteres $0,2 \mathrm{~mm}$ long., soldados a la base foliar pilosa, saliente y persistente. Pecíolo semicilíndrico, 2-7 $\mathrm{mm}$ long., indumento como el del tallo. Lámina herbácea, ovada, angustiovada o elíptica, a veces obovada, 10$35(-42) \times 4-21(-27) \mathrm{mm}$, relación largo:ancho = 1,4-3:1; base atenuada c cuneada, borde aserrado, revoluto, dientes agudos terminados en prominencias glandulares, ápice generalmente agudo; haz pardo-obscura en seco, venas hundidas, pelos simples antrorsos, oblicuamente orientados, de base hinchada y pelos capitado-estipitados; envés castaño claro, con pelos simples delgados y pelos capitadoestipitados muy densos; venas secundarias 58 pares, rectas, ángulo de divergencia $37-50^{\circ}$, dirigidas hacia las escotaduras del borde, con ramas delgadas, ascendentes o descendentes, dirigidas a los dientes; venas terciarias a veces visibles en el envés. Flores axilares, solitarias, trimorfas: longistilas, homostilas y brevistilas. Pedúnculo cilíndrico, libre o soldado hasta 2 $\mathrm{mm}$ al pecíolo, 4-8(-14) $\mathrm{mm}$ long. Profilos lanceolados, (1,6-)4-6,5 x (0,2-)0,5-1 mm, opuestos o ligeramente alternos en el ápice del pedúnculo, con pelos simples largos y cortos y pelos glandulares entremezclados, más largos sobre el envés. Pedicelo 0-0,5 mm long. Cáliz campanulado, (4-)8-15 mm long., tubo (1-)1,5$3 \mathrm{~mm}$ long., por fuera con pelos capitadoestipitados y generalmente con pelos simples largos y cortos, por dentro con pelos simples cortos; lóbulos con pelos más largos que el tubo en la cara externa, glabros en la haz, los internos con bordes membranáceos, ápice ligeramente cuculado, con mucrón 0,5-1 mm long. Corola frecuentemente igual al cáliz, hasta 1,5 $\mathrm{mm}$ más larga o $2 \mathrm{~mm}$ más corta, pétalos totalmente amarillos o con mácula rojiza o purpúrea en la base, rosados en flores pasadas; uña pilosa, soldada al tubo, lámina obovada, (4-)8,5$14 \times(2-) 4-11 \mathrm{~mm}$, borde superior redondeado o apiculado. Filamentos estaminales glabros, complanado-subulados en seco, soldados brevemente en la base al tubo, ápice arqueadoexcurvo; $4 \mathrm{~mm}$ long. en flores longistilas, 4,7-5 $\mathrm{mm}$ long. en flores brevistilas; anteras angustiovadas, $1-2 \times 0,4-0,8 \mathrm{~mm}$, base emarginada, filamento inserto a $0,4 \mathrm{~mm}$ de la base, ápice recurvado a la dehiscencia. Ovario elipsoide, hirsuto, 2-2,5 mm long., placertas 430-ovuladas; estilos cilíndricos, glabros, erectos, 3,5 mm long. en flores longistilas, excurvos, $2 \mathrm{~mm}$ long. en flores brevistilas, estigma paucirramuloso, 0,5-1 mm long. Fruto subesférico, 3,5-8 mm long., valvas ovadas, cara externa granulosa, pilosa, cara interna glabra, lustrosa, jaspeada o de color castaño. Semilla obovoide, recta, 1,4-1,7 x 0,7-1,1 mm, relación largo:ancho = 1,3-2,4:1, exóstoma cónico, rafe linear no prominente, cálaza apical, lateral, redondeada, no prominente, episperma reticulado, negruzco a la madurez, aréolas cuadran- 


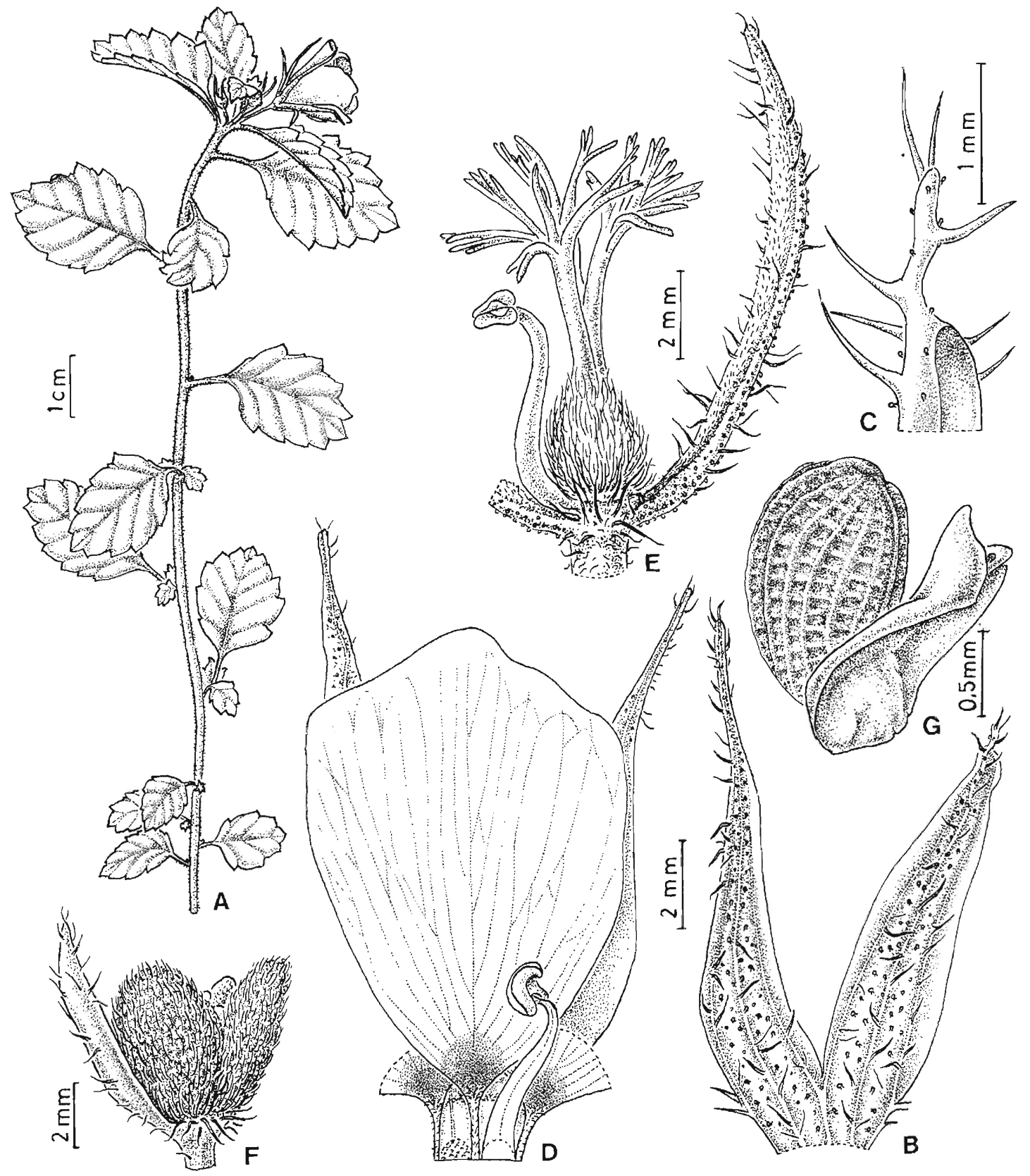

Fig. 20. Turnera chamaedrifolıa. A, rama florífera. B, porción del cáliz, cara externa: lóbulos externo (izquierdo) e interno (derecho). C, extremo superior de un sépalo interno mostrando el mucrón. D, porción del cáliz, cara interna con pétalos y estambre adna tos, flor longistila (se ha marcado la cicatriz dejada al desprender un estambre). E, gineceo con un estambre (flor longistila), un profilo entero y el otro seccionado. F, fruto abierto con un profilo. G, semilla con arilo, vista lateral, la rafe hacia la derecha (Hatschbach et al. 56982 bis). 
gulares, transrectangulares o hexagonales, epidermis lisa; arilo de borde lobulado, más corto o tan largo como la semilla, células papilosas.

Material examinado. Brasil. Sin localidad, Glocker s.n. (BM); 1843, Moricand s.n. (K). Alagoas: Mun. Pão de Açucar, Serra de Pão de Açucar, 10 VI 1981, Lyra et al. 188 (MAC); Mun. Agua Branca, Serra do Caraman, 14 IX 1948, Monteiro Neto 145 (RB). Bahia: 2 km S de Itaberaba, camino a Milagres, 23 I 1980, Arbo et al. 2538 (CTES); Mun. Jacobina, $14 \mathrm{~km}$ SW de BR-324, camino a Varzea Nova, aprox. $1^{\circ} 07^{\prime} \mathrm{S} 40^{\circ} 49^{\prime} \mathrm{W}$, ca. 700 m, 30 XI 1992, Arbo et al. 5445 (CTES, GH, K, HUEFS, LIL, SPF, UB, YUTO); Jacobina, $11^{\circ} 13^{\prime} \mathrm{S} 40^{\circ} 30^{\prime} \mathrm{W}, 463 \mathrm{~m}, 30 \mathrm{XI} 1992$, Arbo et al. 5448 (CTES, HUEFS, IPA, K, SPF, YUTO); Mun. Filadelfia, BR-407, $12 \mathrm{~km}$ S de Filadelfia, aprox. 1051'S 4007'W, ca. 450 m, 30 XI 1992, Arbo et al. 5453 (CTES, HUEFS, K, SPF, UB, YUTO); Mun. Itiuba, $14-19 \mathrm{~km}$ W de Itiuba, camino a Filadelfia, $10^{\circ} 42^{\prime} \mathrm{S} 40^{\circ} \mathrm{W}$, ca. $600 \mathrm{~m}, 1$ XII 1992, Arbo et al. 5461 (CTES, HUEFS, K, SPF, YUTO); $10 \mathrm{~km} \mathrm{~W}$ de Coração de Maria, camino a Feira de Santana, aprox. $12^{\circ} 15^{\prime} \mathrm{S} 38^{\circ} 50^{\prime} \mathrm{W}$, ca. $200 \mathrm{~m}, 2$ XII 1992, Arbo et al. 5507 (CTES, HUEFS, SPF, YUTO); BR-101, 20 km S de Feira de Santana, camino a Cachoeira, aprox. $12^{\circ} 26^{\prime} \mathrm{S} 38^{\circ} 56^{\prime} \mathrm{W}$, ca. $250 \mathrm{~m}, 3$ XII 1992, Arbo et al. 5526 (CTES, GH, HUEFS, K, SPF); Mun. Mucujê, 31 km SW de Mucujê, camino a Barra da Estiva, aprox. $13^{\circ} 13^{\prime} \mathrm{S} 41^{\circ} 28^{\prime} \mathrm{W}$, ca. $1100 \mathrm{~m}, 25 \mathrm{XI} 1992$, Arbo et al. 5761 (CTES, HUEFS, GH, K, SPF, UB, YUTO); Mun. Governador Mangabeira, BR-101, proximidades de la represa Pedra do Cavalho sobre el río Paraguaçu, aprox. $12^{\circ} 35^{\prime} \mathrm{S} 39^{\circ} 01^{\prime} \mathrm{W}, 100-200 \mathrm{~m}, 14 \mathrm{I}$ 1997, Arbo et al. 7217 (CEPEC, CTES, GH, K, LIL); Mun. Candeal, $8 \mathrm{~km}$ al $\mathrm{N}$ de Tanquinho, camino a Ichu, aprox.

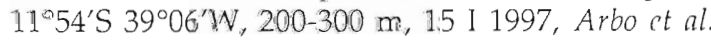
7251 (CEPEC, CTES); $5 \mathrm{~km}$ al SE de Queimadas, camino a Serinha, apro\%. $11^{\circ} 04^{\prime} \mathrm{S} 39^{\circ} 35^{\prime} \mathrm{W}$, ca. 300 m, $15: 1997$, Arbo et al. 7272 (CEPEC, CTES, iLLS); Rio jacurici, $7 \mathrm{~km} \mathrm{~N}$ de Queimadas camino a Cansanção, $10^{\circ} 55^{\prime} \mathrm{S} 39^{\circ} 38^{\prime} \mathrm{W}$, ca. 270 m, 16 I 1997 , Arbo et al. 7284 (CEPEC, CTES, CUVC, U); $11 \mathrm{~km}$ al E de Itiúba, camino a Cansanção, aprox. $10^{\circ} 40^{\prime} \mathrm{S}$ 3946’ W, ca. 300 m, 16 I 1997, Arbo et al. 7296 (ASU, CEPEC, CTES, NY, TEX, US); Serra de itiúba, $1 \mathrm{~km}$ al E de Itiúba, camino a Cansanção, aprox. $10^{\circ} 42^{\prime} \mathrm{S}$

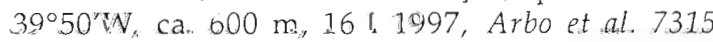
(CEPEC, CTES, K); $22 \mathrm{~km}$ al $\mathrm{W}$ de Itiúba, camino a Filadelfia, aprox. ${ }^{1} 0^{\circ} 43^{\prime} \mathrm{S} 40^{\circ} 03^{\prime} \mathrm{W}$, ca. $400 \mathrm{~m}, 16$ I 1997, Arbo et al. 7325 (CEPEC, CTES); camino de Filadelfia a Pindobaçu, a $14 \mathrm{~km}$ de la BR-407, 1048'S 40⒈' W, 300-400 m, 16 I 1997, Arbo et al. 7332 (CEPEC, CTES, MA, WIS); BR-324, $12 \mathrm{~km} \mathrm{NW} \mathrm{de}$ ,acobina, camino a Umburanas, aprox. $11^{\circ} 06^{\prime} \mathrm{S}$ $40^{\circ} 36^{\prime} \mathrm{W}$, ca. $600 \mathrm{~m}, 17$ I 1997 , Arbo et al. 7371 (CEPEC, CTES, MICH, SI); BA-426, $7 \mathrm{~km}$ al SW de Várzea Nova, camino a Morro do Chapéu, aprox. $11^{\circ} 18^{\prime} \mathrm{S} 40^{\circ} 58^{\prime} \mathrm{W}, 700-800 \mathrm{~m}, 17 \div 1997$, Arbo ct al. 7427 (CEPEC, CTES); 10-15 km al $W$ de Cãpão da Volta, camino a jussiape, aprox. $13^{\circ} 30^{\prime} \mathrm{S} 41^{\circ} 30^{\prime} \mathrm{W}$ 1100-1200 m, 20 I 1997, Arbo et al. 7584 (CEPEC, CTES); Itapuá, III 1961, Athayde s.n. (RB); Itaberaba, Pastc Buffel, 18 VI 1981, Bastos 99 (CTES, MO); Ipirá, Faz. Calderão, 18 VIl 1984, Bastos 502 (ALCB, MO);

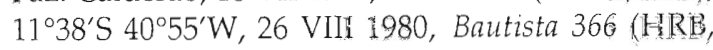
HUEFS); Aramary, 21 XII 1922, Campos Porto 1343 (RB); Mun. Conceição de Feira, margem esquerda do Rio Paraguaçú, 12³2'35"S 3903'06"W, 17 II 1981, Carvalho et al. 538 (ALCB, CTES); Mun. Jequié, Km 7 da estrada Jequié-Ipiaú, 10 II 1983, Carvalho \& Plowman 1586 (CTES, F); Mun. Maracás, 2 km na estrada Maracás/Planaltina, 20 IV 1983, Carvalho et al. 1850 (CTES); Mun. Riachão do Jacuipe, ca. 30 km na estrada de Riachão do Jacuipe para Capim Grosso, 14 III 1990, Carvalho \& Saunciers 2756 (CTES); Mun. Jacobina, ca. $20 \mathrm{~km}$ na rodovia Jacobina / Morro do Chapéu, 15 III 1990, Carvalho \& Saunders 2815 (CTES); Mun. Tucano, Dist. Caldas do Jorro, estrada que liga Caldas do !orro ao Rio Itapicurú, 1 III 1992, Carvalho \& Hind 3865 (CTES); entre Senhor do Bomfin e Gavião, 9 VIII 1964, Castellanos \& Duarte 471 (HB); a $17 \mathrm{~km}$ de Jequié, 11 VII 1964, Castellanos 25081 (CTES), entre Gavião e Riacho Jacuípe, en direção á Petrolina, 9 VIII 1964, Castellanos 25392 (CTES, GUA); Mun. Jacobina, proximidades do Hotel Serra do Ourn, $11^{\circ} 11^{\prime} \mathrm{S} 40^{\circ} 31^{\prime} \mathrm{W}, 650 \mathrm{~m}, 27 \mathrm{VI}$ 1983, Coradm et al. 6142 (CEN, CTES); Ferro Doido, 17 V 1975, Costa \& Barroso s.n. (ALCB); $36 \mathrm{~km}$ de Jequié, 11 VII 1964, Duarte \& Castellanos 352 (CTES, HB); Itapoa at :agoa do Abaeté (E of Salvador), 1020 m, 23 I 1976 , Davis 61044 (UEC); Mun. Salvador, Dunas do Abaeté, $12^{\circ} 56^{\prime} \mathrm{S} 38^{\circ} 21^{\prime} \mathrm{W}, 18$ VIII 1996, Ferrucci et al. 1106 (CEPEC, CTES); Itapoan, 22 VII 1959. Gomes \& Labouriau 879 (RB); Mun. Nossa Senhora dos Milagres, estrada para Itaberaba, $10 \mathrm{~km}$, estradinha para as fazendas Morros e Antonio Romeu, 2 km, 28 i 1973, Gottsberger \& Gottsberger 15-28173 (ULM); Cachoeira, Barragem de Bananeiras, Vale dos Rios Faraguaçú e jacuipe, ca. $12^{\circ} 32^{\prime} \mathrm{S} 39^{\circ} 05^{\prime} \mathrm{W}, 40-120 \mathrm{~m}, \mathrm{~V}$ 1980, Go. Pedra do Cavalo 19 (ALCB, HUEFS, NY); Estação da EMBASA, Cachoeira, Vale dos Rios Paraguaçú e Jacuipe, ca. $12^{\circ} 32^{\prime} \mathrm{S} 39^{\circ} 05^{\prime} \mathrm{W}, 40-120 \mathrm{~m}$, VI 1980, Go. Pedra do Cavalo $16 \hat{3}$ (ALCB, HUEFS); Cachoeira, Barragem de Bananeiras, Vale dos Rios Paraguaçú e Jacuipe, ca. ${ }^{1} 2^{\circ} 32^{\prime} \mathrm{S} 39^{\circ} 05^{\prime} \mathrm{W}, 40-120 \mathrm{~m}$, VII 1980 , Go. Pedra do Cavalo 384 (ALCB, HUEFS); Dias D'Avila, acesso BR-093, 5 VIII 1994, Guedes et al. s.n. (ALCB); Mun. Mata de São João, Santo Antonio, $12^{\circ} 23^{\prime} \mathrm{S} 37^{\circ} 53^{\prime} \mathrm{W}, 21$ IX 1996, Guedes et al. 4058 
(ALCB); Inhambupe, 14 IX 1975, Gusmão 216 (ALCB); $6 \mathrm{~km}$ from Filadelfia on the BA-385 to Itiuba, $400 \mathrm{~m}, 10^{\circ} 45^{\prime} \mathrm{S} 40^{\circ} 04^{\prime} \mathrm{W}, 18$ II 1974 , Harley et al. 16165 (CTES, IPA, K, MO, US); Monte Santo, $10^{\circ} 27^{\prime} \mathrm{S} 39^{\circ} 20^{\prime} \mathrm{W}, 610 \mathrm{~m}, 20$ II 1974, Harley et al. 16402 (CTES, IPA, K, MO, US); Mun. Milagres, Rod. BR116, 16 VII 1982, Hatschbach \& Guimarães 45052 (CTES); Brejoes, 6 km S, 14 IX 1984, Hatschbach 48184 (CTES); Mucugê, $41 \mathrm{~km} \mathrm{S,} 8$ IV 1992, Hatschbach et al. 56851 (CTES, G, GH, K, LIL, LPB, MICH, MO, NY); BR-406, 41 km ESE de Iaçú, Serra da Tartaruga, 10 IV 1992, Hatschbach et al. 56982 (CTES, MBM); Mun. Mata de São João, Praia do Forte, 18 VIII 1995, Hatschbach et al. 63095 (CTES); Estrada BA-5, $15 \mathrm{~km}$ $\mathrm{N}$ de entronque a Tanquinho, 20 IV 1967, Krapovickas 12805 (CTES, F); $10 \mathrm{~km} \mathrm{~S} \mathrm{de} \mathrm{Capim} \mathrm{Grosso,} \mathrm{camino}$ a Baixa Grande, $11^{\circ} 27^{\prime} \mathrm{S} 40^{\circ} 02^{\prime} \mathrm{W}, 150 \mathrm{~m}, 12$ IV 1983 , Krapovickas et al. 38805 (CEN, CTES, G, K, MBivi); Salvador, dunas entre Itapoan e o aeroporto, 1959, Leal Costa 909 (ALCB); Vale do Paraguassu, 26 I 1956, Lordêlo 56-70 (ALCB); Salgado - Castro Alves, 14 III 1956, Lordêlo 56-294 (ALCB); Poções, Cruz das Almas, 6 VI 1956, Lordêlo 56-433 (ALCB); Cravolândia, 13 I 1991, Melo \& França 463 (UB); Tres Braços, Cravolândia, 15 I 1991, Melo \& França 488 (UB); Itatim, Morro do Agenor ou da Madeira, $12^{\circ} 43^{\prime} \mathrm{S}$ 3942'W, 310-430 m, 17 XII 1995, Melo et al. 1405 (CTES, HUEFS); Salvador, dunas de Itapoan, $13 \mathrm{~V}$ 1979, Noblick 1376 (ALCB); Km 33, BR-116, Sainta Bárbara, 30 I 1980, Noblick 1646 (ALCB, CTES, HUEFS, IPA); Salvador, dunas de Itapua, 12056'S $38^{\circ} 21^{\prime} \mathrm{W}, 10$ II 1980, Noblick 1672 (ALCB, CTES, HUEFS, IPA); Piritiba, $11^{\circ} 43^{\prime} \mathrm{S} 40^{\circ} 33^{\prime} \mathrm{W}, 31$ V 1980, Noblick 1854 (ALCB); Feira de Santana, 12 ${ }^{\circ} 15^{\prime}$ S $38^{\circ} 58^{\prime} \mathrm{W}, 20$ IX 1980, Noblick 2035 (HUEFS); Area Controle de Caraiba Metais, $12^{\circ} 29^{\prime} 35^{\prime \prime}-12^{\circ} 40^{\prime}{ }_{1} 7^{\prime \prime} \mathrm{S}$ $38^{\circ} 18^{\prime} 47^{\prime \prime}-38^{\circ} 29^{\prime} 40^{\prime \prime} \mathrm{W}, 14$ XII 1982, Noblick et al. 2476 (HRB, HUEFS); Itaberaba, $25 \mathrm{~km}$ E da cidade, BR$242,12^{\circ} 31^{\prime} \mathrm{S} 40^{\circ} 17^{\prime} \mathrm{W}, 22$ IV 1984, Noblick et al. 3127 (HUEFS); Feira de Santana, Serra de São José, Faz. Boa Vista, $12^{\circ} 15^{\prime} \mathrm{S} 38^{\circ} 58^{\prime} \mathrm{W}, 10 \mathrm{~V}$ 1984, Noblick 3175 (ALCB, CTES, HUEFS); Riachão de Jacuipe, $13 \mathrm{~km}$ SE da cidade, BR-324, $11^{\circ} 22^{\prime} \mathrm{S} 39^{\circ} 49^{\prime} \mathrm{W}, 10$ VII 1985 , Noblick \& L.emos 4094 (HUEFS); Serra Preta, 7 km W do Pontc de Serra Preta, Fazenda Santa Clara, $12^{\circ} 10^{\prime} \mathrm{S} 39^{\circ} 20^{\prime} \mathrm{N}, 17$ VII 1985, Noblick \& Lemos 4145 (HUEFS); Ipecaetá, Fazenda Riachão, Serra Orobozinho, ca. $1 \mathrm{~km}$ da cidade, $12^{\circ} 20^{\prime} \mathrm{S} 39^{\circ} 17^{\prime} \mathrm{W}$, 14 VIII 1985, Noblick \& Lobo 4353 (ALCB, HRB, HUEFS); Pasto Barreiro, Faz. Serra da Monta, Itaberaba, $22: X$ 1981, Olvvetra 366 (HRB); Pasto Caldeirão, Fazenda Serra da Monta, Itaberaba, 10 XI 1982, Oliveira 521 (HRB, MO); São Gonçalo cios Campos, Estação do IBF, 29 IV 1985, Oliveira 3 (HRB); Jacobina, margem esq. do Rio jacuipe, 12 I 1985, Passos 19 (MO); Almas, 9 IX 1956, Pereira 1988
(CTES); Conceição de Jacuipe, IV 1974, Pinto s.n. (ALCB, CTES, IPA); Cruz das Almas, 18 I 1980, Pinto 36/81 (HRB, HUEFS, IPA); Pé da Serra Aporá Muritiba, 31 VII 1956, Pinto 56-35 (ALCB); Mun. Feira de Santana, Campus da UEFS, $12^{\circ} 15^{\prime} \mathrm{S}$ 3858'W, 23 III 1987, Queiroz \& Crepaldi 1482 (CTES, HRB, HUEFS); Mun. Feira de Santana, Campus da UEFS, atras da biblioteca, 24 I 1992, Queiroz 2600 (CTES, HUEFS); Dunas do Abaeté, Salvador, $6 \%$ 1994, Ramos s.n. (ALCB); Salvador, Itapoan, Aivaeté, $3 \mathrm{~V}$ 1993, Rosas et al. 17 (HRB); Salvador, İtapoan, 31 VIi 1964, Santos 2007-Sacco 2268 (R); Mun. Maracás, 8-18 km S de Maracás, pela antiga Rodovia para Jequié, $900-1000$ m, 15 II 1979, Santos et al. 3449 (CTES, NY, TEX); Jacobina, 1890, Schreiner s.n. (R); Cruz das Almas, VI 1950, Teixeira s.n. (RB); bel Maracás, IX 1906, Ule 6971 (HBG, K); Arredores da Cachoeira Paulo Affonso, em Paulo Affonso, IV 1954, Vidal IV-774 (R); liha de Urubús, no rio São Francisco, em frente á Cachoeira Paulo Affonso, em Paulo Affonso, IV 1954, Vidal IV-794 (R). Minas Gerais: Mun. Buenópolis, Curimataí, $40 \mathrm{~km}$ E de BR-135, entre Buenópolis y Joaquim Felicio, 17 ${ }^{\circ} 1^{\prime} \mathrm{S}$ $43^{\circ} 58^{\prime} \mathrm{W}, 600 \mathrm{~m}, 21 \mathrm{~V} 1990$, Arbo et al. 4521 (C, CTES, F, K, MBM, MICH, MO, SPF); Diamond Dist., VII 1840, Gardner 4694 (K); Curimataí, Cachoeira do Simão, 21 III 1994, Sakuragur et al. CFCR 15325 (CTES, SPF). Paraíba: Agreste, Esperança, 15 I 1959, Moraes 2015 (NY, P, US); Mamanguape, Reserva Biologica Guaribas, 9 VIII 1999, Schlindwein CS939 (UHF); Esperança, Smith 2015 (NY, S). Pernambuco: Garanhuns, ao lado do Cruzeiro, Morro do Mogano, 10 I 1972, colector no especificado (RB 151520); Sa. V.Vegra, 11 X 1950, Andrade-Lima 50-673 (IPA); També, Estação Experimental, 9 III 1953, Andrade-Lima 531670 (IPA); Garanhuns, subida do morro Magano, 8 X 1971, Andrade-Lima 71-6533 (IPA); Mun. Venturosa, Parque Pedra Furada, $8^{\circ} 34^{\prime} 30^{\prime \prime} \mathrm{S} 36^{\circ} 52^{\prime} 45^{\prime \prime} \mathrm{W}$, $830 \mathrm{~m}$, sin fecha, Costa et al. 84 (CTES); Mun. de Serra Talhada, Estação Ecológica do Saco-IPA, 4 V 1991, Esteves \& Barros 2565 (CTES, MAC, SPF); Arcoverde, E.E. do IPA, 9 II 1982, Galindo et al. 85 (IPA); Caruaru, $\mathrm{Km} 56$ da estrada Caruaru/ Campina Grande, 11 1982, Giulietti et al. CFPE 33 (IPA) y 45 (IPA); Mun. Cravatá, Rusinha, 3 II 1981, Krapovickas et al. 38004 (C CTES, GH, IPA, LIL, $\mathrm{MICH}) ;$ Mun. ?ombus, alreciedures de Pombos, 3 II 1981, Krapounckas et al. 38019 (CTES); Mun. S.João, 26 VII 1966, Lima 19 (IPA); Triunfo, divisa dos municipios Triunfo-Princesa Isabel, Prop. Petrônio, 25 II 1986, Luma \& Gallindo 7 (IPA); Serra das Russas, 19 VII 1967, Lindeman \& Haas 6186 (U); Gravatá, VII 1926, Pickel 1062 (IPA); Tapera, 24 V 1931, Pickel 2628 (IPA, NY, US); Russinha, Tapera, 3 XI 1931, Pickel 2829 (F, IPA); Russinha, 7 I 1939, Pickel 3483 (IPA, US); També, iI 1937, Vasconcellos Sobrinho s.n. (IPA). 
Piauí: Between Lagoa Comprida et Corimata, II 1839, Gardner 2179 (FI, K, NY, P, W). Rio de Janeiro: environs de Rio de Janeiro, Glaziou 13914 (BR, C, K, LY); Petrópolis, Carangola, 31 VII 1943, Goés \& Constantino 379 (RB). São Paulo: Fazenda do Morro Azul dans le bois, III-IV, Glaziou 12743 (BR, C, K, LY, NY, P) [localidad dudosa]. Sergipe: Areia Branca, 25 IX 1981, Carnciro 75 (IPA).

Argentina. Corrientes: cultivada en Corrientes, proc. de semillas de Noblick 3175, Bahia, 14 XI 1985, Noblick 3175 bis (CTES); cultivada en Corrientes, proc. de Serra da Tartaruga, Bahia, Hatschbach et al. 56982 bis (CTES).

Distribución. Especie propia del nordeste y centro-este de Brasil, de "caatinga, agreste, cerradão, campos gerais, campo rupestre y restinga", desde el nivel del mar hasta los 1100 $m$ de elevación. Florece durante todo el año, el mayor número de colecciones corresponde a los meses del verano.

Glaziou (1909) cita su ejemplar 13914 (Rio de Janeiro) para la siguiente localidad: Minas Gerais, Caraça. Probablemente la localidad de Glaziou 12743 en São Paulo es falsa (Wurdack, 1970), no se conocen otros ejemplares de dicho estado.

Cromosomas: $2 \mathrm{n}=26$, Carvalho et al. 538, Noblick 3175, Noblick 3175 bis (Fernández, 1987; Solís Neffa \& Fernández, 1993).

Obs. En esta especie el gineceo puede ser 0$2 \mathrm{~mm}$ más largo que el androceo o eì androceo ser 0-2 mm más largo que el gineceo, es decir que en la mayoría de las flores las anteras versátiles pueden ponerse en contacto con los estigmas. Con el objeto de analizar la heterostilia se midió la longitud de androceo y gineceo de todas las flores posibles (140). La mayoría de los ejemplares tienen flores longistilas o brevistilas, siendo variable la diferencia en longitud de los verticilos sexuales en las flores de la misma planta, por ejemplo androceo 0,4-1,5 $\mathrm{mm}$ más largo que el gineceo, o gineceo 0,4-2 mm más largo que el androceo; solamente se encontraron 10 flores con androceo y gineceo de igual longitud.

En Hatschbach et al. 56851 (CTES), se encontró una rama con la mayoría de las flores brevistilas, de androceo 1-1,2 mm más largo que el gineceo, y una flor longistila, con gineceo 2 mm más largo que el androceo. Una flor de Arbo et al. 7272 presenta 3 estambres con filamentos cortos (23 mm long.) y 2 estambres con filamentos largos (32 mm long.), siendo el gineceo de $32 \mathrm{~mm}$ long.

En las dos accesiones cultivadas en Corrientes, se observó que las plantas son parcialmente autoincompatibles, en el invernáculo no se producen frutos como resultado de la autopolinización; sin embargo, cultivadas en el exterior, las flores visitadas por insectos forman frutos con escasas semillas (2-4) a pesar del elevado número de óvulos presentes en el ovario (ca. 90).

Las hojas frescas son agradablemente perfumadas, con aroma mentolado, seguramente debido a la secreción de los pelos glandulares. El indumento es variable, hay ejemplares como Arbo et al. 7584 casi sin pelos simples, el cáliz tiene exclusivamente pelos capitadoestipitados por fuera; otros ejemplares son densamente pubescentes (Lordêlo 56-433, Noblick 1646, Gusmão 216). También varía la densidad de los pelos capitado-estipitados, en algunos ejemplares son muy abundantes mientras en otros como Pickel 2628 son escasos.

La base foliar es saliente y persistente, el pecíolo está articulado por encima de la inserción del pedúnculo floral. La absición de la hoja se produce a la altura de la articulación, después que se han desprendido las hojas floríferas se puede ver la cicatriz circular del pedúncuio floral junto a la cicatriz del pecíolo.

\section{Reconocimientos}

Realicé este trabajo con el apoyo de subsidios de CONICET y SEGCYT-UNNE. Los viajes de colección y las visitas a varios herbarios de Brasil fueron financiados con subsidios de la National Geographic Society. Pude estudiar los tipos de numerosos herbarios europeos gracias a la Dra. Alicia Lourteig, quien los solicitó en préstamo para mí. Agradezco a los curadores de todos los herbarios que me proporcionaron material así como las facilidades que me brindaron en las instituciones que visité. Liliana Gómez elaboró todas las ilustraciones. El Ing. A.Krapovickas, la Dra. Carmen L. Cristóbal, el Dr. T.M.Pedersen y la Sra. Nina 
Pedersen me atendieron numerosas consultas. Carlos Zanín revisó las diagnosis latinas. Scott Mori tuvo la gentileza de enviarme diapositivas de las flores con el ejemplar de T.maracasana. Bill D’Arcy me obsequió y me enseñó a usar el software para preparar los mapas de distribución. Mediante la ayuda de Linda Oestry y Mary Stiffler, del Missouri Botanical Garden, dispuse de fotocopias de artículos que no se conseguían en nuestro país.

\section{Bibliografía}

ARBO, M.M. 1981. Novedades en Turneráceas de Brasil. Bonplandia 5(14): 111-122.

- 1986. Paraguay, centro importante de especiación en las Turneráceas. Notulae ad Floram paraquaiensem 6, Candollea 41(1): 211-218.

1993. Nuevas especies americanas de Turnera (Turneraceae). Bonplandia 7(1-4): 63-99.

—. 1995. Turneraceae. Parte I. Piriqueta. Flora Neotropica 67: 1-156, 59 figs.

— 1997a. Addenda a las Turneraceae de la Flora del Paraguay. En Ramella y Perret, Notulae ad Floram Paraquaiensem 58. Candollea 52: 200-211.

—. 1997b. Estudios sistemáticos en Turnera (Turneraceae). I. Series Salicifoliae y Stenodictyae. Bonplandia 9(3-4): 151-208.

ARBO, M.M. \& A.M. GONZÁLEZ. 1998. Caracteres diferenciales morfo-anatómicos entre las series Annulares, Capitatae, Microphyllae y Papillterae de Turnera (Turneraceae). Comunicaciones científicas y Tecnológicas, Universidad Nacional del Nordeste, Tomo 3 (Ciencias Agrarias-Ciencias Biológicas): 6-83 a 6-86.

CORRÊA, P. 1931. Dicionário das plantas úteis do Brasil, 2: 517.

EKMAN, E.L. 1930. A list of plants from the Island of Gonave, Haití. Ark. Bot. 23A(6): 1-73.

FERNÁNDEZ, A. 1987. Estudios cromosómicos enTurnera y Prriqueta (Tumeraceae). Bonplandia 6(1): 1-21.

GARDNER, G. 1975. Viagem ao interior do Brasil, principalmente nas províncias do Norte e nos distritos do ouro e do diamante durante os anos de 1836-1841. 260 págs. Ed. Itatiaia. Belo Horizonte.

GLAZIOU, A. 1909. Liste des plantes du Brésil Central recueillies en 1861-1895. Bull.Soc. Bot.France 56, Mém.
3: 1-611.

GONZÁLEZ, A.M. 1993. Ana tomía y vascularización floral de Piriqueta racemosa, Turnerahassleriana y Turnera joelli (Turneraceae). Bonplandia 7: 143-184.

—. 1998. Colleters in Turnera and Piriqueta (Turneraceae). Bot.J.Linn.Soc. 128: 215-228.

—. 2000. Estudio anatómico de Turnera y Piriqueta (Turneraceae). Tesis doctoral, Univ Nac. de Córdoba.

LEÓN Y ALAIN, I Inos. 1953. Flora de Cuba. Turneraceae. Contrib.Ocas.Mus.Hist.Nat.Colegio "De La Salle" 3: 342-345.

MOURA, C.A.F. de. 1969. A new Turnera from Brazil. Phyton (Horn.) 13 (3-4): 267-269.

SOLÍS NEFFA V.G. \& A. FERNÁNDEZ. 1993. Estudios cromosómicos en especies de Turnera (Turneraceae). Bonplandia 7(1-4): 101-118.

SPENCER K.C. \& D.S. SEIGLER. 1981. Tetraphyllin from Turnera diffusa. Pl. Med. 43: 175-178.

SPENCER K.C., D.S. SEIGLER \& S.W. FRALEY. 1985. Cyanogenic Glycosides of the Turneraceac. Biochem.Syst.Ecol. 13(4): 433-435.

STEYERMARK, I.A. 1981. Erroneous citations of venezuelan localities. Taxon 30(4): 816-817

TANTISEURIE B., H.W.L. RUIJGROK \& R. HEGNAUER. 1969. Die Verbreitung der Blansaüre bei den Cormophyten. 5: Über cyanogene Verbindunger bei den Parietales und bei einigen weiteren. SippenPham. Weekbl. 104: 1341-1355.

URBAN, I. 1882a. Damiana. (Ein neues Aphrodisiacum). Archiv der Pharmacie 220(3): 1-14

—. 1882b. Damiana. Therap.Gaz. June: 209-210 y 1883 (concluded from June, 1882): 194-198.

- 1883a (Marzo). Monographie der familie der Turneraceen. Jahrb.Königl. Bot.Gart.Berlin 2: 1-152.

_.. 1883b (Agosto). Turneraceae en Martius C.F.P., Fl.bras. 13(3): 86-170, láminas 31-48.

-1898. Plantaenovae americanae imprimis Glaziovianae. II. Turneraceae adjectis specierum nonnullarum africanarum descriptionibus. Bot.Jahrb.Syst. 25, Beibl. 60: 2-12.

-1906. Vitae itineraque collectorum botanicorum. En Martius C.F.P., Fl.bras. 1(1): 1-154.

-. 1914. Turneraceae novae II. Repert.Spec.Nov.Regni Veg. 13: 152-159.

WEBERLING, F. 1989. Morphology of flowers and inflorescences. 405 págs. Cambridge University Press.

WURDACK,J.J. 1970. Erroneous data in Glaziou collections of Melastomataceae. Taxon 19(6): 911-913. 


\section{Lista numérica de taxones}

22. T. annularis Urb.

23. T. aromatica Arbo

24. T. breviflora Moura

25. T. odorata Richard

26. T. albicans Urb.

27. T. capitata Cambess.

28. T. dasystyla Urb.

29a. T. hatschbachii Arbo var. hatschbachin

29b.T. hatschbachn Arbo var. minuata Arbo

30. T. maracasana Arbo

31. T. marmorata Urb.

32. T. pernambucensis Urb.
33. T. princeps Arbo

34. T. schomburgkiana Urb.

35. T. waltherioides Urb.

36. T. asymmetrica Arbo

37. T. calyptrocarpa Urb.

38. T. collotricha Arbo

39a.T. diffusa Willd. ex Schult. var. diffusa

39b.T. diffusa Willd. ex Schult. var. aphrodisıaca (Ward) Urb.

40. T. hebepetala Urb.

41. T. cantingana Arbo

42. T. chamaedrifolia Cambess.

\section{Indice de Exsiccatae}

? RB 151520 (42)

? scripsit Balbis (39a)

Acevedo P. et al. 973 (39a)

Acevedo Rdgz. P. Ver Acevedo-Rodriguez P.

Acevedo-Rodriguez P. \& Siaca 3979 (39a); 4415 (39a)

Acevedo-Rodriguez P. et al. 1834 (39a); 4183 (39a)

Adams C.D. 12871 (39a)

Agostini G. \& Agostini 1069 (23)

Aguilar M. 767 (39a)

Agundez J. 8 (39b)

Alain [Bro.]: ver Liogier A.H.

Alain \& Clemente [Bros.] 988 (39a)

Alexander A.M. 219 (39a)

Allart A. 15 en parte (23), en parte (24)

Allemão \& Cysneiros Fr. 797 (37)

Altamirano F. 16 (39a); 4118 (39a)

Andrade-Lima $D=50-441$ (39a); 50-673 (42); 51-851.

(27); 53-1670 (42); 68-5217 (37); 71-6533 (42)

Appun C.F. 2210 (25)

Araque \& Barkley F.A. 275 (23)

Arbo M.M. et al. 2538 (42); 4335 (27); 4521 (42); 5269 (27); 5354 (39a); 5363 (37); 5401 (39a); 5445 (42); 5448 (42); 5453 (42); 5461 (42); 5506 (37); 5507 (42); 5526 (42); 5758 (39a); 5761 (42); $7217(42) ; 7251$ (42); 7272 (42); 7284 (42); 7296 (42); 7315 (42); 7325 (42); 7332 (42); 7363 (39a); 7371 (42); 7394 (39a); 7427 (42); 7440 (39a); 7455 (39a); 7583 (39a); 7584 (42); 7608 (39a); 7643 (41); 7708 (30)

Arbo M.M., Mello-Silva R. \& J.Vicente Nunes 5645 (41); 5694 (36)

Argüelles E. 227(39a); 1560 (39a); 1828 (39a)

Aristeguieta L. 7108 (24)

Arnason 17848 (23)

Arnason \& Lambert 17151 (23)

Arouck Ferreira J.D.C. 42 (39a)

Arraes M.G. et al. s.n. CFCR 6809 (39a)
Arriaga R. \& Lopez H. 224 (39b)

Arvigo R. et al. 350(39a); 384 (23)

Ataide M. et al. 567 (39a)

Athayde P.A. s.n. (42)

Atkins S. et al. CFCR 13802 (27)

Avendano S. 228 (39a)

Axelrod F. \& Escobar L. 2902 (39a)

Badillo V. 7467 (24)

Badini J. s.n. (28)

Bailey L.H. 170 (39a)

Baker R.E.D. 14687 (25)

Baker R.E.D. \& Simmonds 14887 (25)

Bandeira M. 236 (39a)

Barkley F.A. 17 M050 (39a)

Barkley F.A. \& Heard N.T. 14548 (39a)

Barnes C.R. \& Land W.J.G. 107 (39a)

Barnett L.C. et al. 74 (39a)

Baro D. 821 (39a)

Barroso G.M. \& Guimarães E.F. 358 (25)

Bartlett A.W. 10622 (39a); 11005 (39a); 11303 (23); $11376(23)$

Bartlett H.H. 11519 (39b); 17564 (39a)

Basilio Augusto 1198 (39a)

Bastos B.C. 99 (42); 502 (42)

Bautista H. 366 (42)

Beauvois s.n (39a)

Belém R.P. 1850 (31)

Belém R.P. \& Magalhães M. 912 (31)

Belém R.P. \& Pinheiro R.S. 2107 (31); 2109 (31); 2830 (26); 3090 (31)

Bell \& Duke J.A. 16517 (39a)

Berlandier J.C. 321 (39a); 3155 (39a)

Bernardi L. 2218 (23)

Bertero C.G.L. s.n. [Jamaica] (39a); [San Domingo] (39a)

Bezerra P. s.n. (37) 
Black G.A. 38-5094 (39a)

Black G.A. \& Cordeiro E. 52-14575 A (25)

Blanchet J.S. 877 (22); 1267 (22); 2641 (39a); 2939 en parte (37), en parte (39a); 3840 (39a); 3863 (37); 3869 (37)

Bono J. 5020 (23)

Buno P.J. 4887 (23)

Botanic Garders Herbarium 1093 (23); 2820 (23)

Brace L.J.K. 95 (39a); 3992 (39a); 4284 (39a); 4668 (39a)

Brandegee T.S. 227 (39a)

Breedlove D.E. 8417 (39a); 10294 (39a); 11776 (39a); 20109 (39a); 27324 (39a); 35985 (39a); 37251 (39a); 41195 (39b); 50219 (39a)

Breedlove D.E. \& Raven P. H. 13195 (39a)

Breedlove D.E. \& Thorne 30515 (39a)

Brenes A.M. 15586 (39a); s.n. (39a)

Breteler F.J. 4608 (24)

Brigada de Dunas costeras 8 (39a)

Britton N.L. 1146 (39a); 1899 (39a); 2146 (39a); 3184 (39a); 8060 (39a)

Britton N.L. \& Cowell 12576 (39a); 1294 (39a); 13317 (39a)

Britton N.L. \& Fishlock 1113 (39a)

Britton N.L. \& Hazen T.E. 1722 (23)

Britton N.L. \& Millspaugh C.F. 2192 (39a); 2890 (39a); 2993 (39a); 5602 (39a); 5906 (39a)

Britton N.L. \& Rose J.N. 1408 (39a)

Britton N.L. \& Shafer J.A. 1811 (39a)

Britton N.L. \& Wilson 5586 (39a)

Britton N.L. et al. 1771 (39a); 2680 (23); 4825 (39a)

Broadway W.E. 55 (25); 265 (25)

Brokaw N.V.L. \& Schulze M. 212 (23)

Buch W. 257 (39a)

Bucher G.C. 108 (39a)

Burch D. 2435 (39a); 4372 (39a); 6230 (23)

Burchell W.J. 8832 (25); 9151 (25); 9437 (25)

Buschel s.n. [XII 1854](23); s.n. [I 1855](23)

Byrne R. 237 (39a)

Cabrera E. 9927 (39a)

Cabrera E. \& Cabrera H. de 4741 (39a); 6830 (39a)

Cabrera E. \& Durán 686 (23)

Cabrera E. \& Torres R. 1013 (39b)

Calzada 2426 (39a)

Campbell D.G. et al. P22467 (24)

Campos J.L. 54 (39a)

Campos A. \& Toriz G. 3197 (39a)

Campos A. et al. 4505 (39b)

Campos Porto P. 1343 (42)

Carabia J.P. 3746 (39a)

Carneiro E. 75 (42); 167 (37)

Carrillo Parra A. AI-23 (39a)

Carter A. 2600 (39a)

Carter A. et al. 2196 (39a)

Carvalho A.M. de \& Hind D.J.N. 3865 (42)
Carvalho A.M. de \& Plow'man T. 1393 (31); 1586 (42)

Carvalho A.M. de \& Saunders J. 2756 (42); 2815 (42); 2816 (39a); 2828 (39a)

Carvalho A.M. de et al. 215 (31); 538 (42); 1772 (39a); 1780 (39a); 1850 (42)

Casaretto J. 2074 (22)

Castellanos A. 22995 (39a); 2508: (42), 25392 (42)

Castellanos A. \& Duarte L. 47 İ (42)

Castillo G. \& Tapia L. 813 (39a)

Catharino E.L.M. et al. 2154 (27)

Cedillo Trigos R. \& Lorence D. 467 (39a)

Chacón L. 94 (23)

Chardon C.E. \& Otero 1795 (39a)

Chavarría G. 16 (39a)

Chemin Bassler H. 71 (39a)

Cicero et al. s.n. (39a)

Clemente: ver Clemente [Bro.]

Clemente [Bro.] 2121 (39a); 2377 (39a); 6203 (39a); 7020 (39a); 7437 (39a)

Clover E.U. 1686 (39a)

Contreras E. 5710 (23); 5712 (23); 8492 (39a)

Conzatti C. 810 (39a); 1477 (39a); 1877 (39a)

Coradin L. et al. 6066 (39a); 6142 (42); 6216 (39a)

Correll D.S. 32288 (39a); 35466 (39a); 40729 (39a); 41650 (39a); 44456 (39a); 45861 (39a); 46157 (39a); 49257 (39a)

Correll D.S. \& Correll 42454 (39a); 43660 (39a)

Correll D.S. \& Proctor G.R. 48794 (39a)

Correll D.S. \& Wasshausen D. 46756 (39a)

Correll D.S. et al. 50535 (39a); 51213 (39a)

Cory V.L. s.n. [Tiger creek](39a); s.n. [Rio Grande city](39a)

Costa L.V. s.n. (28)

Costa \& Barroso G.M. s.n. (42)

Costa et al. 84 (42)

Coulter T. 798 (39a)

Cowan C.P. 3030 (23)

Cowan C.P. et al. 5356 (39a); 5463 (39a)

Crankshaw 9 (39a)

Croat T.B. 23252 (39a); 23297 (23); 23521 (23); 24016 (39a); 24816 (23); 39951 (39a)

Croizat L. 384 (25); 558 (25)

Crueger H. s.n. (25)

Cumana L. 1977 (24)

Curtiss A.H. 201 (39a)

Czerwenka \& Pelaez 448 (39a)

D'Arcy W. C. 2112 (39a); 4702 (39a); 5111 (39a); 11753 (39a); 11811 (39a)

Daubenmire R.F. 404 (39a)

Davidse G. 2797 (25); 36062 (23)

Davidse G. \& Brant A.E. 32767 (23); 32781 (39a); 32816 (23); 33199 (39a)

Davidse G. \& D'Arcy W.C. 10496 (27)

Davidse G. \& Holland D.L. 37021 (23) 
Davidse G. \& Huber O. 15251 (25)

Davidse G. et al. 11745 (39a)

Davis 866 (25); 61044 (42)

Delgado A. et al. 731 (39a); 755 (39a)

Desportes P. s.n. [Herb. Jussieu 13576](39a)

Dias T.A.B. et al. 271 (25)

Dieckman L. 113 (39b); 153 (23)

Dodge C.W. \& Thomas W.S. 6342 (39a)

Dorantes J. \& Marquez W. 603 (39a)

Dressler R.L. 2089 (39a)

Duarte L. \& Castellanos A.352 (42)

Ducke A. 2411 (37); s.n. (25)

Durán R. et al. 1123 (39a)

Dutilh j.H.A. \& Marcondes Ferreira W. 51 (27)

Dwyer J.D. 9101 (23); 10757 (23); 11219 (23); 11521 (23); 11629 (23); 12395 (23); 12409 (23); 12417 (39a); 12433A (23); 12669 (23); 14508 (39a); 14667 (39a)

Dwyer J.D. \& Pippin 10095 (39a)

Dwyer J.D. et al. 201 (23); 247 (23) ; 319 (39a); 319A (23) ; 662 (39b)

Ebinger J.E. 1031 (39a)

Eggers B. 298 (39a); 354 (39a); 1100 (39a); 3889 (39a); 13380 (24); s.n. (39a)

Ekman E.L. 1014 (39b); 2897 (39a); 5759 (39a); 7714 (39a); 15565 (39a); 16028 (39a); 16332 (39a); 17076 (39a); 18839 (39a)

Emperaire L. 2111 (37)

Endlicher S.L. S.n. (25)

Esteves G.L. \& Barros C.S.S. 2565 (42)

Fabricio s.n. (39a)

Felger R.S. 85 - 32 (39a)

Fendler A. 114 (24)

Fernandes A. et al. s.n. (39a)

Fernández R. 1596 (39a)

Ferrari J.M. s.n. (27); 411 (27)

Ferreira P. s.n. (37)

Ferreyra R. s.n. (25)

Ferrucci M.S. et al. 1106 (42)

Feuillet C. 1320 (25)

Figueiredo L.S. et al. 66 (39a); 91 (39a)

Fisher G.L. 3765 (39a); 35432 (39a); 37193 (39a); s.n. (39a)

Fishlock W.C. 86 (39a); 207 (39a)

Flores J.S. 10012 (39a)

Florschütz J. \& Florschütz P.A. 1524 (25)

Flyr 619 (39a)

Fonseca I. 74 (39a)

Fonseca W.N. da 404 (39a)

Forest Dep.Brit.Guiana G 502 (24); 7517 (24)

Fosberg F,R. 57561 (39a)

Fotius 3415 (37)

França F. et al. 1579 (39a)

Fre. León: ver León J.L.

Freire-Allemão s.n. (25)

Fróes R.L. \& Black G.A. 24740 (24)

Fryxell P. \& Anderson 3631 (39a)
Fryxell P. \& Magill 2259 (39a)

Fuentes S. s.n. (39b)

Fuertes P. 368 (39a)

Galeotti H. 4077 (39a)

Galindo et al. 85 (42)

Ganev W. 780 (39a); 1341 (39a)

García R. y Pimentel J. 2234 (39a)

Gardner G.1154 (32); 1471 (39a); 2062 (40); 2179 (42); $2406(37) ; 3753(25) ; 4440(27) ; 4694$ (42.)

Gaudichaud C. 906 (25)

Gaumer G.F. 538 (39a); 859 (39a); 1834 (39a); 2002 (39a); 23527 (39a)

Gehrt A. s.n. (27)

Gentle P.H. 1095 (23); 3776 (23); 8434 (23); 9453 (23)

Gentry A.H. 1361 (39a); 7615 (23); 7857 (39a); 8068 (23); 8451 (23)

Gentry A.H. \& Berry P. 14452 (25)

Gentry A.H. \& Mejia M. 50766 (39a)

Gentry A.H. \& Stein B. 46344 (25)

Gentry H.S. 5547 (39a); 14484 (39a); 16551 (39a)

Gillis W.T. 9384 (39a); 10692 (39a)

Giulietti A.M. et al. CFPE 33 (42)

Glaziou A. 6812 (22); 9802 (40); 9855 (25); 10877 (37); 10880 (25); 10881 en parte (37), 10881 en parte (39a); 12743 (42); 13914 (42); 17621 (27); 18260 (27)

Glocker C.E.F. s.n. (42)

Go. Pedra do Cavalo 19 (42); 163 (42); 384 (42)

Goés C.C. \& Constantino D. 379 (42)

Goldman E.A. 841 (39a)

Gomes \& Labouriau L. 839 (37); 879 (42)

Gomes A.P.S. et al. 13 (39a)

Gómez-Lorence F. 802 (39a)

González M. 731 (39a)

González-M. et al.: ver González-Medrano F. et al.

González-Medrano F. 840 (39a); 12456 (39a)

González-Medrano F. \& Chimal A. 11755 (39a)

González-Medrano F. et al. 434 (39a); 4530 (39a); 9693 (39a); 12771 (39a)

González Ortega J. 256 (39a); 6121 (39a); 6315 (39a); 6591 (39a); 6753 (39a); 7251 (39a)

González Quintero 2790 (39a)

Gottsberger G.K. \& Gottsberger i.S. 15-28173 (42); 22-3273 (39a)

Gourlay 8 (39a)

Granville J.J. 5110 (25)

Granville j.J. et al. 9574 (25)

Grether R. \& Quero H. 1943 (39b)

Griffis 30-14 (39a); 33-2 (39a)

Grijalva A. \& Grijalva M.V. 1270 (39a)

Grijalva A. et al. 3049 (39a)

Gröger A. 777 (25)

Guedes M.L. \& Sousa J.R. 1016 (39a)

Guedes M.L. et al. 4058 (42); s.n. (42)

Gusmão E.F. 216 (42)

Guzmán M. et al. 1049 (39a)

Haenke T. 23 (39a); s.n (39a) 
Halberg B. 1207 (39a)

Hammerly B.J. 411 (39b)

Hansen et al. 9120 (39a)

Harley R.M. et al. 15262 (39a); 16165 (42); 16402 (42); 16715 (39a); $17602(31) ; 18468(31) ; 18550(31)$; 19157 (39a); 19322 (39a); 19445 (37) ; 21185 (39a); 21201 (39a); 21210 (39a); 22060 (31) ; 22955 (39a); 26453 (39a); 27724 (37)

Harmón W.E. \& Dwyer J.D. 3539 (39a)

Harmón W.E. \& Fuentes 6334 (39a)

Harris W. 91, 105, 121 (39a); 9608 (39a); 9679 (39a)

Hatschbach G. 39583 (39a); 44234 (39a); 46557 (41); 48184 (42)

Hatschbach G., Anderson W., Barneby R. \& Gates B. 36434 (38)

Hatschbach G. \& Guimarães O. 45052 (42)

Hatschbach G. \& Kummrow R. 45579 (27)

Hatschbach G. \& Hatschbach M. 59721 (29b); 59722 (29a)

Hatschbach G. et al. 27315 (38); 55140 (40); 56611 (40); 56634 (39a); 56846 (39a); 56851 (42); 56876 (39a); 56982 (42); 56982 bis (42); 63095 (42); 65059 (40); 65137 (39a); 65850 (39a); 66360 (39a); 67773 (39a); 69774 (38)

Heard N.T. \& Barkley F.A. 14548 (39a)

Heithaus E.R. 215 (39a)

Heller A.A. s.n. (39a)

Herb. Desvaux A.N. (39a)

Herb. Lamarck s.n. (39a)

Herb. Poiret [Cayenne](25); [Jamaica](39a)

Herb. Schwacke C.A.W. 9973 (28)

Herb. Willdenow 6092 (39a)

Herb. Martius C.F.P. s.n. (33)

Herb. Richard L.C. [Santo Domingo](39a)

Hermano Ginés 2774 (24); 3359 (24)

Hernández R. 137 (39a); 630 (39a); 3939 (39a)

Hernández R. \& Trigos R.C. 714 (39a)

Hernández R. \& Vázquez de Hdez. Y. 1731a (39a)

Hernández R. et al. 6243 (39a)

Heyde N.M. \& Lux 3041 (39a)

Hill S.R. 465 (39a); 2156 (39a); 27325 (25)

Finton G.B. et al. 13081 (39a); 20797 (39a)

Hioram [Brother] \& Ramsden 2321 (39a)

Hiriart P. et al. 741 (39a); 795 (39a)

Hitchcock C.L. s.n. (39a)

Hitchcock C.L. \& Stanford L.R. 7262 (39a)

Hoehne F.C. 1226 (27); 6889 (27)

Hoffmannsegg C. s.n. (25)

Holdridge L.R. 1079 (39a)

fulmes s.n. (39a)

I lopkins M.J.G. et al. 744 (25)

Hostmann F.W. 252 (25); 1303 (25)

Houghton W.M. et al. 1221 (39a); 1227 (39a)

Howard R.A. 5107 (39b); 12105 (39a)

Howard R.A. \& Howard E.S. 8372 (39a); 8641 (39a); $9586(39 a)$
Howell J.T. 10590 (39a)

Huber O. 2719 (25)

Huber O. \& Gorzula 11155 (35)

Huber O. \& Tillett 914 (25)

Huber O. et al. 7232 (35)

Humboldt A. \& Bonpland A. s.n. (25)

Hunt D.R. 61 (23)

Huston J.S. 552 (23); 560 (39a)

Illsley 1186 (39a)

Irwin H.S. et al. 23245 (39a); 28509a (27); 30589 (28); 30732 (37); 31196 (39a); 32331 (39a); 32449 (39a); $47413(25)$

Irwin H.S., S.F. da Fonsêca, R.Souza, R.Reis dos Santos \& J.Ramos 27623 (33)

Jansen-Jacobs M.J. et al. 35 (25); 67 (25); 853 (23); 2080 (25); 3249 (25); 3554 (25); 3673 (25); 3959 (25)

Janzen D.H. 11700 (39a); 11851 (39a)

Jardim J.G. 1032 (22)

Jenman G.S. 3755 (25)

Jiménez T.J. 452 (39a)

Jobert C. 1040 (40); 291 (25)

Johnston 288 (23)

Johnston et al. 11126 (39a)

Joly A.B. 1128 (27)

Jones S. et al. 5177 (39a)

Karsten E. s.n. (24)

Kenoyer A. 417 (39a); s.n. (39a)

Kenoyer A. \& Crum 3514 (39a); 3643 (39a)

King M. 462 (39a); 561 (39a); 1233 (39a); 1670 (39a); 1817 (39a)

Koch S.D. \& Fryxell P.A. 82219 (39b)

Kral R. 27766 (39a)

Krapovickas A. 12805 (42); 12807 (39a)

Krapovickas A. \& Cristóbal C.L. 33396 (27)

Krapovickas A. et al. 38004 (42); 38019 (42); 38071 (39a); 38805 (42); 40176 (25)

Krebs H.J. s.n. (39a)

Kuhlmann J.G. \& Edmundo L. s.n. (27)

Lagorce J.F. ver Hioram [Brother]

Landsberger 260 (24)

Le Roy 5 (39b)

Le Sueur D.H. 302 (39a); 604 (39a)

Leal Costa A. 909 (42)

Leal Costa A. \& Barroso G.M. s.n. (39a)

Leavenworth W.C. 71 (39a)

Leitão Filho H.F. et al. 1607 (27); 9657 (28)

Lemée A.M.V. s.n. (25)

Lemos M.J.S. 47 (37)

León [Bro.]: ver León J.L.

León \& Alain [Bros.] 19225 (39a)

León \& M.Victorin [Bros.] 17658 (39a)

León et al. [Bros.]: ver León J.L. et al.

León J.L. 4275 (39a); 9270 (39b); 11943 (39a); 12106 (39a); 12124 (39a); 15711 (39a); 16342 (39a); 23376 (39a)

León J.L. \& Cazanas 5933 (39a) 
León J.L. et al. 17704 (39a); 20213 (39b); 20760 (39b); 22488 (39a)

Leonard E.C. 2882 (39a); 4114 (39a); 7104 (39a); 8893 (39a); 8931 (39a); 9958 (39a)

Leonard E.C. \& Leonard G.M. 11564 (39a); 11850 (39a); 11891 (39a); 14692 (39a)

Leprieur M. 121 (25)

Lewis G.P. et al. s.n. CFCR 6999 (37)

Liebmann F.M. 4270 (39a); 4271 (39a); 4272 (39a); 4273 (39a); 4276 (39b); 4277 (39a); 4278 (39a)

Liesner R.L. 1426 (23); 3417 (39a); 4822 (39a); 18660 (25)

Liesner R.L. \& González A. 5520 (25); 5601 (25); $10710(23)$

Liesner R.L. \& Guariglia M. 11685 (23)

Liesner R.L. et al. 2664 (39a)

Lima A. 19 (42)

Lima V.C. \& Gallindo 7 (42)

Lima-Verde L.W. \& Andrade I.M. de 930 (37)

Lindeman J.C. \& Haas J.H. 6186 (42)

Linden 831 (39a); 1802 (39a); 1852 (39a); 2065 (39a); s.n. $(39 a)$

Lindman 3217 (25)

Liogier A.H. 807 (39a); 1575 (39a); 1596 (39a); 12676 (39a); 17570 (39a); 18834 (39a); 20153 (39a); 20561 (39a); 33627 (39a)

Liogier A.H. et al. 29539 (39a); 31150 (39a)

Lockhart s.n. (25)

Löfgren A. 990 (39a)

Lordêlo 56-294 (42); 56-433 (42); 56-70 (42); 57-20 (37); 58-19 (37)

Lott E.J. 1695 (39a)

Lott E.J. \& Hernández R. 1463 (39a)

Lund P.W. 33 (22)

Lundell C.L. 71 (23); 432 (23); 4192 (23); 6981 (39b)

Lundell C.L. \& Lundell A.A. 12341 (39a)

Lyra et al. 188 (42)

Maas P.J.M. \& Westra L.Y.Th. 4062 (25)

MacDaniels L.H. 156 (39a)

Magalhães H. de s.n. (28)

Magalhães Gomes 1265 (27); 2622 (28)

Maguire B. 40267 (34)

Maguire B. et al. 31590 (25)

Malme G. 2672 (25); 2672a (25)

M.Victorin, Clemente \& Alain [Bros.]: ver MarieVictorin et al.

Marie-Victorin et al. 21452 (39a); 21551 (39b); 21704 (39a)

Márquez A.E. \& Visconti 395 (39a)

Martínez 1.3165 (39a)

Martínez C. 93 (39a); 648 (39a); 1741 (39a)

Martínez E. \& Ramos Díaz A.R. 682 (39a)

Martínez E. et al. 4890 (39a)

Martínez S. \& Stevens W.D. 23281 (39a); 23286 (23)

Martínez S. et al. 14588 (23)
Martius C.F.P. 2293 (22)

Matos F.J.A. s.n. (37)

Mattos Silva L.A. et al. 1268 (31); 1414 (26)

Matuda E. 1448 (39b); 5739 (39a)

Maxwell 14 (39a)

McDaniel S. 12851 (39b); 12852 (23)

McDaniel S. \& Clark 14305 (39a)

Medina E. 479 (25)

Medrano F.G. et al. 4166 (39a); 8955 bis (39a)

Mejia M. 131 (39a); 26293 (39a)

Mejia M. \& Zanoni T. 6141 (39a)

Mell C.D. 2103 (39a); 2138 (39a)

Mello Barreto H.L. 8182 (27)

Mello Filho L.E. 1758 (39a)

Melo E. de \& França F. 463 (42); 488 (42); 3210 (30)

Melo E. de et al. 1405 (42); 1413 (37); 1458 (37)

Méndez Guerrero A. s.n. (39a)

Mercier M.P. 321 (39a)

Merlier G.Y. 236 (25)

Messer E. 135 (39a)

Meyer 113 (23)

Michaux A. 86 (39a)

Miller O.O. 266 (39a)

Miller O.O. \& Johnston J.O. 223 (23); 266 (23)

Milliken W. \& Bowles S. 391 (25)

Millspaugh C.F. 2289 (39a)

Miranda F. 5043 (39a)

Miranda et al. 1746 (39a)

Molina A. 57 (23); 1672 (39a); 4015 (39a); 14616 (39a);

22653 (39a); 22697 (39a)

Monteiro Neto H. 145 (42)

Montes 1572 (23)

Moore H.E. 1648 (39a); 476 (25)

Moore H.E. \& Wood C.E. Jr. 3843 (39a)

Moraes J.C. de 1083 (22); 2015 (42)

Morales J.F. y Salazar H. 1477 (39a)

Moreno P.P. 3560 (39a); 9861 (39a); 10516 (39a)

Mori S.A. \& Benton F. 13465 (39a)

Mori S.A. \& Santos T.S. dos 11774 (30)

Mori S.A. et al. 10924 (26); 11467 (31)

Moricand M.E. s.n. (42)

Moritz J.W.K. 519 (24)

Morton C.V. \& Alain 8888 (39a)

Moura C. s.n. [5 II 1965](27); [5 VII 1975](27)

Narvaez Montés M. \& Salazar 810 (39a)

Nash G.V. \& Taylor 881 (39a); 1410 (39a); 1541 (39a)

Nava D. et al. 44 (39a)

Nealley G.C. 12 (39a); 267 (39a)

Nee M. 23045 (39a)

Nelson C. \& Cruz G. 8732 (23)

Nelson C. \& Andino R. 11754 (39a); 11935 (39a); 13443 (39a)

Nelson E.W. 2056 (23); 2780 (39a); 8457 (23)

Nelson E.W. \& Goldman E.A. 1450 (39a)

Nevling L.I. \& Gomez Pompa A. 2394 (39a) 
Noblick L.R. 1376 (42); 1646 (42); 1672 (42); 1854 (42); 2035 (42); 3175 (42); 3175 bis (42)

Noblick L.R. \& Clodoaldo 3779 (39a)

Noblick L.R. \& Lemos 4094 (42); 4145 (42)

Noblick L.R. \& Lobo 4353 (42)

Noblick L.R. et al. 2476 (42); 3127 (42)

Nunes E. et al. s.n. [5708] (39a); s.n. [5709] (37)

Oldeman B. 788 (25)

Oldenburger F.H.F. et al. 621 (25)

Oliveira E.E.P. 3 (42)

Oliveira E.L.P.G. 366 (42); 521 (42)

$\mathrm{O}^{\prime}$ Neill H. 8785 (39a); 8786 (39b); 8834 (23)

Opler 579 (39a)

Orcutt C.R. 4482 (39a)

Orsted 569 (39a); 4269 (39a)

Ortega J.: ver González Ortega J.

Ortega J.C. \& Ucan 1493 (39a)

Otero J.I. \& López R.A. 465 (39a)

Palmer E. 11 (39b); 41 (39b); 133 (39a); 452 (39a); 738 (39a); 1071 (39b)

Parke, Davis \& Co. s.n. [prope Todos Santos] (39a); s.n. [Mexico occid.] (39b)

Parry C.C. \& Palmer E. 93 (39a)

Passus 19 (42)

Peck M.E. 66 (23); 228 (39b)

Pennell F.W. 17631 (39a); 18025 (39a)

Pereira E. 1988 (42); 2150 (39a)

Pereira E. 9605 - G. Pabst 8494 (3I)

Pereira R. \& Lima V.C. s.n. (39a)

Phelps K.D. 323 (35)

Picarda L. 1552 (39a)

Pickel D.B. 1062 (42); 2628 (42); 2829 (42); 2967 (22); 3483 (42)

Picón Nava G. 1086 (35)

Pinto G.C.P. $20 / 80$ (37); 36/81 (42); 56-35 (42); 42321 (39a); s.n. (42)

Pittier H. 6158 (24); 7028 (24); 8240 (24); 8654 (24); 8655 (24); 9451 (24); 10304 (24); 11041 (24); 11845 (24); 12455 (24)

Plowman T. et al. 9028 (24)

Pohl J.E. 68 (25)

Poiteau P.A. s.n. (25)

Potter D. 5028 (39a)

Prance G.T. et al. 29296 (39a); 9305 (25)

Pringle C.G. 3644 (39a); 5121 (39a); 5122 (39a); 6692 (39a); 11455 (39a)

Proctor G.R. 28113 (39a); 30503 (39a); 36182 (23); 38387 (39a); 39116 (39a)

Proctor G.R. \& Gillis 33222 (39a)

Pruski \& Steyermark J.A. 1464 (25)

Purpus C.A. 1234 (39a); 1396 (39a); 2005 (39b); 4924 (39a); 4924a (39a); 6691 (39a); 7135 (39a); 9159 (39a); $16040(39 b)$

Queiroz L.P. 356 (39a); 379 (37); 568 (39a); 2600 (42); 2611 (41); 4806 (39a); 4822 (39a)

Queiroz L.P \& Crepaldi I. 1479 (37); 1482 (42)
Queiroz L.P. \& Nascimento N.S. 4548 (39a)

Rabelo B.V. \& Nonato R. 1318 (25)

Ramos A.M.C. s.n. (42)

Raunkiaer C.C. s.n. (39a)

Read R.W. 269 (39a)

Rech 27 (25)

Record S.J. s.n. (23)

Regnell A.F. s.n. (27)

Reid N. s.n. (39a)

Reitz R. \& Klein R.M. 2845 (27); 4002 (27)

Rewinkel s.n. (39a)

Richard L.C. s.n. (25)

Riedel L. 8 (22); 743 (26); 758 (25); 1372 (27); 1402 (27); 1996 (27); s.n. [Bahia](22); s.n. [Rio Coxim] (25)

Rivera C. I-153 (23)

Rohr R. 46 (25); s.n. (25)

Romero-Castañeda 7559 (23)

Roque N. et al. CFCR 14948 (39a); CFCR 14960 (37)

Rosales J. \& Briceño E. 254 (25)

Rosario C. \& Taylor 134 (25)

Rosas E. et al. 17 (42)

Ruse J.N. 1612 (39a); 3536 (39a); 16361 (39a); 21823 (24)

Rose J.N. \& Rose J.S. 9674 (39a)

Rose J.N. et al. 3820 (39a); 8957 (39a); 9768 (39a); 9958 (39a)

Roth L. 91 (27)

Rothery H.C. 112 (25); 251 (25)

Rothrock J.T. s.n. (39a)

Rozynski von 34 (39a)

Runyon R. 150 (39a); 316 (39a); 1102 (39a); 2535 (39a)

Rusby H.H. 1972 (25)

Sagot P.A. 54 (25); 1288 (25); s.n. (25)

Saint Hilaire A. 770 (27); B 1531 (42); D 562 (27)

Sakuragui C.M. et al. CFCR 15325 (42)

Sales M.F. 365 (39a)

Salgado O.A. 373 (39a)

Salinas A. et al. 4183 (39a)

Sanders R. et al. 1596 (39a)

Sandino J.C. 3137 (39a)

Sant'Anna S.C. de et al. 487 (39a); 515 (39a)

Santino 236 (40)

Santoro J. 801 (27)

Santos E.B. 229 (31); 1282 (26)

Santos E. 2007- Sacco J.C. 2268 (42)

Santos Lima \& Brade A.C. s.n. (27)

Santos T.S. et al. 2169 (31); 2887 (31); 3449 (42)

Sargent F.H. 156 (39a)

Schaffner J.G. 166 (39a); 560 (39b)

Schlindwein C. CS939 (42)

Schoenwetter JSOX-109 (39a)

Schomburgk s.n. (25)

Schomburgk R.I I. 45 (39a); 624 (34); 922 (34)

Schott H.W. 142 (39a); s.n. (39a)

Schreiner s.n. (42) 
Seigler D. et al. 13199 (39a)

Seler C. \& Seler E. 865 (39a); 3029 (39a)

Sellow F. s.n. [Brasil](27); [ad Nazareth] (31)

Sendulsky T. 408 (27); 824 (27)

Service Forestier 3351 (25)

Shafer J.A. 8.38 (39a); 1289 (39a); 2814 (39a); 2932 (39a); 2936 (39a); 3047 (39a)

Shiller I. 885 (39a)

Shreve F. 7244 (39a); 7289 (39a)

Shreve F. \& Tinkham E.R. 9569 (39a)

Silva J. de S. 632 (39a)

Silva G.P. et al. 1265 (25)

Silva M.G. \& Rosario G. 4936 (25)

Silva S.I. et al. $764(39 a)$

Sintenis P. 530 (39a); 530 b (39a); 3434 (39a); 3535 (39a); s.n. (39a)

Smith 10124 (39a); 10539 (39a)

Smith A.C. 2015 (42); 2353 (25); 3121 (25)

Smith L.B. 6220 (27)

Smith L.B. et al. 3136 (39b)

Smith L.C. 519 (39a)

Sohmer S.H. 9237 (39a)

Sorensen 7079 (39b)

Soubirou s.n. (25)

Spellman D. 1507 (23); 1526 (23)

Spellman D. et al. 291 (23)

Sperling C.R. et al. 6171 (24)

Spruce R. 3597 (25)

Stahel G. \& Gonggrijp j.W. 3124 (25)

Stahl A. 1033 (39a)

Standley P.C. 10155 (39a); 14941 (39a); 22967 (39a); 29049 (39a); 62556 (39a); 76852 (39a); 82210 (39a); 82744 (39a)

Standley P.C. et a]. 1301 (39a)

Stanford L.R. et al. 2238 (39a)

Stannard B. \& Silva T. H52705 (39a)

Steere W.C. 1466 (39a)

Stergios B. et al. 3456 (24); 3469 (24)

Stevens W.D. 1220 (39a); 9760 (39a); 11157 (39a); 14670 (39a); 23034 (39a)

Stevens W.D. et al. 17263 (39a)

Steyermark J.A. 31262 (39a); 50899 (39a); 51479 (39a); 55186 (23); 55188 (24); 74699 (34)

Steyermark J.A. \& Bunting G.S. 102295 (24)

Steyermark J.A. \& Manara B. 107902 (23)

Steyermark J.A. \& Carreño V. 117874 (35)

Steyermark J.A. et al. 94096 (23); 108150 (23); 113047 (25); $120134(23) ; 131455$ (25)

Strudwick J.J. et al. 4503 (25)

Sutton et al. 165 (23)

Swainson W. s.n. (39a)

Taylor Edwards M.E. 7441 (39a)

Teixeira I. s.n. (42)

Téllez O. \& Cabrera E. 1657 (23); 2128 (23); 2455 (23); $3614(23)$
Téllez O. et al. 5777 (23); 8054 (39a)

Tenorio P. \& Hernández R. 261 (39a)

Tenorio P. \& C. Romero de T. 10641 (39a)

Tenorio P. et al. 14585 (39b)

Thomas W. et al. 9734 (26)

Thomson A. s.n. (23)

Torres R. \& Cedillo T., R. 1524 (39a)

Torres R. \& Cortes A., L. 8771 (39a)

Torres R. \& Hernández H. 3396 (39a)

Torres R. \& Martínez 5676 (39a)

Torres R. et al. 5349 (39a)

Tún Ortiz R. 1093 (23)

Türckheim H. von 1200 (39a)

Ule E. 6971 (42); 7511 (39a); 7739 (25) ; 7954 (25) ; 8421 (35) ; 9041 (25)

Underwood L.M. \& Griggs R.F. 682 (39a)

Usteri A. 22 (27)

Valera A. 181 (23)

Valeur E.J. 97 [Jicome](39a); [Monción] 97 (39a)

Vara \& Arias 188 (39a)

Vasconcellos Subrinho s.n. II 1937 (42); s.n. X 1937 (37)

Vega R. et al. 3213 (39a)

Velez I. 2330 (25); 2451 (25)

Ventura E. \& López E. 6411 (39a); 6390 (39a); 8949 (39a)

Vidal J. IV-774 (42); IV-794 (42); IV-814 (37); IV-876 (39a)

Viereck H.W. 100 (39a); 327 (39a); 664 (39a)

Villanueva R. 375 (39a); 423 (39a); 502 (39b)

Villarreal J.A. 1798 (39a)

Virlet d'Aoust 1519 (39a); 584 (39a)

Vogl C. 372 (24); 409 (24); 701 (24)

Votava \& Liogier A.II. 42 (39a); 49 (39a)

Wagner R.J. 351 (39a); 1327 (39a)

Walker E.J. 17813 (39a); 79416 (39a)

Warming E. s.n. (27)

Warnra 542 (39a)

Weaver R.E. 2052 (39a)

Webster G. 3869 (39a)

Webster G. \& Armbruster W.S. 20869 (39b)

Webster G. et al. 12035 (39a)

Whitefoord C. 2509 (39b); 2536 (39a); 2704 (23)

Wiggins I.L. 6320 B (39a)

Wiley J.R. 105 (39a); 194 (39a); 235 (23); 274 (23)

Williams L.C. \& Assis V. 7364 (27)

Williams L.O. \& A. Molina-R. 10272 (39a); 11216 (39a); 23249 (39a)

Williams L.O. et al. 22509 (39a); 40023 (39a)

Williams Ll. 175 (39a); 9865 (39a); 10109 (24); 11358 (25); 11711 (25); 12779 (25); 15941 (25); 18922 (39a); $42803(39 a)$

Williams Ll. \& Alston A.H.G. 48 (24)

Wilson \& Browne 406 (25)

Wingfield R. \& Werff H.v.d.6625 (23) 
Wiud $530(39 a)$

Wooton 38 (39a); s.n. (39a)

Worthington 21231 (23); 21243 (39a)

Wright C. 210 (39a)

Wullschlaegel H.R. $773(25)$

Wurdack J.J. \& Monachino J.V. 39815 (25)
Zanoni T. 26038 (39a)

Zanoni T. \& Mejia 24666 (39a)

Zanoni T. \& Pimentel 25900 (39a)

Zanoni T. et al. 19666 (39a); 21915 (39a); 27657 (39a); 28396 (39a)

Zehntner 99 (39a)

\section{Índice de nombres científicos citados en el texto'}

\section{Annulares Urb., 3}

Anomalae Urb., 3

Bohadschia humifusa Presl, 49

Bohadschia microphylla (Desv.) Griseb., 49

Canaligerae Urb., 3

Capitatae Urb., 16

Leiocarpae Urb., 3

Microphyllae Urb., 41.

Papilliferae Urb., 65

Piriqueta Aubl., 17

Salicifoliae Urb., 2

Stenodrctyae Urb., 2

Triacis microphylla (Desv.) Griseb., 49

Turnera L., 1

Turnera albicans Urb., 18

Turnera annularns Urb., 5

Turnera annularis Urb. var. $\alpha$ Urb., 5

Turnera annularis Urb. var. conglomerata Urb., 5

Turnera aphrodisiaca Ward, 62

Turnera aromatica Arbo, 7

Turnera asymmetrica Arbo, 43

Turnera blanchetiana Urb. 16

Turnera breviflora Muura, 9

Turnera caatingana Arbo, 66

Turnera capitata Cambess., 20

Turnera capitata Cambess. subsp. capitata forma rufescens Urb., 20

Turnera capitata Cambess. subsp. intermedia Urb., 35

Turnera chamaedrifolia Cambess., 68
Turnera chamaedryfolia Cambess., 68

Turnera collotricha Arbo, 48

Turnera calyptrocarpa Urb., 45

Turnera corchorifolia Willd. ex Schult., 12

Turnera dasystyla Urb., 23

Turnera dichotoma Gardn., 16

Turnera diffusa Willd. ex Schult. var. aphrodiszaca (Ward) Urb., 62

Turnera diffusa Willd. ex Schult. var. diffusa, 49

Turnera frutescens Aubl. var. latifolia DC., 12

Turnera glaziovii Urb., 33

Turnera hatschbachii Arbo var. hatschbachii, 27

Tumera hatschbachii Arbo var. minata Arbo, 29

Turnera hebepetala Urban, 63

Turnera hexandra Spreng., 12

Turnera humifusa (Presl) Endl. ex Walp., 49

Turnera maracasana Arbo, 29

Turnera marmorata Urb., 31

Turnera microphylla Desv., 49

Tumera odorata Rich., 12

Turnera parviflora Benth., 12

Turnera pernambucensis Urb., 35

Turnera princeps Arbo, 35

Turnera pringlei Rose, 49

Turnera pumilea auct. non L., 49

Turnera schomburgkiana Urb., 37

Turnera stipularts Urb., 16

Turnera tomentosa Kunth, 12

Turnera waltherioudes Urb., 39

'Los nombres válidus en bastardilla 
BONPLANDIA 10 (1-4) 2000

\section{Índice de nombres vulgares citados en el texto}

cabeza de negro 9, 15

clavo de especie amarilla 15

clavo de especie de savana 15

damiana 61,63

escoba lisa 61

guaxuma 48

hierba de la pastora 61

hierba del Venado 61

malva 7

mejorana 61

moro 61

oreganillo 61 orégano cimarrón 61

poporamoe 15

radier anglais 15

rompe camisa macho 61

skabon che 9

swamp bush 61

thé-bourrique 61

wild damiana 9

yerba del moro 63

yerba del pastor 61

yerba del venado 61 